\title{
Atomic Layer Deposition-Sequential Self-limiting Surface Reactions for Advanced Catalyst “bottom-up” Synthesis
}

\author{
Junling Lu, ${ }^{\text {a,* Jeffrey W. Elam, }{ }^{\text {b }} \text { Peter C Stair. }}$
}

${ }^{a}$ Department of Chemical Physics, Hefei National Laboratory for Physical Sciences at the Microscale, CAS Key Laboratory of Materials for Energy Conversion, and Collaborative Innovation Center of Chemistry for Energy Materials (iChem),University of Science and Technology of China, Hefei 230026, China

${ }^{b}$ Energy Systems Division, Argonne National Laboratory, Argonne, Illinois 60439, USA

${ }^{c}$ Department of Chemistry, Northwestern University, Evanston, Illinois 60208; Chemical Sciences and Engineering Division, Argonne National Laboratory, Argonne, IL 60439 USA

*To whom correspondence should be addressed: junling@ustc.edu.cn 


\section{Abstract:}

Catalyst synthesis with precise control over the structure of catalytic active sites at the atomic level is of essential importance for the scientific understanding of reaction mechanisms and for rational design of advanced catalysts with high performance. Such precise control is achievable using atomic layer deposition (ALD). ALD is similar to chemical vapor deposition (CVD), except that the deposition is split into a sequence of two self-limiting surface reactions between gaseous precursor molecules and a substrate. The unique self-limiting feature of ALD allows conformal deposition of catalytic materials on a high surface area catalyst support at the atomic level. The deposited catalytic materials can be precisely constructed on the support by varying the number and type of ALD cycles. As an alternative to the wet-chemistry based conventional methods, ALD provides a cycle-by-cycle “bottom-up” approach for nanostructuring supported catalysts with near atomic precision.

In this review, we summarize recent attempts to synthesize supported catalysts with ALD. Nucleation and growth of metals by ALD on oxides and carbon materials for precise synthesis of supported monometallic catalyst are reviewed. The capability of achieving precise control over the particle size of monometallic nanoparticles by ALD is emphasized. The resulting metal catalysts with high dispersions and uniformity often show comparable or remarkably higher activity than those prepared by conventional methods. For supported bimetallic catalyst synthesis, we summarize the strategies for controlling the deposition of the secondary metal selectively on the primary metal nanoparticle but not on the support to exclude monometallic formation. As a review of the surface chemistry and growth behavior of metal ALD on metal surfaces, we demonstrate the ways to precisely tune size, composition and structure of bimetallic metal nanoparticles. The cycle-by-cycle "bottom up" construction of bimetallic (or multiple components) nanoparticles with near atomic precision on supports by ALD is illustrated. Applying metal oxide ALD over metal nanoparticles can be used to precisely synthesize nanostructured metal catalysts. In this part, the surface chemistry of $\mathrm{Al}_{2} \mathrm{O}_{3}$ ALD on metals is specifically reviewed. Next, we discuss the methods of tailoring the catalytic performance of metal catalysts including activity, selectivity and stability, through selective blocking of the low-coordination sites of metal nanoparticles, the confinement effect, and the formation of new metal-oxide interfaces. Synthesis of supported metal oxide catalysts with high dispersions and "bottom up" nanostructured photocatalytic architectures are also included. Therein, the surface chemistry and morphology of oxide ALD on oxides and carbon materials as well as their catalytic performance are summarized. 


\section{Contents}

\section{Introduction}

1.1 A brief introduction to atomic layer deposition (ALD)

1.2 Motivation of ALD in catalysis

1.3 Outline of this review

2 General surface chemistry of ALD

2.1 General characteristics of ALD

2.2 Temperature effect

2.3 Type of ALD

3 Metal ALD on oxides and carbon materials: precise synthesis of supported monometallic catalysts

\subsection{Pt ALD}

3.1.1 Nucleation and growth of Pt ALD on oxides

3.1.2 Temperature effect

3.1.3 Nucleation and growth of Pt ALD on carbon materials

\subsection{Pd ALD}

3.2.1 Nucleation and growth of Pd ALD on oxides

3.4.2.1 Synthesis of ultrafine Pd clusters using low-temperature ABCtype ALD

3.2.2 Nucleation and growth of Pd ALD on carbon materials

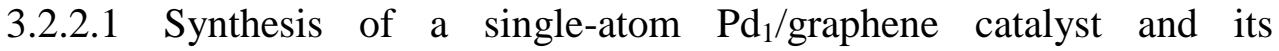
performance

3.3 Ir ALD

3.3.1 Nucleation and growth of Ir ALD on oxides

\subsection{Ag ALD}

$3.5 \mathrm{Cu}$ ALD

3.6 Ni ALD

3.7 Other metals ALD

4 Selective metal ALD on metals: precise synthesis of supported bimetallic catalysts

4.1 Challenges of synthesizing supported bimetallic catalysts using ALD

4.2 Strategies for selective metal ALD

4.3 Precise synthesis of bimetallic catalysts with core-shell structure
4.3.1 Pd ALD on Pt
4.3.2 Pd ALD on $\mathrm{Au}$ 
4.3.3 Pt ALD on Pd

4.3.4 Ru ALD on Pt

4.3.5 Cu ALD on $\mathrm{Ni}$

4.3.6 Cu ALD on Pt and Pd

4.4 Precise synthesis of well-mixed alloy bimetallic catalysts

4.4.1 RuPt alloy ALD

4.4.2 PdCu alloy ALD

4.4.3 PdPt alloy ALD

\subsection{Summary}

5 Oxide ALD on metals: precise synthesis of nanostructured metal catalysts

$5.1 \mathrm{Al}_{2} \mathrm{O}_{3}$ ALD on $\mathrm{Pd}$

5.1.1 Surface chemistry

5.1.2 Structures of $\mathrm{Pd} / \mathrm{Al}_{2} \mathrm{O}_{3}$ catalysts with ALD alumina overcoat

5.1.3 Catalytic performance of $\mathrm{Pd} / \mathrm{Al}_{2} \mathrm{O}_{3}$ catalysts tailored by $\mathrm{ALD}$ alumina overcoats

$5.2 \quad \mathrm{Al}_{2} \mathrm{O}_{3}$ ALD on Pt

$5.3 \mathrm{Al}_{2} \mathrm{O}_{3}$ ALD on Ir

$5.4 \quad \mathrm{Al}_{2} \mathrm{O}_{3} \mathrm{ALD}$ on $\mathrm{Ag}$

$5.5 \mathrm{Al}_{2} \mathrm{O}_{3}$ ALD on $\mathrm{Au}$

5.6 $\mathrm{Al}_{2} \mathrm{O}_{3} \mathrm{ALD}$ on $\mathrm{Cu}$

5.7 $\quad \mathrm{TiO}_{2}$ ALD on metals

5.8 Summary

6 Oxide ALD on oxide and carbon materials: synthesis of supported metal oxide catalysts and photocatalytic architectures

6.1 ALD of highly dispersed oxide species on oxide surfaces

6.1.1 $\mathrm{VO}_{\mathrm{x}}$ ALD on alumina

6.1.2 $\mathrm{WO}_{\mathrm{x}}$ ALD on SBA-15

6.1.3 $\mathrm{SiO}_{2}$ ALD on $\gamma$-alumina

6.2 Conformal ALD coatings on mesoporous materials for enhanced acidity

6.2.1 $\mathrm{Al}_{2} \mathrm{O}_{3}$ ALD on mesoporous zeolite

6.2.2 $\mathrm{Nb}_{2} \mathrm{O}_{5}$ ALD on SBA-15

6.3 ALD oxide architectures for photocatalysis

6.4 Oxide ALD using single-molecule sacrificial templates: Atomically-precise "bottom-up” synthesis of selective catalysts. 
6.5 Oxide ALD on carbon materials

6.6 Summary.

7 Conclusions and outlook

Acknowledgement

References 


\section{Introduction}

\subsection{A brief introduction to atomic layer deposition (ALD)}

ALD is a thin film deposition technique, originally developed by Dr. Tuomo Suntola and co-workers in the mid-1970s with the motivation for the need to produce high quality thin films in electroluminescent (TFEL) flat panel displays [1, 2]. ALD shows the capability of conformal coating on complex substrates with high aspect ratio and/or high surface areas where other thin film techniques, such as physical vapor deposition, chemical vapor deposition, pulsed laser deposition etc. often fail. Moreover, the film thickness can be precisely controlled at the atomic level by varying the number of ALD cycles [3-5]. Consequently, ALD has attracted tremendous attention and applications have extended far beyond microelectronics into fields such as catalysis [5-13], photovoltaics [14-18], batteries [19], fuel cells [11, 20], and polymers [21-23].

ALD was originally named "atomic layer epitaxy (ALE)” by Dr. Tuomo Suntola and coworkers [24]. It was changed to the term of ALD in near 2000, because the ALD-grown materials are mostly found to be amorphous, without showing any epitaxial structure to the underlying substrates [25]. ALD is similar to chemical vapor deposition (CVD), except that the deposition is performed in cycles each of which is a sequence of two self-limiting surface reactions between gaseous precursor molecules and a substrate [5, 21, 24, 26]. After each surface reaction step, inert gas purging is performed to remove any unreacted precursor and volatile reaction products, as shown in the schematic model in Fig. 1. The principle of sequential binary surface reactions in ALD was originally demonstrated as "molecular layering (ML)" in the early 1960s by Professors Aleskovskii and Koltsov of the USSR Academy of Sciences for controlled catalyst synthesis; wherein silica gel with high surface area was alternatively exposed to $\mathrm{TiCl}_{4}$ and water [27-29]. These early studies are the origin of ALD as applied to catalyst synthesis, even though they were overlooked by researchers from outside the Soviet Union since they were published only in Russian.

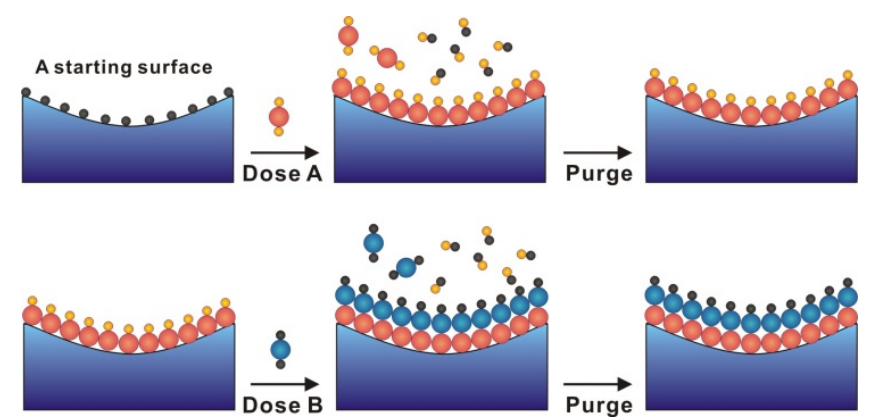

Fig. 1. A schematic model of general ALD binary reaction sequence. Precursor $\mathbf{A}$ and $\mathbf{B}$ are sequentially introduced to a substrate surface with inert gas purging in between. Reprinted 
with permission from [5]. Copyright @ 2013, American Chemical Society.

During ALD, each surface reaction step is self-limiting, thus the thickness of deposited film can be precisely tuned at the atomic level by varying the number of ALD cycles. The self-limiting feature of ALD allows conformal deposition on high aspect ratio structures. Thus, it meets the challenging requirements in fabricating high-k dielectric gate materials in MOSFET, trench capacitors for DRAM and other devices [3, 30, 31]. The success of ALD in the microelectronics industry for the down-scaling of device dimensions has driven a tremendous growth in ALD processes, applications and commercially available ALD equipment. Today, more than 1000 ALD processes have been developed to include a majority of elements in the periodic table in the formation of oxides, nitrides, sulfides, and metals etc. (Fig. 2) [26].

\section{ALD Thin Film Materials}

\begin{tabular}{|c|c|c|c|c|c|c|c|c|c|c|c|c|c|c|c|c|c|}
\hline $\mathrm{H}$ & & & & & & & & & & & & & & & & & $\mathrm{He}$ \\
\hline${ }^{\star} \mathrm{Li}$ & & & & & & & & & & & & ${ }_{B}$ & C & $\mathrm{N}$ & o & $\mathrm{F}$ & $\mathrm{Ne}$ \\
\hline $\mathrm{Na}$ & ${ }^{*} \mathrm{Mg}$ & & & & & & & & & & & Al & $\mathrm{Si}$ & $\mathbf{P}$ & $\mathrm{S}$ & $\mathrm{Cl}$ & $\mathrm{Ar}$ \\
\hline K & $\mathrm{Ca}$ & ${ }^{\star} \mathrm{Sc}$ & ${ }^{*}{ }_{\mathrm{Ti}}^{\circ}$ & ${ }^{\star} \mathrm{V}$ & ${ }^{\star} \mathrm{Cr}$ & $\mathrm{Mn}$ & 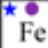 & $\star \mathrm{Co}$ & ${ }^{\star} \mathrm{Ni}$ & ${ }^{\star} \mathrm{Cu}$ & ${ }^{\star} \mathrm{Zn}^{0}$ & $\mathrm{Ga}$ & $\mathrm{Ge}$ & As & $\mathrm{Se}$ & $\mathrm{Br}$ & $\mathrm{Kr}$ \\
\hline $\mathrm{Rb}$ & $\mathrm{Sr}$ & 1 & ${ }^{*} \mathrm{Zr}$ & ${ }^{k_{N}}$ & ${ }_{\mathrm{M}}^{\circ}$ & $\mathrm{Tc}$ & ${ }^{\star}{ }_{\mathrm{Ru}}$ & * $\mathrm{Rh}$ & $\stackrel{\bullet}{\mathrm{Pd}}$ & $\stackrel{\circ}{\mathrm{Ag}}$ & ${ }^{\star} \mathrm{Cd}$ & In & $\mathrm{Sn}$ & $\stackrel{\bullet}{\mathrm{Sb} b}$ & $\mathrm{Te}$ & I & $\mathrm{Xe}$ \\
\hline Cs & $\mathrm{Ba}$ & $\mathrm{La}$ & ${ }^{\star} \mathrm{Hf}$ & ${ }^{\circ} \mathrm{Ta}$ & 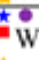 & $\operatorname{Re}$ & ${ }_{0}^{\circ}$ & Ir & ${ }^{\star 0} \mathrm{Pt}$ & $\mathrm{Au}$ & $\mathrm{Hg}$ & $\mathrm{Tl}$ & $\mathrm{Pb}$ & $\mathrm{Bi}$ & Po & At & $\mathrm{Rn}$ \\
\hline $\mathrm{Fr}$ & $\mathrm{Ra}$ & $\mathrm{Lr}$ & $\mathrm{Rf}$ & $\mathrm{Db}$ & $\mathrm{Sg}$ & $\mathrm{Bh}$ & $\mathrm{Hs}$ & Mt & & & & & & & & & \\
\hline & & & ${ }^{\star} \mathrm{Ce}$ & ${ }^{\star} \operatorname{Pr}$ & $\mathrm{N}$ & $\mathrm{Pm}$ & $\mathrm{Sn}$ & ${ }^{\star} \mathrm{Eu}$ & ${ }^{\star} \mathrm{Gd}$ & $\mathrm{Tb}$ & Dy & $\mathrm{Ho}$ & $\mathrm{Er}$ & $\mathrm{Tm}$ & ${ }^{\star} \mathrm{Yb}$ & $\mathrm{Lu}$ & \\
\hline & & & Th & $\mathrm{Pa}$ & $\mathrm{U}$ & $\mathrm{Np}$ & $\mathrm{Pu}$ & $\mathrm{Am}$ & $\mathrm{Cm}$ & $\mathrm{Bk}$ & $\mathrm{Cf}$ & Es & $\mathrm{Fm}$ & Md & No & Lw & \\
\hline
\end{tabular}

* Oxide

- Nitride

- Phosphide/Arsenide

Sulfide/Selenide/Telluride
- Element

- Carbide

- Fluoride

Silicide

Fig. 2. Overview of elements used for ALD materials. Reprinted with permission from [26].

\subsection{Motivation of ALD in catalysis}

Catalysis is an essential technology for petroleum refining, chemical upgrading, automobile exhaust treatment, Fischer-Tropsch synthesis and fuel cells [32]. Heterogeneous catalysts with the catalytic active materials dispersed on a high surface area solid material is the preferred form in most industrial processes, since the catalyst can be easily separated from reaction products. The conventional methods for synthesis of heterogeneous catalyst are wet-chemistry-based ion exchange, impregnation, and precipitation $[33,34]$. In the $20^{\text {th }}$ 
century, tremendous efforts were made to improve catalytic activities, and remarkable progresses were achieved for many catalytic processes. Nonetheless, in many cases, the resulting catalytic materials show poor uniformity of catalytic active site dispersion, which leads to a low selectivity to desired products. From the scientific point of view, the heterogeneity of catalytic active sites makes it extremely difficult to link the catalytic properties with the specific active site structure. Improving catalyst selectivity to desired products is an essential goal in the $21^{\text {st }}$ century for sustainable environment. To achieve this goal, methods of advanced catalyst synthesis with precise control over the catalytic active site structure at the atomic level are required. Moreover, such atomically-precisely controlled synthesis would facilitate the scientific understanding of reaction mechanisms and development of structure-activity relationships. Colloidal synthesis shows great opportunities to control over the size, composition, and morphology of metal nanoparticles/nanocrystals in liquid phase [35-37]. The shape and composition of the resulting metal nanoparticles is possible to be further finely tuned via atomic addition and subtraction through oxidative etching [38]. However, depositing colloidal nanoparticles to a catalyst support along with the capping agents removal is a crucial step to prepare a stable and active heterogeneous metal catalyst [39]; therein it remains challenges to maintain the size and shape of metal nanoparticles after removing the capping agents [34].

Under severe reaction conditions, catalyst deactivation is the major issue [40]. Sintering of supported metal catalysts to form larger metal particles can occur during high temperature reactions [40-42], and such metal catalyst deactivation may only be partially reversible in certain cases $[43,44]$. Coke formation is also a major route to catalyst deactivation in hydrocarbon reactions, by blocking the catalytic active sites via carbon deposition [45-47]. In harsh liquid-phase reactions, the leaching of active sites from the support is also a common route to catalyst deactivation [48]. In many cases, sintering, coking, and leaching of active sites occur simultaneously. The deactivated catalyst has to be replaced or regenerated. This process is costly since reaction processes have to be interrupted. Moreover, during the deactivation process there will be a loss in catalyst uniformity and hence the potential for decreased selectivity. An effective method is required to simultaneously inhibit these deactivation routes, while preserving the catalytic function. Systematic modification of the structure and composition of catalytic active sites and their chemical surroundings at the atomic level is one viable strategy both to improve catalyst stability and to better understand the materials properties that improve stability. Encapsulation of metal nanoparticles with an oxide protecting layer using techniques such as CVD and sol-gel chemistry provides an 
effective way to improve the stability of metal nanoparticles [49-53]. However, the thick protective layer (usually tens of nanometers thick) often results in a large decrease in catalytic activity due to mass transfer resistance. A method of atomically precise control over the thickness and composition of protective layers is highly desirable to preserve catalytic activity to the greatest extent while improving the stability.

In the mid-1990s, Lakomaa and Suntola at Microchemistry Ltd., carried out the pioneering studies of ALD in catalysis, wherein the capability to uniformly depositing catalytic materials (metal oxides and metals) onto high surface area porous substrates using ALD were demonstrated [4, 54-58]. Indeed, when catalytic materials are deposited on a high surface support using ALD, the catalytic species can be precisely constructed on the support surface step-by-step as increasing ALD cycles. As an alternative to the wet-chemistry based conventional methods, ALD provides a "bottom-up” approach for synthesis of supported catalysts with near atomic precision, which addresses the essential need for achieving the goals related with an atomic-level understanding of reaction mechanisms and rational design of advanced catalysts with high performance.

\subsection{Outline of this review}

Following the introduction, Section 2 first gives a brief summary of the general growth behaviors of ALD to get an overall picture of this approach. It includes the general characteristics of ALD, temperature effects, and the type of ALD.

Metal ALD on oxides and carbon materials for precise synthesis of supported monometallic catalysts is reviewed in Section 3. Synthesis of supported metal catalysts using ALD is often carried out using only a few cycles of ALD $[5,13]$, thus we mainly focus on the nucleation and growth of metal ALD on these substrates. In most cases, deposited metal atoms aggregate to form metal clusters or nanoparticles on these supports, and the metal particle size varies with the number of ALD cycles. It is challenging to synthesize singleatom metal catalyst using ALD at elevated temperatures due to the accelerated metal atom aggregation. However, the preparation of single-atom metal catalysts can be achieved using ALD through careful control over the type and density of nucleation sites $[59,60]$. The catalytic performance of the resulting supported metal catalysts by ALD is also reviewed.

Section 4 describes the synthesis of supported bimetallic catalysts using ALD. The challenge of combing two metal ALD processes to form bimetallic nanoparticles synthesis is first addressed. Next, the strategies developed for selective metal-on-metal ALD for precise synthesis of supported bimetallic catalysts while excluding monometallic formation are 
particularly highlighted. We describe strategies used to precisely tune structure, composition, and size of bimetallic metal nanoparticles. The surface chemistry and growth behavior of metal ALD on metal surfaces is also discussed for several cases to illustrate our understanding of the growth mechanism and the resulting bimetallic structures.

Section 5 reviews oxide ALD on metals for precise synthesis of nanostructured metal catalysts. This section includes the surface chemistry of $\mathrm{Al}_{2} \mathrm{O}_{3}$ ALD on metals. We also discuss the methods for tailoring the catalytic activity, selectivity and stability of metal catalysts, through selectively blocking the low-coordination sites of metal nanoparticles, the confinement effect, and the resulting new metal-oxide interfaces.

Synthesizing supported metal oxide catalysts with high dispersions and "bottom-up" nanostructured photocatalytic architectures are discussed in Section 6. In this case, the surface chemistry and morphology of oxide ALD on oxide and carbon materials are reviewed, followed by the catalytic performance. A summary and outlook are provided in a concluding section.

\section{General surface chemistry of ALD}

\subsection{General characteristics of ALD}

In case of CVD, gaseous precursor reactants are co-introduced into a heated reaction chamber. Therein, homogeneous reactions in the gas phase and heterogeneous reactions on and near the hot surfaces take place simultaneously, resulting in a film deposition on the substrate surface [61]. The principle of ALD is similar to CVD, except that precursors are sequentially introduced into the reaction chamber with inert gas purge in between, and the deposition is achieved through sequential surface reactions. Such "isolated" exposures of precursors effectively inhibit the homogeneous gas phase reactions between precursors, making the deposition in a more controlled manor [5, 21, 24, 26]. Each ALD cycle consists of four characteristic four steps (Fig. 1): First, introduce precursor A to the reactor, and a reaction between precursor $\mathrm{A}$ and reactive sites on a substrate starts taking place. The saturation of precursor A on the substrate surface is reached once all available reactive sites are consumed. Second, remove all unreacted precursor and volatile by-products from the substrate by inert gas purging. Third, precursor B is introduced to the substrate to conduct the second surface reaction and convert the surface back to the starting surface with the same reactive sites. Fourth, remove the unreacted precursors and byproducts through a second inert gas purge. These four steps can be repeated to produce more ALD cycles.

Most ALD processes are based on the binary reaction sequence described above, which is 
called AB-type ALD, while other variations have also emerged. For example, a new ABCtype ALD process was recently developed for noble metal depositions at lower temperatures, where ALD is carried out based on a sequence of chemisorption, combustion and reduction steps [62-66]. The steps in each ALD cycle can be automatically under computer control. When the ALD conditions for different materials are similar, the ALD processes of these components can be easily combined together in a controlled sequence to construct a variety of structures. An example is the nanolaminate (Fig. 3) [21, 67, 68]. This flexibility in ALD sequences makes it an attractive method in catalyst synthesis. This will be shown in the synthesis of supported bimetallic catalysts discussed in Section 3 and oxide architectures for photocatalysis discussed in Section 6 [69].
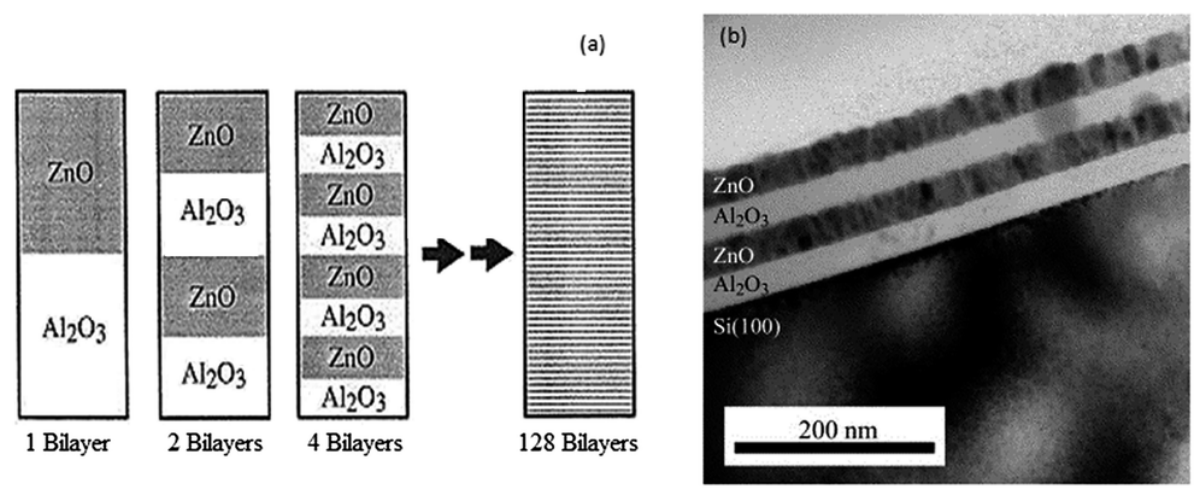

Fig. 3. A schematic, on the left hand side, that illustrates the materials design of an $\mathrm{Al}_{2} \mathrm{O}_{3}-$ ZnO nanolaminate. The right hand side shows a cross-sectional transmission electron micrograph of an $\mathrm{Al}_{2} \mathrm{O}_{3}-\mathrm{ZnO}$ nanolaminate where the layer thickness is about 30 nanometers. Reprinted with permission from [67].

Two factors have been identified as responsible for the saturation of two half-reaction cycles during ALD: the number of reactive surface sites and steric hindrance of precursor ligands [26]. The number of reactive sites provides an upper limit on the amount of chemisorbed precursor. When the density of reactive sites is too high and the size of precursor ligands too large, steric constrains imposed by the precursor ligands governs the saturation. Three models have been developed for analyzing the growth rate based on the steric hindrance effect, as shown in Fig. 4 [26]. The saturation density can be estimated based on the size of $M L_{n}$ reactant (Fig. 4a) [70,71], the size and geometry of the adsorbed $\mathrm{ML}_{\mathrm{z}}$ species (Fig. 4b) [72], and the size and number of adsorbed ligands L (Fig. 4c) [73-75]. Obviously, the deposited ALD material in each cycle is less than a monolayer, although it is called atomic layer deposition. For instance, the growth rate of $\mathrm{Al}_{2} \mathrm{O}_{3}$ ALD is about 1.1-1.3 $\AA$ /cycle, much less than the estimated monolayer thickness of $3.8 \AA[21,76]$. As a 
consequence, the thickness of deposited film can be precisely controlled down to submonolayer coverage, which is essentially important for synthesis of supported catalysts with near atomic precision.
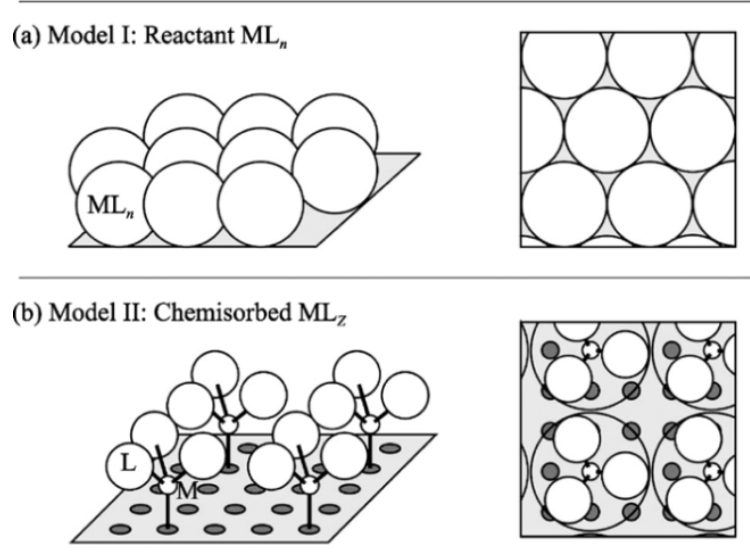

(c) Model III: Ligand L
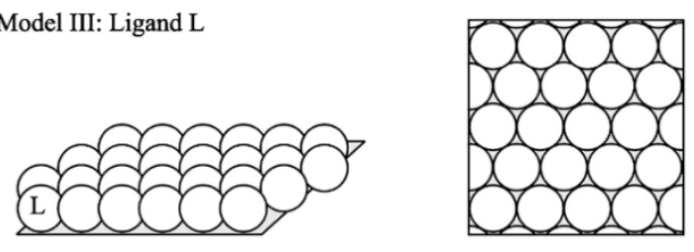

Fig. 4. Schematic illustration for analyzing sterically hindered chemisorption on the basis of the size of the $M L_{n}$ reactant (a), the size and geometry of the chemisorbed $M L_{z}$ species (b), and the size and number of ligands L (c). Reprinted with permission from [26].

\subsection{Temperature effect}

The ALD growth rate usually varies with reaction temperature. the temperature dependence is induced by several factors: (i) a change in the number and type of reactive sites present on the substrate surface with temperature. (ii) the effect of temperature on the reaction mechanism. For instance, the ligand to metal $(\mathrm{L} / \mathrm{M})$ ratio in the chemisorbed $\mathrm{ML}_{\mathrm{z}}$ species (Fig. 4b) changes with increasing the reaction temperature. (iii) uncontrolled growth via condensation of precursors on the substrate at low temperatures. (iv) uncontrolled growth via precursors thermal decomposition at high temperatures. A schematic representation of ALD growth rate with growth temperature is shown in Fig. 5. For each ALD process, there is usually a temperature regime within which self-limiting growth can be achieved. This temperature regime is often called the "ALD process window” [5, 21, 24, 26]. Uncontrolled growth via either condensation or thermal decomposition of precursors has to be avoided in order to achieve conformal deposition on substrates, especially in the case of catalyst synthesis, where longer precursors dose times are required to achieve saturation on high 
surface area substrates $[5,7,13,77]$.

The growth temperature can also have a significant impact on the crystallinity and surface roughness of deposited films. For example, $\mathrm{TiO}_{2} \mathrm{ALD}$ films formed using $\mathrm{TiCl}_{4}$ and water are amorphous at a deposition temperature of $100-165^{\circ} \mathrm{C}$. The structure changes to anatase phase in films grown at $165-350{ }^{\circ} \mathrm{C}$; while rutile dominates in the films obtained at temperatures above $350{ }^{\circ} \mathrm{C}$ [78]. Surface roughness can also increase due to crystallization. Indeed, using atomic force microscopy (AFM), King et al. showed that $\mathrm{TiO}_{2}$ films grown at different temperatures yielded a root-mean-square (RMS) roughness of $0.2 \mathrm{~nm}$ at $100{ }^{\circ} \mathrm{C}, 2.1$ $\mathrm{nm}$ at $300{ }^{\circ} \mathrm{C}$, and $9.6 \mathrm{~nm}$ at $600{ }^{\circ} \mathrm{C}$ [79]. In the case of supported metal catalyst synthesis, the growth temperature has a large impact on the nucleation and dispersion of metal nanoparticles, which will be discussed in Section 3.

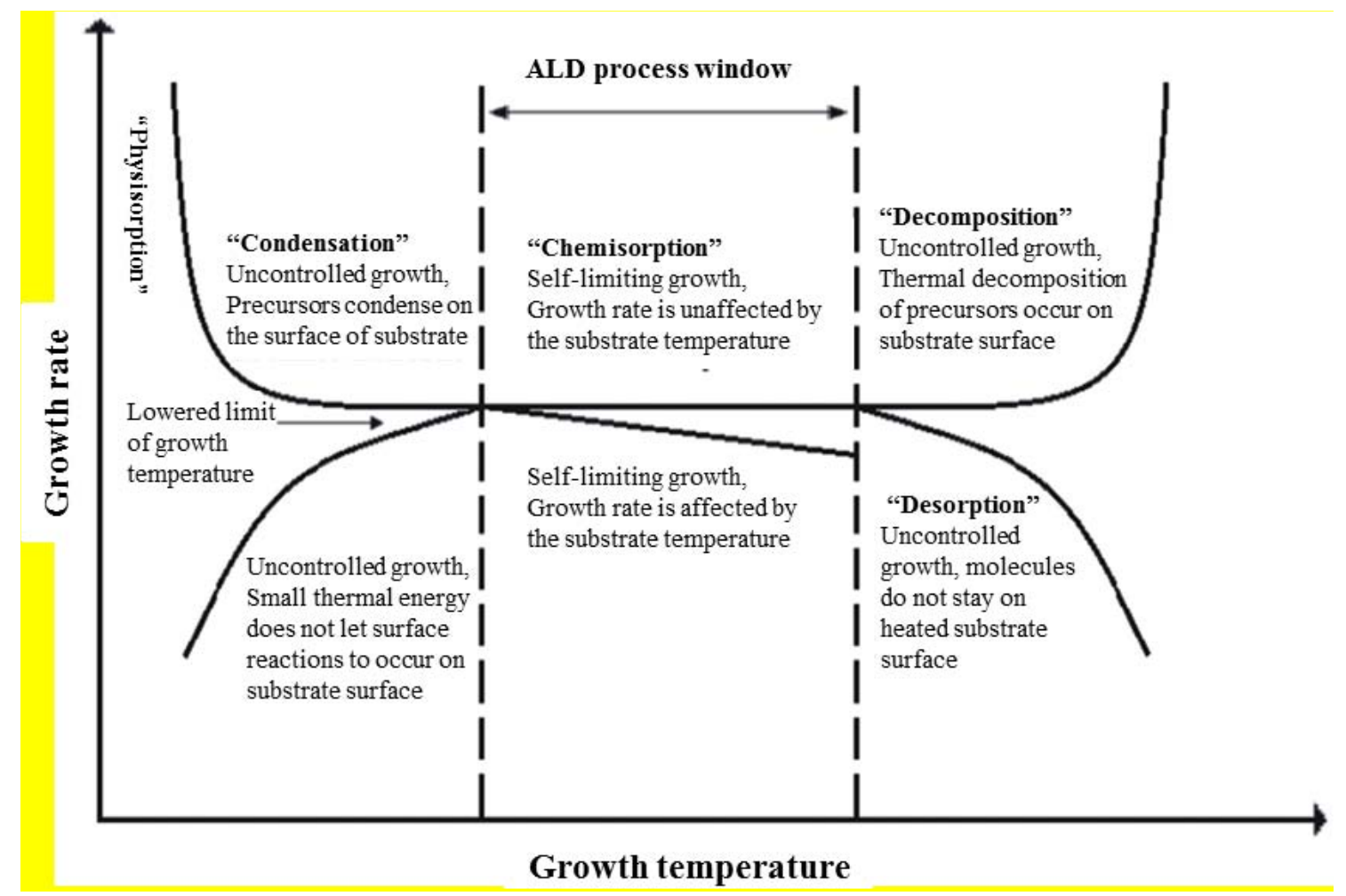

Fig. 5. Schematic of ALD process with temperature. Reprinted with permission from Picosun.

\subsection{Type of $A L D$}

In general, there are three types of ALD processes: Thermal ALD, catalytic ALD, and plasma-enhanced ALD (PE-ALD). In case of thermal ALD, the two precursor reactions are driven by forming thermodynamically favored surface species and volatile byproducts [21]. For instance, $\mathrm{Al}_{2} \mathrm{O}_{3}$ ALD using trimethylaluminum (TMA) and water is a highly exothermic 
process with an extremely high reaction enthalpy of $\Delta \mathrm{H}=-376 \mathrm{kcal}$ for the overall reaction [80]. ALD reactions are similar to the formation of $\mathrm{Al}_{2} \mathrm{O}_{3}$, with negative heats of reaction. Thermal ALD systems includes deposition of noble metals such as Pt, Pd, Ag, Ru, Re, Rh, metal oxides such as $\mathrm{Al}_{2} \mathrm{O}_{3}, \mathrm{TiO}_{2}, \mathrm{ZnO}, \mathrm{ZrO}_{2}, \mathrm{Nb}_{2} \mathrm{O}_{5}, \mathrm{Ta}_{2} \mathrm{O}_{5}$, metal nitrides such as TiN, TaN, $\mathrm{W}_{2} \mathrm{~N}$, and sulfides such as $\mathrm{ZnS}, \mathrm{CdS}$. $\mathrm{Cu}_{2} \mathrm{~S}$ (also seen in the review paper elsewhere by Puurunen [26] and the references therein). Up to now, the application of ALD in catalyst synthesis has been carried out using thermal ALD [5, 13].

(a)

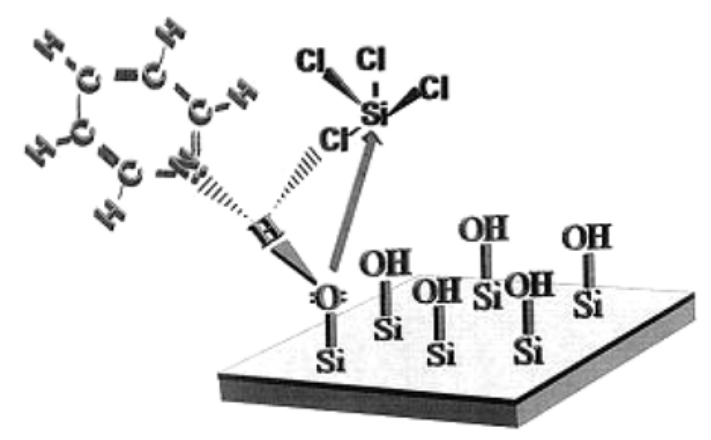

(b)

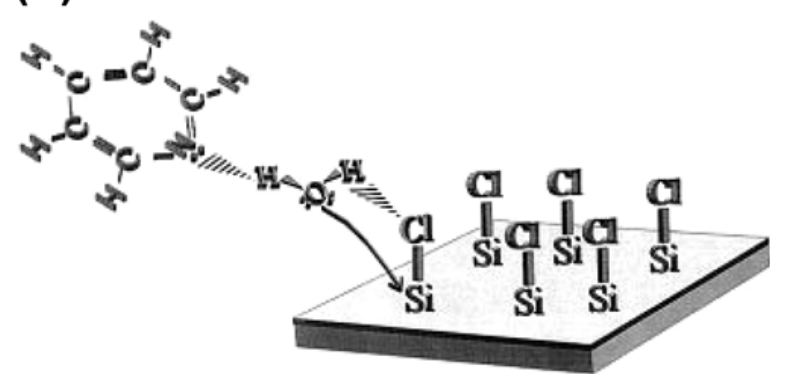

Fig. 6. Proposed mechanism for Lewis base catalysis of $\mathrm{SiO}_{2} \mathrm{ALD}$ during (a) the $\mathrm{SiCl}_{4}$ reaction and (b) the $\mathrm{H}_{2} \mathrm{O}$ reaction. Reprinted with permission from [81]. Copyright (C) 1997, The American Association for the Advancement of Science.

Catalytic ALD is a less common process; therein, a catalyst reagent vapor is introduced to the reaction via cofeeding with ALD precursors to facilitate surface reactions at low temperatures. One of the most investigated ALD systems is $\mathrm{SiO}_{2} \mathrm{ALD}$ using $\mathrm{SiCl}_{4}$ and $\mathrm{H}_{2} \mathrm{O}$. For the thermal ALD process, the ALD surface reactions are very slow and only occur at a high temperature above $300{ }^{\circ} \mathrm{C}$ after very large $\mathrm{SiCl}_{4}$ and $\mathrm{H}_{2} \mathrm{O}$ exposures [82]. When pyridine or ammonia was used as a Lewis base catalyst, the growth temperature was lowered to room temperature with a growth rate of $2.1 \AA$ /cycle; the reactant flux required for complete reaction was also significantly reduced from $\sim 10^{9}$ to $\sim 10^{4}$ Langmuirs. The catalytic 
mechanism was proposed to be activation of the $\mathrm{OH}$ bond via hydrogen bonding between the Lewis base and either the $\mathrm{SiOH}^{*}$ surface species during the $\mathrm{SiCl}_{4}$ reaction or the $\mathrm{H}_{2} \mathrm{O}$ reactant during the $\mathrm{H}_{2} \mathrm{O}$ reaction (Fig. 6) [81, 83]. Additional studies have shown that Lewis bases can also catalyze $\mathrm{SiO}_{2}$ ALD using other silicon precursors such as tetraethoxysilane (TEOS) [84] and tris(tert-pentoxy)silanol [85]. Low temperature ALD is important for deposition on thermally fragile substrates such as electronic circuits, polymers and biological samples.

PE-ALD (or Radical-enhanced ALD) is an important process for the deposition of singleelement ALD materials, such as metals and semiconductors, since these materials are very difficult to deposit using thermal ALD processes [21, 86, 87]. Typical plasmas used during PE-ALD are those generated in $\mathrm{O}_{2}, \mathrm{H}_{2}, \mathrm{~N}_{2}$ and $\mathrm{NH}_{3}$ reactant gases or combinations thereof. Such plasmas can be employed to deposit metal oxides, metal nitrides and metal films. The radicals or other energetic species in the plasma help to induce reactions that are not possible using thermal energy. A schematic diagram of hydrogen radical-enhanced ALD is shown in Fig. 7 [21]. As a consequence, PE-ALD has several benefits over conventional thermal ALD, such as a reduced process temperature, improved film qualities, and an increased scope of reactions [87]. Nevertheless, radical recombination could cause non-conformal coating on substrates with complex structures [88]. Indeed, on a trenched sample with a high aspect ratio of 40:1, a Ta film produced by PE-ALD was not conformal in the trenches [89]. The Ta film was considerably thicker on the top of trench than on the bottom due to hydrogen radical recombination on the walls of the trench. Therefore, the application of PE-ALD in catalyst synthesis might be challenging, since catalyst supports often contain a large pore volume in order to achieve high surface area. In this review, we consider only thermal ALD processes.

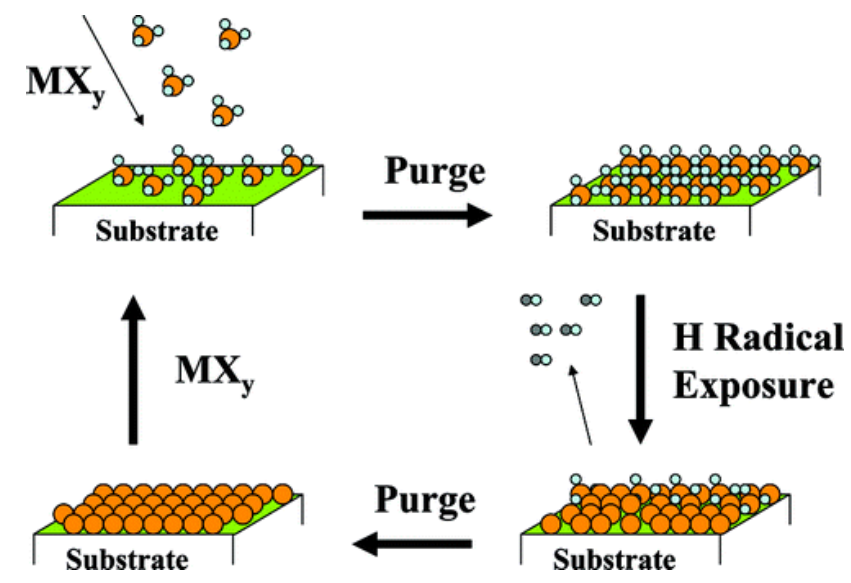

Fig. 7. Schematic diagram of hydrogen radical-enhanced ALD using a metal reactant and hydrogen radicals. Reprinted with permission from [21]. Copyright (c) 2010, American Chemical Society. 


\section{Metal ALD on oxides and carbon materials: precise synthesis of supported monometallic catalysts}

Transition-metal nanoparticles supported on oxides or carbon-based materials are objects of great interest in heterogeneous catalysis due to their unique chemical and physical properties. They are widely used in automobile exhaust treatment [32, 90], Fischer-Tropsch synthesis [91, 92], biomass conversions [93, 94], electrocatalysis[95, 96], and many other processes [35, 97, 98]. Catalytic performance depends strongly on the size, composition, and morphology of the metal nanoparticles [96, 99-101]. As a consequence, substantial efforts to optimize the synthesis procedure and explore new synthesis methods have been devoted to improving control over these factors to obtain metal particles high uniformity that are expected to exhibit higher activity and selectivity [102-104] .

Metal ALD on various oxides and carbon-based materials has been widely investigated. Metal nanoparticles, instead of uniform metal films, are often formed due to the considerably higher surface energies of metals compared to oxides (or carbon) and the ALD conditions at elevated temperatures, which promote surface metal particle nucleation and growth. Interestingly, it was found that metal particle size varies almost linearly with the number of ALD cycles, while preserving a narrow particle size distribution. Such behavior is detrimental to the preparation of thin-film electroluminescent devices and microelectronics, but it sparks a new application in catalysis [5, 13]. Precise control over the size and composition of metal nanoparticles is expected due to the molecular reaction character of ALD, thus ALD provides an alternative method for catalyst synthesis that complements conventional methods based on wet chemistry.

\subsection{Pt ALD}

Thermal Pt ALD is one of the most extensively investigated metal ALD processes. It is usually performed using (methylcyclopentadienyl)trimethylplatinum ( $\mathrm{MeCpPtMe}$ ) as the $\mathrm{Pt}$ precursor and molecular oxygen as the nonmetal precursor at a relatively high temperature between 200 and $300{ }^{\circ} \mathrm{C}$ [105-109]; The growth rate is about 0.3 and $0.5 \AA$ /cycle at 200 and $300{ }^{\circ} \mathrm{C}$, respectively [106]. By quantitatively analysis of in situ infrared spectroscopy, mass spectroscopy and ellipsometry measurements, Kessels et al, [107] proposed that $\mathrm{MeCpPtMe}_{3}$ reacts with surface oxygen on the previously formed Pt film to form $\mathrm{MeCpPtMe}_{2}$ * surface species and $\mathrm{CO}_{2}, \mathrm{CH}_{4}$, and $\mathrm{H}_{2} \mathrm{O}$ gaseous products (Equation 1); next, molecular oxygen burns away the remaining Pt precursor ligand to form $\mathrm{CO}_{2}$ and $\mathrm{H}_{2} \mathrm{O}$ while oxidizing the Pt surface 
(Equation 2). The produced $\mathrm{O} *$ surface species during oxygen exposure provide new reactive sites for the subsequent ALD cycles.

$$
\begin{aligned}
& 2 \mathrm{MeCpPtMe}_{3}(\mathrm{~g})+3 \mathrm{O} * \rightarrow 2 \mathrm{MeCpPtMe}_{2}^{*}+\mathrm{CH}_{4}(\mathrm{~g})+\mathrm{CO}_{2}(\mathrm{~g})+\mathrm{H}_{2} \mathrm{O}(\mathrm{g}) \\
& 2 \mathrm{MeCpPtMe}_{2}{ }^{*}+24 \mathrm{O}_{2}(\mathrm{~g}) \rightarrow 2 \mathrm{Pt}^{*}+3 \mathrm{O}^{*}+16 \mathrm{CO}_{2}(\mathrm{~g})+13 \mathrm{H}_{2} \mathrm{O}(\mathrm{g})
\end{aligned}
$$

Considering the catalytic nature of Pt film, they further proposed that the formation of $\mathrm{CH}_{4}$ during $\mathrm{MeCpPtMe}_{3}$ exposure can be attributed to the hydrogenation of methyl surface species by hydrogen atoms released from dehydrogenation of the precursor ligands. This suggests that the surface chemistry during Pt ALD includes reactions and species not indicated in Equations 1-2. See, for example, Fig. 8 [110].
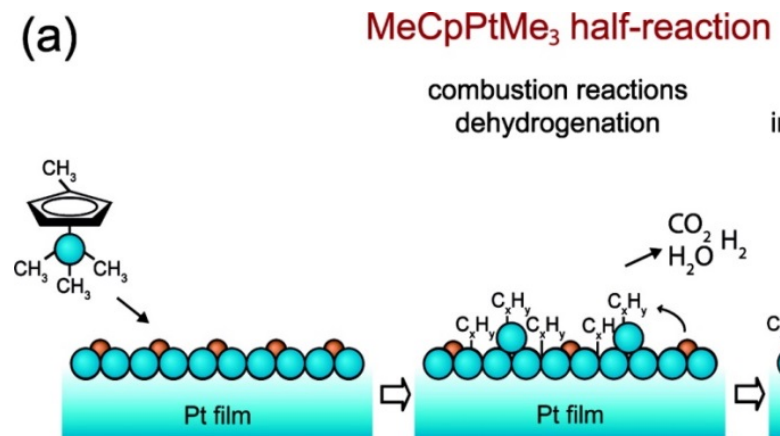

(b)
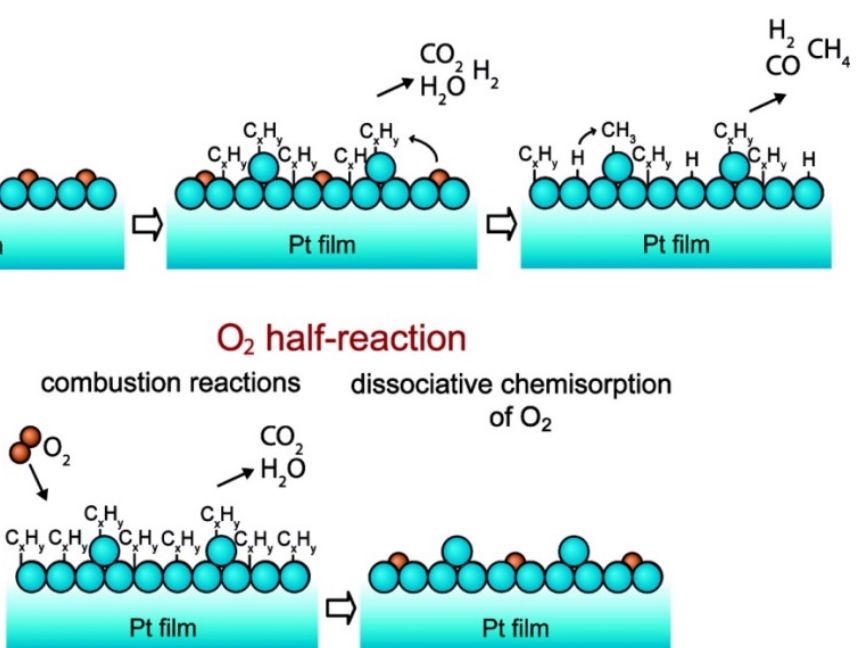

Fig. 8. Schematic representation of the surface reactions during Pt ALD. (a) At the start of the $\mathrm{MeCpPtMe}_{3}$ half-reaction when the surface is covered with $\mathrm{O}$ atoms, the $\mathrm{MeCpPtMe}_{3}$ molecules undergo combustion and dehydrogenation reactions upon adsorption, resulting predominantly in $\mathrm{CO}_{2}$ and $\mathrm{H}_{2} \mathrm{O}$ reaction products. The reactions continue when $\mathrm{O}$ becomes depleted with dehydrogenation and incomplete oxidation, which leads to $\mathrm{H}_{2}, \mathrm{CO}$, and $\mathrm{CH}_{4}$ and additional hydrogenation products. (b) During the $\mathrm{O}_{2}$ pulse, the carbonaceous layer formed in the $\mathrm{MeCpPtMe}_{3}$ pulse is combusted, and $\mathrm{O}_{2}$ dissociatively chemisorbs at the surface providing surface-bound oxygen for the next ALD cycle. Reprinted with permission from [110]. Copyright (C 2012, American Chemical Society.

\subsubsection{Nucleation and growth of Pt ALD on oxides}

When Pt ALD is performed on oxide surfaces, a nucleation period was frequently observed in the initial ALD cycles before reaching a stable linear growth, where Pt ALD grows on a 
continuous Pt film (Fig. 9) [109, 111-113]. It is generally believed that surface hydroxyl groups on oxide surfaces are the nucleation sites for Pt ALD [114, 115]. The strong dependence of the Pt nucleation on oxide compositions might be attributed to the reactivity of hydroxyls with the Pt precursor and to the interaction between the resulting Pt nanoparticles and the oxide support [109]. Using in-situ X-ray absorption spectroscopy (XAS), Marshall and co-workers investigated the initial stage of Pt nanoparticle formation during Pt ALD on a $\gamma-\mathrm{Al}_{2} \mathrm{O}_{3}$ support [114]. They demonstrated that the temperature, precursor exposure time, treatment gas, and number of ALD cycles influence the Pt particle size and density. The results suggest that $\mathrm{MeCpPtMe}$ reacts with surface hydroxyls on the $\gamma-\mathrm{Al}_{2} \mathrm{O}_{3}$ support and to form $\mathrm{MeCpPtMe}_{2}{ }^{*}$ surface species upon exposure of $\mathrm{MeCpPtMe}_{3}$. At $300{ }^{\circ} \mathrm{C}$, reaction of $\mathrm{MeCpPtMe}_{2}$ * with air leads to PtO. In subsequent ALD cycles, $\mathrm{MeCpPtMe}_{3}$ reduces the PtO to metallic Pt with a stoichiometry of one precursor molecule per PtO. In addition, $\mathrm{H}_{2}$ treatment of the $\mathrm{MeCpPtMe}_{2}{ }^{*}$ surface species also removed the ligands and formed $\mathrm{Pt}$ nanoparticles, even though Pt ALD is not normally performed using $\mathrm{H}_{2}$ as the second reagent. In line with this observation, Medlin et al. also demonstrated that using $\mathrm{H}_{2}$ as the second reagent during Pt ALD leads to smaller Pt particle sizes than $\mathrm{O}_{2}$ on alumina supports [115]. Surprisingly, using in-situ Fourier transform infrared spectroscopy (FTIR), they found that the $\mathrm{OH}$ group concentration did not show any discernible changes during Pt ALD using $\mathrm{MeCpPtMe}_{3}-\mathrm{O}_{2}$. They proposed that the Pt ALD with $\mathrm{O}_{2}$ serves to (re)oxidize the surface to form a nearly constant level of surface hydroxyls.

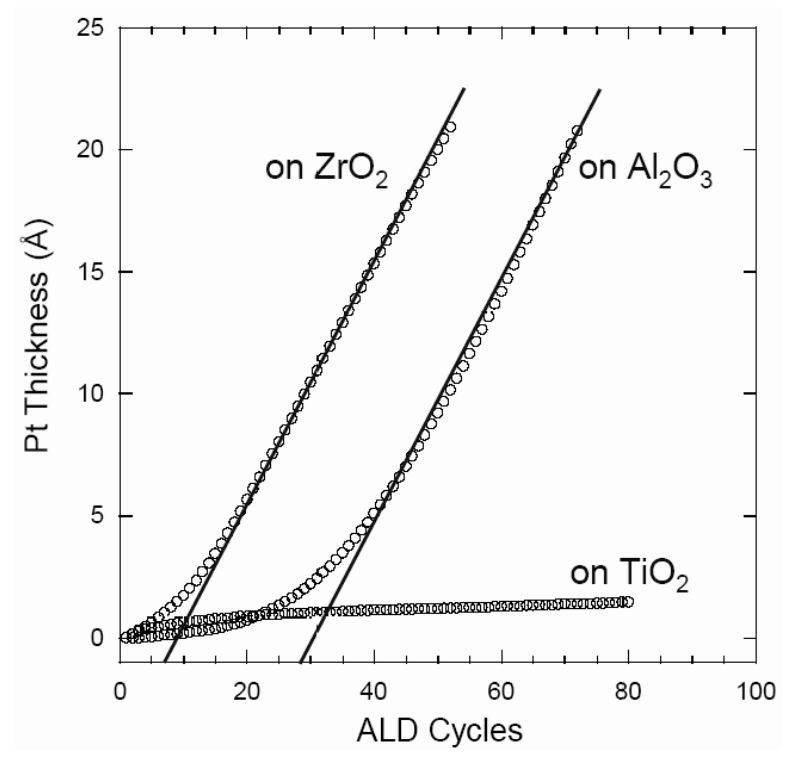

Fig. 9. $\mathrm{QCM}$ measurements of $\mathrm{Pt} \mathrm{ALD}$ on $\mathrm{ZrO}_{2}, \mathrm{Al}_{2} \mathrm{O}_{3}$ and $\mathrm{TiO}_{2}$ surfaces at $300^{\circ} \mathrm{C}$. Reprinted with permission from [109]. Copyright 2003, The Electrochemical Society. 


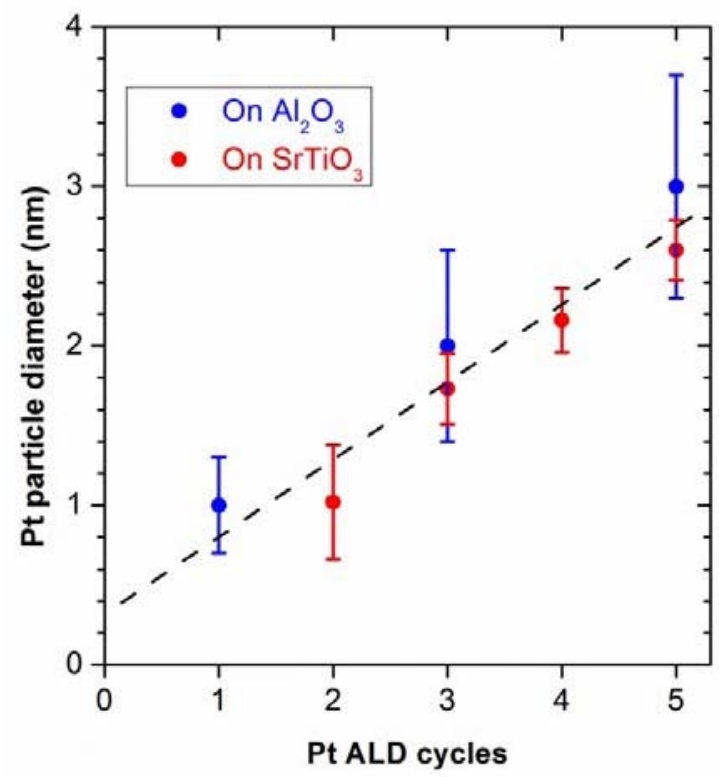

Fig. 10. ALD Pt nanoparticle diameter versus number of Pt ALD cycles deposited on $\mathrm{Al}_{2} \mathrm{O}_{3}$ nanospheres at $300{ }^{\circ} \mathrm{C}$ and measured using TEM (blue symbols), and deposited on $\mathrm{SrTiO}_{3}$ nanocubes and measured using X-ray diffraction (red symbols). Reprinted with permission from [5]. Copyright (C) 2013, American Chemical Society.

In the application to catalysis, the main focus has been on the nucleation in the first several cycles. As shown in Fig. 10, the Pt nanoparticle size is directly proportional to the number of ALD cycles and can be controlled with a precision of $\sim 0.5 \mathrm{~nm}$ [5]. Moreover, the particle size is not strongly influenced by the substrate as evidenced by the similarity between depositions on the $\mathrm{Al}_{2} \mathrm{O}_{3}$ and $\mathrm{SrTiO}_{3}$ surfaces. It is noteworthy that such digitally precise control over the metal particle size is an advantage for ALD in the application to catalysis. For the water-gas-shift (WGS) reaction, Marshall et al. pointed out that the ALD Pt catalysts exhibit excellent catalytic activity and stable WGS reaction rates that are comparable to those of catalysts prepared by conventional incipient wetness impregnation [114, 116].

\subsubsection{Temperature effect}

At the standard deposition temperature of $300{ }^{\circ} \mathrm{C}$, 1-cycle Pt ALD on oxide supports often results in the formation of highly dispersed Pt nanoparticles with $\sim 1 \mathrm{~nm}$ size, as shown in Fig. 10. To prepare Pt nanoparticles in the sub-nanometer range, one convenient method is to decrease the deposition temperature so that sintering of Pt nanoparticles during the ALD process can be limited. In this case, a stronger oxidizing reagent such as $\mathrm{O}_{3}$, instead of $\mathrm{O}_{2}$ has to be employed to effectively combust the Pt precursor ligands. For instance, the Pt particle size remained at $\sim 1 \mathrm{~nm}$ even after 12 cycles of Pt ALD on an $\mathrm{Al}_{2} \mathrm{O}_{3}$ support using 
$\mathrm{MeCpPtMe}_{3}$ and $\mathrm{O}_{3}$ at $150{ }^{\circ} \mathrm{C}$ [69].

We recently developed a strategy of low-temperature ABC-type metal ALD for synthesizing subnanometer metal clusters with high loadings, as depicted in Fig. 11 [117, 118]. This procedure combines the deposition of catalytic metal at low temperatures (50-150 ${ }^{\circ} \mathrm{C}$ ), the A-reaction, with deposition of new support material, the $\mathbf{B}$ - and $\mathbf{C}$-reactions. Here the newly created support not only provides additional nucleation sites for metal deposition (Fig. 11d,e) but also retards agglomeration during the activation step (Fig. 11f). As a consequence, ultrafine uniform metal clusters, such as Pd, Pt and Ag supported on alumina and titania have been achieved. Fig. 12 shows a $\mathrm{Pt} / \mathrm{TiO}_{2}$ catalyst with an average particle size of $0.5 \mathrm{~nm}$ at a loading of $1.2 \mathrm{wt} \%$ synthesized using the $\mathrm{A} / \mathrm{B} / \mathrm{C}$ sequence: $\mathrm{MeCpPtMe}_{3}-$ titanium isopropoxide (TTIP)- $\mathrm{H}_{2} \mathrm{O}$.

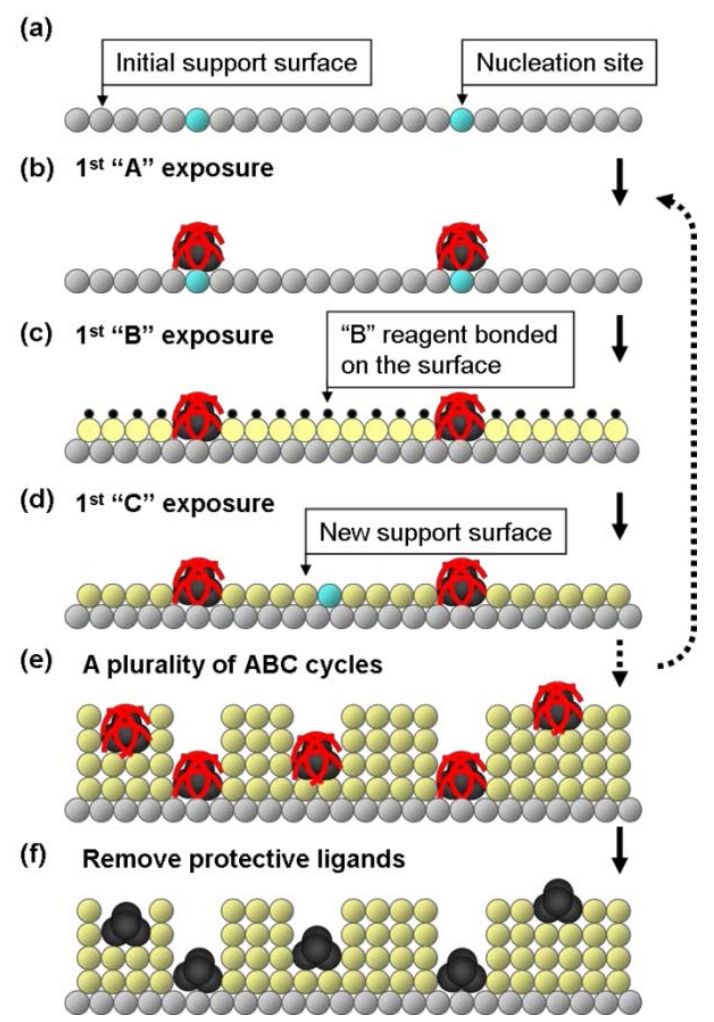

Fig. 11. A schematic illustration of ABC-type ALD: (a) An initial support with nucleation sites; (b) A volatile metal precursor $\mathbf{A}$ is introduced to the surface to form metal nanoparticles with part of ligands retained (red curves); The reagent $\mathbf{B}$ and $\mathbf{C}$ is then introduced to the surface sequentially to form a new support surface (c) and (d) ; (e) New support and metal nanoparticles protected by ligands are formed on the initial support surface after a plurality of ABC cycles; (f) The protective ligands are removed to activate metal nanoparticles. Reprinted with permission from [118]. Copyright (C) 2010 WILEY - VCH Verlag GmbH \& Co. KGaA, Weinheim. 

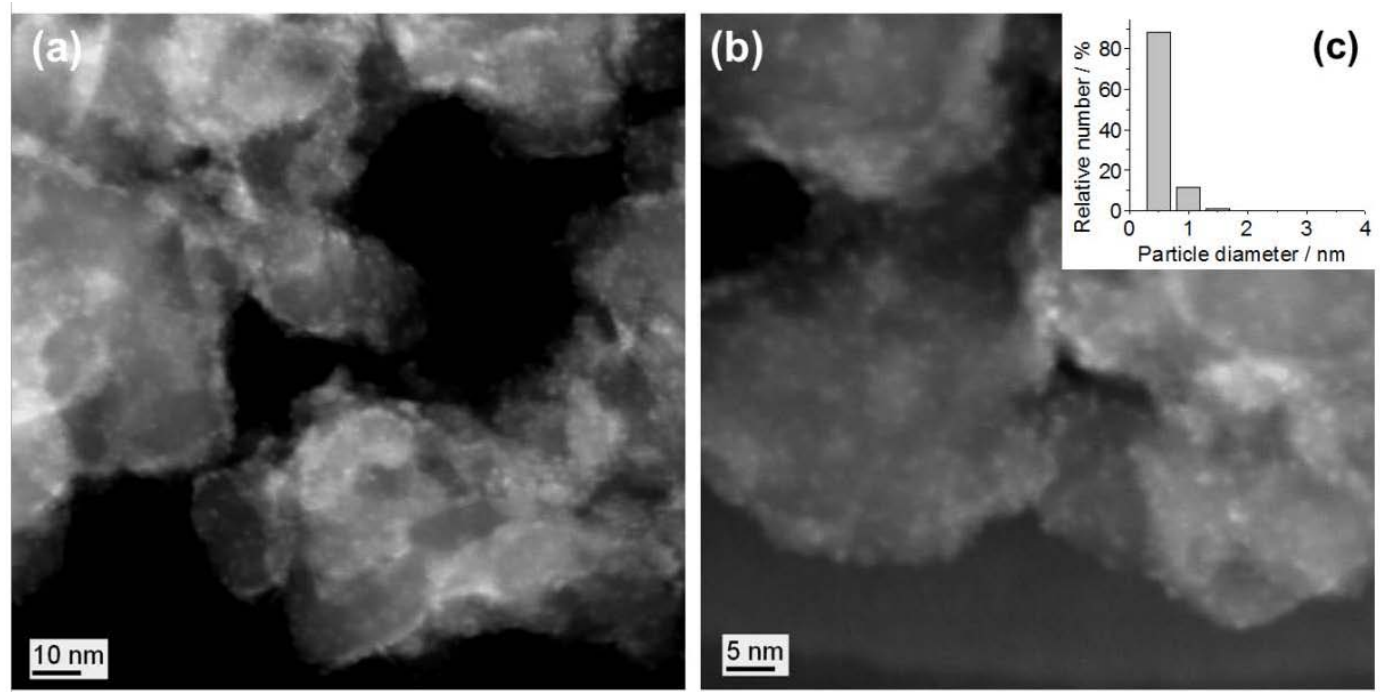

Fig. 12. Morphology (a-b) and size distribution (c) histogram of subnanometer Pt clusters synthesized by 4-cycle ABC-type Pt ALD on a high surface area 20-cycle $\mathrm{TiO}_{2}$ coated silica gel support at $50{ }^{\circ} \mathrm{C}$. Reprinted with permission from [118]. Copyright (C) 2010 WILEY VCH Verlag GmbH \& Co. KGaA, Weinheim.

\subsubsection{Nucleation of Pt ALD on carbon-based materials}

Carbon-based materials, such as carbon nanotubes (CNTs), graphene, and active carbon are another common class of catalyst support, especially in electrocatalysis application due to their high surface areas, good thermal and electrical conductivity, as well as mechanical and chemical stability. Pt is the well-known bench-mark metal [95, 119, 120]. Improving the atom efficiency to reduce cost while retaining the high catalytic activity of Pt remains a challenge. The advantage of precise control over the metal particle size by ALD has attracted a lot attention for design of high performance electrode materials. A number of studies of Pt ALD on carbon-based materials have been reported [11, 121-124]; therein conformal Pt deposition on carbon supports with high surface area was demonstrated, and higher Pt utilization efficiency was achieved by precisely controlling the Pt particle size and loadings through the numbers of ALD cycles. For instance, Bent et al, reported that Pt nanoparticles deposited on carbon aerogels by ALD exhibited high catalytic activity for the oxidation of CO even at loading levels as low as $\sim 0.05 \mathrm{mg} \mathrm{Pt} / \mathrm{cm}^{2}$ with a conversion efficiency of nearly $100 \%$ in the $150-250{ }^{\circ} \mathrm{C}$ temperature range [11].

Regarding the nucleation and growth of Pt ALD on carbon-based materials at the initial stage, it was found that ALD does not grow on the surface of pristine graphene, carbon 
nanotubes, carbon cloth $[60,122,123,125]$ due to the chemically inert nature of high quality graphitic carbon, since the initiation of ALD growth requires the presence of functional surface groups or defects that act as nucleation sites for the ALD precursors. Functionalization of the carbon surface is required prior to the deposition (also seen in the review paper elsewhere by Pinna et al. [126] and the references therein). Kim and co-workers reported that Pt nanoparticles were predominantly deposited on graphene's grain boundaries, folds and cracks due to the enhanced chemical reactivity of these line defect [125]. In order to facilitate the nucleation of ALD on carbon, chemical treatment of carbon based on mineral acids, such as $\mathrm{HNO}_{3}, \mathrm{H}_{2} \mathrm{SO}_{4}$, or strong oxidizing agent, such as $\mathrm{O}_{3}$ are commonly carried out to generate oxygen containing groups at the surface [127-129]. The resulting oxygen containing functional groups, such as $-\mathrm{COH}$ and $-\mathrm{COOH}$ acts as the nucleation sites for ALD growth. On nitric acid treated CNTs, Qin et al. observed an uniform dispersion of subnanometer Pt clusters up to 10 cycles of Pt ALD at $300{ }^{\circ} \mathrm{C}$ using $\mathrm{O}_{3}$ as oxidant, even though the Pt loading was as high as 2.3\%. The subnanometer Pt clusters showed high activity in styrene hydrogenation reaction [130].

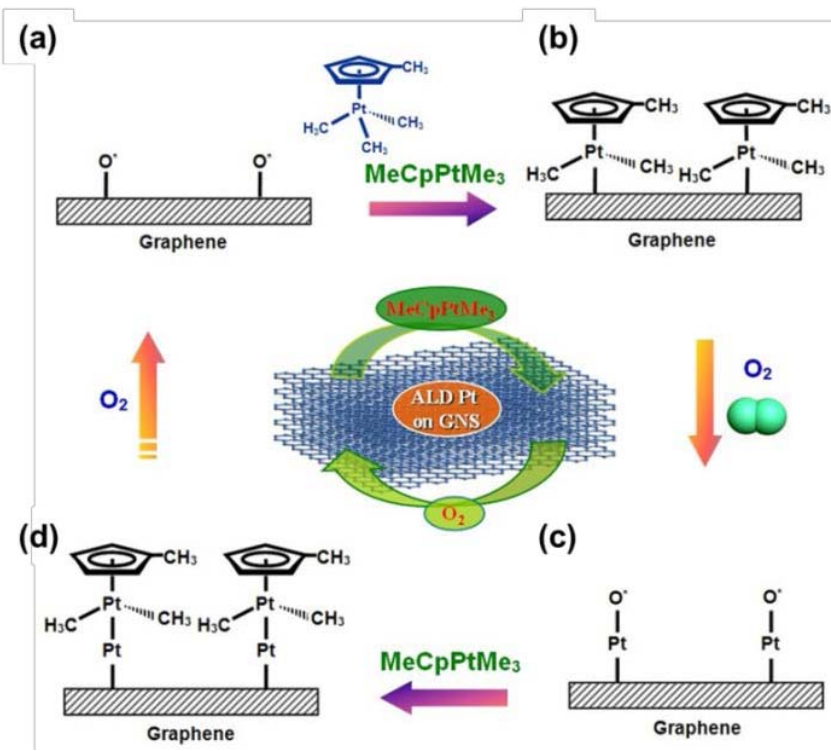

Fig. 13. Schematic illustrations of Pt ALD mechanism on graphene nanosheets. (a) oxygen containing function group on graphene nanosheets; (b) Reaction of $\mathrm{MeCpPtMe}_{3}$ with oxygen containing function group during the $\mathrm{MeCpPtM}_{3}$ exposure step; (c) the subsequent oxygen combust the remained ligand while forming a new adsorbed oxygen layer on the Pt surface; (d) Pt deposition is precisely controlled by tuning the number of ALD cycles. Here, '*' represents an active surface species, and Pt-O* represents oxygen molecules (or dissociated oxygen ions) that are adsorbed on the Pt surface. Reprinted with permission from [60]. Copyright (C) 2013, Rights Managed by Nature Publishing Group. 

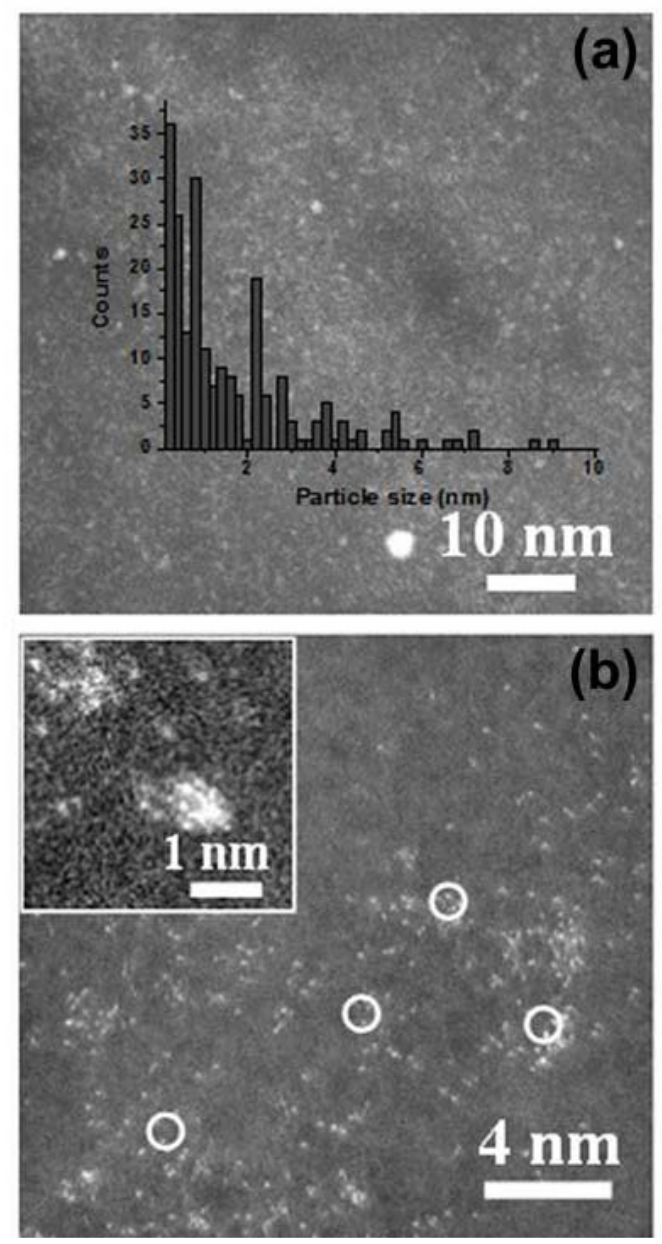

Fig. 14. HAADF-STEM images of a Pt/GNS sample synthesized by Pt ALD at $250 \mathrm{C}$ for 50 cycles, the inset in (a) shows the corresponding histogram of Pt on GNS. Reprinted with permission from [60]. Copyright (C) 2013, Rights Managed by Nature Publishing Group.

Sun et al. [60] proposed a general schematic model for Pt ALD on oxygen functionalized graphene support as shown in Fig. 13, $\mathrm{MeCpPtMe}_{3}$ reacts with surface oxygen species to form $\mathrm{MeCpPtMe}_{2}$ * by releasing $\mathrm{CO}_{2}$ and water during the $\mathrm{MeCpPtMe}$ exposure step (Fig. 13b); next, oxygen combusts off the remained ligands, and forms PtO (Fig. 13c). However, the detailed reaction mechanism during each step in the first ALD cycle is still unclear, and questions remain regarding how the isolated oxygen-containing functional group reacts with $\mathrm{MeCpPtMe}_{3}$ to produce $\mathrm{CO}_{2}$ and $\mathrm{H}_{2} \mathrm{O}$. Nevertheless, this was the first observation that a large fraction of isolated Pt atoms along with Pt nanoparticles were formed on the reduced graphene nanosheet (GNS) after 50 cycles of Pt ALD at $250{ }^{\circ} \mathrm{C}$ as shown in Fig. 14. The disagreement between the presence of isolated Pt atoms even after 50 Pt ALD cycles with the schematic model in Fig. 13, seems to be very likely due to the unsaturated exposure in each cycle, since the exposure time for $\mathrm{MeCpPtMe}_{3}$ was only about $1 \mathrm{sec}$ in their work, much 
shorter than the exposure time typically required for ALD on high surface area supports (tens to hundreds of seconds are typical). In the application to direct methanol fuel cells (DMFC), the authors further demonstrated that this single-atom catalyst exhibits significantly improved catalytic activity (up to 10 times) over the state-of-the-art commercial Pt/C catalyst. X-ray absorption fine structure (XAFS) analyses revealed that a low-coordination and partially unoccupied densities of states in the Pt $5 \mathrm{~d}$ orbital that might be responsible for the excellent performance.

\subsection{Pd ALD}

Thermal Pd ALD is another well-investigated metal ALD process. Unlike Pt ALD where the second reagent is $\mathrm{O}_{2}$ used to combust the ligands, Pd ALD was successfully achieved through a hydrogenation reaction, by alternatively exposing palladium(II)hexafluoroacetylacetonate $\left(\mathrm{Pd}(\mathrm{hfac})_{2}\right)$ and formalin $\left(\mathrm{or} \mathrm{H}_{2}\right)$ as a reducing agent at $200{ }^{\circ} \mathrm{C}$ [131]. Even though $\mathrm{O}_{2}$-based combustion reaction processes for Pd ALD process was later developed using $\mathrm{Pd}(\text { thd })_{2}-\mathrm{O}_{2}$ (thd $=$ 2,2,6,6-tetramethyl-3,5-heptanedionato) at $180{ }^{\circ} \mathrm{C}$ [132], $\mathrm{Pd}(\text { thd })_{2}-\mathrm{O}_{3}$ at $130-160{ }^{\circ} \mathrm{C}$ [63], $\mathrm{Pd}(\text { thd })_{2}-\mathrm{O}_{3}-\mathrm{H}_{2}$ at $130-160{ }^{\circ} \mathrm{C}$ [63], or $\mathrm{Pd}\left(\mathrm{keim}_{2}\right)_{2}-\mathrm{O}_{2}\left(\mathrm{keim}_{2}=\mathrm{CF}_{3} \mathrm{C}(\mathrm{O}) \mathrm{CH}-\mathrm{C}\left(\mathrm{CF}_{3}\right) \mathrm{NBu}^{n}\right)$ at 250-275 ${ }^{\circ} \mathrm{C}$ [106]. Detailed studies of these processes are limited. Therefore, we only discuss the Pd ALD process using Pd(hfac) $)_{2}-$ formalin (or $\mathrm{H}_{2}$ ) here.

With the sequence $\mathrm{Pd}(\mathrm{hfac})_{2}$-formalin, Elam et al. reported that the growth rate is about $0.22 \AA$ /cycle at $200{ }^{\circ} \mathrm{C}$ [131]. Based on the QCM measurements, a reaction mechanism was proposed in Equations (3,4):

$\mathrm{Pd}-\mathrm{H}^{*}+\mathrm{Pd}(\mathrm{hfac})_{2}(\mathrm{~g}) \rightarrow$ Pd-Pdhfac* + Hhfac $(\mathrm{g})$

Pd-Pdhfac* + HCHO $\rightarrow$ Pd-Pd-H* + CO (g) + Hhfac (g)

In each step, one hfac ligand of $\mathrm{Pd}(\mathrm{hfac})_{2}$ precursor is released in the form of Hhfac. In fact, HCHO can be replaced by molecular $\mathrm{H}_{2}$, once Pd ALD is growing on the Pd film itself as shown in Equation (5).

Pd-Pdhfac* $+\mathrm{H}_{2}(\mathrm{~g}) \rightarrow$ Pd-Pd-H* + Hhfac $(g)$

\subsubsection{Nucleation and growth of Pd ALD on oxides}

When Pd ALD is conducted on oxide surfaces, the Pd growth rate is initially low and then gradually increases to reach a steady state growth rate of $0.22 \AA$ /cycle, similar to Pt ALD on oxides shown in Fig. 9. Surface hydroxyl groups were proposed as the nucleation sites [131, 133]. For instance, on alumina, $\mathrm{Pd}(\mathrm{hfac})_{2}$ reacts with hydroxyl groups to form Al-O-Pdhfac* 
surface species and Hhfac (Equation 6). This mechanism is supported by evidence of a reduced Pd loading, $\sim 24 \%$, caused by a decrease in hydroxyl density via thermal treatment at $600{ }^{\circ} \mathrm{C}$ [134]. Using angle-dependent X-ray photoelectron spectroscopy (XPS) measurements, Elam et al. showed that the Hhfac product remains on the alumina surface as a poison, producing an extended nucleation period for Pd ALD [131].

$\mathrm{Al}-\mathrm{OH}+\mathrm{Pd}(\mathrm{hfac})_{2} \rightarrow \mathrm{Al}-\mathrm{O}-\mathrm{Pdhfac} *+$ Hhfac
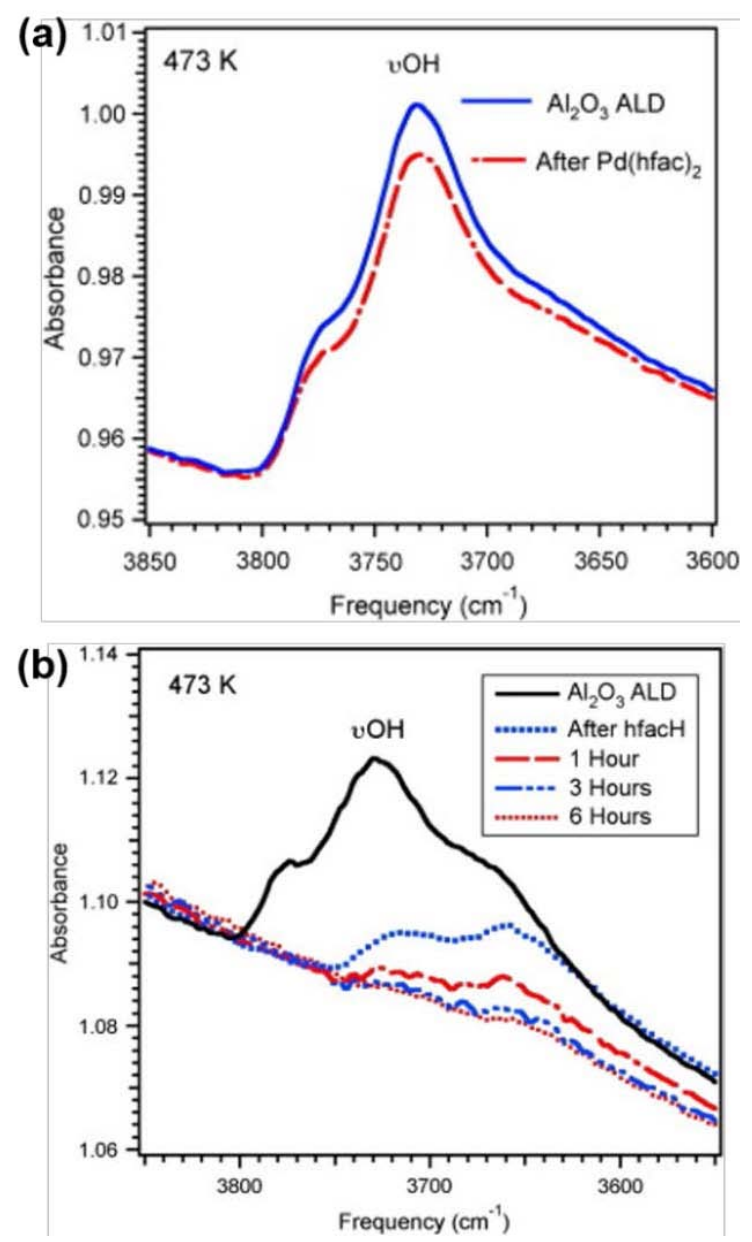

Fig. 15. (a) FTIR spectra in the $\mathrm{O}-\mathrm{H}$ stretching vibration region showing the spectra for the initial hydroxylated $\mathrm{Al}_{2} \mathrm{O}_{3}$ ALD surface at $200{ }^{\circ} \mathrm{C}$ and the surface after a saturation $\mathrm{Pd}(\mathrm{hfac})_{2}$ exposure at $200{ }^{\circ} \mathrm{C}$. (b) FTIR spectra in the $\mathrm{O}-\mathrm{H}$ stretching vibration region showing the spectra for the initial hydroxylated $\mathrm{Al}_{2} \mathrm{O}_{3}$ ALD surface at $200{ }^{\circ} \mathrm{C}$ and the surface after a saturation Hhfac exposure at $200{ }^{\circ} \mathrm{C}$. Reprinted with permission from [135]. Copyright (C) 2011 Elsevier B.V. All rights reserved.

George et al. further investigated the nucleation of Pd ALD on alumina using in situ FTIR [135]. They found that the adsorption of $\mathrm{Pd}(\mathrm{hfac})_{2}$ to hydroxylated alumina produced only a slight loss of hydroxyls in sharp contrast with exposure to Hhfac as shown in Fig. 15. They 
suggest that $\mathrm{Pd}(\mathrm{hfac})_{2}$ adsorbs primarily through dissociative adsorption without hydroxyl group reaction (Equation 7). The slight loss of hydroxyl groups may be due to the readsorption of the Hhfac product according to the Equation 8. Indeed, Alhfac surface species were identified as a poison.

$\mathrm{Al}^{*}+*+\operatorname{Pd}(\mathrm{hfac})_{2}(\mathrm{~g}) \rightarrow-$ Pdhfac $*+$ Alhfac $^{*}$

$\mathrm{Hhfac}+\mathrm{AlOH}^{*} \rightarrow$ Alhfac* $+\mathrm{H}_{2} \mathrm{O}(\mathrm{g})$

Next, when the surface decorated by Pdhfac* and Alhfac* is exposed to formalin, Pdhfac* species are reduced and Pd nanoparticles are formed, while Alhfac* remains on the surface. The Pd nanoparticles will be new nucleation sites for the next $\mathrm{Pd}(\mathrm{hfac})_{2}$ exposure in the subsequent ALD cycles, thus the size of Pd nanoparticles is precisely tuned with increasing ALD cycles (Fig. 16) [133]. Applying in situ FTIR, in situ XAS, and in situ pair distribution function (PDF) measurements under practical ALD conditions, Elam et al. followed the process of the $\mathrm{Pd}(\mathrm{hfac})_{2}$ deligation, evolution of the surface species, and formation of $\mathrm{Pd}$ nanoparticles [136]. It should be noted that hfac ligands may also decompose to form $\mathrm{CF}_{3}$ * species during the Pd ALD process. Therefore, an extent of surface contamination by carbon and fluorine is expected, when a Pd catalyst is synthesized using Pd ALD with the sequence $\operatorname{Pd}(\text { hfac })_{2}$ and formalin [135].

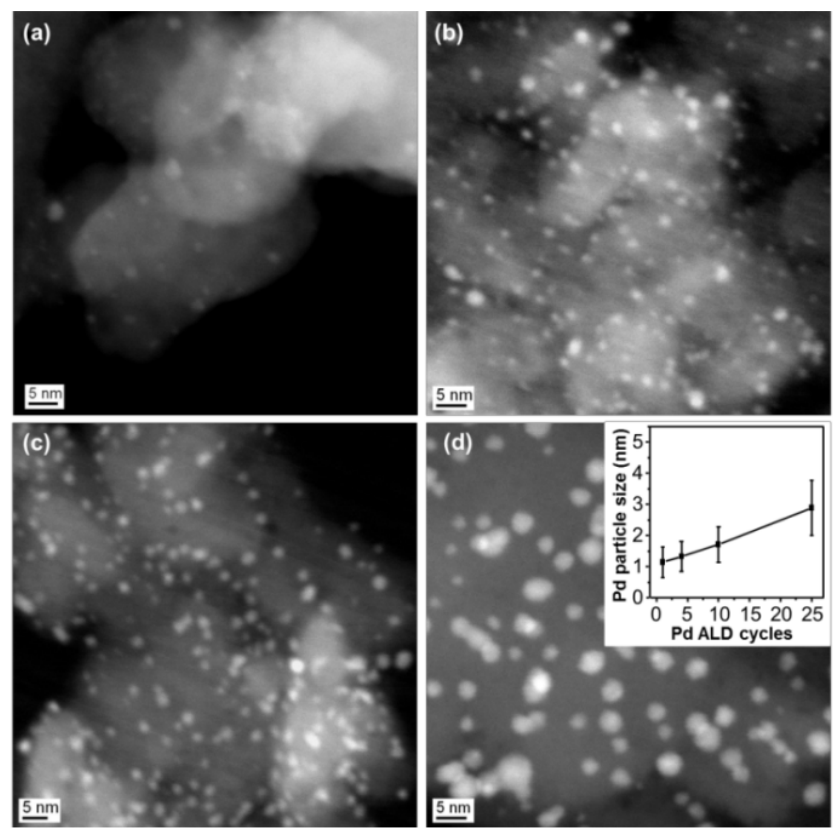

Fig. 16. STEM images of Pd ALD samples synthesized by Pd ALD on 10-cycle $\mathrm{Al}_{2} \mathrm{O}_{3}$ coated silica gel at $200{ }^{\circ} \mathrm{C}$ with different cycles: (a) 1-cycle Pd, (b) 4-cycle Pd; (c) 10-cycle Pd, (d) 25-cycle Pd. The insert shows the increase of Pd particle size as the number of Pd ALD cycles. Reprinted with permission from ref [133]. Copyright (C) 2010, American Chemical Society. 
The nucleation rate of Pd also depends on the type of oxide substrate. For instance, the nucleation of Pd ALD on $\mathrm{TiO}_{2}$ is obviously faster than on $\mathrm{Al}_{2} \mathrm{O}_{3}$, and Pd does not grow on silica [133], in contrast with Pt ALD, where a significantly faster nucleation rate was observed on $\mathrm{Al}_{2} \mathrm{O}_{3}$ than on $\mathrm{TiO}_{2}$ (Fig. 9) [109]. Elam et al. [7] evaluated the catalytic performance of $\mathrm{ALD}$ resulting $\mathrm{Pd} / \mathrm{Al}_{2} \mathrm{O}_{3}$ catalysts in the methanol decomposition reaction and found that the specific activity (based on the amount of metal) of Pd nanoparticles with a particle size of 1 to $2 \mathrm{~nm}$ was higher than the majority of Pd catalysts synthesized by other methods. Higher activity was attributed to the ultrauniform dispersion and small particle size obtained by the ALD method. Indeed, they further illustrated that large Pd particles (> $2 \mathrm{~nm})$ were a factor of 2 less active than the smaller Pd particles in their following studies [134].

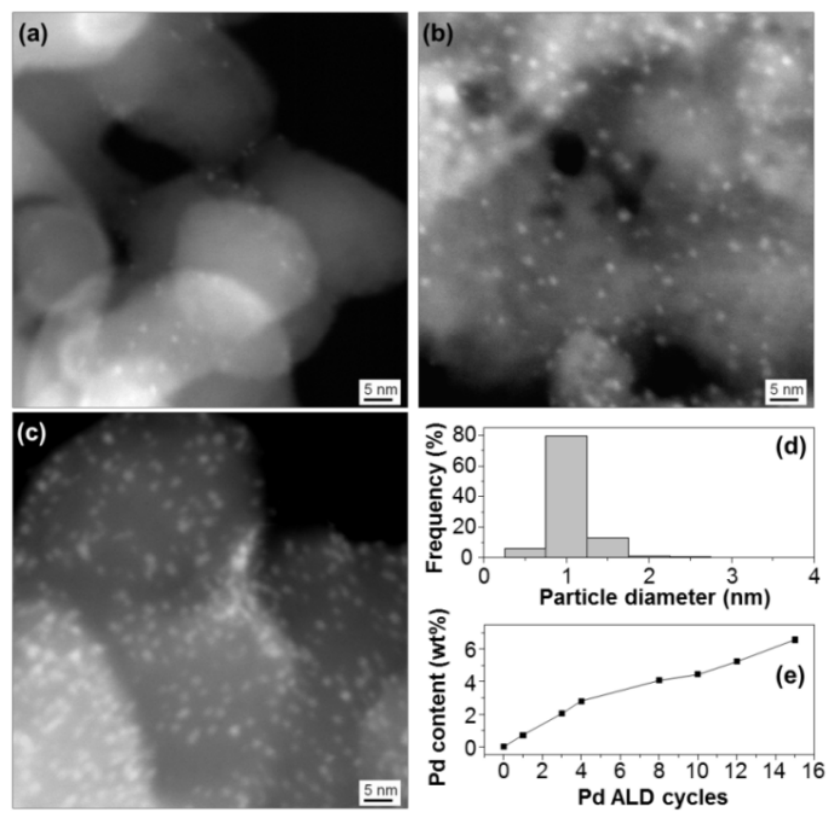

Fig. 17. STEM images of as-prepared Pd clusters on high surface area 10-cycle $\mathrm{Al}_{2} \mathrm{O}_{3}$ coated silica gel support by different cycles of ABC-type Pd ALD using Pd(hfac) ${ }_{2}-\mathrm{TMA}-\mathrm{H}_{2} \mathrm{O}$ at 80 ${ }^{\circ} \mathrm{C}$ : (a) 1 cycle; (b) 4 cycles (c) 15 cycles. (d) Size distribution histogram of Pd clusters on the as-prepared sample with 15 cycles. (e) Pd content by weight percentage for different Pd ALD cycles. Reprinted with permission from ref [118]. Copyright (C) 2010 WILEY - VCH Verlag GmbH \& Co. KGaA, Weinheim.

\subsubsection{Synthesis of ultrafine Pd clusters using low-temperature ABC-type ALD}

Using low-temperature ABC-type Pd ALD as depicted in Fig. 11, the size of Pd nanoparticles can be further downsized to about $1 \mathrm{~nm}$ with extremely high uniformity, while varying the Pd loadings over a wide range (Fig. 17) [118]. In this case, treatment with 
formalin at $200{ }^{\circ} \mathrm{C}$ was used to remove the capping hfac ligands leaving the metal particles accessible for chemisorption and catalytic function. Diffuse reflectance infrared Fourier transform spectroscopy (DRIFTS) measurements of chemisorbed CO, performed after each step in the ABC process, support the capping, ligand removal, and accessibility of the metal particles depicted in Fig. 11. STEM measurements on the active Pd catalysts suggest that ultrafine Pd clusters are stable after removing the capping hfac ligands by formalin, which is most likely a consequence of the surrounding oxide formed during the BC-portion of the ABC cycles.

\subsubsection{Nucleation of Pd ALD on carbon materials.}

When Pd ALD is performed on carbon-based materials, it was generally found that the increase of average Pd nanoparticle size as a function of ALD cycles is significantly faster than on oxide surfaces. Elam et al. reported that the Pd nanoparticle size was about 2.6, 5.5, and $8 \mathrm{~nm}$ following 1, 3 and 10 ALD cycles of Pd on porous carbon, as shown in Fig. 18 [137]. By comparison, Feng et al. reported that the Pd particle size was about 8.4, 11.4 and $11.8 \mathrm{~nm}$ for 1, 2, and 3 cycles of Pd ALD on activated carbon (AC) (Fig. 19) [138]. On the contrary, 1 ALD cycle of Pd on alumina under similar conditions, yields Pd nanoparticles with a diameter of $\sim 1 \mathrm{~nm}$ and 25 ALD cycles of Pd only increased the nanoparticle size to $2.9 \pm 0.9 \mathrm{~nm}$ (Fig. 16) [133]. In addition, it should be noted that the metal oxide surfaces yield a higher density of Pd nanoparticles compared to the porous carbon. These results suggest that there are fewer nucleation sites for the Pd ALD on carbon supports as compared to metal oxides, and that Pd diffuses more rapidly on the carbon, yielding a smaller density Pd particles with a larger size [137].

Feng et al. investigated acid and thermal pretreatment effects on the nucleation of Pd ALD [138]. They found that pretreatment of AC using nitric acid produces a significant amount of surface oxygen-containing functional groups $(-\mathrm{OH},-\mathrm{COC}-$, and $-\mathrm{COOH})$, which facilitated the nucleation and promoted the dispersion of Pd nanoparticles. On an AC support which was oxidized in $\mathrm{HNO}_{3}$ followed by annealing at $650{ }^{\circ} \mathrm{C}$ in an inert atmosphere, the average $\mathrm{Pd}$ sizes were 2.5, 4.6 and $5.1 \mathrm{~nm}$ after 1, 2 and 3 cycles of Pd ALD, considerably smaller than the ones obtained on untreated AC (Fig. 19). They pointed out that the surface functional groups play different roles at the different stages of Pd ALD: they promote dispersion of Pd species during the metal precursor exposure; on the other hand, instability of - $\mathrm{COOH}$ will facilitate agglomeration of metal nanoparticles during the formalin reduction step. Therefore, 
modifying the type and concentration of surface functional groups on the AC support will provide a measure of control over the Pd particle size. Highly dispersed Pd nanoparticles can be produced on the AC support with a low concentration of $-\mathrm{COOH}$ but with a fair concentration of surface $-\mathrm{OH}$ groups.
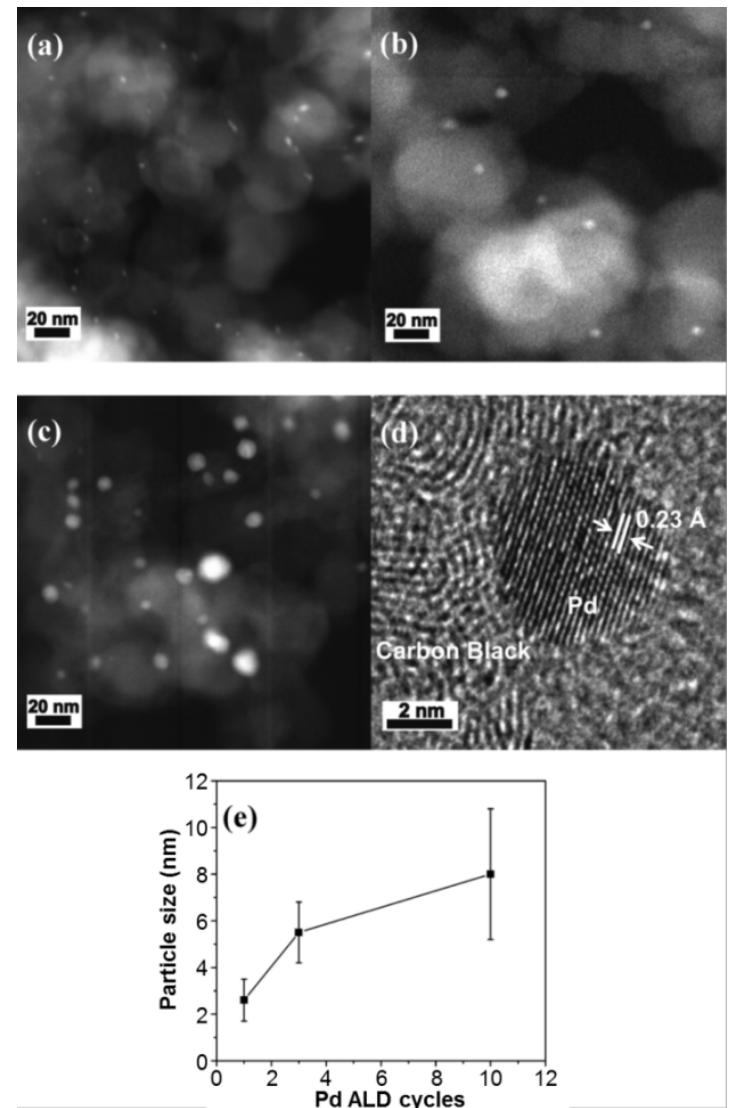

Fig. 18. STEM images of (a) 1c-Pd/C, (b) 3c-Pd/C, and (c) 10c-Pd/C. (d) HRTEM of a Pd nanoparticle $\sim 5.5 \mathrm{~nm}$ in diameter prepared by ALD supported over carbon. (e) Pd particle size as a function of ALD cycles. Reprinted with permission from [137]. Copyright (C) 2013, American Chemical Society.

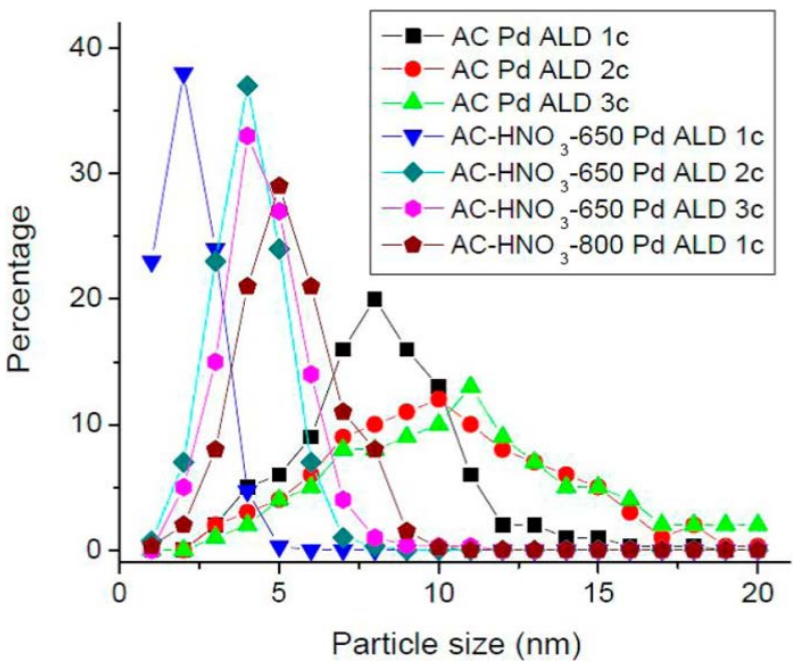


Fig. 19. Particle size distributions of ALD Pd/AC catalysts: 1,2 , and 3 cycles of Pd ALD on untreated AC (designated as AC Pd ALD xc); 1, 2, and 3 cycles of Pd ALD on pretreated AC where AC was treated in $\mathrm{HNO}_{3}$ followed by annealing at $650{ }^{\circ} \mathrm{C}$ in an inert atmosphere (designated as $\mathrm{AC}-\mathrm{HNO}_{3}-650 \mathrm{Pd} \mathrm{ALD}$ xc); and 1 cycle of Pd ALD on pretreated AC where AC was treated in $\mathrm{HNO}_{3}$ followed by annealing at $800{ }^{\circ} \mathrm{C}$ in an inert atmosphere (designated as $\mathrm{AC}-\mathrm{HNO}_{3}-650 \mathrm{Pd} \mathrm{ALD}$ xc). Reprinted with permission from [138]. Copyright (C) 2015, American Chemical Society.

\subsubsection{Synthesis of a single-atom $P d_{1} /$ graphene catalyst and its performance}

Atomically dispersed noble metal catalysts have attracted rapidly increasing attention due to their unique catalytic properties and maximal atom efficiency for low-cost [139-148]. The synthesis of single-atom metal catalysts via gas phase deposition is a grand challenge, since it is usually carried out at elevated temperatures, which would significantly accelerate metal atom aggregation during synthesis. Indeed, Sun et al. observed the formation of a mixture of atoms, clusters and nanoparticles with Pt ALD on graphene (Fig. 14) [60]. Botton et al. also reported the formation of a mixture of Pt atoms and clusters on a $\mathrm{N}$-doped graphene support using Pt ALD [149].

Very recently, we successfully demonstrated that atomically dispersed Pd on graphene can be achieved using ALD by a careful control over the oxygen-containing functional groups on the graphene surface (Fig. 20). Therein, by combining XPS, aberration-corrected HADDF STEM, and XAS measurements, isolated phenol groups were identified to be the active sites for anchoring the $\mathrm{Pd}(\mathrm{hfac})_{2}$ precursor, by forming $-\mathrm{O}-\mathrm{Pd}-\mathrm{hfac} *$ surface species and gaseous Hhfac product, similar to the reaction between $\mathrm{Pd}(\mathrm{hfac})_{2}$ and hydroxyls on oxide surfaces [131]. Isolated Pd single atoms are formed after removing the remaining hfac ligand by formalin exposure [131]. On the other hand, other oxygen-containing functional groups such as $-\mathrm{COOH}$ should cause the Pd nanoparticle formation, in line with the previous results that instability of - $\mathrm{COOH}$ facilitates agglomeration of Pd nanoparticles [138]. It should be noted that Pd ALD does not grow on pristine graphene or over reduced graphene, even though a large number of edges and defects sites are present. This appears to be different from Pt and alumina ALD, where the nucleation of Pt and alumina both can take place at the edges and defects of graphene $[125,150]$.

When the resulting single-atom $\mathrm{Pd}_{1} /$ graphene catalyst was evaluated in selective hydrogenation of 1,3-butadiene, it revealed superior catalytic performance, with $100 \%$ selectivity to butenes, and the highest ever 1-butene selectivity of $\sim 70 \%$ at a conversion of $95 \%$ 
under mild reaction temperature of ca. $50{ }^{\circ} \mathrm{C}$ (Fig. 21a,b). In the presence of an excess of propene, the propene stream was effectively unreacted with a conversion limited to only $0.1 \%$ at a 1,3-butadiene conversion of $98 \%$ (Fig. 21c). The effect of temperature on the butene selectivity was minor. We speculate that the mono- $\pi$-adsorption mode of $1,3-$ butadiene and the enhanced steric effect induced by 1,3- butadiene adsorption on isolated Pd atoms both play important roles in the improvement of butene selectivity (Fig. 21e). More importantly, $\mathrm{Pd}_{1} /$ graphene showed excellent durability against deactivation via either metal atom aggregation or coking during $100 \mathrm{~h}$ on stream. This work suggests that single-atom metal catalyst can open up new opportunities in hydrogenation reactions for improved selectivity and durability in addition to water-gas shift (WGS) and oxidation reactions [139].

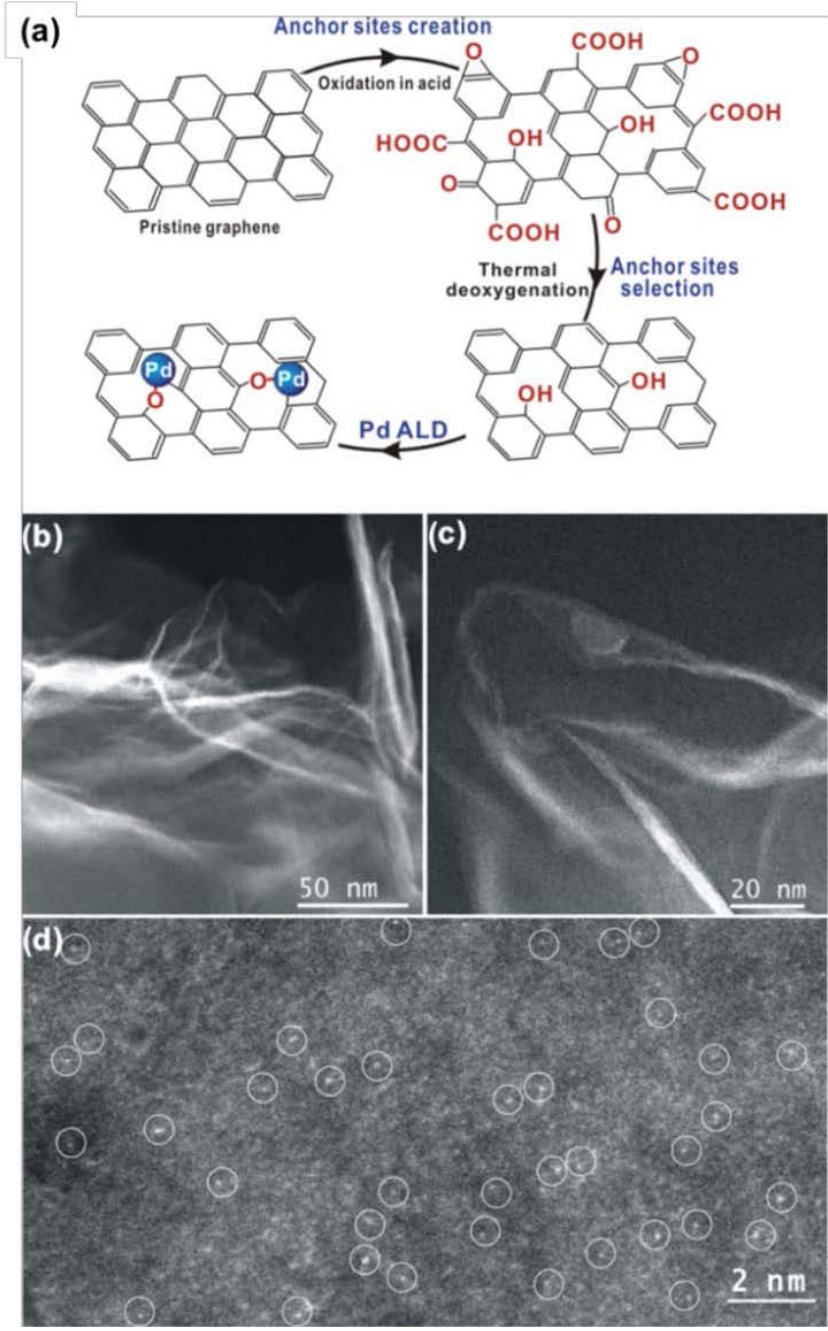

Fig. 20. (a) A schematic illustration of single-atom $\mathrm{Pd}_{1}$ /graphene catalyst synthesis via a process of anchor sites creation and selection and Pd ALD on pristine graphene. Representive HAADF-STEM images of $\mathrm{Pd}_{1} /$ graphene at low (b-c) and high (d) magnifications. Atomically dispersed Pd atoms in image (d) are highlighted by the white circles. Reprinted with permission from [59]. Copyright (C) 2015, American Chemical Society. 

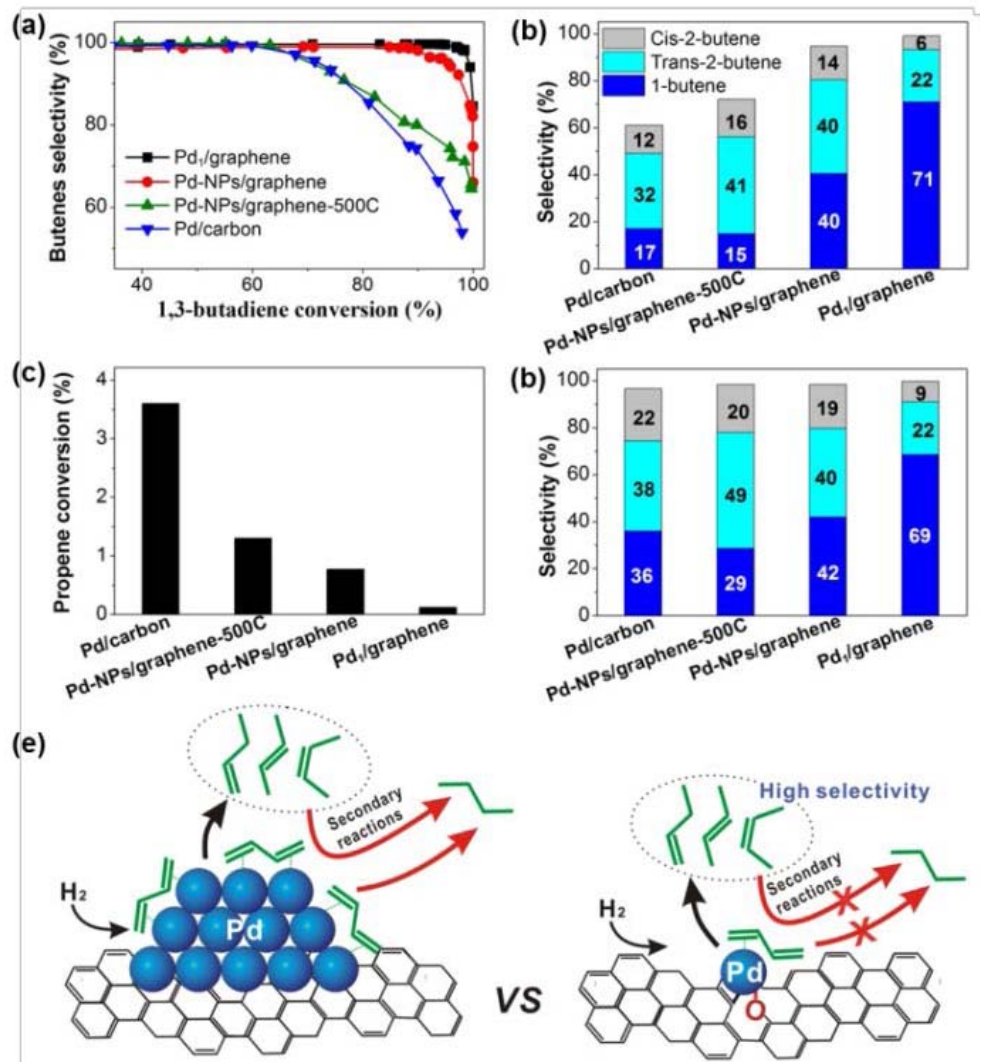

Fig. 21. Catalytic performances of $\mathrm{Pd}_{1}$ /graphene, Pd-NPs/graphene, Pd-NPs/graphene-500C, and $\mathrm{Pd} /$ carbon samples in selective hydrogenation of 1,3-butadiene. (a) Butenes selectivity as a function of conversion by changing the reaction temperatures; (b) the distribution of butenes at 95\% conversion. Propene conversion (c) and the distribution of butenes (d) at 98\% 1,3-butadiene conversion in hydrogenation of 1,3-butadiene in the presence of propene. (e) Schematic illustration of improvement of butenes selectivity on single-atom $\mathrm{Pd}_{1} /$ graphene catalyst. Note: the figure legend in (b) also applies to (d). Reprinted with permission from [59]. Copyright (C) 2015, American Chemical Society.

\section{$3.3 \operatorname{Ir} A L D$}

Conventional thermal Ir ALD has been carried out using a sequential combustion-type surface reactions using molecular oxygen as the oxidant at temperatures above $22{ }^{\circ} \mathrm{C}$. The

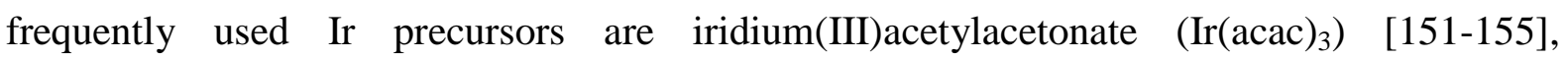
(ethylcyclopentadienyl)(1,3-cyclohexadiene)iridium $\quad(\operatorname{Ir}(\mathrm{EtCp})(\mathrm{CHD})) \quad$ [64, 156], and (ethylcyclopentadienyl)(1,5-cyclooctadiene)iridium (EtCpIr(COD)) [157-159]. Ir(acac) 3 has a lower vapor pressure than the latter two precursors, which necessitates heating to at least $150{ }^{\circ} \mathrm{C}$ to get a reasonable vapor pressure for the ALD process [65]. Nevertheless, we mainly focus on $\operatorname{Ir}(\mathrm{acac})_{3}$-based Ir ALD process, since this precursor has been employed for the 
synthesis of supported Ir catalysts.

The growth rate of metallic Ir film using $\operatorname{Ir}(\mathrm{acac})_{3}-\mathrm{O}_{2}$ depends on the deposition temperature [155]. It is about $0.2 \AA$ /cycle at $225^{\circ} \mathrm{C}$ and gradually increases with temperature. The maximum growth rate is about $0.4 \AA$ /cycle at $375{ }^{\circ} \mathrm{C}$ and slightly decreases at $400{ }^{\circ} \mathrm{C}$. Using ozone as the oxidant, the deposition temperature can be further decreased to $165^{\circ} \mathrm{C}$ with a growth rate of about $0.2 \AA$ /cycle. However, $\mathrm{IrO}_{2}$ films, in this case, are formed rather than metallic Ir [152].

When the deposition temperature is higher than $225{ }^{\circ} \mathrm{C}$, in situ QMS measurements showed that $(14 \pm 2) \% \mathrm{CO}_{2}$ and $(57 \pm 2) \% \mathrm{H}_{2} \mathrm{O}$ released during each ALD cycle are produced by the $\operatorname{Ir}(\mathrm{acac})_{3}$ exposures, indicating that the a fraction of the acac ligands react with surface oxygen at this temperature [160]. During the following oxygen exposure, the remaining acac ligands are combusted releasing the balance of the $\mathrm{CO}_{2}$ and $\mathrm{H}_{2} \mathrm{O}$ and regenerating the surface oxygen. No other gaseous reaction byproducts (e.g. Hacac) were detected. In contrast, the $\operatorname{Ir}(\mathrm{acac})_{3}-\mathrm{O}_{3}$ process releases $\mathrm{CO}_{2}$ and $\mathrm{H}_{2} \mathrm{O}$ only during the $\mathrm{O}_{3}$ exposures at temperature below $200{ }^{\circ} \mathrm{C}$. The authors suggested that $\operatorname{Ir}(\mathrm{acac})_{3}$ adsorbs molecularly on the $\mathrm{IrO}_{2}$ surface in this case, different from the dissociative chemisorption observed at higher temperatures [160].

Besides the conventional AB-type Ir ALD described above, Hämäläinen and coworkers first reported that adding an additional reduction step to each $\mathrm{IrO}_{2}$ ALD cycle in an ABC-type process ( $\operatorname{Ir}(\mathrm{acac})_{3}-\mathrm{O}_{3}-\mathrm{H}_{2}$ ) can produce metallic Ir films at temperatures as low as $165{ }^{\circ} \mathrm{C}$ [62]. It is worth noting that this ABC-type ALD process using ozone and molecular hydrogen as co-reactants was later successfully extended to three additional noble metals: Rh, Pt and Pd $[63,64]$.

\subsubsection{Nucleation and growth of Ir ALD on oxides}

Several mechanisms have been proposed or identified for bonding of the general class of metal $\beta$-diketonate molecules on oxide supports [151]: (i) ligand exchange reactions where the metal $\beta$-diketonate molecule reacts with surface hydroxyls to release 1-2 Hacac into gas phase, (ii) dissociative adsorption, where the molecule splits onto coordinatively unsaturated sites or oxygen bridges leaving both parts bound to the surface, (iii) saturating associative adsorption where the molecule remains intact and either the center metal atom or the ligands interact with surface sites. The amount of metal adsorbed on the support surface in a selflimiting gas-solid reaction with $\beta$-diketonates is primarily controlled by the number of reactive sites on the support surface and by the size of the $\beta$-diketonate ligands. On oxide 
supports the reactive sites are considered to consist of $\mathrm{OH}$ groups, coordinatively unsaturated sites and oxygen bridges $[161,162]$. On alumina, the primary reactive sites for metal $\beta$ diketonates are the basic $\mathrm{OH}$ groups, and on silica they are the isolated $\mathrm{OH}$ groups [163]. In the case of $\operatorname{Ir}(\mathrm{acac})_{3}$, it has been found that ligand exchange reaction takes places on alumina, alumina-silica, silica, and $\beta$-zeolite, according to elemental analysis and IR measurements [151, 164]. Moreover, partially blocking the reactive sites with Hacac provides additional way to tune the Ir loading on these supports. Vuori et al. pointed out that ALD can be beneficial in preparing highly active iridium catalysts with a small metal particle size (ca. 1-3 $\mathrm{nm}$ ) compared with conventional impregnation methods [165].

\subsection{Ag ALD}

Unlike other noble metal ALD, Ag ALD has been challenging due to the lack of stable and volatile Ag precursors. The PE-ALD of Ag thin films has been demonstrated using $\mathrm{Ag}(\mathrm{fod})\left(\mathrm{PEt}_{3}\right)$ (fod = 2,2-dimethyl-6,6,7,7,8,8,8-heptafluorooctane-3,5-dionato, and $\mathrm{PEt}_{3}=$ triethyl-phosphine) and a hydrogen plasma [166]. Very recently, Stair et al. reported a thermal Ag ALD process using trimethylphosphine-(hexafluoroacetylacetonato)silver(I) ((hfac) $\left.\mathrm{Ag}\left(\mathrm{PMe}_{3}\right)\right)$ as the metal precursor, and formalin as the reducing reagent in a relatively narrow temperature range between 170 and $200{ }^{\circ} \mathrm{C}$ [167]. The silver growth rate is low, about only $0.07 \AA$ /cycle at $200{ }^{\circ} \mathrm{C}$. The following reaction mechanism was proposed: During the (hfac) $\mathrm{Ag}\left(\mathrm{PMe}_{3}\right)$ exposure step, (hfac)Ag( $\left.\mathrm{PMe}_{3}\right)$ dissociatively chemisorbs on the Ag surface by forming $\mathrm{Ag}(\mathrm{hfac})$ surface species while releasing the $\mathrm{PMe}_{3}$ ligand; next, $\mathrm{HCHO}$ removes the remained hfac ligand.
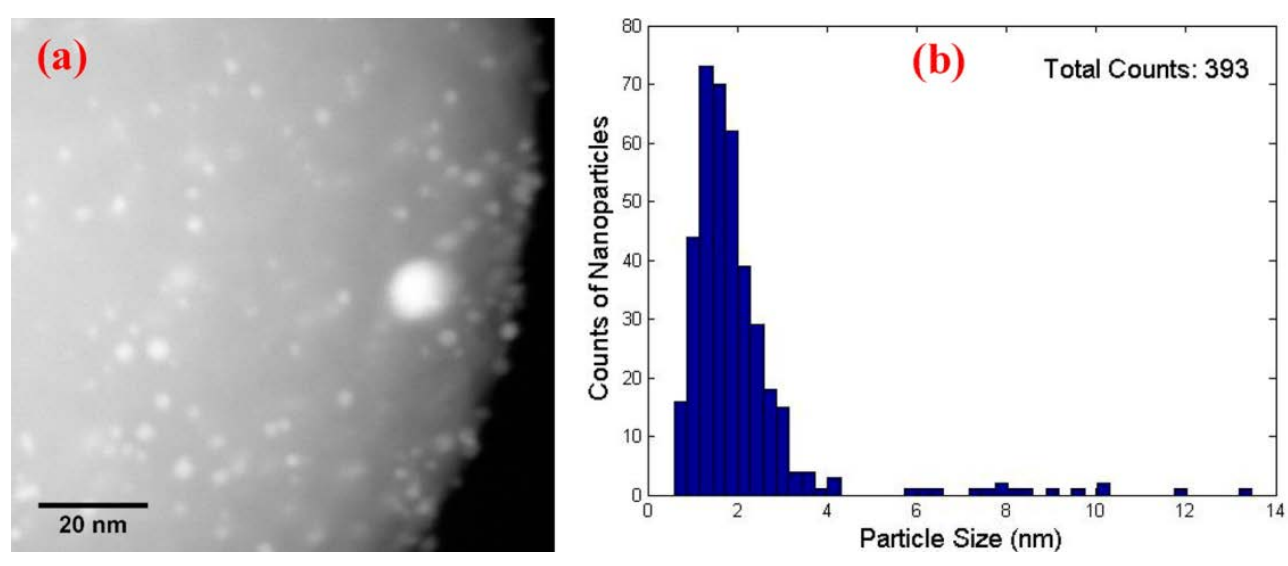

Fig. 22. HAADF STEM image (a) and the size distribution histogram (b) of as-prepared 10 cycles of Ag ALD nanoparticles on alumina-coated silica gel at $200{ }^{\circ} \mathrm{C}$. Reprinted with permission from [167]. Copyright @ 2014, American Chemical Society 
On oxide surfaces such as alumina, a nucleation period was observed in the initial Ag ALD cycles. The nucleation sites for (hfac) $\mathrm{Ag}\left(\mathrm{PMe}_{3}\right)$ were suggested to be surface oxygen, where the surface reactions in each exposure step is in a similar manor with the ones of Ag ALD on Ag surface in the linear growth region. On a high surface area alumina-coated silica gel, this process generated Ag nanoparticles with diameter of $1.8 \pm 0.4 \mathrm{~nm}$ after 10 cycles of Ag ALD, as shown in Fig. 22.

\section{$3.5 C u A L D$}

$\mathrm{Cu}$ ALD has attracted much attention due to the variety of industrial applications, including replacing aluminum in microelectronic interconnections because of its higher electrical conductivity and superior resistance to electromigration [168]. Such broad applications have boosted tremendous efforts to develop a large number of thermal $\mathrm{Cu}$ ALD processes: $\mathrm{CuCl}-$ $\mathrm{H}_{2}$ at $360-410{ }^{\circ} \mathrm{C}[169,170], \mathrm{Cu}(\text { thd })_{2}-\mathrm{H}_{2}$ at $150-350{ }^{\circ} \mathrm{C}$ [171-173], $\mathrm{Cu}(\text { acac })_{2}-\mathrm{H}_{2}$ at about $250{ }^{\circ} \mathrm{C}$ [174], $\mathrm{Cu}$ (dialkylacetamidinate) $)_{2} / \mathrm{H}_{2}$ at $180-300{ }^{\circ} \mathrm{C}[175,176], \mathrm{Cu}(\mathrm{dmap})_{2}-\mathrm{ZnEt}_{2}$, $($ damp $=$ methylamino-2-propoxide $)$ at $100-120{ }^{\circ} \mathrm{C}$ [177], Cu(pyrim) $)_{2}-\mathrm{ZnEt}_{2}($ pyrim $=\mathrm{N}$ ethyl-2-pyrrolylaldiminate) at $120-150{ }^{\circ} \mathrm{C}$ [178], $\mathrm{Cu}(\mathrm{dmamb})_{2}-\mathrm{HCOOH}-\mathrm{N}_{2} \mathrm{H}_{4}$ (dmamb = dimethylamino-2-methyl-2-butoxide) at 100-170 ${ }^{\circ} \mathrm{C} \quad[179], \quad \mathrm{Cu}(\mathrm{dmap})_{2}-\mathrm{HCOOH}-$ $\mathrm{BH}_{3} \mathrm{NHMe}_{2}$ at $130-160{ }^{\circ} \mathrm{C}$ [180], and $\mathrm{Cu}(\mathrm{hfac})_{2}$-isopropanol at about $260{ }^{\circ} \mathrm{C}$ [181].

Among these precursors, copper acetamidinates are one of the most promising precursor families due to their relative resistance to reactions with air and their reasonable vapor pressure [175, 176, 182, 183]. For instance, copper(I) $N, N^{\prime}$-di-sec-butylacetamidinate $\left(\left(\mathrm{Cu}\left({ }^{\mathrm{S}} \mathrm{Bu}-\mathrm{amd}\right)\right)_{2}\right)$ developed by Gordon et al, has a vapor pressure of 0.1 Torr at $85^{\circ} \mathrm{C}[184]$. Using $\left(\mathrm{Cu}\left({ }^{\mathrm{s}} \mathrm{Bu}-\mathrm{amd}\right)\right)_{2}$ as the metal precursor and molecular hydrogen as the reducing agent, $\mathrm{Cu}$ ALD was achieved in a relative low temperature range of $150-190{ }^{\circ} \mathrm{C}$ [176]. The growth rate varied from 1.5-2 $\AA$ /cycle on $\mathrm{SiO}_{2}$ or $\mathrm{Si}_{3} \mathrm{~N}_{4}$, but was only $0.1-0.5 \AA$ /cycle on metallic $\mathrm{Ru}, \mathrm{Cu}$, and Co surfaces. On oxide surfaces, the $\left(\mathrm{Cu}\left({ }^{\mathrm{s}} \mathrm{Bu}-\mathrm{amd}\right)\right)_{2}-\mathrm{H}_{2}$ process forms isolated copper crystallites that merge into rough polycrystalline films after more deposition cycles. On $\mathrm{Ru}$ and Co metal surfaces, the ALD Cu nucleates densely, forming smooth and strongly adherent films that are continuous even for only 4 atomic layers [176].

Using in situ FTIR measurements and DFT calculations, Chabal et al. investigated the initial surface chemistry and growth mechanisms of $\mathrm{Cu}$ ALD on $\mathrm{SiO}_{2}$ surfaces using $\left(\mathrm{Cu}\left({ }^{\mathrm{s}} \mathrm{Bu}-\mathrm{amd}\right)\right)_{2}$ and molecular hydrogen [185]. They showed that the initial surface reaction of $\left(\mathrm{Cu}\left({ }^{\mathrm{S}} \mathrm{Bu}-\mathrm{amd}\right)\right)_{2}$ with hydroxylated $\mathrm{SiO}_{2}$ takes place by displacement of one of the secbutylacetamidinate ligands at a surface -OH site, thus forming a $\mathrm{Si}-\mathrm{O}-\mathrm{Cu}-(\mathrm{sBu}-\mathrm{amd}) *$ surface 
species (as shown in the schematic model in Fig. 23a,b). During the subsequent molecular hydrogen exposure, hydrogen reacts with most of the sec-butylacetamidinate ligands bound to $\mathrm{Cu}$ by releasing free amidine vapor product, leaving $\mathrm{Cu}$ atoms free to agglomerate on the surface (Fig. 23c-e); meanwhile, more reactive sites becomes available for the next $\left(\mathrm{Cu}\left({ }^{\mathrm{s}} \mathrm{Bu}-\right.\right.$ amd) $)_{2}$ pulse. When the ALD temperature was above $220^{\circ} \mathrm{C}$, the thermally activated ligand rearrangement from bidentate- to monodentate- binding of the sec-butylacetamidinate ligand occurred through hydrogenation of the ligand by surface hydroxyl groups, accompanied by releasing a $\mathrm{Cu}$ atom.

(a)
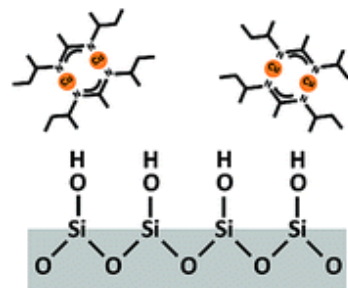

(c)

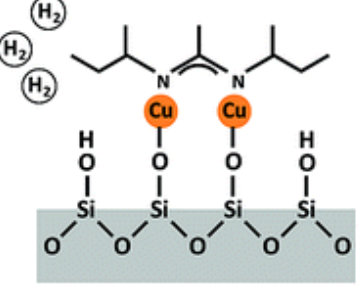

(b)

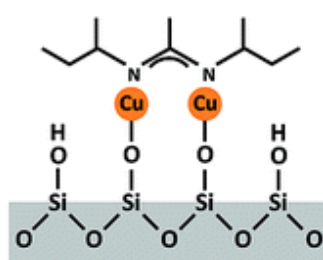

(d)

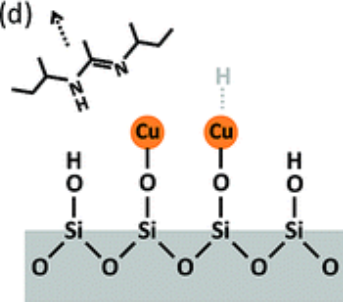

(e)

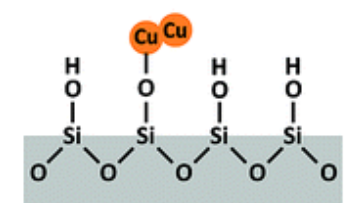

Fig. 23. Schematic model of the reactions of $\left(\mathrm{Cu}\left({ }^{\mathrm{s}} \mathrm{Bu}-\mathrm{amd}\right)\right)_{2}$ (a, b) and $\mathrm{H}_{2}$ (c, d) on the $\mathrm{SiO}_{2}$ surface. A free amidinate in panel (d) represents a gas-phase byproduct after ligand removal by $\mathrm{H}_{2}$. Panel (d) shows a possible intermediate $\mathrm{Cu}-\mathrm{H}$ bond, which is not observed experimentally (possibly due to its very short lifetime at $185{ }^{\circ} \mathrm{C}$ ). Panel (e) shows agglomeration of $\mathrm{Cu}$ atoms in a schematic way. Reprinted with permission from [185]. Copyright (C) 2010, American Chemical Society.

Zaera et al. studied the detailed surface reactions of $\left(\mathrm{Cu}\left({ }^{\mathrm{s}} \mathrm{Bu}-\mathrm{amd}\right)\right)_{2}$ on $\mathrm{Cu}(100)$ surfaces using temperature programmed desorption (TPD) and XPS under ultrahigh vacuum to establish the $\mathrm{Cu}$ ALD process on Cu surfaces [186]. As shown in Fig. 24, they discovered that adsorption of the copper acetamidinate dimer from the gas phase leads to its partial dissociation on the surface at $90 \mathrm{~K}$. Molecular desorption was first seen at below $300 \mathrm{~K}$. 
Additional amidinate desorption was seen at $480 \mathrm{~K}$, indicating a relatively high thermal stability for the amidinate intermediate. With increasing temperature, the amidinate decomposed as evidenced by the formation of butane, butene, and hydrogen, at temperatures slightly below $500 \mathrm{~K}$.

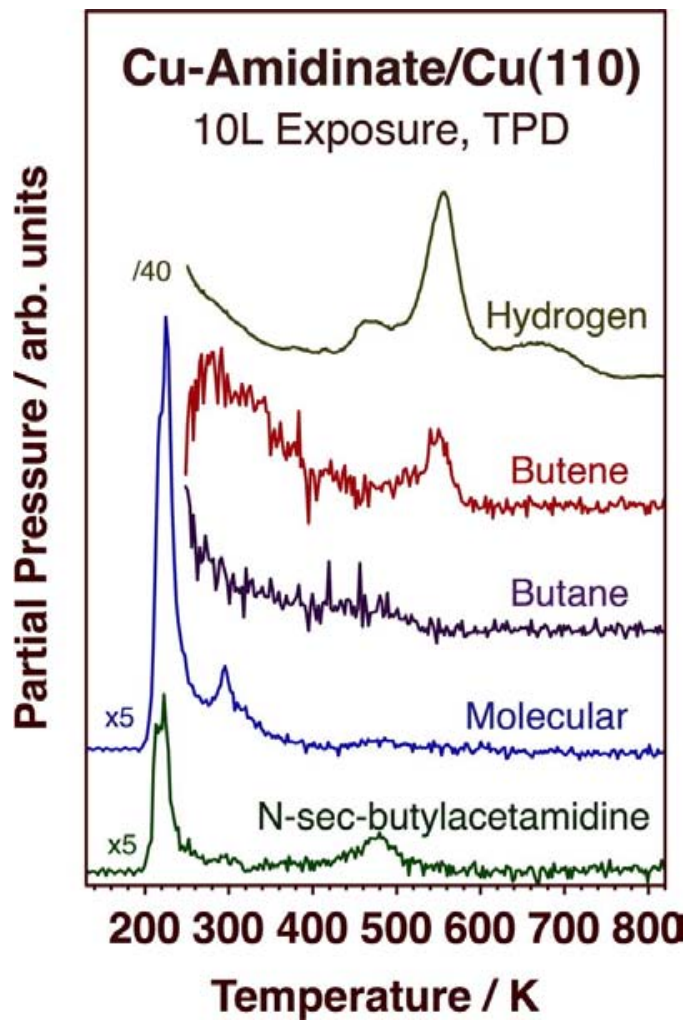

Fig. 24. Survey TPD data from $10.0 \mathrm{~L}$ of $\left(\mathrm{Cu}\left({ }^{\mathrm{s}} \mathrm{Bu}-\mathrm{amd}\right)\right)_{2}$ dosed on $\mathrm{Cu}(110)$ at $90 \mathrm{~K}$. Traces are shown for the desorption of the main products detected in the gas phase, namely (from top to bottom): hydrogen, butene, butane, the original $\left(\mathrm{Cu}\left({ }^{\mathrm{s}} \mathrm{Bu}-\mathrm{amd}\right)\right)_{2}$, and amidinate. The signals for 2, 56, 58, 170 and 114 amu were used to follow these products, respectively. Reprinted with permission from [186]. Rights managed by AIP Publishing LLC.

In the application of $\mathrm{Cu}$ ALD for catalysis, Chen et al, has performed extensive studies of the catalytic activity of $\mathrm{Cu} / \mathrm{SiO}_{2}$ catalysts in the reverse water-gas-shift (RWGS) [172]reaction, and the WGS $[187,188]$ reactions, where $\mathrm{ALD} \mathrm{Cu} / \mathrm{SiO}_{2}$ catalysts were prepared using $\mathrm{Cu} A L D$ with $\mathrm{Cu}(\mathrm{thd})_{2}$ at $160{ }^{\circ} \mathrm{C}\left(\mathrm{ALE}-\mathrm{Cu} / \mathrm{SiO}_{2}\right)$. The activity of the ALE$\mathrm{Cu} / \mathrm{SiO}_{2}$ catalyst was compared with a $\mathrm{Cu} / \mathrm{SiO}_{2}$ catalyst synthesized using impregnation method (IM-Cu/SiO 2$)$ and commercial $\mathrm{Cu} / \mathrm{ZnO} / \mathrm{Al}_{2} \mathrm{O}_{3}, \mathrm{Pd} / \mathrm{SiO}_{2}$ and $\mathrm{Pt} / \mathrm{SiO}_{2}$ catalysts. It was found that the ALE-Cu/SiO 2 provided a higher TOF than the $\mathrm{IM}-\mathrm{Cu} / \mathrm{SiO}_{2}$ within $12 \mathrm{~h}$ by a factor of about 14-24, and was comparable to the Pt and Pd catalysts in the RWGS reaction (Fig. 25A,B) [172]. According to the CO TPD spectra, they showed that the ALE-Cu/SiO ${ }_{2}$ 
catalyst exhibited a very different behavior compared to typical Cu-based catalysts. The ALE-Cu/SiO 2 catalyst showed two CO desorption peaks at approximately 343-353 and 443$463 \mathrm{~K}$ (Fig. 25C), whereas CO generally desorbs from Cu surfaces below room temperature. The authors suggested that the smaller $\mathrm{Cu}$ particle sizes (Fig. 26) produced by ALD might strongly bind the CO, leading to a high catalytic activity in RWGS. Later, they showed that this ALE-Cu/SiO 2 catalyst is also very active in the WGS reaction [187, 188]. Two major active sites were identified on the copper surface, namely defect sites on small $\mathrm{Cu}$ particles or isolated $\mathrm{Cu}$ atoms by using DRIFTS CO chemisorption measurements. In brief, their work provides a good example, illustrating the advantages of the ALD method for catalyst synthesis.
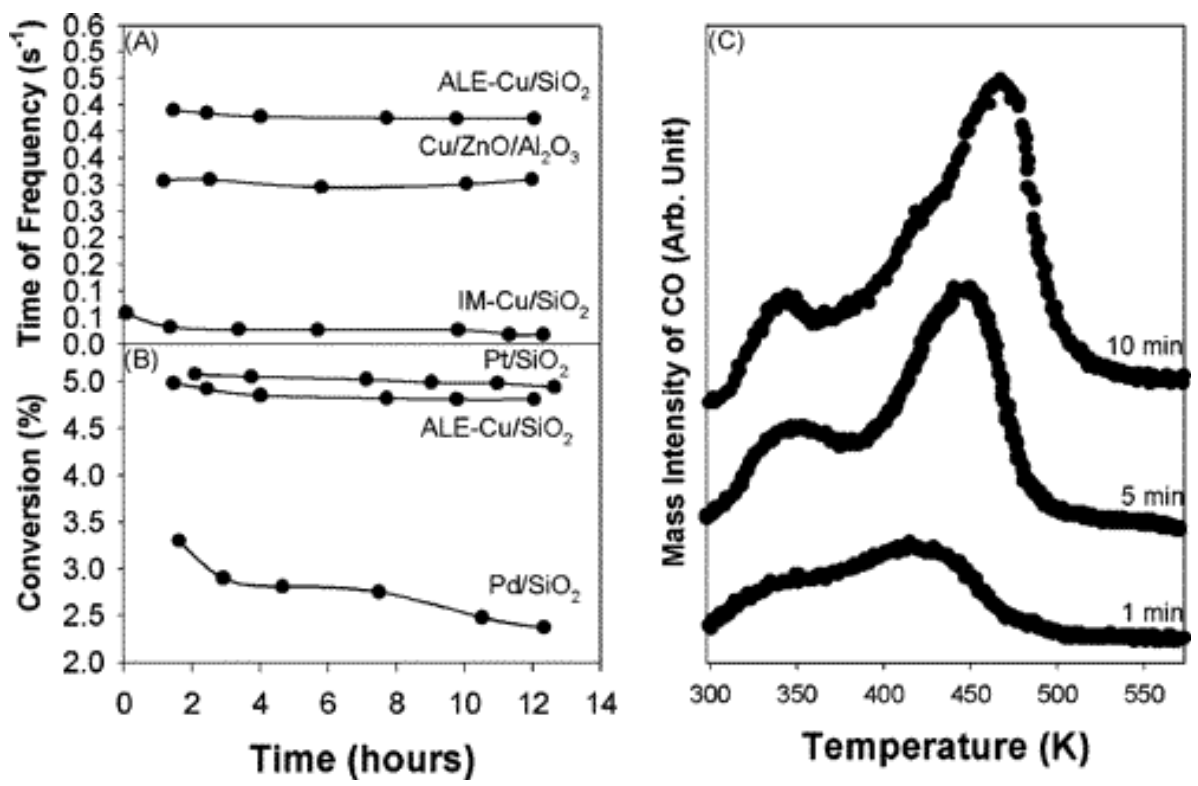

Fig. 25. (A and B) The dependence of $\mathrm{CO}_{2}$ conversion on reaction time for $\mathrm{H}_{2} / \mathrm{CO}_{2}$ with 1:1 ratio and $100 \mathrm{ml} / \mathrm{min}$ over catalysts at $773 \mathrm{~K}$. (C) TPD spectra of CO from 2.4\% ALE$\mathrm{Cu} / \mathrm{SiO}_{2}$ with various dosing amounts of $\mathrm{CO}$. The adsorption of $\mathrm{CO}$ was carried out in a $\mathrm{CO}$ stream with $30 \mathrm{ml} / \mathrm{min}$ flow rate. Reprinted with permission from [172]. Copyright (C) 2006, American Chemical Society.

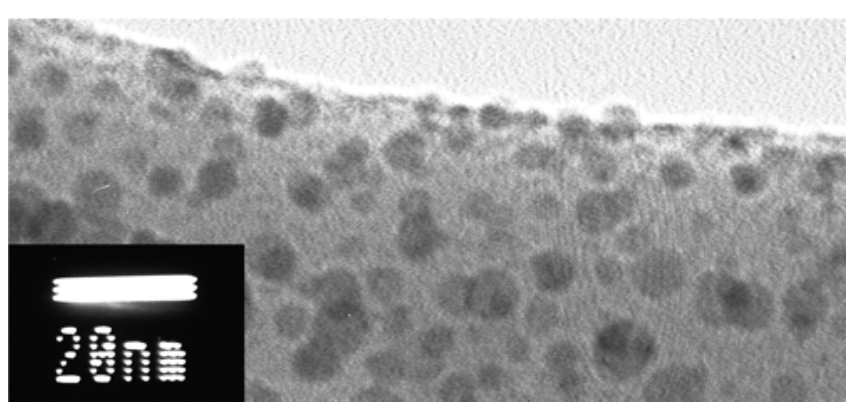

Fig. 26. TEM image of $\mathrm{ALE}-\mathrm{Cu} / \mathrm{SiO}_{2}$ after calcinations and reduction. Reprinted with permission from [172]. Copyright (C) 2006, American Chemical Society. 


\subsection{Ni ALD}

Unlike the ALD of noble metals (e.g. Pt, Rh, and Ru), the ALD of Ni (a transition metal) using $\mathrm{O}_{2}$ or $\mathrm{O}_{3}$ as the co-reactant yields $\mathrm{NiO}$ instead of metallic $\mathrm{Ni}$ at $143-300{ }^{\circ} \mathrm{C}[174,189$ 191]. Using water as the co-reactant also produced NiO films [192-197]. The ALD of metallic Ni has been achieved by a hydrogenation-reaction surface chemistry using either $\mathrm{H}_{2}$ or $\mathrm{NH}_{3}$ as the reductant, similar to Pd ALD [131]. So far, the successful Ni ALD processes are: $\mathrm{Ni}(\mathrm{iPro}-\mathrm{AMD})_{2}-\mathrm{H}_{2}$ (iPr-AMD = N,N'-diisopropylacetamidinato) at $250{ }^{\circ} \mathrm{C}$ [175], $\mathrm{Ni}(\mathrm{dmamb})_{2}-\mathrm{H}_{2}$ at $200-250{ }^{\circ} \mathrm{C}$ [198], (dmamb = dimethylamino-2-methyl-2-butoxo), and $\mathrm{Ni}(\mathrm{dmamb})_{2}-\mathrm{NH}_{3}$ at $300{ }^{\circ} \mathrm{C}$ [199]. Other processes such as $\mathrm{Ni}(\mathrm{acac})_{2}-\mathrm{H}_{2}$ at $250{ }^{\circ} \mathrm{C}$ [174] and $\mathrm{Ni}(\mathrm{Cp})_{2}-\mathrm{H}_{2}$ at $300{ }^{\circ} \mathrm{C}(\mathrm{Cp}=$ cyclopentadienyl) [200] were have been reported, but these studies did not include measurements of self-limiting chemistry, linearity, and film uniformity. In the $\mathrm{Ni}(\mathrm{dmamb})_{2}-\mathrm{H}_{2}$ process, significant carbon contamination was observed [198]. However, by replacing molecular $\mathrm{H}_{2}$ with $\mathrm{NH}_{3}$, Kim deposited high purity Ni films with only a small amount of oxygen and negligible amounts of nitrogen and carbon, and the Ni growth rate was $0.64 \AA$ /cycle [199]. In addition to the processes described above, metallic $\mathrm{Ni}$ films have been prepared first depositing ALD NiO, and subsequently converting this to Ni using a post-deposition reduction step [174, 201].

The synthesis of supported Ni catalysts with high dispersions via Ni ALD has been investigated by several groups. For instance, Medlin, et al. synthesized ALD Ni/ $\mathrm{Al}_{2} \mathrm{O}_{3}$ catalysts using $\mathrm{Ni}(\mathrm{Cp})_{2}-\mathrm{H}_{2}$ at $300{ }^{\circ} \mathrm{C}$. By varying the number of ALD Ni cycles from 1 to 15, the average $\mathrm{Ni}$ particle size was precisely tuned from $2.4 \pm 0.1$ to $3.3 \pm 0.1 \mathrm{~nm}$, and the $\mathrm{Ni}$ loading was adjusted between 4.7-16.7 wt.\% [200]. The ALD Ni/ $\mathrm{Al}_{2} \mathrm{O}_{3}$ catalysts had a higher activity in the hydrogenolysis reaction compared to comparable $\mathrm{Ni}$ catalysts prepared by incipient wetness impregnation (IWI), and this was attributed to a larger fraction of defect sites (steps and kinks) on the Ni surface of the ALD catalyst compared to the IWI catalyst. On a $\mathrm{SiO}_{2}$ support, Liang et al, recently reported a Ni particle size of $\sim 2.4 \mathrm{~nm}$ after 1 cycle $\mathrm{Ni}$ ALD and only a slight increase to $2.6 \mathrm{~nm}$ after 15 cycles [202]. The ALD Ni/SiO 2 catalyst with high dispersion could activate hydrazine hydrate as a reducing agent in the transfer hydrogenation of aryl nitro compounds into the corresponding amines with high selectivity and high yield.

Qin, et al. recently reported a general approach to synthesize multiply confined $\mathrm{Ni} / \mathrm{Al}_{2} \mathrm{O}_{3}$ catalyst by first growing $\mathrm{NiO}$ nanoparticles on carbon nanocoils as sacrificial templates using $\mathrm{NiO}$ ALD through a $\mathrm{Ni}(\mathrm{Cp})_{2}-\mathrm{O}_{3}$ process at $200{ }^{\circ} \mathrm{C}$ [203]. Next, $\mathrm{Al}_{2} \mathrm{O}_{3}$ ALD was 
carried out to coat the entire surface. Finally, calcination and reduction at $550{ }^{\circ} \mathrm{C}$ yielded $\mathrm{Ni}$ nanoparticles confined within the $\mathrm{ALD} \mathrm{Al}_{2} \mathrm{O}_{3}$ nanotubes and embedded in the inner $\mathrm{Al}_{2} \mathrm{O}_{3}$ wall (Ni-in-ANTs). The Ni nanoparticles were about 4.8, 6.1 and $7.5 \mathrm{~nm}$ in diameter for 50, 150 and $300 \mathrm{NiO}$ ALD cycles, respectively. They further demonstrated that the multiply confined $\mathrm{Ni} / \mathrm{Al}_{2} \mathrm{O}_{3}$ catalyst has significantly higher activities in cinnamaldehyde and nitrobenzene hydrogenation reactions with improved stability, compared with the same ALD Ni catalyst where the $\mathrm{Ni}$ was supported on the outer surfaces of the $\mathrm{Al}_{2} \mathrm{O}_{3}$ nanotubes (Ni-out-ANTs). This enhanced performance was attributed to the rich $\mathrm{Ni}-\mathrm{Al}_{2} \mathrm{O}_{3}$ interfacial sites (Fig. 27).

In summary, highly dispersed Ni catalysts can be obtained through either directly metallic Ni ALD with molecular $\mathrm{H}_{2}$ (or $\mathrm{NH}_{3}$ ) as the reductant or using $\mathrm{NiO}$ ALD followed by high temperature reduction. In both cases, a slow increase in $\mathrm{Ni}$ particle size as the number of ALD cycles was observed.
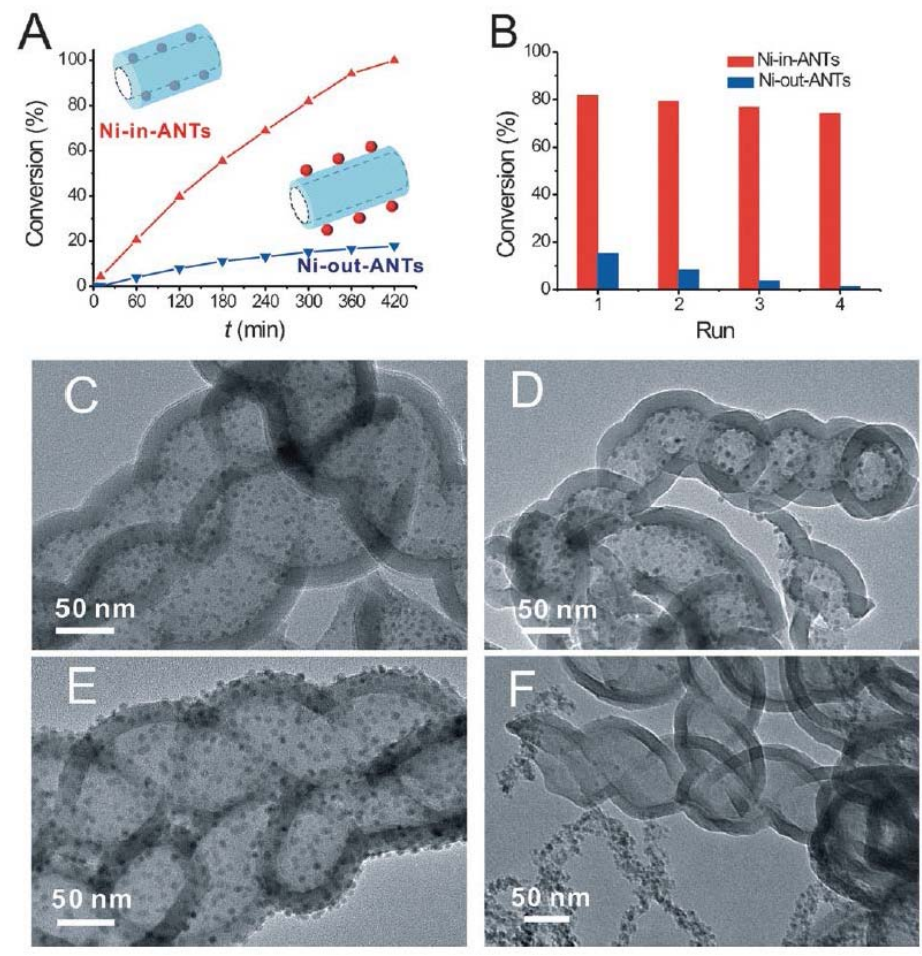

Fig. 27. A) The evolution of cinnamaldehyde conversion with reaction time and B) the recycling results for the catalysts in the hydrogenation of cinnamaldehyde. TEM images of Ni-in-ANTs, on which $150 \mathrm{NiO}$ ALD cycles was performed, C) after reaction for $10 \mathrm{~min}$ and D) after the fourth run; and of Ni-out-ANTs, on which $150 \mathrm{NiO}$ ALD cycles was performed, E) after reaction for $10 \mathrm{~min}$ and F) after the fourth run. Reprinted with permission from [203]. (C) 2015 WILEY - VCH Verlag GmbH \& Co. KGaA, Weinheim. 


\subsection{Other metals ALD}

In addition to the metals described above, the ALD of other metals, including Ru [204213], Rh [63, 214-216], Co [175, 217, 218], Fe [175], Mo [219], and W [220-223], have been reported. However, the application of these metals to catalysis has thus far been limited. Both $\mathrm{Rh}$ and $\mathrm{Ru}$ have been prepared by ALD using either $\mathrm{O}_{2}$ or $\mathrm{O}_{3}$ as the oxidant at temperatures above $200{ }^{\circ} \mathrm{C}$, very similar to the cases of Pt and Ir ALD. Rh(acac) $)_{3}$ is the commonly used precursor for Rh ALD [63, 214-216]. A wide variety of ALD Ru precursors have been explored including metallocenes, $\beta$-diketonates, and their derivatives [204-212]. Among these, the most widely studied and applied Ru ALD precursors are metallocenes and their derivatives, for instance, bis(ethylcyclopentadienyl)ruthenium $\left(\operatorname{Ru}(\mathrm{EtCp})_{2}\right)$ [206, 208, 209, 213].

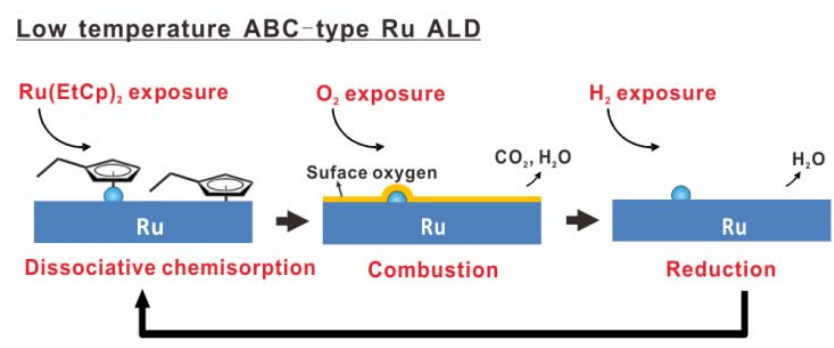

Fig. 28. Schematic illustration of low temperture ABC-type Ru ALD using $\mathrm{Ru}(\mathrm{EtCp})_{2}-\mathrm{O}_{2}-$ $\mathrm{H}_{2}$. Reprinted with permission from [66]. Copyright (C) 2015, American Chemical Society.

As pointed out previously, this oxygen-based, combustion-type noble metal ALD typically requires temperatures above $200{ }^{\circ} \mathrm{C}\left(\sim 300^{\circ} \mathrm{C}\right.$ in most cases), to burn off the organic ligands [65, 106, 204-211, 224]. In order to reduce the growth temperature for broader applications, Hämäläinen and coworkers demonstrated that Ir, Rh, Pt and Pd ALD can be performed at a significantly lower temperature by using ozone and molecular hydrogen as co-reactants in an ABC-type ALD process (also seen in the review paper [65] and the references therein) [63, 64]. Very recently, we demonstrated that Ru ALD can be performed at as low as $150{ }^{\circ} \mathrm{C}$ by using $\mathrm{O}_{2}$ and $\mathrm{H}_{2}$ as the co-reactants. In situ QCM and QMS measurements both indicated that this ABC-type ALD occurs through sequential steps of dissociative chemisorption, combustion, and reduction for the $\mathrm{Ru}(\mathrm{EtCp})_{2}$, oxygen and hydrogen, respectively [66]. Therein, the $\mathrm{Ru}(\mathrm{EtCp})_{2}$ undergoes dissociative chemisorption on the existing $\mathrm{Ru}$ metal surface to form $\mathrm{Ru}(\mathrm{EtCp})^{*}$ and $\mathrm{EtCp}^{*}$ surface species during the $\mathrm{Ru}(\mathrm{EtCp})_{2}$ exposure. Next, the $\mathrm{O}_{2}$ combusts the EtCp* surface species releasing $\mathrm{CO}_{2}$ and $\mathrm{H}_{2} \mathrm{O}$ gaseous products, and forms $\mathrm{Ru}$ oxide. Finally, the $\mathrm{H}_{2}$ reduces the $\mathrm{Ru}$ oxide to $\mathrm{Ru}$ metal releasing $\mathrm{H}_{2} \mathrm{O}$ vapor, and regenerating new chemisorption sites for the next $\mathrm{Ru}(\mathrm{EtCp})_{2}$ exposure (Fig. 28). This 
molecular $\mathrm{O}_{2}$ and $\mathrm{H}_{2}$ based ABC-type ALD could be exploited for the ALD of other noble metals to lower the deposition temperature and reduce oxygen impurites.

Gordon introduced a new family of homoleptic $N, N^{\prime}$-dialkylacetamidinato metal compounds as ALD precursors for depositing transition metals including $\mathrm{Cu}, \mathrm{Ni}, \mathrm{Co}$, and $\mathrm{Fe}$ using molecular hydrogen gas as the co-reactant [175]. The surface reactions using these compounds were found to be complementary and self-limiting, and yielded highly uniform and conformal coatings. $\mathrm{NH}_{3}$ was later shown to be an efficient reductant for these $N, N^{\prime}-$ dialkylacetamidinato metal compounds. For instance, Kim et al. showed that ALD Co films with excellent conformality and nanoscale thickness controllability can be produced using $\mathrm{Co}(\mathrm{iPr}-\mathrm{amd})_{2}-\mathrm{NH}_{3}$ at $350{ }^{\circ} \mathrm{C}$ [217]. In the cases of both ALD Co and $\mathrm{Ni}$, the $\mathrm{NH}_{3}$ reductant provided significantly lower carbon, oxygen and nitrogen impurities compared to $\mathrm{H}_{2}$ [199, 217].

$\mathrm{W}$ and Mo are catalytically relevant metals that have both been deposited by ALD, but using a much different strategy than the metals discussed above. The $\mathrm{W}$ and Mo ALD use volatile metal fluorides in combination with silane precursors, such as $\mathrm{SiH}_{4}$ and $\mathrm{Si}_{2} \mathrm{H}_{6}$ [220223, 225], and the overall equations for the $\mathrm{W}$ and Mo ALD were determined to be:

$$
\begin{aligned}
& 4 \mathrm{WF}_{6}+3 \mathrm{Si}_{2} \mathrm{H}_{6} \rightarrow 4 \mathrm{~W}+2 \mathrm{SiHF}_{3}+7 \mathrm{H}_{2}+4 \mathrm{SiF}_{4}+2 \mathrm{HF} \\
& \mathrm{MoF}_{6}+\mathrm{Si}_{2} \mathrm{H}_{6} \rightarrow \mathrm{Mo}+2 \mathrm{SiHF}_{3}+2 \mathrm{H}_{2}
\end{aligned}
$$

These reactions are highly exothermic and have heats of reaction of $\Delta H=-331$ and $-221 \mathrm{kcal}$, for Equations (9) and (10), respectively [219]. The driving force for these reactions is the formation of the very stable Si-F bonds in the volatile fluorosilane products. W ALD can be performed over a wide temperature range of $30-325^{\circ} \mathrm{C}[220,221]$. The $\mathrm{W}$ ALD growth rates typically range from 4.0-6.0 $\AA$ /cycle depending on the growth temperature [221]. The lower temperatures in this range are sufficiently mild to permit W ALD on polymer substrates [226, 227]. Mo ALD can also be performed at relatively low temperatures of $90-150{ }^{\circ} \mathrm{C}$ with a growth rate of 6.0-7.0 $\AA$ /cycle [219]. Despite the favorable attributes for these ALD processes, there have been no reports describing their use in supported metal catalysts except as model systems [228, 229].

\section{Selective metal ALD on metals: precise synthesis of supported bimetallic catalysts}

Supported bimetallic catalysts often show superior catalytic properties compared to those of their parent monometallic counterparts due to the synergistic effect [230-245], which may originate from the ensemble effect (specific metal atoms arrangements that are required for facilitating a particular catalytic process) or the electronic effect (modification of electronic 
states resulting from hetero-nuclear metal-metal bond formation). Therefore, achieving atomically precise control over the size, structure, and composition of bimetallic nanoparticles are the essential goal for synthesis of supported bimetallic catalysts.

Traditional methods for bimetallic nanoparticle synthesis such as successive impregnation or co-impregnation often fail to provide precise control over composition and structure, yielding a mixture of monometallic and bimetallic particles with various compositions [233, 240, 246-249]. Other strategic routes have been reported that provide better control, such as electroless deposition [250] anion coordination protocol [251], sacrificial hydrogen method [252], surface-specific reductants [253], redox transmetalation reactions [254], and controlled simultaneous reduction [255]. Nevertheless, a facile method for bimetallic nanoparticle synthesis with atomically-precise control is still missing.

\subsection{Challenges of synthesis of supported bimetallic catalysts using ALD}

Due to the self-limiting feature, ALD can (in principle) achieve independent control over the size, composition, and structure of the bimetallic nanoparticles with near atomic precision: The size of the bimetallic particles is determined by the total number of ALD cycles performed; the composition is dictated by the relative number of ALD cycles used for each component; and the structure of the bimetallic nanoparticles is controlled by the order in which the individual cycles are executed [5, 69]. Nonetheless, it has turned out that synthesis of supported bimetallic catalysts using ALD remains as a challenge, even though ALD has shown success in synthesis of supported monometallic catalysts as discussed in Section 3. The major reasons are that the two metals do not share a common ALD temperature window and the surface chemistries might be incompatible. For instance, Pd ALD is often carried out at $200{ }^{\circ} \mathrm{C}$ based on a hydrogenation surface chemistry [131], while Pt ALD is usually performed at about $300{ }^{\circ} \mathrm{C}$ based on a combustion surface chemistry [105-109]. As a consequence, there have been only few reports describing the synthesis of supported bimetallic nanoparticles by ALD [9, 256-259]. Besides the above issues, it is challenging to restrict the secondary metal growth to be only on the primary metal nanoparticle but not on the support, especially given the natural tendency for ALD materials to grow uniformly on all surfaces.

\subsection{Strategies for selective metal ALD}

Up to now, three strategies have been developed for controlling the deposition of the 
secondary metal selectively on the primary metal nanoparticle but not on the support, thereby excluding monometallic formation:

(1) Reduce the oxygen partial pressure. For Pt ALD using $\mathrm{MeCpPtMe}_{3}-\mathrm{O}_{2}$ at $300{ }^{\circ} \mathrm{C}$, Kessels et al. reported that Pt ALD on $\mathrm{Al}_{2} \mathrm{O}_{3}$ surface can be inhibited by decreasing the $\mathrm{O}_{2}$ partial pressure to 7.5 mTorr [112, 260, 261]. As shown in Fig. 29d, no Pt growth was observed on $\mathrm{Al}_{2} \mathrm{O}_{3}$, even after 600 Pt ALD cycles [260]. On the other hand, the Pt grew immediately on a Pd substrate at a rate of $\sim 0.45 \AA$ /cycle. The Pt ALD process at an $\mathrm{O}_{2}$ pressure of 7.5 mTorr was considered as selective toward Pd versus $\mathrm{Al}_{2} \mathrm{O}_{3}$. Indeed, they deposited Pt shells on Pd particles supported on planar substrates using the low oxygen pressure at $300{ }^{\circ} \mathrm{C}$, where the Pd core was prepared by Pd PEALD at $100{ }^{\circ} \mathrm{C}$ using a $\mathrm{H}_{2}$ plasma as the reducing agent. The selective deposition was indicated by an increase in the average particle size while the nanoparticle number density remained constant (Fig. 29e,f). Aberration-corrected HAADF STEM imaging further showed the presence of the Pt shell. However, the need to perform the growth of the two metals at different temperatures is inconvenient, and makes the growth of bimetallic alloy nanoparticles, where the two ALD metal processes must be frequently alternated, practically impossible.
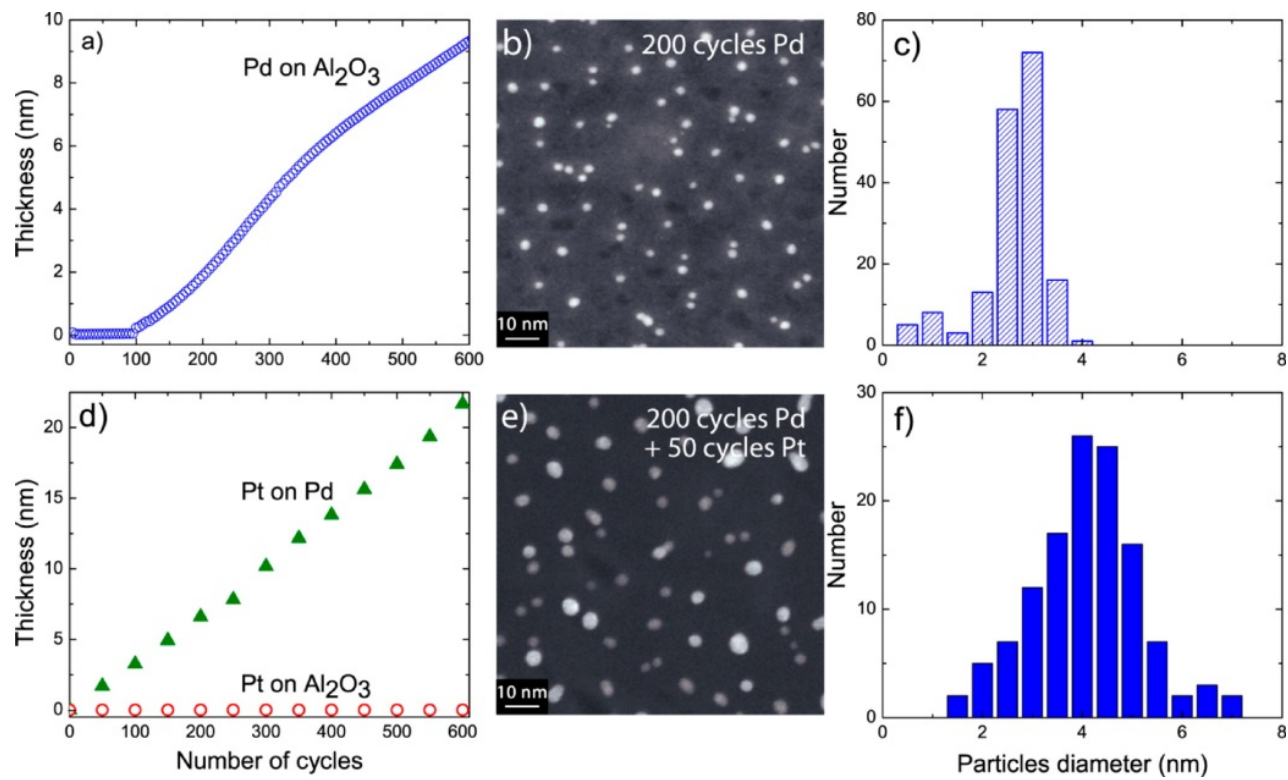

Fig. 29. (a) Thickness evolution of Pd during ALD using the $\mathrm{Pd}(\mathrm{hfac})_{2}$ and a $\mathrm{H}_{2}$ plasma on $\mathrm{Al}_{2} \mathrm{O}_{3}$ at $100{ }^{\circ} \mathrm{C}$, obtained from in situ spectroscopic ellipsometry (SE). (b) HAADF-STEM image of Pd nanoparticles obtained by applying 200 cycles of plasma-assisted ALD of Pd on an $\mathrm{Al}_{2} \mathrm{O}_{3}$ covered $\mathrm{Si}_{3} \mathrm{~N}_{4}$ TEM window. (c) Particle size distribution extracted from part b. (d) Thickness evolution of Pt during Pt ALD on $\mathrm{Pd}$ and $\mathrm{Al}_{2} \mathrm{O}_{3}$ surfaces from $\mathrm{MeCpPtMe}_{3}$ and $\mathrm{O}_{2}$ gas at a pressure of $7.5 \mathrm{mTorr}$ at 
$300{ }^{\circ} \mathrm{C}$. The data was obtained from in situ SE. (e) HAADF-STEM image of Pd/Pt nanoparticles supported on an $\mathrm{Al}_{2} \mathrm{O}_{3}$ covered $\mathrm{Si}_{3} \mathrm{~N}_{4}$ TEM window. The nanoparticles were obtained by applying 200 cycles of plasma-assisted ALD of Pd and subsequently 50 cycles of ALD of Pt. (f) Particle size distribution extracted from part e. Reprinted with permission from [260]. Copyright (C) 2012, American Chemical Society.

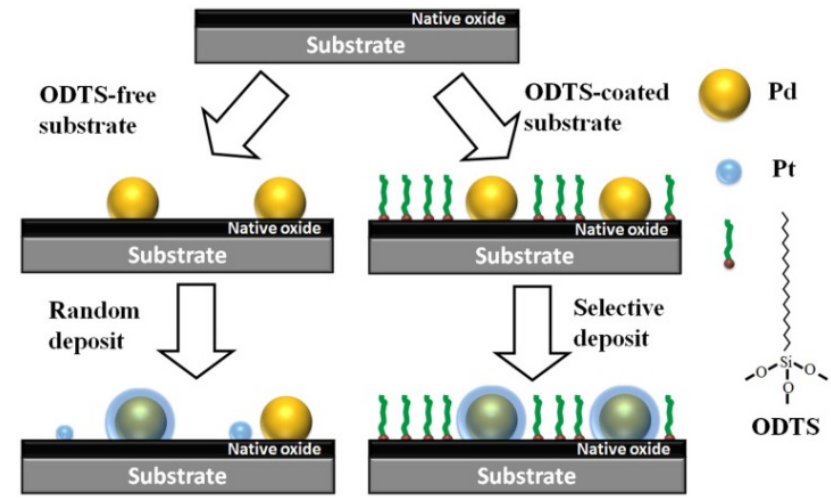

Fig. 30. Schematic illustration for fabricating the core shell nanoparticles through AS-ALD on ODTS modified substrate. Reprinted with permission from [262]. Copyright (C) 2015, Rights Managed by Nature Publishing Group.

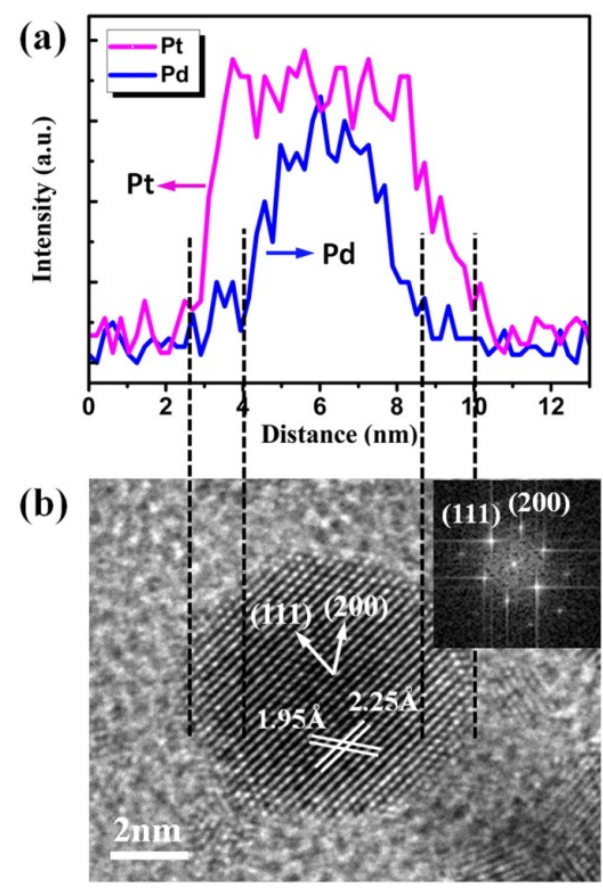

Fig. 31. Cross-sectional compositional line profile on a single Pd/Pt core shell NP, (b) bright field HRTEM image of the Pd/Pt core shell NP and corresponding Fourier transform pattern. Reprinted with permission from [262]. Copyright (C) 2015, Rights Managed by Nature Publishing Group. 
(2) Use self-assembled monolayers (SAMs). Chen et al. demonstrated that octadecyltrichlorosilane (ODTS) SAMs can be utilized to modify a substrate surface to achieve area-selective ALD [262]. Therein, pinholes in the unsaturated ODTS SAMs layer were utilized as active sites for the initial ALD nucleation of the primary metal cores (Fig. 30). Next, the closely packed ODTS layer enables selective growth of the secondary metal onto the primary metal formed in the pinholes to form uniformly distributed core-shell nanoparticles, while prohibiting monometallic nanoparticle formation. In this case, the core-shell nanoparticles were obtained using typical ALD recipes for the two metals without special adjustment. For instance, Pd@Pt core-shell nanoparticles were synthesized by first selectively depositing the $\mathrm{Pd}$ core into the pinholes at $200{ }^{\circ} \mathrm{C}$ using $\mathrm{Pd}(\mathrm{hfac})_{2}$-formalin, followed by Pt ALD at $300{ }^{\circ} \mathrm{C}$ using $\mathrm{MeCpPtMe}_{3}-\mathrm{O}_{2}$. Formation of the core-shell structure was confirmed by high resolution TEM as shown in Fig. 31. They further showed that annealing in an ambient environment at $400{ }^{\circ} \mathrm{C}$ for $1 \mathrm{~h}$ removed the ODTS SAMs from the substrate while preserving the core-shell structure.

(3) Use a lower deposition temperature and a proper co-reactant. As discussed in Section 3, the ALD of metals on oxide surfaces typically exhibits a nucleation period during the initial cycles characterized by an apparent lower growth rate compared to the steady-state (Fig. 9) [109, 111-113, 131, 133]. We demonstrated that at sufficiently low deposition temperatures the nucleation period for metal ALD on oxide surfaces can be extended indefinitely while the growth on metal surfaces persists. For instance, at $150{ }^{\circ} \mathrm{C}$ the ALD of Pd, Pt and Ru were essentially zero on oxide surfaces $\left(\mathrm{TiO}_{2}, \mathrm{Al}_{2} \mathrm{O}_{3}\right.$ and $\mathrm{ZrO}_{2}$ ), but on metal surfaces the metal ALD was linear as demonstrated by in situ QCM measurements in Fig. 32 [69]. It is worthwhile to note that an ABC-type strategy was adopted for Ru ALD using the exposure sequence $\mathrm{Ru}(\mathrm{EtCp})_{2}-\mathrm{O}_{2}-\mathrm{H}_{2}$ for the low temperature growth [66]. The higher initial $\mathrm{Ru}$ growth rates observed on the Pd and Pt surfaces at $150{ }^{\circ} \mathrm{C}$ suggest that these metals facilitate the $\mathrm{Ru}$ nucleation (Fig. 32c) [69]. In line with our observations, Johansson et al reported that Ru ALD does not proceed on alumina surfaces below $250^{\circ} \mathrm{C}$ [263].

More recently, we performed Pd ALD on a high surface area silica support using $\mathrm{Pd}(\mathrm{hfac})_{2}-\mathrm{H}_{2}$ at $150{ }^{\circ} \mathrm{C}$ and measured no $\mathrm{Pd}$ using inductively coupled plasma atomic emission spectroscopy (ICP-AES) even after 8 Pd ALD cycles [264]. In contrast, the Pd loadings increased considerably on an $\mathrm{Au} / \mathrm{SiO}_{2}$ catalyst with the 
number of Pd ALD cycles. Evidently, the Pd grows selectively on the $\mathrm{Au}$ nanoparticles but not on the $\mathrm{SiO}_{2}$ support and exclusively forms AuPd bimetallic nanoparticles without any monometallic Pd nanoparticles.
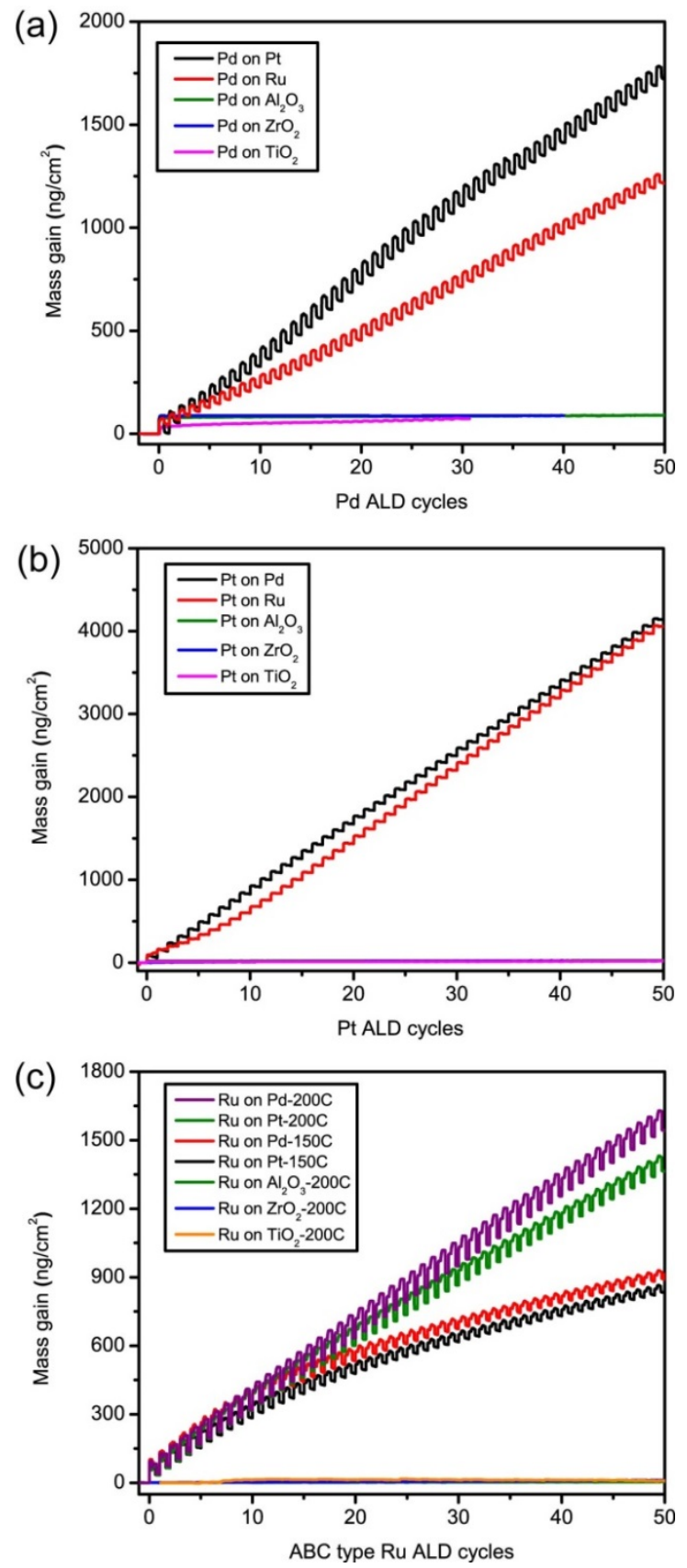

Fig. 32. In situ QCM measurements of metal ALD on metal and oxides surfaces. (a) Pd ALD on Pt, $\mathrm{Ru}, \mathrm{Al}_{2} \mathrm{O}_{3}, \mathrm{TiO}_{2}$, and $\mathrm{ZrO}_{2}$ using $\mathrm{Pd}(\mathrm{hfac})_{2}$ and $\mathrm{H}_{2}$ at $150{ }^{\circ} \mathrm{C}$. (b) $\mathrm{Pt}$ ALD on $\mathrm{Pd}, \mathrm{Ru}, \mathrm{Al}_{2} \mathrm{O}_{3}, \mathrm{TiO}_{2}$, and $\mathrm{ZrO}_{2}$ using $\mathrm{MeCpPtMe}_{3}$ and $\mathrm{O}_{2}$ at $150{ }^{\circ} \mathrm{C}$. (c) ABC-type Ru ALD on Pd and Pt at 150 and $200{ }^{\circ} \mathrm{C}$, and on $\mathrm{Al}_{2} \mathrm{O}_{3}, \mathrm{TiO}_{2}$, and $\mathrm{ZrO}_{2}$ at $200{ }^{\circ} \mathrm{C}$ using $\mathrm{Ru}(\mathrm{EtCp})_{2}, \mathrm{O}_{2}$, and $\mathrm{H}_{2}$. Reprinted with permission from ref [69]. Copyright (C) 2014, Rights Managed by Nature Publishing Group. 
The selective deposition of $\mathrm{Cu}$ on $\mathrm{Pd}$ and Pt metal surfaces using $\mathrm{Cu}(\mathrm{thd})_{2}-\mathrm{H}_{2}$, was also reported [173, 265, 266]. It was found that the temperature window for selective $\mathrm{Cu}$ growth is $190-260{ }^{\circ} \mathrm{C}$. At higher temperatures, the selectivity was lost, and nucleation was independent of substrate material. Selective growth was explained by the different reaction mechanisms on hydroxylated oxide surfaces and on metals [173]. On the hydroxyl-terminated oxide surface, $\mathrm{Cu}(\text { thd })_{2}$ reacts with the hydroxyl group and one of the ligands is then removed as a volatile $\mathrm{H}($ thd) molecule. The second ligand cannot be removed at the low temperatures, thus the deposition process stops. However, $\mathrm{Cu}(\text { thd })_{2}$ might dissociate on metal surfaces. Upon hydrogen adsorption, electrons are supplied to the substrate and the ligands can be completely removed as $\mathrm{H}$ (thd) through reaction with the dissociated surface hydrogen. As a consequence, selective deposition of $\mathrm{Cu}$ on Pd and Pt metal surfaces but not on oxides supports was achieved. Taken together, the above results from several independent research groups suggest that the catalytic nature of noble metals compared with oxides plays the essential role in facilitating the selective ALD on metals at lower temperatures.

Along with reducing the deposition temperature, the choice of co-reactant can also facilitate selective metal ALD. For instance, using $\mathrm{H}_{2}$ instead of HCHO as the coreactant for Pd ALD effectively suppresses Pd ALD on oxide surfaces, while maintaining Pd growth on metal surfaces at $150{ }^{\circ} \mathrm{C}$ [69]. Similarly, no Pt ALD is observed on oxide surfaces at $150{ }^{\circ} \mathrm{C}$ using $\mathrm{MeCpPtMe}_{3}-\mathrm{O}_{2}$. However, when the $\mathrm{O}_{2}$ is replaced with $\mathrm{O}_{3}$, Pt ALD proceeds on oxide surfaces. More importantly, the ALD of well-mixed bimetallic alloy nanoparticles can be conveniently accomplished by alternating between the ALD processes for the individual metals, since these noble metal ALD processes can be performed at the same temperature of $150{ }^{\circ} \mathrm{C}$. We will discuss this point in a later subsection.

\subsection{Precise synthesis of bimetallic catalysts with core-shell structure}

The selective ALD of metals on metal surfaces but not on oxide supports leads exclusively to bimetallic nanoparticles without forming monometallic nanoparticles of the primary or the secondary metal. Using the methods described above, bimetallic core-shell nanoparticles can in principle be formed on oxide surfaces with precise control over the shell thickness by adjusting the number of ALD cycles for the secondary metal. Next, the surface chemistry and morphology of metal ALD on metal surfaces will be discussed in the following subsections. 


\subsubsection{Pd ALD on Pt.}

Using the three strategies for selective metal ALD presented above, Pt@Pd core-shell nanoparticles have been synthesized with great precision [69, 260, 262]. Using $\mathrm{Pd}(\mathrm{hfac})_{2}-\mathrm{H}_{2}$ at $150{ }^{\circ} \mathrm{C}$, in situ QCM measurements showed that Pd ALD on Pt exhibited linear growth without any nucleation delay, indicating a layer-by-layer growth mode (Fig. 32a). Using CO as a probe molecule, in situ FTIR was employed to map the atomic-scale evolution of the surface composition and thereby infer the nanoparticle structure after each ALD cycle during the bimetallic nanoparticle synthesis (e.g. core-shell vs. well-mixed alloy). As shown in Fig. 33, the IR spectrum taken after $1 \mathrm{Pd}$ cycle on a $\mathrm{Pt} / \mathrm{Al}_{2} \mathrm{O}_{3}$ sample (1c-Pd) revealed the disappearance of a broad shoulder at $2010 \mathrm{~cm}^{-1}$, indicating that Pd preferentially nucleated at the low-coordination Pt surface sites. This finding is in excellent agreement with the theoretical prediction by Fortunelli, et al. that Pd mainly decorates at the steps and corners of Pt in multi-shell PdPt alloy nanoparticles [267]. Meanwhile, we assigned the new peak at $1900 \mathrm{~cm}^{-1}$ to bridge-bonded CO on the PdPt mixture [268]. With increasing Pd ALD cycles, the linear $\mathrm{CO}$ on Pt continuously decreased in intensity and red shifted, implying that the number of surface Pt atoms diminished. Surprisingly, the $1900 \mathrm{~cm}^{-1}$ peak remained and the characteristic bridge CO peak at $1931 \mathrm{~cm}^{-1}$ for pure Pd surfaces was not observed even after 30 Pd cycles ( 3.5 ML Pd). This finding suggests that Pt atoms diffused to the surface during the Pd shell growth, thus resulting in a Pd-rich PdPt shell under current ALD conditions. Such structure was further confirmed by aberration-corrected HAADF-STEM measurement along with the energy-dispersive spectroscopy (EDS).

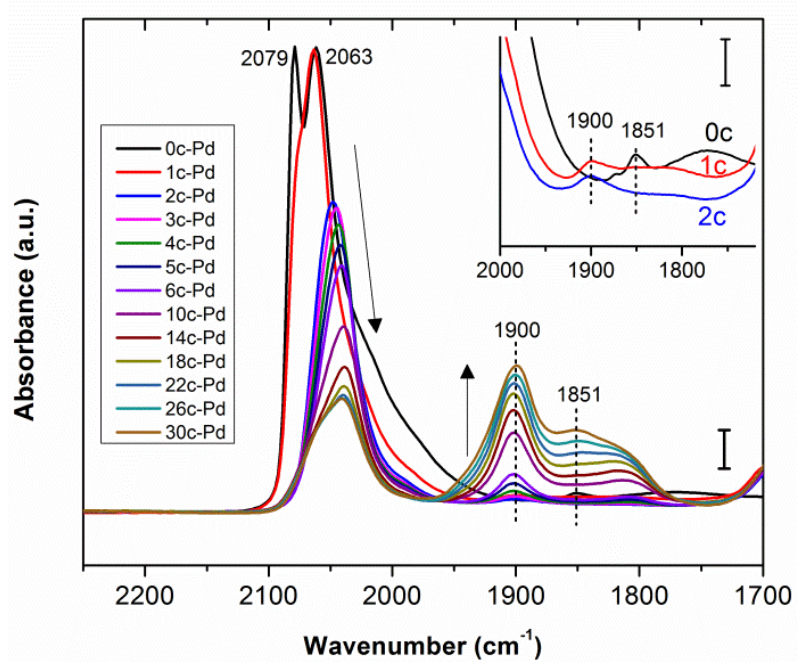

Fig. 33. In situ CO chemisorption FTIR measurements during ALD of Pd shell on an ALD $\mathrm{Pt} / \mathrm{Al}_{2} \mathrm{O}_{3}$ sample at $150{ }^{\circ} \mathrm{C}$. Scale bar, 3\%, scale bar for the inset, $1 \%$. Reprinted with 
permission from [69]. Copyright (C) 2014, Rights Managed by Nature Publishing Group.

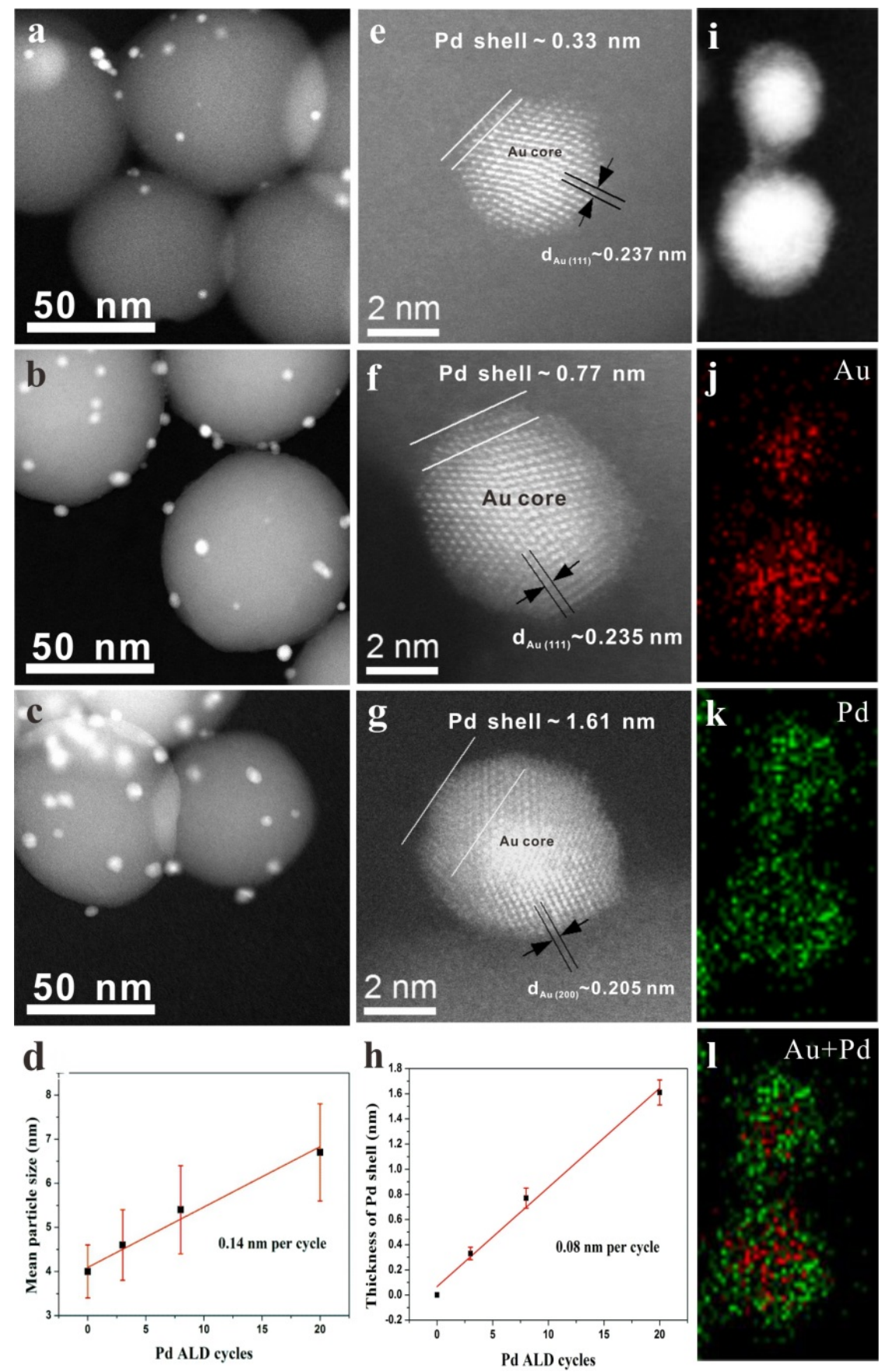

Fig. 34. Aberration-corrected HAADF-STEM images of different bimetallic catalysts at low and high magnifications: (a) and (e) $\mathrm{Au} @ 3 \mathrm{Pd} / \mathrm{SiO}_{2}$; (b) and (f) $\mathrm{Au} @ 8 \mathrm{Pd} / \mathrm{SiO}_{2}$; (c) and (g) $\mathrm{Au} @ 20 \mathrm{Pd} / \mathrm{SiO}_{2}$. (d) The growth of Au@Pd particle size as a function of Pd ALD cycles. (h) The Pd shell thickness as a function of Pd ALD cycles. (i) A lower magnification HAADFSTEM image of $\mathrm{Au@8Pd/SiO}$, and corresponding EDX mapping images: (j) Au Lal and (k) Pd Lal signals, and (l) the reconstructed Au-Pd bimetallic composition image. Reprinted with permission from [264]. Copyright (C) 2015 Elsevier Inc. All rights reserved. 


\subsubsection{Pd ALD on $\mathrm{Au}$}

AuPd bimetallic catalysts have showed superior catalytic performance in many reactions including CO oxidation [269, 270], direct synthesis of hydrogen peroxide [271, 272], direct synthesis of vinyl acetate [273], formic acid decomposition [274, 275], and alcohol oxidation [276-287]. Recently, we synthesized $\mathrm{SiO}_{2}$ supported Au@Pd core-shell catalysts with precisely controlled Pd shell thickness using a combination of wet-chemistry and ALD: An $\mathrm{Au} / \mathrm{SiO}_{2}$ catalyst was first synthesized using the deposition-precipitation method, and then $\mathrm{Pd}$ was selectively deposited on the surface of $\mathrm{Au}$ nanoparticles but not on the $\mathrm{SiO}_{2}$ support using Pd ALD to form uniform Au@Pd core-shell nanoparticles. Using Pd(hfac) $)_{2}-\mathrm{H}_{2}$ at 150 ${ }^{\circ} \mathrm{C}$, a linear growth of the Pd shell at $\sim 0.08 \mathrm{~nm}$ /cycle was observed on the Au nanoparticles, as indicated by both an increase in mean particle size and an increase in the Pd shell thickness in aberration-corrected HAADF-STEM images (Fig. 34) [264]. Note that Pd appears darker than $\mathrm{Au}$ in these images due to Z-contrast. DRIFTS CO chemisorption measurements further revealed the gradual evolution of Pd species on the Au nanoparticle surfaces with increasing Pd ALD cycles: from isolated Pd adatoms or very small aggregates to larger ensembles, and to continuous islands or films according to the development of linear- and bridge-bonded CO (Fig. 35) [288, 289]. XPS further illustrated that the thinner the Pd shell, the more negative the shift in $\mathrm{Pd} 3 \mathrm{~d}_{5 / 2}$ binding energy, which strongly indicates that the modification of $\mathrm{Pd}$ electronic properties by Au depends tightly on the Pd shell thickness. In solvent-free aerobic oxidation of benzyl alcohol, the Au@Pd core-shell bimetallic catalysts showed a clear volcano-like trend as a function of the Pd shell thickness, wherein the Au@Pd core-shell catalyst with a Pd shell thickness of $0.6 \sim 0.8 \mathrm{~nm}$ showed a maximum TOF of $27600 \mathrm{~h}^{-1}$ (or a specific activity of $9800 \mathrm{~h}^{-1}$ ). Combining the results of DRIFTS CO chemisorption, UV-Vis, and XPS, the catalytic activity enhancement was suggested to be a synergistic effect combining both ensemble and electronic promotion.

\subsubsection{Pt ALD on Pd}

The selective ALD of Pt on Pd using $\mathrm{MeCpPtMe}{ }_{3}-\mathrm{O}_{2}$ can be accomplished by reducing the oxygen partial pressure [260] or by decreasing the deposition temperature to $150{ }^{\circ} \mathrm{C}$ [69], and yields a linear growth at $\sim 0.4 \AA$ /cycle. When selective low-temperature Pt ALD was executed on a Pd/ $\mathrm{Al}_{2} \mathrm{O}_{3}$ catalyst to grow Pd@Pt core-shell nanoparticles at $150{ }^{\circ} \mathrm{C}$, in situ FTIR CO chemisorption performed after each Pt ALD cycle clearly demonstrated a progressive change in surface composition [69]. The gradual decrease of bridge-bonded CO 
on Pd $\left(1917 \mathrm{~cm}^{-1}\right)$, and simultaneous increase of the linear CO on Pt (at between 2054-2075 $\mathrm{cm}^{-1}$ ), provide direct evidence for the continuous deposition of $\mathrm{Pt}$ on the Pd nanoparticle surface with increasing Pt ALD cycles (Fig. 36). Completion of a continuous Pt shell on the Pd nanoparticle core occurred after $\sim 10$ Pt ALD cycles ( 1.5 ML), as indicated by the disappearance of the bridge-bonded CO peak on Pd, in contrast with the Pt@Pd growth where Pt diffusion to the surface was observed (Fig. 33). Consequently, the Pt shell thickness on Pd nanoparticles can be precisely tuned by increments of $\sim 0.15 \mathrm{ML}$ per cycle. The formation of Pd@Pt core-shell nanoparticles was further confirmed by aberration-corrected HAADF-STEM measurements along with EDS line profile analysis.

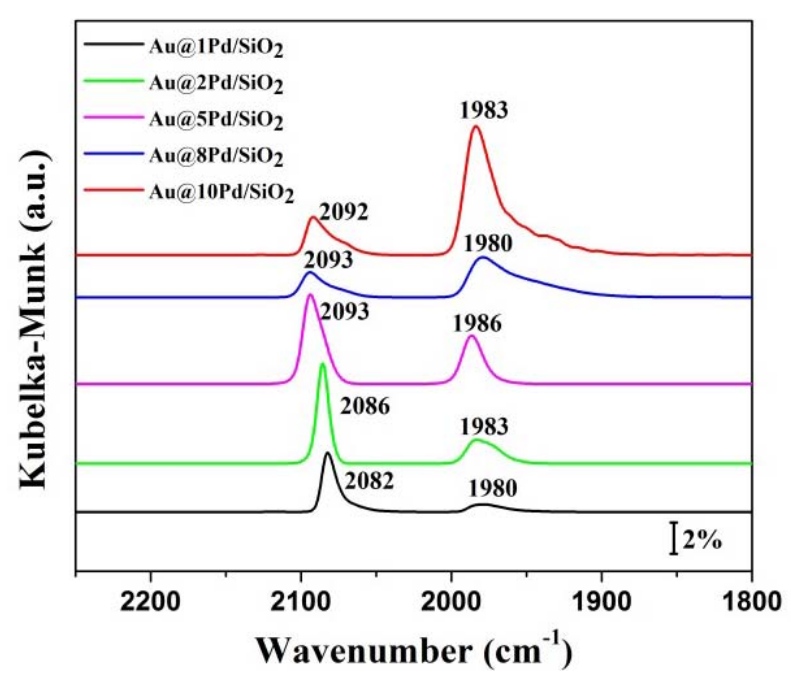

Fig. 35. DRIFT spectra of $\mathrm{CO}$ chemisorption at $298 \mathrm{~K}$ on various $\mathrm{Au} @ x \mathrm{Pd} / \mathrm{SiO}_{2}$ catalysts at the CO saturation coverage. Here $x$ denotes the number of Pd ALD cycles. Reprinted with permission from [264]. Copyright (C) 2015 Elsevier Inc. All rights reserved.

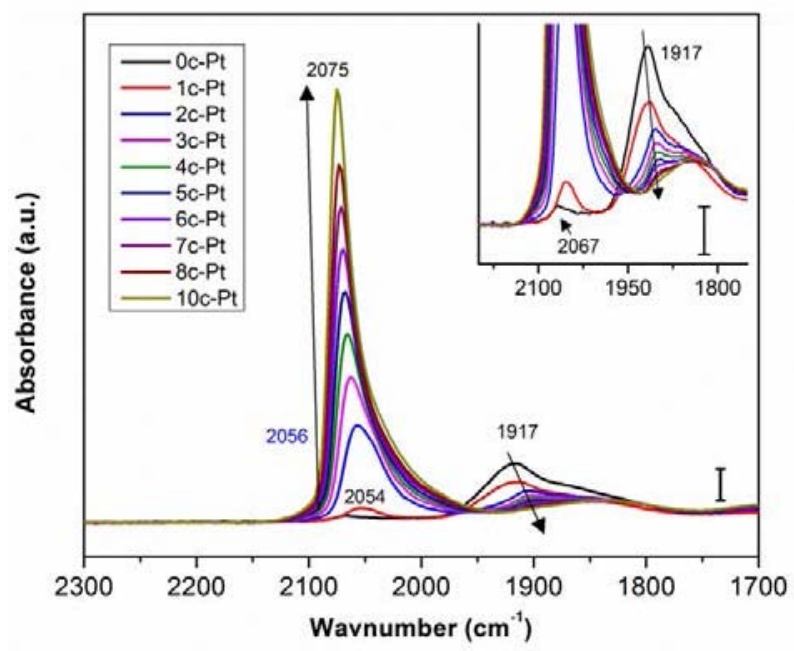

Fig. 36. In situ CO chemisorption FTIR measurements during ALD of Pt shell on an ALD $\mathrm{Pd} / \mathrm{Al}_{2} \mathrm{O}_{3}$ sample at $150{ }^{\circ} \mathrm{C}$. Scale bar, $1 \%$, scale bar for the inset, $0.5 \%$. Reprinted with 
permission from [69]. Copyright (C) 2014, Rights Managed by Nature Publishing Group.

\subsubsection{Ru ALD on Pt.}

$\mathrm{Ru}$ ALD on Pt surfaces using $\mathrm{Ru}(\mathrm{EtCp})_{2}-\mathrm{O}_{2}-\mathrm{H}_{2}$ exhibited linear growth at a rate of $\sim 0.21$ $\AA$ A/cycle (22.4 ng/ $\mathrm{cm}^{2}$ per cycle) at $200{ }^{\circ} \mathrm{C}$ (Fig. 32c). At $150{ }^{\circ} \mathrm{C}$, a higher initial Ru growth rate observed on $\mathrm{Pt}$ surface, suggesting that $\mathrm{Pt}$ accelerates the $\mathrm{Ru}$ nucleation at low temperatures [69]. In situ CO chemisorption FTIR studies of $\mathrm{Ru} A L D$ on a $\mathrm{Pt} / \mathrm{Al}_{2} \mathrm{O}_{3}$ sample at $200{ }^{\circ} \mathrm{C}$ demonstrated a gradual increase in $\mathrm{Ru}$ surface coverage with increasing Ru ALD cycles (Fig. 37), as evidenced by the decease of linear CO on Pt $\left(2069 \mathrm{~cm}^{-1}\right)$ and the growth of a new peak at $2010 \mathrm{~cm}^{-1}$ in intensity, assigned to linear CO on Ru [290]. The peak of linear $\mathrm{CO}$ on Pt persisted even after $35 \mathrm{Ru}$ ALD cycles ( $3 \mathrm{Ru} \mathrm{ML})$, suggesting diffusion of Pt to the surface during Ru ALD. EDS line profile analysis further confirmed the presence of Pt atoms on the surface of a Pt-core Ru-shell sample.

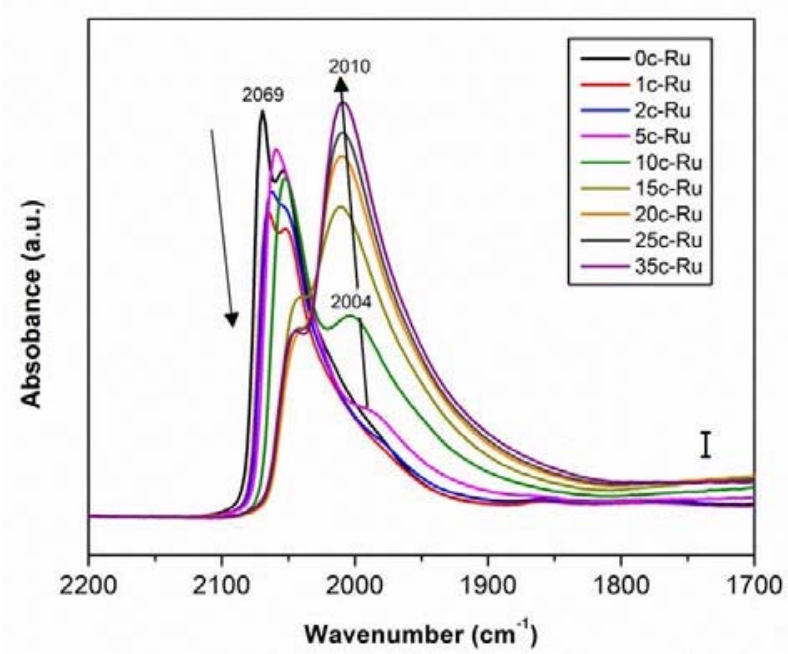

Fig. 37. In situ CO chemisorption FTIR measurements during ALD of Ru shell on an ALD $\mathrm{Pt} / \mathrm{Al}_{2} \mathrm{O}_{3}$ sample at $200{ }^{\circ} \mathrm{C}$. Scale bar, 2\%. Reprinted with permission from [69]. Copyright (C) 2014, Rights Managed by Nature Publishing Group.

Shim et al. investigated Ru ALD on sputtered Pt columns using high resolution TEM. The $\mathrm{Ru}$ ALD was conducted using $\mathrm{Ru}(\mathrm{EtCp})_{2}-\mathrm{O}_{2}$ at $320{ }^{\circ} \mathrm{C}$. They discovered "island growth" of $\mathrm{Ru}$ ALD on the Pt, which they attributed to lack of appropriate functional groups on the Pt surface for Ru nucleation, and the higher surface energy of Ru (3.9 J/m²), compared to Pt (2.7 $\mathrm{J} / \mathrm{m}^{2}$ ) (Fig. 38) [291, 292]. The formation of Ru clusters would be thermodynamically favored as this would lower the surface energy. In line with this observation, Johansson et al. also reported "island growth" of Ru ALD on Pt nanoparticles which were supported on nitrogen- 
doped multi-walled carbon nanotubes [263]. When the sputtered Pt anode coated with 100 cycles of Ru ALD film was employed in DMFCs, the performance was improved by more than 1 order of magnitude in terms of power output. XPS measurements revealed that increasing the $\mathrm{Ru}$ coverage results in a dramatic reduction in the amount of surface-bound CO that would otherwise passivate the Pt anode [291].
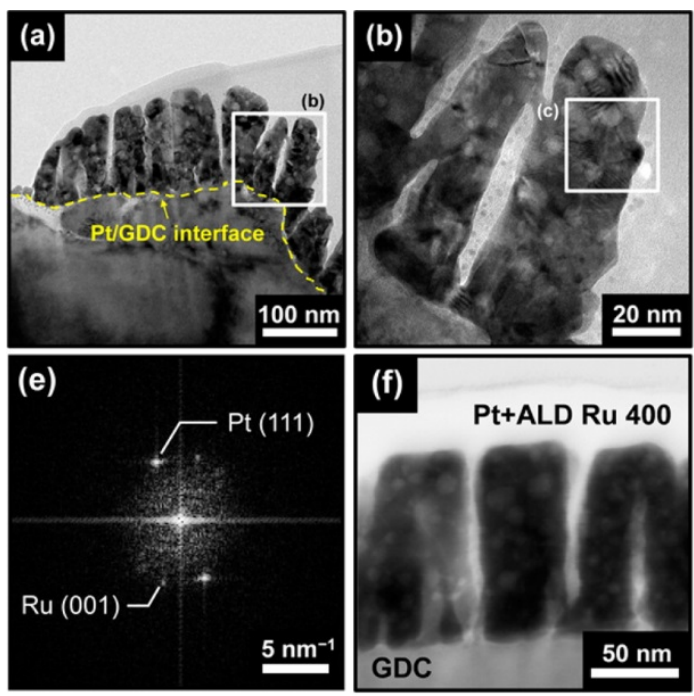
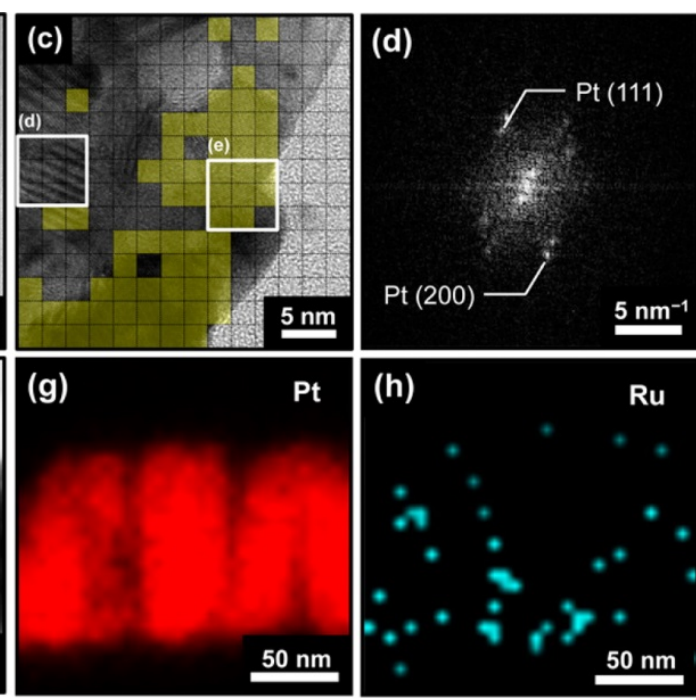

Fig. 38. (a-c) HRTEM cross-sectional images of a sputtered Pt anode surface after 400 cycles of $\mathrm{Ru}$ ALD using $\mathrm{Ru}(\mathrm{EtCp})_{2}-\mathrm{O}_{2}$ at $320^{\circ} \mathrm{C}$. (c) The presence of deposited $\mathrm{Ru}$ is indicated in yellow. (d) and (e) show the corresponding diffraction patterns for Pt and Ru at the points marked in (c). (f-h) HRTEM cross-sectional image of the Pt/Ru ALD 400 anode surface with EDS composition analysis. Reprinted with permission from [291]. Copyright (C) 2015, American Chemical Society.

\subsection{5 $\mathrm{Cu} A L D$ on $\mathrm{Ni}$}

Employing surface-science characterization techniques under UHV conditions, Zaera, et al. investigated the surface chemistry for $\mathrm{Cu}$ ALD on $\mathrm{Ni}(110)$ using $\left(\mathrm{Cu}\left({ }^{\mathrm{s}} \mathrm{Bu}-\mathrm{amd}\right)\right)_{2}-\mathrm{H}_{2}[184$, 293]. They found that $\left(\mathrm{Cu}\left({ }^{\mathrm{s}} \mathrm{Bu}-\mathrm{amd}\right)\right)_{2}$ dissociatively adsorbed on the nickel surface above $300 \mathrm{~K}$, indicated by the observation of metallic copper according to the $\mathrm{Cu} 2 \mathrm{p}_{3 / 2}$ XPS peak at $932.5 \mathrm{eV}$ (Fig. 39). The optimum deposition temperature was identified to be $\sim 350 \mathrm{~K}$, where self-limiting adsorption was achieved (Fig. 39b). The $\mathrm{Cu}$ film growth rate was about 0.75 $\AA$ A/cycle. Above $400 \mathrm{~K}$, Cu multilayer deposition and even decomposition was observed. Very interestingly, they reported no detectable changes in deposition rate or surface chemistry upon presaturation of the nickel substrate with hydrogen (Fig. 39b). They attributed this to the early desorption of hydrogen from the nickel surface at temperatures below those required 
for the $\mathrm{Cu}$ ALD. They pointed out that significant $\mathrm{H}$ surface coverages could be maintained under $\mathrm{H}_{2}$ pressures above $\sim 10^{-6}$ bar, which is the case in typical ALD processing conditions. In addition, their work suggests that the organic intermediates may form on the surface upon thermal activation of adsorbed copper acetamidinate, which needs to be stable at the temperatures used in ALD in order to be available for hydrogenation and removal from the surface in the second half-cycle. Otherwise, these organic intermediates are likely to dehydrogenate and form irreversible adsorbates, thus ultimately incorporate carbon and/or nitrogen impurities into the grown films.
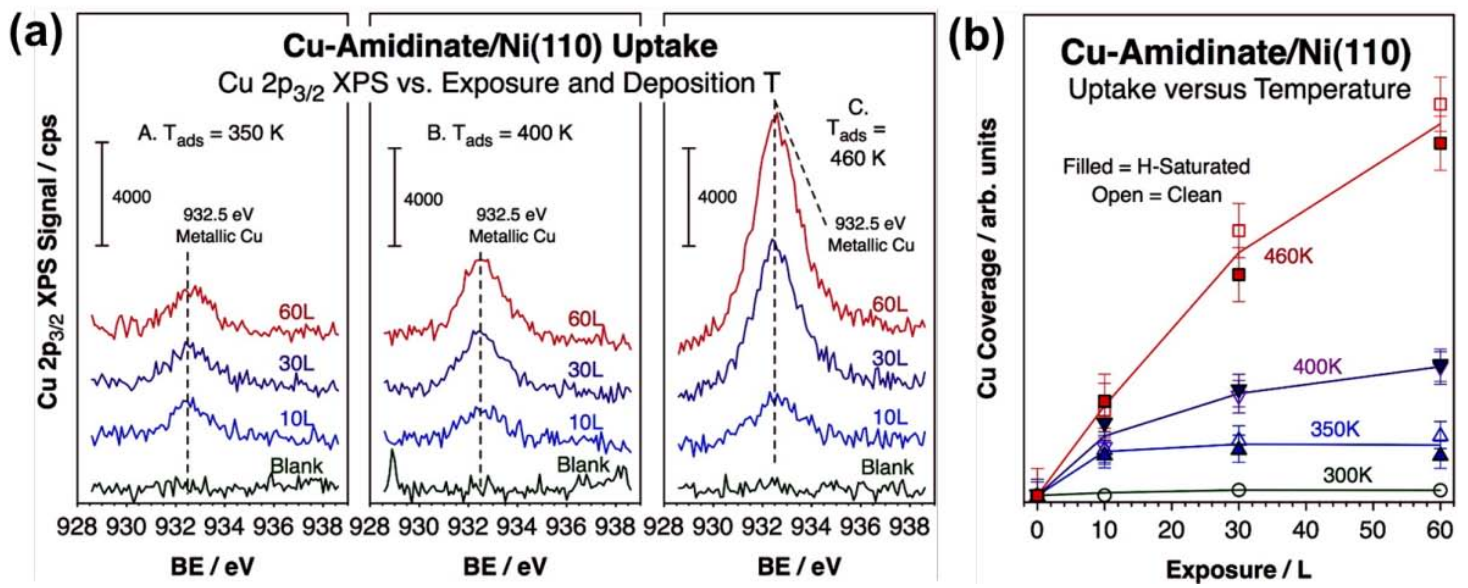

Fig. 39. (a) $\mathrm{Cu} 2 \mathrm{p}_{3 / 2}$ XPS uptake for $\left(\mathrm{Cu}\left({ }^{\mathrm{s}} \mathrm{Bu}-\mathrm{amd}\right)\right)_{2}$ on $\mathrm{Ni}(110)$ at 350 (left), 400 (center) and 460 (right) K. All peaks are centered at $932.5 \mathrm{eV}$, a value typical for metallic copper. (b) Copper uptake estimated from $\mathrm{Cu} 2 \mathrm{p}_{3 / 2}$ XPS experiments shown in (a) for $\left(\mathrm{Cu}\left({ }^{\mathrm{s}} \mathrm{Bu}-\mathrm{amd}\right)\right)_{2}$ on clean (open symbols) and hydrogen presaturated (150 L $\mathrm{H}_{2}$ at $90 \mathrm{~K}$; filled symbols) $\mathrm{Ni}(110)$ as a function of surface temperature. No significant differences are observed between the surfaces with versus without preadsorbed hydrogen. Reprinted with permission from [184]. Copyright (C) 2010, American Chemical Society.

\subsubsection{Cu ALD on Pt and Pd}

With the sequence $\mathrm{Cu}$ (thd) $)_{2}-\mathrm{H}_{2}$, selective $\mathrm{Cu} \mathrm{ALD}$ on $\mathrm{Pd}$ and Pt surfaces but not on $\mathrm{SiO}_{2}$ was achieved in the temperature range $190-260{ }^{\circ} \mathrm{C}[173,265,266]$. It was suggested that $\mathrm{Cu}$ (thd $)_{2}$ dissociatively chemisorbs on the Pd and Pt surfaces, similar to the case of copper acetamidinate on $\mathrm{Ni}[184,293]$. Upon hydrogen adsorption, the thd ligands are completely removed as $\mathrm{H}(\mathrm{thd})$ through reaction with the dissociated surface hydrogen. Using auger electron spectroscopy (AES), glancing incidence x-ray diffraction (GIXRD) and XPS, Willis et al, revealed a significant Pd surface segregation to form a CuPd alloy, where a Cu film was deposited onto a Pd seed layer (XPS results are shown in Fig. 40). Based on the in-situ real- 
time spectroscopic ellipsometry measurements, they proposed that precursor adsorption is reversible, and dissociatively adsorbed hydrogen is the stable surface intermediates between growth cycles; therein, strong $\mathrm{H}^{*}$ binding to $\mathrm{Pd}$ is responsible for the continuous diffusion of Pd from the underlying seed layer into the deposited $\mathrm{Cu}$ film. Less intermixing occurs at lower growth temperatures and shorter cycle times as a consequence of the reduced $\mathrm{Cu} / \mathrm{Pd}$ inter-diffusion [265]. In contrast, Cu ALD on the Pt seed layers showed a clear Cu-Pt interface without any Pt surface segregation [266]. In line with these results, Winter et al. observed a more pronounced $\mathrm{Cu} / \mathrm{Pd}$ inter-diffusion than $\mathrm{Cu} / \mathrm{Pt}$ when $\mathrm{Cu}$ metal films were grown on $\mathrm{Pd}$ and $\mathrm{Pt}$ using an ABC-type $\mathrm{Cu}$ ALD with a sequence of $\mathrm{Cu}\left(\mathrm{OCHMeCH} \mathrm{NMe}_{2}\right)_{2}$-formic acid- $\mathrm{BH}_{3}\left(\mathrm{NHMe}_{2}\right)$ at $135-165{ }^{\circ} \mathrm{C}[180]$.

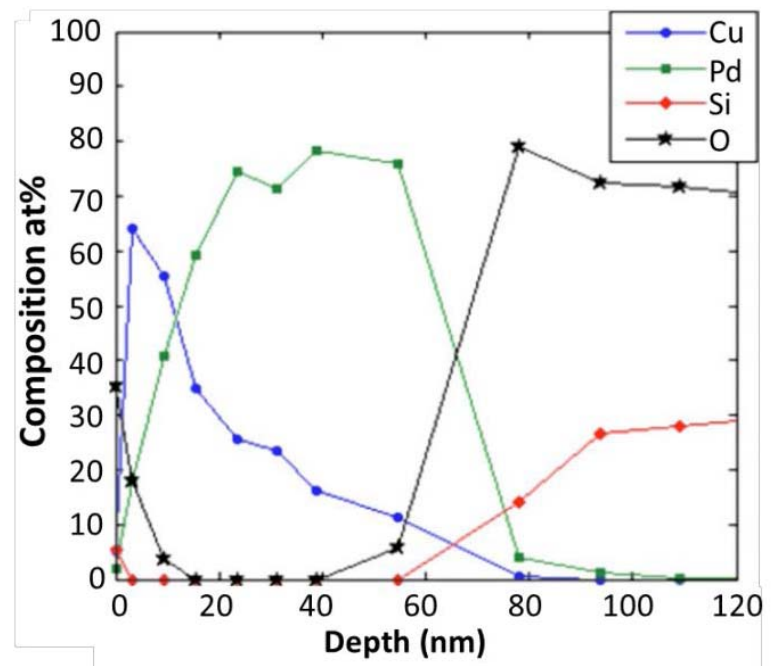

Fig. 40. XPS depth profile of a sample of Pd seed layer on silicon wafer after 600 cycles of $\mathrm{Cu}$ ALD at $235^{\circ} \mathrm{C}$. Here the layers of the film are removed with an argon ion sputter gun. Reprinted with permission from [266]. Rights managed by AIP Publishing LLC.

\subsection{Precise synthesis of well-mixed alloy bimetallic catalysts}

Bimetallic alloy ALD can be accomplished by alternating between the ALD processes for the individual metals; therein, the composition is tuned by the relative number of ALD cycles used for each component $[5,69,294]$. When the ALD processes of two metals share the same deposition temperature and mutually compatible surface chemistries, these two ALD processes can be directly combined together [153, 294, 295]. For instance, Pt and Ir ALD are both carried out at $300{ }^{\circ} \mathrm{C}$ based on a combustion-like surface chemistry, using $\mathrm{MeCpPtMe}_{3}-$ $\mathrm{O}_{2}$ and $\operatorname{Ir}(\mathrm{acac})_{3}-\mathrm{O}_{2}$, respectively $[105,107]$. Elam et al. demonstrated that the QCM step ratios and QMS product distributions did not change for the Pt and Ir ALD cycles in the 1:1 mixed metal film, compared to the corresponding signals for the pure metals (Fig. 41). These 
results indicate that the growth mechanisms for the Pt and Ir were not perturbed by the presence of the other metal [153].
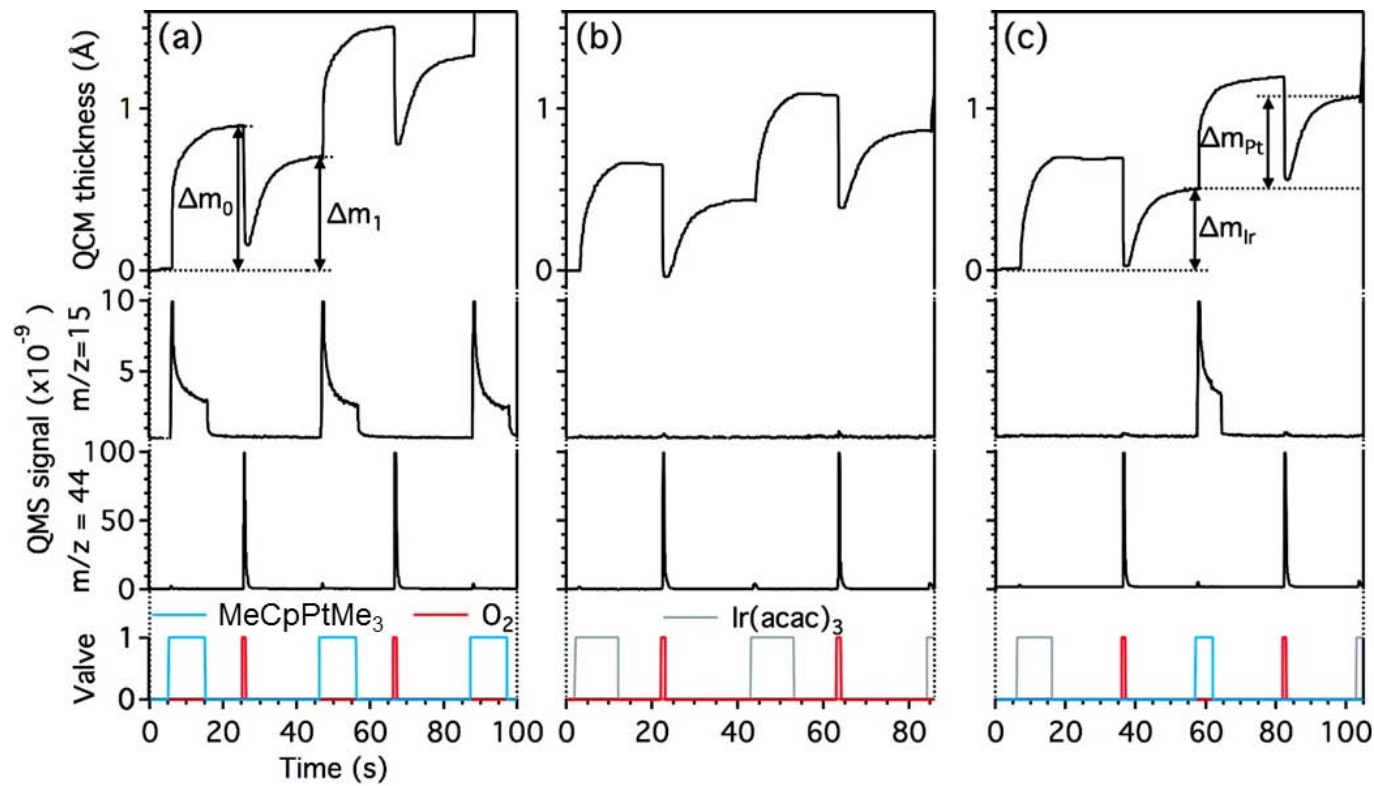

Fig. 41. In situ QCM and QMS data for (a) Pt ALD, (b) Ir ALD, and (c) Ir-Pt mixed-metal ALD using a 1:1 $\operatorname{Ir}(\text { acac) })_{3}: \mathrm{MeCpPtMe}_{3}$ cycles ratio at $300{ }^{\circ} \mathrm{C}$. The QCM thickness trace for Pt in (a) shows an increase during $\operatorname{Pt}(\mathrm{MeCp}) \mathrm{Me}_{3}$ adsorption $\left(\Delta \mathrm{m}_{0}\right)$ and a smaller decrease from the $\mathrm{O}_{2}$ dose to yield a net Pt thickness increase (denoted as $\Delta \mathrm{m}_{1}$ ). In panel (c), the QCM thickness trace yields the net thickness increases from individual Ir ALD cycles $\left(\Delta \mathrm{m}_{\mathrm{Ir}}\right)$ and Pt ALD cycles $\left(\Delta \mathrm{m}_{\mathrm{Pt}}\right)$, which enable determination of the film composition. The middle section shows the reaction byproducts of $\mathrm{m} / \mathrm{z}=15$ for $\mathrm{CH}_{4}$ and $\mathrm{m} / \mathrm{z}=44$ for $\mathrm{CO}_{2}$ from in situ QMS data. The bottom sections of the graphs show the precursor valve operation, where a value of 1 indicates that the respective precursor dosing valve is open. Reprinted with permission from [153]. Copyright (C) 2010, American Chemical Society.

When the ALD processes of two metals do not share a common deposition temperature, or the surface chemistries are incompatible, this can make the alloy film growth extremely challenging or impractical. Fortunately, low-temperature selective metal ALD seems to satisfy these strict requirements for many bimetallic systems [69]. The incompatibility between ALD processes can be rectified by adding a $\mathrm{H}_{2}$-reduction step at the end of combustion-reaction based ALD and an $\mathrm{O}_{2}$-oxidation step at the end of hydrogenationreaction based ALD in each alloy ALD cycle (Fig. 42). For instance, Pd ALD is a hydrogenation reaction process where surface $\mathrm{H}^{*}$ are the active sites [131, 296]; while Pt ALD is a combustion reaction process, where surface $O^{*}$ are the active sites $[105,107]$. The 
direct combination of AB type Pd ALD (Pd(hfac) $)_{2}-\mathrm{H}_{2}$ ) with AB type Pt ALD (MeCpPtMe ${ }_{3}-$ $\mathrm{O}_{2}$ ) caused decomposition of the hfac ligands on the O-terminated surface, which contaminates the surface with carbon and fluorine according to in situ QMS and suppress further Pd growth according to in situ QCM [69]. On the other hand, an $\mathrm{O}_{2}$ exposure added after the $\mathrm{H}_{2}$ exposure in each Pd ALD cycle will oxidize and O-terminate the Pd surface in preparation for the $\mathrm{MeCpPtMe}_{3}$ adsorption in the subsequent Pt cycle. Similarly, a $\mathrm{H}_{2}$ exposure added after the $\mathrm{O}_{2}$ exposure in each Pt ALD cycle can reduce and $\mathrm{H}$-terminate the surface for the $\mathrm{Pd}(\mathrm{hfac})_{2}$ adsorption in the subsequent Pd ALD cycle. Implementing this ABC strategy can satisfy the surface chemistries of both ALD process and facilitate the growth of the two components. Indeed, the growth rate of PtPd alloy ALD is $136.4 \mathrm{ng} / \mathrm{cm}^{2}$ per alloy cycle using $\mathrm{MeCpPtMe}{ }_{3}-\mathrm{O}_{2}-\mathrm{H}_{2}-\mathrm{Pd}(\mathrm{hfac})_{2}-\mathrm{H}_{2}-\mathrm{O}_{2}$, much greater that using $\mathrm{MeCpPtMe}_{3}-\mathrm{O}_{2}-$ $\mathrm{Pd}(\mathrm{hfac})_{2}-\mathrm{H}_{2}\left(90.9 \mathrm{ng} / \mathrm{cm}^{2}\right.$ per cycle).

In the following subsections, we discuss the synthesis, structure, and catalytic activities of several ALD alloy catalysts.
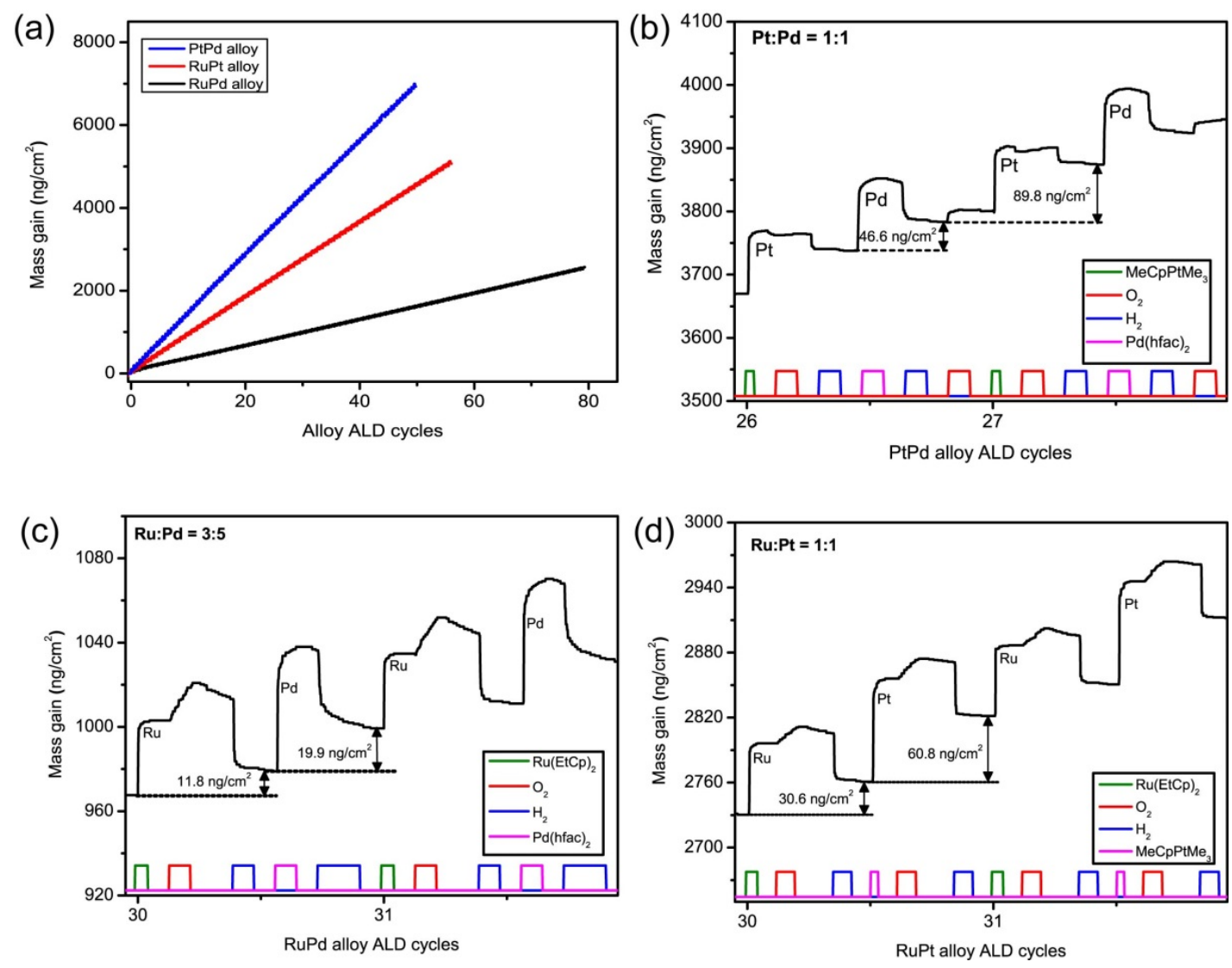

Fig. 42. In situ QCM studies of low temperature metal alloy ALD at $150{ }^{\circ} \mathrm{C}$. (a) Linear growth of PtPd, RuPd, and RuPt alloys by alternating between the ALD processes for the two metals. PtPd alloy ALD sequence: $\mathrm{MeCpPtMe}_{3}-\mathrm{O}_{2}-\mathrm{H}_{2}-\mathrm{Pd}(\mathrm{hfac})_{2}-\mathrm{H}_{2}-\mathrm{O}_{2} ; \mathrm{RuPd}$ alloy sequence: $\mathrm{Ru}(\mathrm{EtCp})_{2}-\mathrm{O}_{2}-\mathrm{H}_{2}-\mathrm{Pd}(\mathrm{hfac})_{2}-\mathrm{H}_{2} ; \quad \mathrm{RuPt}$ alloy sequence: $\mathrm{Ru}(\mathrm{EtCp})_{2}-\mathrm{O}_{2}-\mathrm{H}_{2}-$ 
$\mathrm{MeCpPtMe}_{3}-\mathrm{O}_{2}-\mathrm{H}_{2}$. (b) Detailed mass changes during two PtPd alloy supercycles. (c) Detailed mass changes during two RuPd alloy supercycles. (d) Detailed mass changes during two RuPt alloy supercycles. The mole ratios of these metals in the alloy ALD are indicated. The sequential exposure steps of each reactant are shown as columns in color at the bottom of each figure, nitrogen purge step is in between the columns. Reprinted with permission from [69]. Copyright (C) 2014, Rights Managed by Nature Publishing Group.
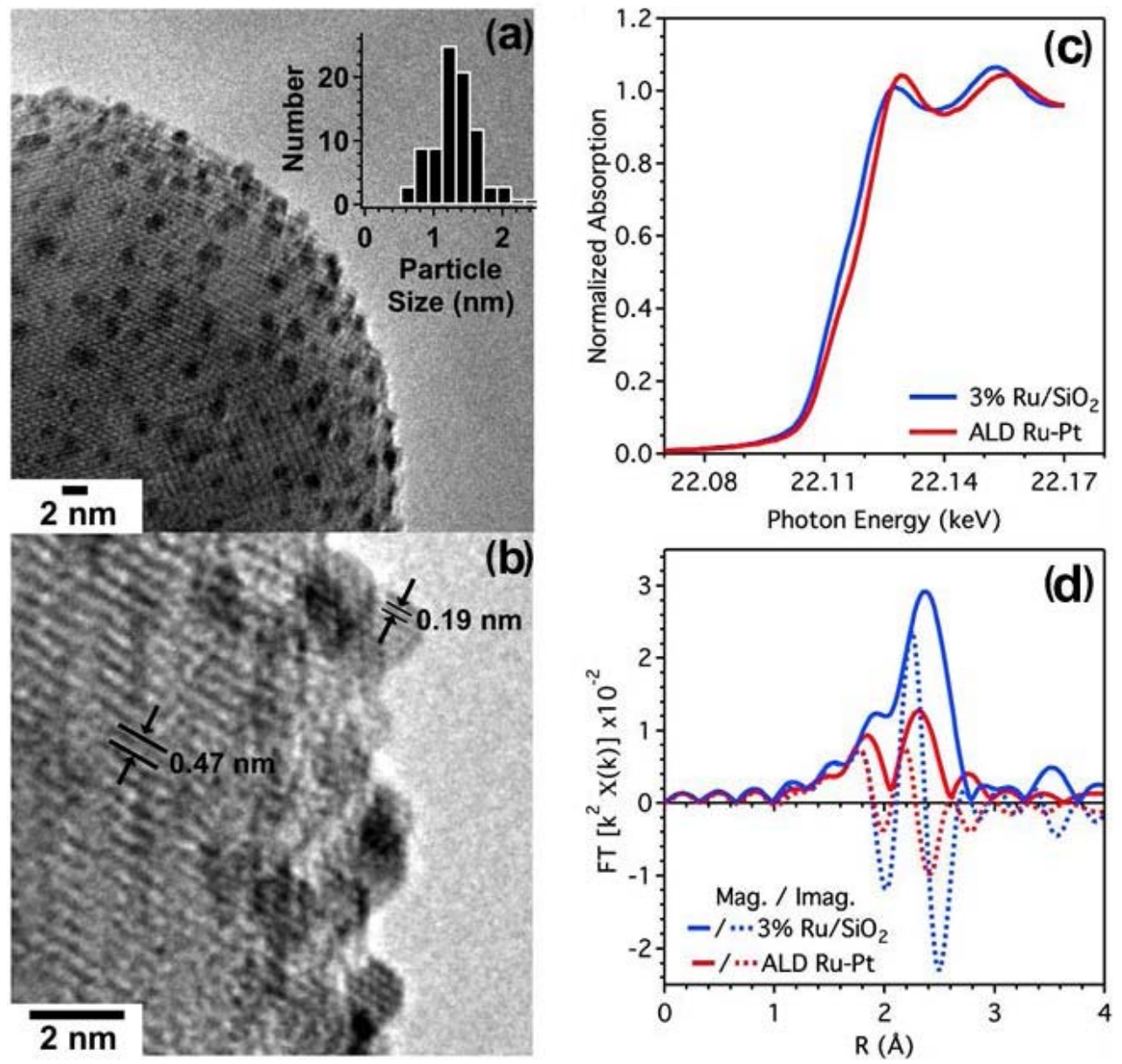

Fig. 43. TEM images of ALD RuPt bimetallic nanoparticles on $\mathrm{Al}_{2} \mathrm{O}_{3}$ synthesized using 2 cycles Ru ALD, 1 cycle Pt ALD and 1cycle Ru ALD at $300{ }^{\circ} \mathrm{C}$. The mean particle diameter is $1.2 \mathrm{~nm}$ with a distribution width of $0.3 \mathrm{~nm}$. (b) High-resolution TEM image showing lattice fringes for the $\mathrm{Al}_{2} \mathrm{O}_{3}$ and the $\mathrm{Ru}-\mathrm{Pt}$ nanoparticles. (c) X-ray absorption spectra at $\mathrm{Ru} \mathrm{K}$-edge for $\mathrm{ALD} \mathrm{Ru}-\mathrm{Pt} / \mathrm{Al}_{2} \mathrm{O}_{3}$ and a reference $3 \% \mathrm{Ru} / \mathrm{SiO}_{2}$. For the ALD catalysts, the Ru K-edge is shifted $3 \mathrm{eV}$ higher and has a distinctly different line profile compared to the $\mathrm{Ru}$ reference. (d) Fourier transforms of the absorption spectra where the solid line shows the magnitude and the broken line shows the imaginary part. Peaks at 2 and $2.5 \AA$ are smaller for the ALD catalyst when compared to the Ru reference. Reprinted with permission from [9]. Copyright (C) 2010, American Chemical Society. 


\subsubsection{RuPt alloy ALD}

$\mathrm{Ru}$ and $\mathrm{Pt}$ ALD share the same deposition temperature of $300{ }^{\circ} \mathrm{C}$ and the compatible combustion-like surface chemistry. Elam et al. observed that the growth rates for Ru and Pt in the RuPt alloy ALD at $300{ }^{\circ} \mathrm{C}$ were very similar to the growth rates for the corresponding pure metal, in a similar fashion as Ir-Pt ALD alloy, indicating little perturbation of the growth chemistries upon transitioning between materials [9]. A bimetallic RuPt/ $\mathrm{Al}_{2} \mathrm{O}_{3}$ catalyst was synthesized on high surface are $\mathrm{Al}_{2} \mathrm{O}_{3}$ powder using RuPt alloy ALD with the following scheme: 2 cycles Ru ALD, 1 cycle Pt ALD, and 1 cycle Ru ALD. High resolution TEM revealed that the $\mathrm{Ru}-\mathrm{Pt}$ deposited as discrete nanoparticles with a diameter of $1.2 \pm 0.3$ $\mathrm{nm}$ on the alumina support, and EXAFS measurements confirmed that the $\mathrm{Ru}-\mathrm{Pt}$ nanoparticles were bimetallic (Fig. 43). In the $\mathrm{CH}_{3} \mathrm{OH}$ decomposition reaction, the resulting bimetallic RuPt/ $\mathrm{Al}_{2} \mathrm{O}_{3}$ catalyst yielded a considerably higher catalytic activity compared to a physical mixture of $\mathrm{Ru} / \mathrm{Al}_{2} \mathrm{O}_{3}$ and $\mathrm{Pt} / \mathrm{Al}_{2} \mathrm{O}_{3}$ catalysts.

When Ru and Pt ALD were used to grow RuPt alloy nanoparticles on N-doped multiwalled carbon nanotubes at $250{ }^{\circ} \mathrm{C}$, Johansson et al, [294] also observed a linear correlation between the Ru:Pt content ratio and the Ru:Pt ALD cycle ratio. Consequently, the composition was easily tuned by varying the relative number of ALD cycles. The ALD RuPt alloy catalysts were tested toward the CO oxidation and methanol oxidation reaction (MOR) in a three-electrode electrochemical set-up. They found that the catalysts with a Ru content of 29 at.\% exhibited the highest catalytic activity and attributed this to a bifunctional mechanism [295].

\subsubsection{PdCu alloy ALD}

Molenbroek et al. synthesized $\mathrm{PdCu}$ alloy nanoparticles on $\mathrm{SiO}_{2}$ and $\mathrm{Al}_{2} \mathrm{O}_{3}$ supports using 1 cycle $\mathrm{Cu}$ ALD followed by 1 cycle Pd ALD with $\mathrm{Cu}(\text { thd })_{2}, \mathrm{Pd}(\text { thd })_{2}$ and $\mathrm{O}_{2}$ as reactants. The deposition temperature was $170{ }^{\circ} \mathrm{C}$ for the metal precursor exposure step and $450{ }^{\circ} \mathrm{C}$ for the $\mathrm{O}_{2}$ oxidation step. TEM showed that the resulting $\mathrm{PdCu}$ particles had a high dispersion and particle sizes of 2.5-7.0 nm on $\mathrm{SiO}_{2}$ and 2.0-6.0 nm on $\mathrm{Al}_{2} \mathrm{O}_{3}$. Interestingly, their EXAFS measurements showed that the type of alloying in the $\mathrm{PdCu}$ system depended on the support. Surface segregation of $\mathrm{Cu}$ was observed for the alumina-supported samples, but random alloying was seen for the silica-supported samples [256].

\subsubsection{PdPt alloy ALD}


As discussed previously, Pd and Pt ALD have dissimilar surface chemistries. Direct combination of the conventional AB type Pd ALD (Pd(hfac $)_{2}-\mathrm{H}_{2}$ ) with $\mathrm{Pt}$ ALD $\left(\mathrm{MeCpPtMe}_{3}-\mathrm{O}_{2}\right)$ would cause decomposition of the hfac ligands on the O-terminated surface, producing carbon and fluorine contamination and also suppressing the Pd growth [69]. On the other hand, adding an $\mathrm{O}_{2}$ oxidation step at the end of each Pd ALD cycle, and a $\mathrm{H}_{2}$ reduction step at the end of each Pt ALD cycle can satisfy the surface chemistries of each ALD process and thus facilitate the growth of the two components. Using the ABC sequences of $\mathrm{MeCpPtMe}_{3}-\mathrm{O}_{2}-\mathrm{H}_{2}$ and $\mathrm{Pd}(\mathrm{hfac})_{2}-\mathrm{H}_{2}-\mathrm{O}_{2}$ to alternatively deposit Pt and Pd, PdPt alloy nanoparticles can in principle be formed. In situ CO chemisorption FTIR provided solid evidence for the formation of a well-mixed PdPt alloy using ABC sequences for the Pt and Pd ALD. As illustrated in Fig. 44a, the linear CO peak on Pt $\left(2067 \mathrm{~cm}^{-1}\right)$ was suppressed while the $1931 \mathrm{~cm}^{-1}$ peak (bridge-bonded CO on Pd) increased after each Pd ALD step, clearly demonstrating that the Pd covered a fraction of the surface Pt atoms. Similarly, each Pt ALD step reversed these trends, indicating that Pt covered some of the surface Pd atoms. These reversible changes in the spectral features persisted over multiple PtPd alloy supercycles, indicating the formation of a well-mixed PdPt alloy. High resolution HAADF-STEM along with elemental line profile analysis further confirmed the well-mixed PtPd alloy structure (Fig. 44b).
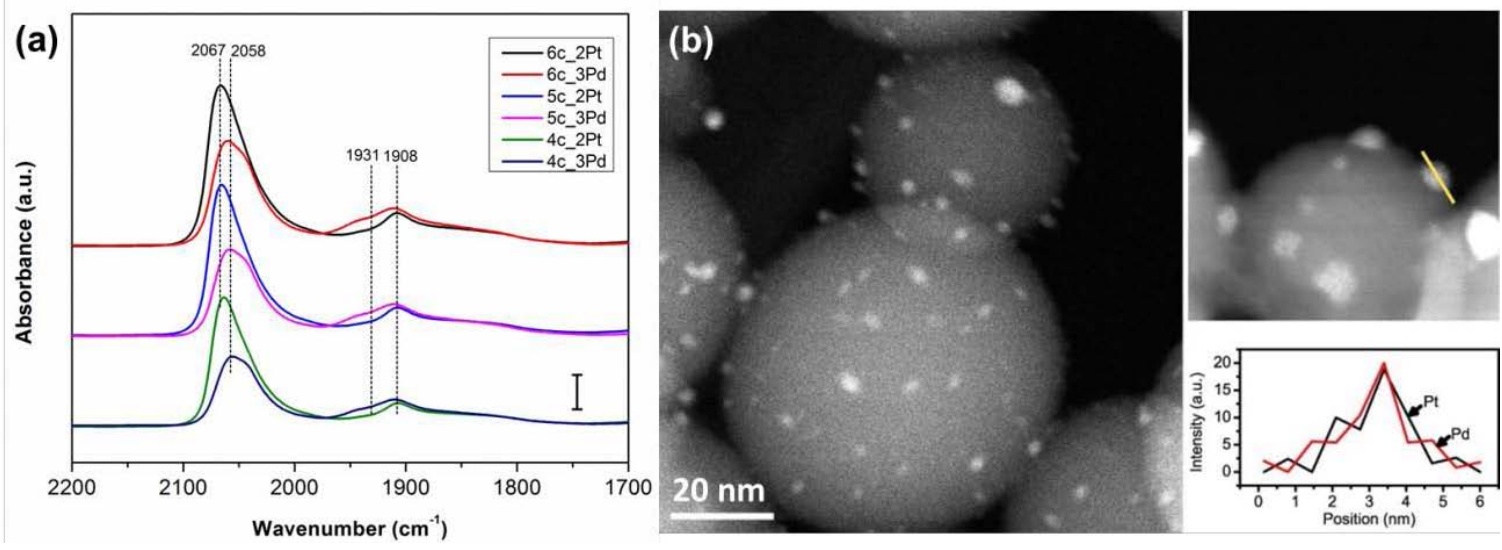

Fig. 44. (a) In situ CO chemisorption FTIR measurements during PtPd alloy ALD on an ALD $\mathrm{Pt} / \mathrm{Al}_{2} \mathrm{O}_{3}$ sample at $150{ }^{\circ} \mathrm{C}$. "Supercycles” of the PdPt alloy ALD were performed comprising 3c-Pd ALD followed by 2c-Pt ALD, and CO chemisorption was performed after each 3c-Pd and each 2c-Pt to probe the surface composition. Scale bar, 10\%. (b) Representative aberration-corrected HAADF-STEM images and corresponding EDS line profiles of PtPd alloy bimetallic nanoparticles on spherical alumina support. Reprinted with permission from [69]. Copyright (C) 2014, Rights Managed by Nature Publishing Group. 


\subsection{Summary}

Due to the unique self-limiting character, ALD provides a promising way to precisely synthesize supported bimetallic nanoparticles on the atomic level. The major challenge is to ensure that the ALD processes for two metals share a common deposition temperature and compatible surface chemistries. The temperature requirement is less important for bimetallic nanoparticles with core-shell structure, since the temperature need only be changed once when commencing growth of the shell metal.

An essential goal in catalysis science is to establish catalyst structure-activity relationships. Selective metal ALD on metal surfaces but not on supports to exclude any monometallic nanoparticle formation is a powerful means to achieve this goal. ALD enables the atomicallyprecise synthesis of supported bimetallic nanoparticles by digitally tailoring the ALD pulse sequences. The bimetallic particle size is determined by the total number of ALD cycles performed, the composition is dictated by the relative number of ALD cycles used for each component, and the structure of the bimetallic nanoparticles is controlled by the order in which the individual cycles are executed. Such cycle-by-cycle "bottom up" construction of bimetallic (or multimetallic) nanoparticles on supports shows obvious advantages over conventional methods such as successive impregnation. For example, the thickness of Pt shell on Pd@Pt core-shell nanoparticles can be precisely tuned by 0.15 ML per cycle (Fig. 36) [69]. Such controlled supported bimetallic catalysts synthesis facilitates the establishment of the correlation between the bimetallic nanoparticles structures and their catalytic performance, thus providing insights for understanding the reaction mechanism and the rational design of improved catalysts. Nevertheless, we have shown that interdiffusion or surface segregation of metal atoms can occur during bimetallic nanoparticle synthesis, resulting in a different structure than intended. In such cases, depositing the metals at a lower temperature might supress the metal atom interdiffusion or surface segregation.

\section{Oxide ALD on metals: precise synthesis of nanostructured metal catalysts}

The sintering of supported metal catalysts, especially under severe reaction conditions, is one major technical issue in applied catalysis. Improving the stability of metal particles against sintering under reaction conditions has drawn tremendous attentions [40-42]. Encapsulation of metal nanoparticles with porous oxide layers is the most commonly used methods. The protective oxide layer is often grown using the techniques including CVD and sol-gel chemistry to form core-shell structures. With an oxide protective layer, such as mesoporous silica [49, 53], tin oxide [297], zirconia [298], or ceria [50, 299], the 
encapsulated metal nanoparticles sometimes show good sintering resistance up to $800{ }^{\circ} \mathrm{C}$. However, in most cases there is a large decrease in catalytic activity due to mass transfer resistance associated with the thick protective shell (usually tens of nm's thick). Atomicallyprecise control over the thickness of protective layers can be critical to achieve an optimal balance between sintering resistance and high catalytic activity.

Motivated by the atomically-precise thickness and composition control afforded by ALD, a large number of studies have been performed to improve the stability of metal nanoparticles against sintering and leaching using ALD oxide overcoats, where conformal ultrathin ALD metal oxide layers are deposited on metal nanoparticles as well as the support [8, 12, 300303]. The ability to form ultrathin ALD coatings on metal particles illustrates the potential to minimize the mass transfer resistance.

In an effort to maintain high catalytic activity, several methods for generating and controlling the porosity of ALD oxide overcoats have been developed, including selfinhibited growth [304], high-temperature treatment [12, 305], organic porogens [301], and

selective growth [306]. These methods were discussed in previous reviews [5, 13]. Here we will mainly focus on the surface chemistry of oxide ALD on metals and the catalytic performance of the resulting overcoated metal catalysts in this section. In particular, the selective blocking of low-coordination sites of metal nanoparticles, the confinement effect, and the creation of new metal-oxide interfaces will be discussed.

\section{1 $\mathrm{Al}_{2} \mathrm{O}_{3} \mathrm{ALD}$ on $\mathrm{Pd}$}

\subsubsection{Surface chemistry}

$\mathrm{Al}_{2} \mathrm{O}_{3}$ ALD performed using TMA and water is one of the most successful ALD procedures, and has been extensively investigated [26, 307-310]. The mechanism for $\mathrm{Al}_{2} \mathrm{O}_{3}$ ALD on oxide surfaces is well understood: first, TMA reacts with hydroxyl groups on the starting surface forming $\mathrm{Al}\left(\mathrm{CH}_{3}\right)_{\mathrm{x}} *(\mathrm{x}=1-2)$ surface species and $\mathrm{CH}_{4}$ gaseous product; next, exposure to $\mathrm{H}_{2} \mathrm{O}$ transforms the $\mathrm{Al}\left(\mathrm{CH}_{3}\right)_{\mathrm{x}}{ }^{*}$ terminated surface to an $\mathrm{Al}(\mathrm{OH})_{\mathrm{x}}{ }^{*}(\mathrm{x}=1-2)$ terminated surface and again releases $\mathrm{CH}_{4}[26,309,310]$. The ratio of the total mass gain in one ALD cycle $\left(\Delta \mathrm{m}_{0}\right)$ to the mass gain after the TMA exposure $\left(\Delta \mathrm{m}_{1}\right)$ is about 1.1 according to in situ QCM measurements [26, 309, 311].

However, the growth mechanism for $\mathrm{Al}_{2} \mathrm{O}_{3}$ ALD on metal surfaces can be quite different. For instance, we observed a significantly higher mass ratio of $\Delta \mathrm{m}_{0 / \Delta \mathrm{m}_{1}}=1.6$ in the first $\mathrm{Al}_{2} \mathrm{O}_{3}$ ALD cycle on Pd using in situ QCM measurements (Fig. 45a) [304, 312]. Furthermore, 
in situ QMS measurements detected $\mathrm{C}_{2} \mathrm{H}_{6}$ during the first TMA exposure and $\mathrm{H}_{2}$ during the first $\mathrm{H}_{2} \mathrm{O}$ exposure along with the dominant $\mathrm{CH}_{4}$ product (Fig. 45b). DFT calculations performed on $\operatorname{Pd}(111)$ and $\operatorname{Pd}(211)$ revealed that TMA adsorbs most strongly on the 3-fold (hcp) site, and quickly dissociates to $\mathrm{Al}\left(\mathrm{CH}_{3}\right)^{*}$ (also with a slight preference for hcp adsorption) and $\mathrm{CH}_{3}$ * surface species (Equations 11,12). The formation of $\mathrm{Al}\left(\mathrm{CH}_{3}\right)^{*}$ surface species was further confirmed by scanning tunnelling microscopy (STM), which showed locally-ordered species with a height of about $0.15 \mathrm{~nm}$ and a separation distance of $\sim 0.43 \mathrm{~nm}$ [312]. Some $\mathrm{Al}\left(\mathrm{CH}_{3}\right)^{*}$ might further dissociate into $\mathrm{Al} *$ and $\mathrm{CH}_{3} *$ on step edges (Equation 13). Zemlyanov et al. later reported the formation of a Pd-Al alloy phase after TMA exposure on Pd as evidenced by a Pd 3d higher binding energy shift of $0.6 \mathrm{eV}$ from the metallic phase using XPS, in line with our results [313]. The ethane observed by QMS likely forms through the coupling of two adjacent $\mathrm{CH}_{3}{ }^{*}$ species according to Equation 15, which further support the existence of a large concentration of $\mathrm{CH}_{3}{ }^{*}$ on the Pd surface from TMA dissociation. More interestingly, the DFT results demonstrate that the step sites are much more thermodynamically favorable for TMA dissociative adsorption than the $\operatorname{Pd}(111)$ terraces by about $0.81 \mathrm{eV}$.

$$
\begin{gathered}
\mathrm{Al}\left(\mathrm{CH}_{3}\right)_{3} *+\rightarrow \mathrm{Al}\left(\mathrm{CH}_{3}\right)_{2} *+\mathrm{CH}_{3}^{*} \\
\mathrm{Al}\left(\mathrm{CH}_{3}\right)_{2}^{*}+* \rightarrow \mathrm{Al}\left(\mathrm{CH}_{3}\right)^{*}+\mathrm{CH}_{3}^{*} \\
\mathrm{Al}\left(\mathrm{CH}_{3}\right)^{*}+\rightarrow \mathrm{Al}^{*}+\mathrm{CH}_{3} * \\
\mathrm{CH}_{3} *+\mathrm{H}^{*} \rightarrow \mathrm{CH}_{4}(\mathrm{~g})+2^{*} \\
\mathrm{CH}_{3}^{*}+\mathrm{CH}_{3}^{*} \rightarrow \mathrm{C}_{2} \mathrm{H}_{6}(\mathrm{~g})+2^{*} \\
\mathrm{AlCH}_{3} *+\mathrm{H}_{2} \mathrm{O}(\mathrm{g}) \rightarrow \mathrm{Al}(\mathrm{OH})^{*}+\mathrm{CH}_{4}(\mathrm{~g}) \\
\mathrm{Al}(\mathrm{OH})^{*}+\mathrm{H}_{2} \mathrm{O}(\mathrm{g}) \rightarrow \mathrm{H}_{2} \mathrm{O}-\mathrm{Al}(\mathrm{OH})^{*} \\
\mathrm{H}_{2} \mathrm{O}-\mathrm{Al}(\mathrm{OH})^{*}+* \rightarrow \mathrm{Al}(\mathrm{OH})_{2} *+\mathrm{H}^{*} \\
\mathrm{Al}(\mathrm{OH})_{2} *+\mathrm{H}_{2} \mathrm{O}(\mathrm{g}) \rightarrow \mathrm{H}_{2} \mathrm{O}-\mathrm{Al}(\mathrm{OH})_{2} * \\
\mathrm{H}_{2} \mathrm{O}-\mathrm{Al}(\mathrm{OH})_{2}^{*}+* \rightarrow \mathrm{Al}(\mathrm{OH})_{3} *+\mathrm{H}^{*} \\
\mathrm{H}^{*}+\mathrm{H}^{*} \rightarrow \mathrm{H}_{2}(\mathrm{~g})+2^{*}
\end{gathered}
$$

In the water exposure, the transformation of $\mathrm{Al}\left(\mathrm{CH}_{3}\right)^{*}$ into $\mathrm{Al}(\mathrm{OH}) *$ accompanied by methane release is represented by Equation 16. This reaction is highly exothermic, and has a free energy change of $\sim 1.3 \mathrm{eV}$, on both the $\operatorname{Pd}(111)$ and $\operatorname{Pd}(211)$ surfaces. Additional reaction with water to form $\mathrm{Al}(\mathrm{OH})_{2}$ * and $\mathrm{Al}(\mathrm{OH})_{3}$ * (Equations 17-20), was found to be thermodynamically favorable on both $\mathrm{Pd}(111)$ and $\mathrm{Pd}(211)$ surfaces. In fact, $\mathrm{Al}(\mathrm{OH})_{3}{ }^{*}$ was the most thermodynamically stable intermediate on the Pd surfaces following $\mathrm{H}_{2} \mathrm{O}$ exposure. These $\mathrm{H}^{*}$ can react with either $\mathrm{CH}_{3} *$ species to release methane, (Equation 14), or combine 
with an additional $\mathrm{H}^{*}$ to form molecular hydrogen (Equation 21), consistent with the observation of both methane and hydrogen by QMS during the initial water exposures (Fig. $45 b)$.
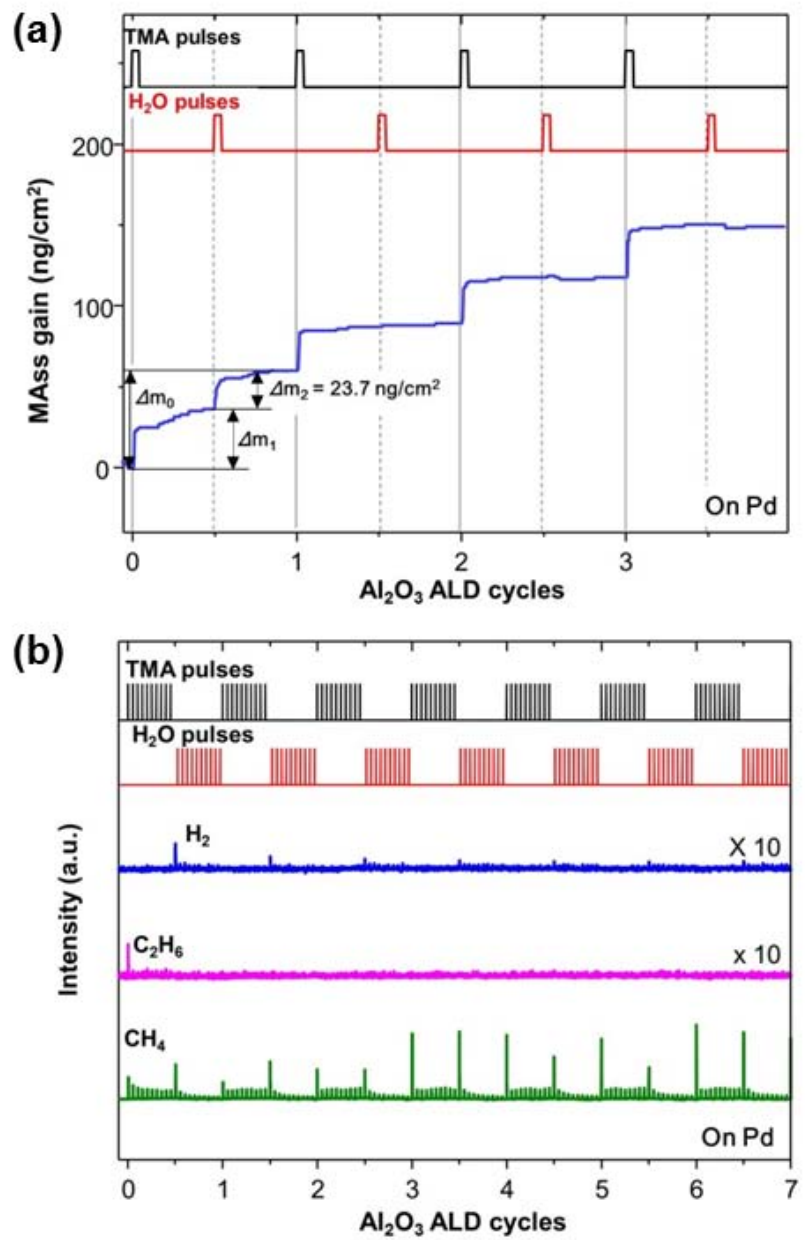

Fig. 45. (a) In situ QCM measurements of $\mathrm{Al}_{2} \mathrm{O}_{3} \mathrm{ALD}$ on a Pd surface at $200{ }^{\circ} \mathrm{C}$ during the first 4 cycles. (b) In situ QMS measurements of $\mathrm{Al}_{2} \mathrm{O}_{3}$ ALD on the Pd surface at $200{ }^{\circ} \mathrm{C}$ during the first 7 cycles. Continuously produced $\mathrm{CH}_{4}$ in each TMA micropulse is from the cracking pattern of TMA during ionization. The $\mathrm{H}_{2}$ and $\mathrm{C}_{2} \mathrm{H}_{6}$ QMS signals were multiplied by 10 . The TMA and water exposures are indicated at the top of each figure. Reprinted with permission from [312]. Copyright (C) 2014, American Chemical Society.

A high concentration of $\mathrm{CH}_{3} *$ species formed on Pd surface could inhibit the $\mathrm{Al}_{2} \mathrm{O}_{3}$ ALD by blocking the potential TMA adsorption sites. This site blocking is expected to be only temporary, since the $\mathrm{CH}_{3}$ * species are released as $\mathrm{CH}_{4}$ during the following water dose, thereby "cleaning” the Pd for TMA adsorption. This self-poisoning, self-cleaning process continues for $\sim 7$ cycles, as demonstrated by the persistent but gradually decreasing $\mathrm{H}_{2}$ production [304]. This mechanism will allow the continuous nucleation of new $\mathrm{Al}_{2} \mathrm{O}_{3}$ islands 
on the exposed Pd sites as well as the growth of existing $\mathrm{Al}_{2} \mathrm{O}_{3}$ patches in three dimensions. As a consequence, the $\mathrm{Al}_{2} \mathrm{O}_{3}$ grows as a discontinuous film rather than a continuous, pinholefree coating typical for ALD, which was further confirmed by the STM measurements (Fig. 46a). More interestingly, once the ALD alumina film was annealed at $500{ }^{\circ} \mathrm{C}$ in UHV for $1 \mathrm{~h}$, the density of clusters significantly decreased on the terraces and the step edges were decorated with strips of alumina clusters (Fig. 46b), providing direct evidence for the preferential decoration of low-coordination Pd sites with $\mathrm{ALD} \mathrm{Al}_{2} \mathrm{O}_{3}$ layers, especially after high temperature treatment $[8,12]$. This observation is also consistent with the DFT calculations.
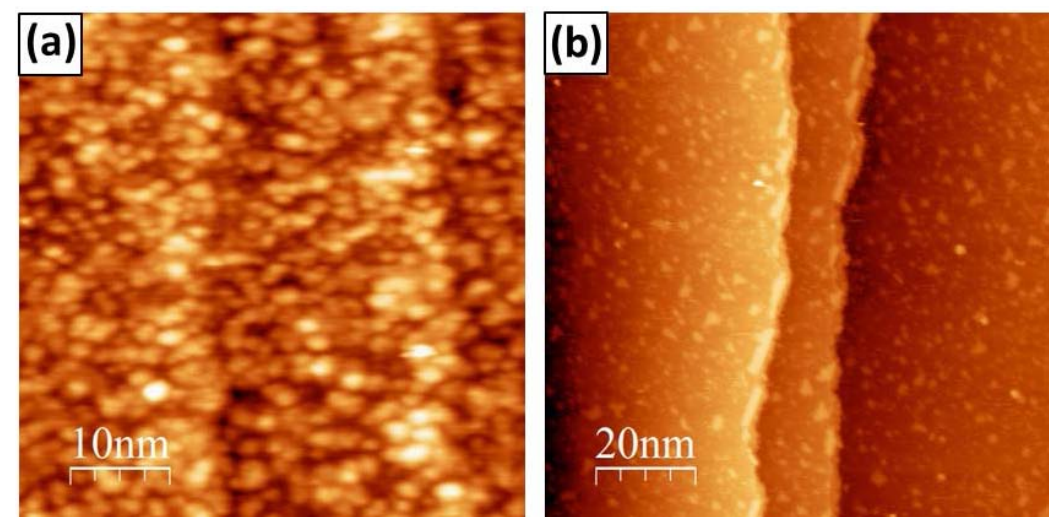

Fig. 46. STM images of 4-cycle ALD alumina films prepared at $200{ }^{\circ} \mathrm{C}$ on $\mathrm{Pd}$ (111) (a) asdeposited, and after annealing at $500{ }^{\circ} \mathrm{C}$ in UHV for one hour (b). The scanning parameters for (a) and (b) are $\mathrm{V}=1 \mathrm{~V}, \mathrm{I}=0.1 \mathrm{nA}$ and $\mathrm{V}=-2 \mathrm{~V}, \mathrm{I}=0.2 \mathrm{nA}$, respectively. Reprinted with permission from [312]. Copyright (C) 2014, American Chemical Society.

\subsubsection{Structures of $\mathrm{Pd} / \mathrm{Al}_{2} \mathrm{O}_{3}$ catalysts with $\mathrm{ALD}$ alumina overcoat}

When $\mathrm{Al}_{2} \mathrm{O}_{3}$ ALD was performed on a $\mathrm{Pd} / \mathrm{Al}_{2} \mathrm{O}_{3}$ catalyst, the thickness of ALD $\mathrm{Al}_{2} \mathrm{O}_{3}$ overcoats was found to grow linearly with the number of ALD cycles at a growth rate of 0.16 $\mathrm{nm} /$ cycle (Fig. 47). This value is consistent with $\mathrm{ALD}$ of $\mathrm{Al}_{2} \mathrm{O}_{3}$ on boron nitride and $\mathrm{ZrO}_{2}$ high surface area powders reported in the literature [305, 314], but slightly higher than the growth rate on planar surfaces, possibly due to some CVD during the long precursor exposure times. Even though the presence of porosity within ALD $\mathrm{Al}_{2} \mathrm{O}_{3}$ overcoats was suggested by in situ QMS and STM [304, 312], directly imaging porosity within the amorphous $\mathrm{Al}_{2} \mathrm{O}_{3}$ overcoats by high resolution TEM has proved challenging. Nevertheless, the porosity of $\mathrm{ALD} \mathrm{Al}_{2} \mathrm{O}_{3}$ overcoats can be verified by nitrogen BET measurements. On a $\mathrm{Pd} / \mathrm{Al}_{2} \mathrm{O}_{3}$ catalyst with 20 cycles of ALD alumina overcoat, we observed a micropore size of $\sim 1 \mathrm{~nm}$ in diameter. Once this sample was calcined at $350{ }^{\circ} \mathrm{C}$ in $10 \% \mathrm{O}_{2}$ for $1 \mathrm{~h}$, larger pores 
with a size between 2-4 nm were formed (Fig. 48) [77]. Similarly, we observed that micropores of $\sim 2 \mathrm{~nm}$ were formed within an $8 \mathrm{~nm}$ thick ALD alumina overcoat after calcination at $700{ }^{\circ} \mathrm{C}$ for two hours in $10 \%$ oxygen in helium [12]. We proposed that the pores are formed as a result of structural changes in the amorphous $\mathrm{Al}_{2} \mathrm{O}_{3}$ over-coating layer (e.g. densification) caused by dehydration [305], and the removal of carbon residues from the ALD process, and dewetting of the $\mathrm{Al}_{2} \mathrm{O}_{3}$ overcoats from the Pd nanoparticle surface [12].
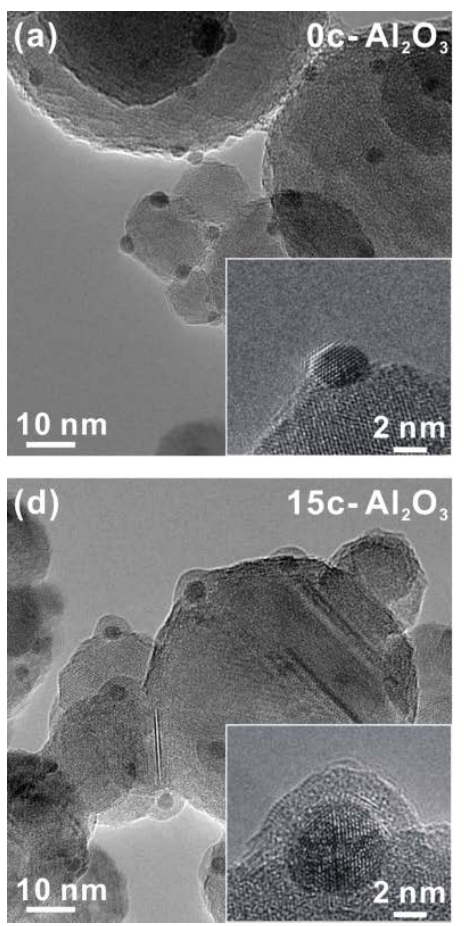
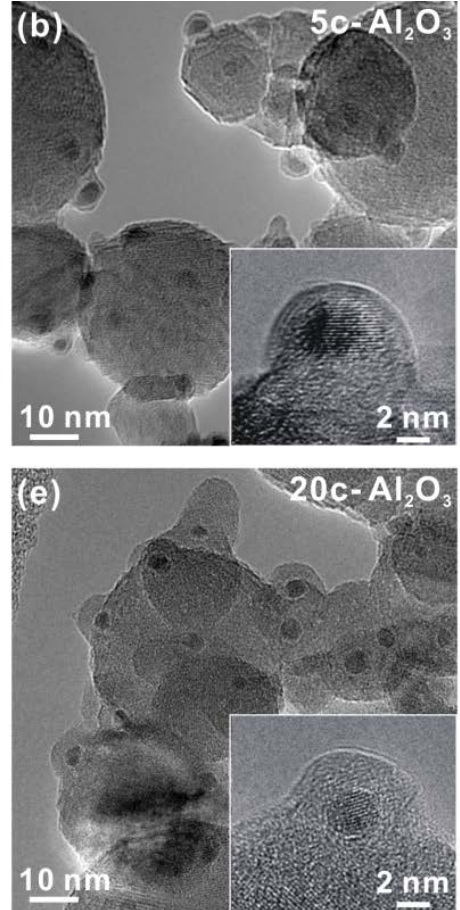

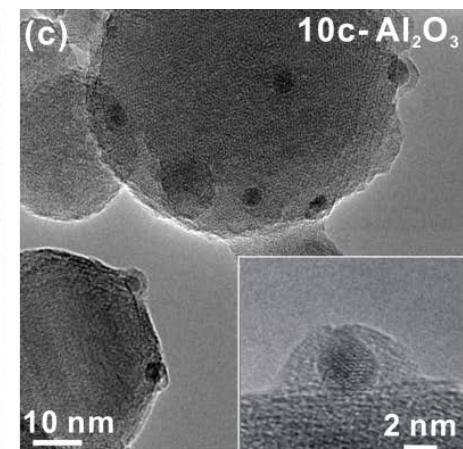

(f)

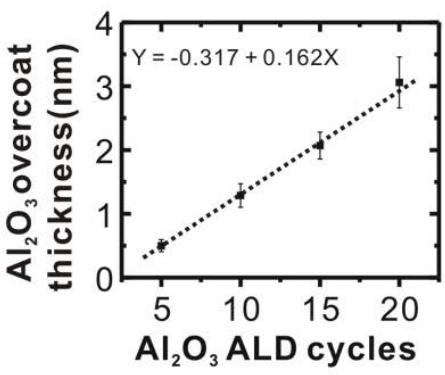

Fig. 47. TEM images of spherical alumina supported Pd catalysts with different numbers of $\mathrm{Al}_{2} \mathrm{O}_{3}$ ALD overcoating cycles (insets show higher magnification images). (a) 0 cycle $\mathrm{Al}_{2} \mathrm{O}_{3}$; (b) 5 cycles $\mathrm{Al}_{2} \mathrm{O}_{3}$; (c) 10 cycles $\mathrm{Al}_{2} \mathrm{O}_{3}$; (d) 15 cycles $\mathrm{Al}_{2} \mathrm{O}_{3}$; (e) 20 cycles $\mathrm{Al}_{2} \mathrm{O}_{3}$; (f) thickness of $\mathrm{Al}_{2} \mathrm{O}_{3}$ overcoats versus ALD cycles. Reprinted with permission from [304]. Copyright (C) 2012, American Chemical Society.

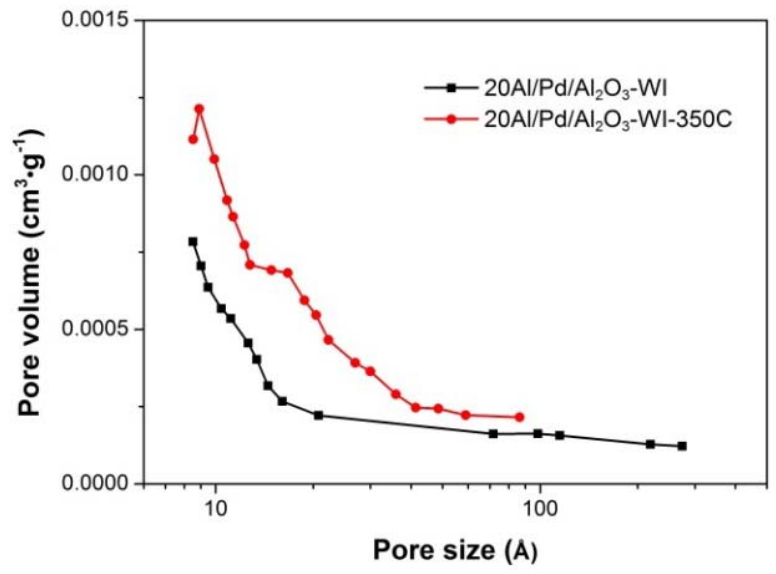


Fig. 48. Pore size distributions calculated based on the DFT model from the $\mathrm{N}_{2}$ adsorption isotherms of the as-prepared $20 \mathrm{Al} / \mathrm{Pd} / \mathrm{Al}_{2} \mathrm{O}_{3}-\mathrm{WI}$ and $20 \mathrm{Al} / \mathrm{Pd} / \mathrm{Al}_{2} \mathrm{O}_{3}-\mathrm{WI}-350 \mathrm{C}$ samples. Here the 20Al/Pd/ $\mathrm{Al}_{2} \mathrm{O}_{3}$-WI-350C sample was obtained by calcining the $20 \mathrm{Al} / \mathrm{Pd} / \mathrm{Al}_{2} \mathrm{O}_{3}-\mathrm{WI}$ sample at $350{ }^{\circ} \mathrm{C}$ in $10 \% \mathrm{O}_{2}$ in $\mathrm{Ar}$ for $1 \mathrm{~h}$ followed by reduction at $150{ }^{\circ} \mathrm{C}$ in $10 \% \mathrm{H}_{2}$ in $\mathrm{Ar}$ for another $1 \mathrm{~h}$. Reprinted with permission from [77]. Copyright (C 2015, American Chemical Society.

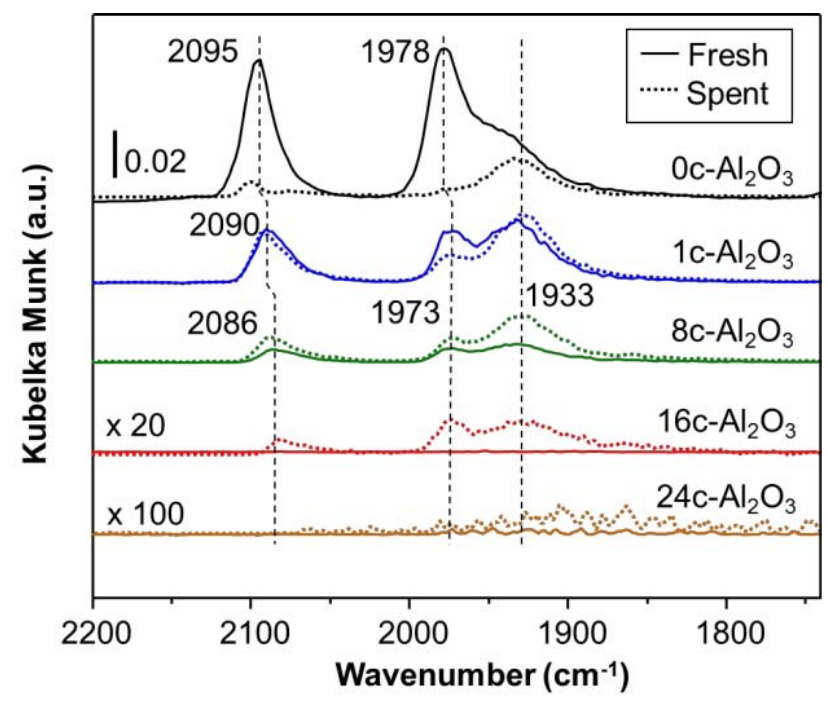

Fig. 49. DRIFTS spectra of CO chemisorption at saturation coverage on fresh and used Pd catalysts with different numbers of $\mathrm{ALD} \mathrm{Al}_{2} \mathrm{O}_{3}$ over-coating cycles (0c, 1c, 8c, 16c, and 24c$\mathrm{Al}_{2} \mathrm{O}_{3}$ ). Spectra for fresh and used $16 \mathrm{c}$ and $20 \mathrm{c}-\mathrm{Al}_{2} \mathrm{O}_{3}$ samples were enlarged by x20. Spectra for fresh and used $24 \mathrm{c}-\mathrm{Al}_{2} \mathrm{O}_{3}$ samples were enlarged by 100 . Reprinted with permission from [8]. Copyright (C) 2011, Springer Science+Business Media, LLC.

Using CO as a probe molecule, DRIFTS measurements clearly revealed that the embedded Pd nanoparticles within the ALD alumina overcoats remained accessible [8]. More interestingly, we found that the first $\mathrm{ALD} \mathrm{Al}_{2} \mathrm{O}_{3}$ cycle preferentially nucleates at Pd edge and corner sites, revealed by a more pronounced decrease in the CO peaks at 2095 and $1978 \mathrm{~cm}^{-1}$, compared with the peak at $1933 \mathrm{~cm}^{-1}$, which are assigned to linear CO on the Pd corner atoms, $\mu_{2}$ bridge-bonded CO on the step and edge sites of Pd NPs, and $\mu_{2}$ bridge-bonded CO on $\mathrm{Pd}(111)$ facets, respectively (Fig. 49) [8, 315, 316]. Preferential nucleation of $\mathrm{ALD} \mathrm{Al}_{2} \mathrm{O}_{3}$ at the low-coordination Pd sites agrees very well with our STM measurements and DFT calculations [304, 312]. With increasing $\mathrm{ALD} \mathrm{Al}_{2} \mathrm{O}_{3}$ overcoat cycles, the Pd gradually becomes encapsulated such that no chemisorbed CO is observed by DRIFTS for the 24c$\mathrm{Al}_{2} \mathrm{O}_{3}$ overcoated Pd sample. 


\subsubsection{Catalytic performance of $\mathrm{Pd} / \mathrm{Al}_{2} \mathrm{O}_{3}$ catalysts tailored by $\mathrm{ALD}$ alumina overcoats}

On the $\mathrm{Pd} / \mathrm{Al}_{2} \mathrm{O}_{3}$ catalysts with $\mathrm{ALD}$ alumina overcoats, the catalytic performance including selectivity, activity and stability might be significantly altered by either selective blocking of the low-coordination sites of Pd nanoparticles or the confinement effect induced by the micropores within the overlayer. A study of methanol decomposition on a $\mathrm{Pd} / \mathrm{Al}_{2} \mathrm{O}_{3}$ catalyst with and without alumina overcoats demonstrates the effect on both catalytic activity and stability [8]. Surprisingly, a single $\mathrm{ALD} \mathrm{Al}_{2} \mathrm{O}_{3}$ cycle $(\sim 0.1 \mathrm{~nm})$ was sufficient to suppress sintering of Pd nanoparticles during methanol decomposition at $270{ }^{\circ} \mathrm{C}$ for 6 hours, while considerabe sintering occurred on the uncoated sample. The catalytic activity was nearly identical for the Pd samples with 1 to 16 cycles of alumina overcoats, which were all slightly higher than the uncoated Pd sample. Beyond 16 ALD cycles, the catalytic activity decreased (Fig. 50). The slightly enhanced activity for the Pd samples with 1 to 16 cycles of alumina overcoats is attributed to the selective blockage of the low-coordination sites of $\mathrm{Pd}$ nanoparticles, since the low-coordination Pd sites contribute little to the dehydrogenation reaction pathway for methanol decomposition [317]. On the contrary, the uncoated $\mathrm{Pd}$ nanoparticles lost a large number of active sites due to sintering, resulting in lower activity. This study demonstrates a good example showing the importance of precise control over the oxide overcoat thickness.

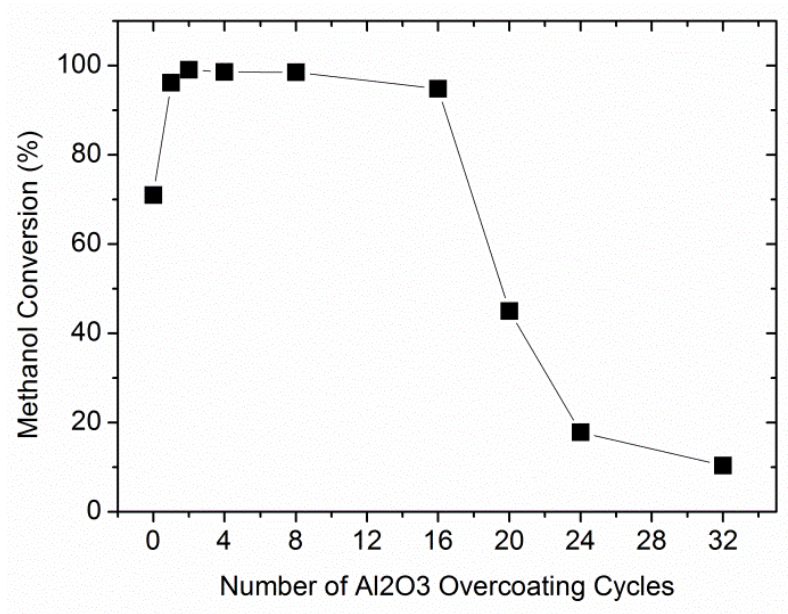

Fig. 50. Methanol conversion for Pd catalysts with 0 to 32 cycles of $A L D ~ \mathrm{Al}_{2} \mathrm{O}_{3}$ over-coating in the methanol decomposition reaction carried out at $270{ }^{\circ} \mathrm{C}$. Reprinted with permission from [8]. Copyright (C) 2011, Springer Science+Business Media, LLC.

In oxidative dehydrogenation of ethane (ODHE) at $675^{\circ} \mathrm{C}$, an $8 \mathrm{~nm}$ thick ALD alumina overcoat (45 ALD cycles) is necessary in order to achieve long term stability of $\mathrm{Pd}$ 
nanoparticles against sintering [12]. In this reaction, the initial ethane conversion on the uncoated $\mathrm{Pd} / \mathrm{Al}_{2} \mathrm{O}_{3}$ catalyst was $55 \%$ with $\mathrm{CO}$ and $\mathrm{CO}_{2}$ as the major products, while the yield of the desired ethylene product was only 1.9\% (Fig. 51). This Pd catalyst completely deactivated in less than 30 minutes due to heavy coke formation and severe sintering, in line with the literature [318]. In contrast, $\mathrm{Pd}$ nanoparticles with $\sim 8 \mathrm{~nm} \mathrm{ALD} \mathrm{Al}_{2} \mathrm{O}_{3}$ overcoat exhibited excellent thermal stability against sintering and resistance to coke formation over two days of reaction testing at $675{ }^{\circ} \mathrm{C}$, and produced an ethylene yield of 23\%. Meanwhile, the yields of undesired products, $\mathrm{CO}, \mathrm{CO}_{2}$ and $\mathrm{CH}_{4}$, were remarkably suppressed and stable at $5.1 \%, 3.9 \%$, and $0.9 \%$, respectively. In this study, we discovered that the edge and corner Pd atoms played a central role for sintering, coking and undesired reactions from C-C bond breaking [319]. As a consequence, exceptional resistance to sintering and coking in high temperature catalytic reactions, along with significantly enhanced selectivity, were simultaneously achieved because the edge and corner atoms were selectively blocked and stabilized by the $\mathrm{ALD} \mathrm{Al}_{2} \mathrm{O}_{3}$ overcoats.

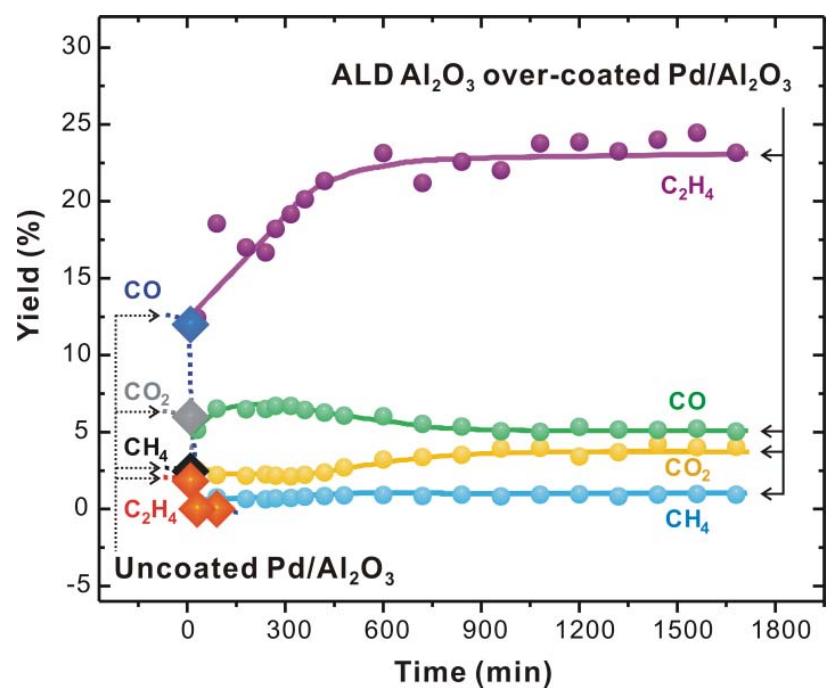

Fig. 51. Products yield on the $\mathrm{Pd} / \mathrm{Al}_{2} \mathrm{O}_{3}$ samples with and without $\mathrm{ALD} \mathrm{Al}_{2} \mathrm{O}_{3}$ over-coat during the ODHE reaction as a function of reaction time at $675{ }^{\circ} \mathrm{C}$ under the identical reaction conditions. Diamonds with dash line: product yields on the uncoated $\mathrm{Pd} / \mathrm{Al}_{2} \mathrm{O}_{3}$ sample; circles with solid line: product yields on the $45 \mathrm{Al} / \mathrm{Pd} / \mathrm{Al}_{2} \mathrm{O}_{3}$ sample. Reprinted with permission from [12]. Copyright (C) 2012, The American Association for the Advancement of Science.

Marshall and co-workers investigated ALD alumina overcoated Pd catalysts in the selective hydrogenation of furfural, a biomass platform molecule. Along with a decrease in the activity with the number of ALD cycles, they found that the selectivity to furan increased 
with increasing the ratio of terrace to edge sites. DFT calculations revealed that the furfural hydrogenation to furfuryl alcohol on step sites is more thermodynamically favorable than on terrace sites, whereas the furfural hydrogenation to furan on step sites is less favorable than on terrace sites [320].

Besides the selective blocking of low-coordinated Pd sites, the confinement effect induced by the micropores within the overlayer can be also utilized to tailor the catalytic performance of Pd catalysts. In selective hydrogenation of 1,3-butadiene, we recently demonstrated that at high conversions, the selectivity to all butenes increased remarkably with ALD alumina overcoat thickness [77]. On a $\mathrm{Pd} / \mathrm{Al}_{2} \mathrm{O}_{3}$ catalyst with 30 cycles of ALD alumina overcoat (30Al/Pd/ $/ \mathrm{Al}_{2} \mathrm{O}_{3}$ ), the selectivity to all butenes was $99 \%$ at a conversion of $95 \%$, comparable to Au catalyst [321, 322]. On the contrary, it was only $46 \%$ at the same conversion on the uncoated $\mathrm{Pd} / \mathrm{Al}_{2} \mathrm{O}_{3}$ catalyst (Fig. 52a). Compared to trans-2-butene and cis-2-butene, the improvement of 1-butene selectivity with increasing overcoat thickness was most pronounced at a conversion of 95\% (Fig. 52b). It should be noted that high temperature pretreatment of ALD alumina coated Pd samples caused a large decrease in butenes selectivity due to the formation of larger pores (greater than $2 \mathrm{~nm}$ in diameter as shown in Fig. 48). Therefore, the remarkable increase in butenes selectivity is attributed to the confinement effect within the $\sim 1$ $\mathrm{nm}$ micropores in the overcoat according to the $\mathrm{N}_{2}$ physisorption measurements (Fig. 48). The Pd surfaces exposed by the micropores would consist of small Pd ensembles on which the adsorbed 1,3-butadine might favor selective hydrogenation due to steric effect. Meanwhile, the isomerization of 1-butene to trans-2-butene and cis-2-butene was retarded by the confinement effect [323]. In addition, long term durability against progressive deactivation was achieved on the $\mathrm{Al}_{2} \mathrm{O}_{3}$ coated Pd catalysts during $124 \mathrm{~h}$ on stream without any visible activity decline or selectivity changes.
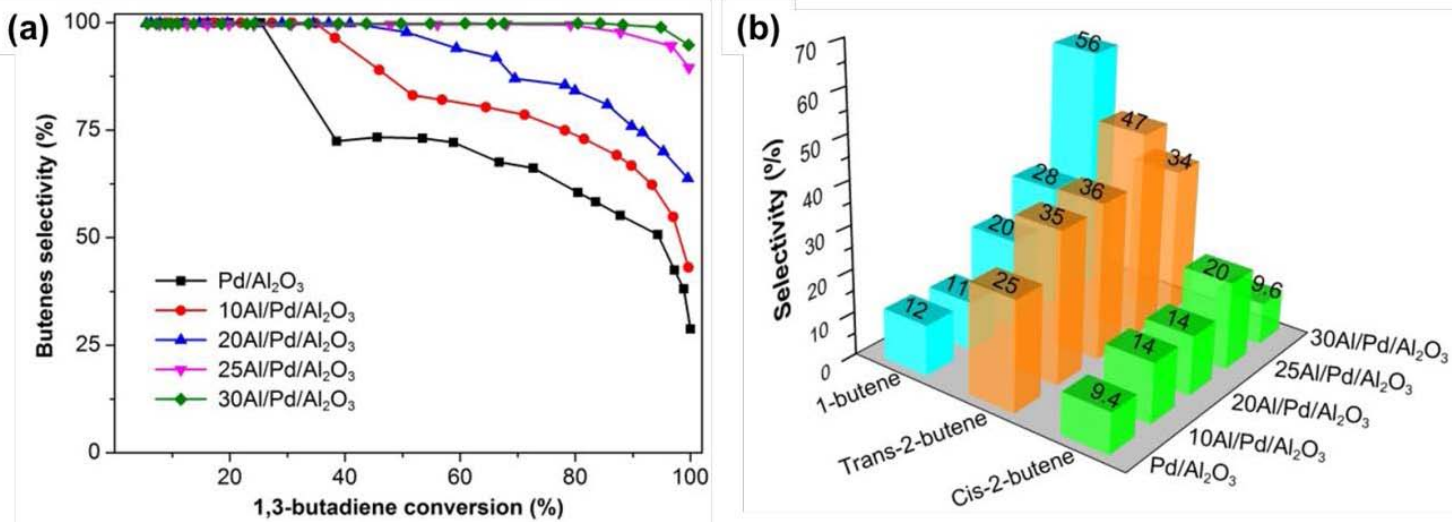

Fig. 52. Catalytic performance of $\mathrm{Pd} / \mathrm{Al}_{2} \mathrm{O}_{3}$ samples with and without ALD alumina overcoats in selective hydrogenation of 1,3-butadiene. (a) The selectivity to all butenes as a 
function of 1,3-butadiene conversion. (b) The detailed selectivities to 1-butene, trans-2butene and cis-2-butene at a conversion of 95\%. The feed gas was 1.9\% 1,3-butadiene and 4.7\% $\mathrm{H}_{2}$ with $\mathrm{Ar}$ as the balance gas at a total flow rate of $25 \mathrm{ml} / \mathrm{min}$. Reprinted with permission from [77]. Copyright (C) 2015, American Chemical Society.

\section{$5.2 \mathrm{Al}_{2} \mathrm{O}_{3} \mathrm{ALD}$ on $\mathrm{Pt}$}

Similar to $\mathrm{Al}_{2} \mathrm{O}_{3}$ ALD on Pd discussed above (Fig. 45), in situ QCM and QMS measurements for $\mathrm{Al}_{2} \mathrm{O}_{3}$ ALD on Pt also showed a significantly higher $\Delta \mathrm{m}_{0} / \Delta \mathrm{m}_{1}$ mass ratio and the production of $\mathrm{C}_{2} \mathrm{H}_{6}$ and $\mathrm{H}_{2}$ during the first ALD alumina cycle [312]. DFT calculations revealed that TMA undergoes dissociative chemisorption to form $\mathrm{Al}\left(\mathrm{CH}_{3}\right)^{*}$ on and Pt, and then transform into $\mathrm{Al}(\mathrm{OH})_{3}$ * during the subsequent water exposure (Fig. 53), analogous to $\mathrm{Al}_{2} \mathrm{O}_{3} \mathrm{ALD}$ on $\mathrm{Pd}$. On $\mathrm{Pt}(211), \mathrm{Al}\left(\mathrm{CH}_{3}\right)^{*}$ could also dissociate to form $\mathrm{Al}^{*}$ and $\mathrm{CH}_{3}$ * (Fig. 53a). In general, TMA decomposition is more exothermic on Pt than on Pd. However, we discovered that the difference in free energy change for alumina ALD on the (111) and (211) facets of Pd (0.81 eV for TMA and $0.39 \mathrm{eV}$ for water) are much greater than the corresponding free energy changes on Pt (0.35 and $0.22 \mathrm{eV})$. These differences explain the preferential decoration of step edges on Pd but not on Pt observed by STM after high temperature treatment. Moreover, $\mathrm{On} \mathrm{Pd}, \mathrm{C}_{2} \mathrm{H}_{6}$ is likely produced at the low-coordinated sites through direct $\mathrm{CH}_{3}{ }^{*}-\mathrm{CH}_{3}$ * coupling with a barrier of $1.02 \mathrm{eV}$ [304], while on Pt, $\mathrm{C}^{*}$ and $\mathrm{CH}_{3} *$ coupling appears to be a more plausible route, since the decomposition of $\mathrm{CH}_{3} *$ to form $\mathrm{C}^{*}$ is thermodynamically more favorable on Pt compared to $\mathrm{Pd}$, and this facilitates $\mathrm{C}_{2} \mathrm{H}_{6}$ production via C-C bond formation and subsequent hydrogenation [312].

\section{3 $\mathrm{Al}_{2} \mathrm{O}_{3} \mathrm{ALD}$ on $\mathrm{Ir}$}

Similar to our findings on Pd and Pt, DFT calculations showed that TMA dissociation on Ir is highly exothermic. However, the difference in free energy changes for TMA dissociation on the Ir terrace and step sites (2.19 eV) is much higher than the Pd and Pt [312]. On Ir, $\mathrm{CH}_{3}$ * species from TMA dissociation can easily decompose into $\mathrm{CH}^{*}$ and $\mathrm{H}^{*}$, where the energy barriers for $\mathrm{C}-\mathrm{H}$ bond breaking are 0.44 and $0.04 \mathrm{eV}$, respectively in the sequential decomposition steps on $\operatorname{Ir}(111): \mathrm{CH}_{3} *+* \rightarrow \mathrm{CH}_{2} *+\mathrm{H}^{*}$ and $\mathrm{CH}_{2} *+* \rightarrow \mathrm{CH}^{*}+\mathrm{H}^{*}$. The considerably lower energy barrier for $\mathrm{C}-\mathrm{H}$ bond cleavage in the first decomposition step compared to both $\mathrm{Pd}(111)(0.77 \mathrm{eV})$ and $\mathrm{Pt}(111)(0.73 \mathrm{eV})$, results in abundant $\mathrm{H}^{*}$ species on Ir. Thus, $\mathrm{H}_{2}$ production via the recombination of two $\mathrm{H}^{*}$ is more facile on $\mathrm{Ir}$ compared to $\mathrm{Pd}$ and Pt. Indeed, $\mathrm{H}_{2}$ was observed during the first TMA exposure by in situ QMS 
measurements along with the main $\mathrm{CH}_{4}$ product. During the subsequent hydration steps, the hydroxylation of $\mathrm{Al}\left(\mathrm{CH}_{3}\right) *$ to $\mathrm{Al}(\mathrm{OH})_{3}$ * is more thermodynamically favorable on $\operatorname{Ir}(111)$ compared to Pd and Pt. While on $\operatorname{Ir}(211), \mathrm{O}-\mathrm{Al}(\mathrm{OH})_{2}{ }^{*}$ was found to be the most stable intermediate, which is about $0.28 \mathrm{eV}$ lower than the $\mathrm{Al}(\mathrm{OH})_{3} *$ intermediate.

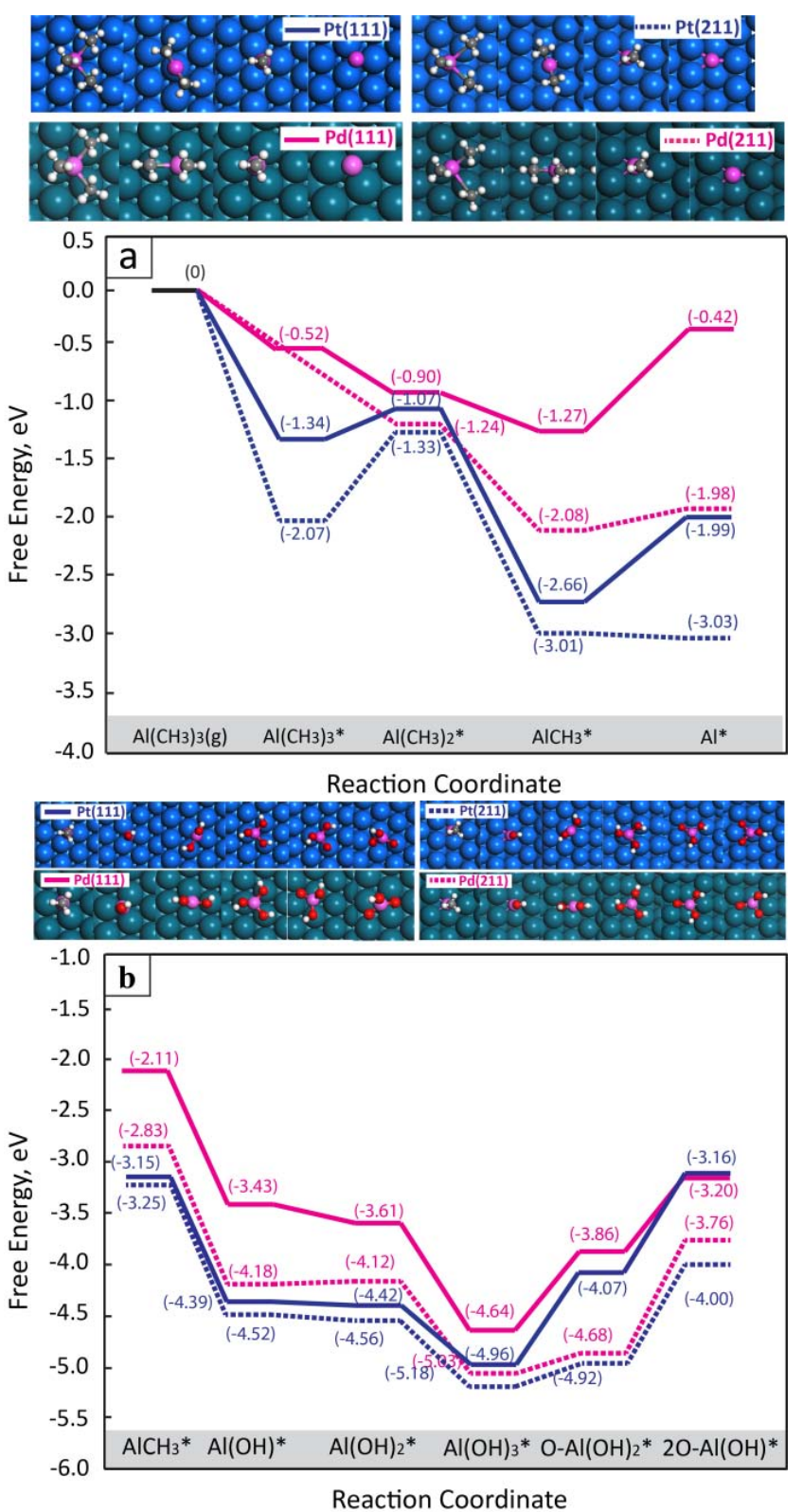

Fig. 53. Free energy diagrams (at $200{ }^{\circ} \mathrm{C}$ and $1 \mathrm{~atm}$ ) for (a) TMA exposure; and (b) water exposure on Pt (111) (solid blue line) and Pt (211) (dashed blue line), Pd(111) (solid magenta line) and Pd (211) (dashed magenta line), respectively. The gas phase TMA, clean surface, and a pre-adsorbed $\mathrm{H}$ atom are used as the reference state (the black bar at $0 \mathrm{eV}$ in panel a). Schematic representations of surface species are also presented. Numerical values in parentheses are the free energies corresponding to each intermediate state. The initial states for water exposure assume the desorption of one molecule of methane, i.e. $\mathrm{CH}_{3} *+\mathrm{H}^{*} \rightarrow$ 
$\mathrm{CH}_{4}$ (g). Reprinted with permission from [312]. Copyright (C) 2014, American Chemical Society.
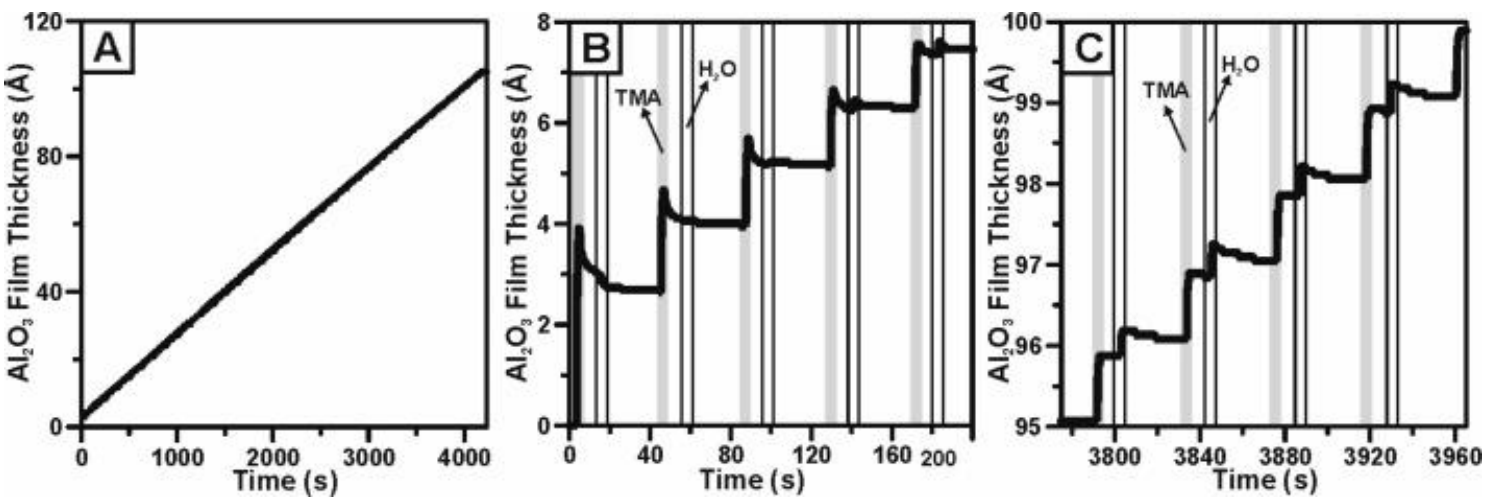

Fig. 54. Plots of growth rate and QCM step ratio vs $\mathrm{Al}_{2} \mathrm{O}_{3} \mathrm{ALD}$ cycles measured with QCM on a $50 \mathrm{~nm}$ Ag film at $50^{\circ} \mathrm{C}$. QCM measurements of $0-100$ cycles (A), first 5 cycles (B) and the final 4 cycles (c). The shaded areas represent the time periods that the TMA and water dosing valves were open. Reprinted with permission from [324]. Copyright (c) 2005, American Chemical Society.

\section{$5.4 \mathrm{Al}_{2} \mathrm{O}_{3} \mathrm{ALD}$ on $\mathrm{Ag}$}

Van Duyne and co-workers investigated the growth of $\mathrm{Al}_{2} \mathrm{O}_{3}$ ALD on Ag using in situ QCM measurement, where a $50 \mathrm{~nm}$ Ag film was deposited directly on the QCM crystal by e-beam [324]. As shown in Fig. 54, QCM measurements demonstrated highly linear $\mathrm{Al}_{2} \mathrm{O}_{3}$ growth on Ag without any initial delay. Moreover, a large thickness change of 3-4 $\AA$ during the first TMA exposure and a slight thickness decrease following the $\mathrm{H}_{2} \mathrm{O}$ doses and purges were observed during the early cycles (Fig. 54B), in contrast with $\mathrm{Al}_{2} \mathrm{O}_{3}$ ALD on Pd (Fig. 45a), Pt, and Ir, which showed a considerable larger mass gain during the first water exposure [312]. The authors suggested that the TMA reacts directly with the Ag, even though a small amount of surface hydroxyls bound to a thin native oxide layer on the Ag might partially contribute to the TMA adsorption. The thickness decreases during the TMA purge periods in the initial $\mathrm{Al}_{2} \mathrm{O}_{3}$ ALD cycles may result from the reaction of surface methyl groups and the subsequent desorption of methane. The decreases in thickness following the water exposures may result from the absence of $\mathrm{OH}$ groups on the metallic Ag surface. The SEM analysis further confirmed the layer-by-layer growth of $\mathrm{ALD} \mathrm{Al}_{2} \mathrm{O}_{3}$ on the triangular Ag nanoparticles (Fig. $55)$.

The authors further demonstrated that the localized surface plasmon resonance (LSPR) nanosensor can detect $\mathrm{Al}_{2} \mathrm{O}_{3}$ film growth with atomic spatial resolution normal to the 
nanoparticle surface, which is approximately 10 times greater spatial resolution than that in long-range distance-dependence study using multilayer self-assembled monolayer shells [324]. Compared to the bare Ag nanoparticles, $1.0 \mathrm{~nm}$ thick $\mathrm{ALD} \mathrm{Al}_{2} \mathrm{O}_{3}$ layer improved the stability of the Ag nanoparticles against femtosecond laser exposures by a factor of 10 [325]. Moreover, after depositing a sub-1-nm alumina layer by ALD, silver film-over-nanosphere (AgFON) substrates demonstrated twice the sensitivity with 6 times shorter data acquisition time and 7 times longer temporal stability in the application of surface-enhanced Raman spectroscopy (SERS) [302].
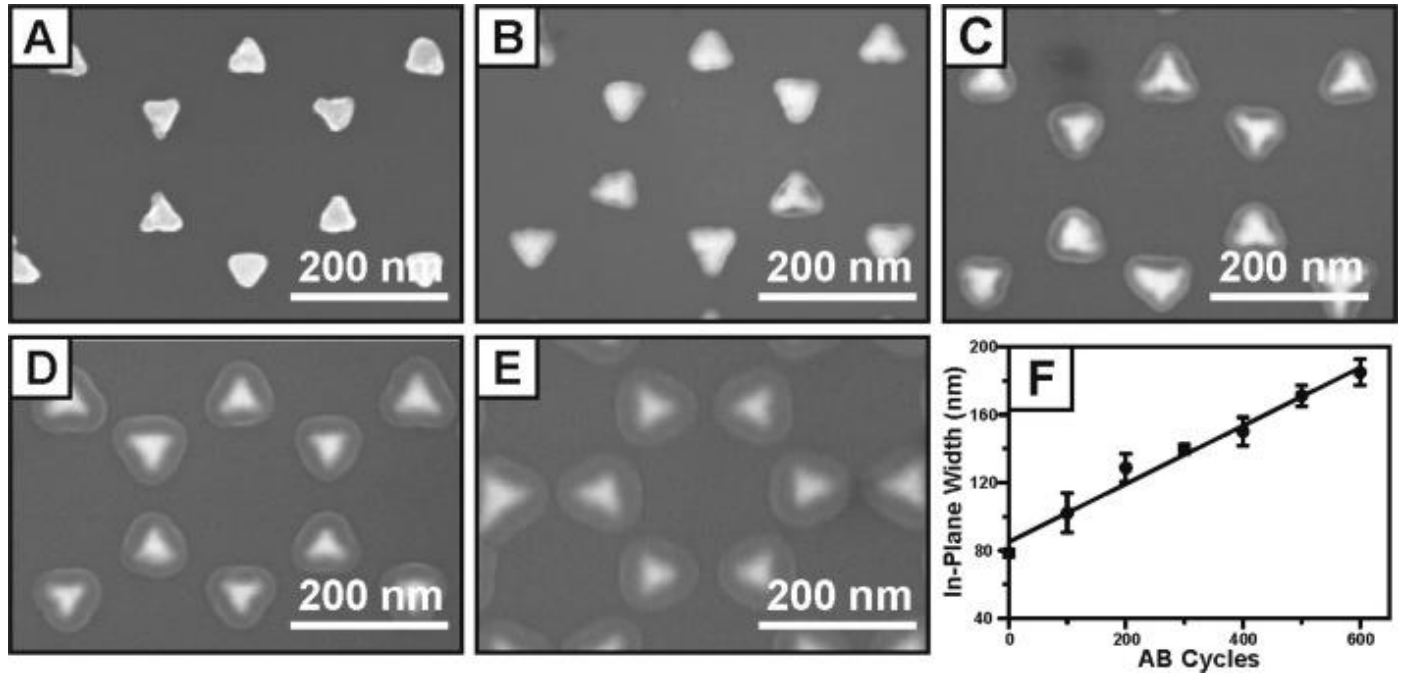

Fig. 55. SEM images of (A) bare Ag nanoparticles ( $a=90 \mathrm{~nm}, b=51 \mathrm{~nm})$ and Ag nanoparticles following (B) 100, (C) 200, (D) 400, and (E) $600 \mathrm{Al}_{2} \mathrm{O}_{3}$ ALD cycles at $50{ }^{\circ} \mathrm{C}$. (F) Plot of in-plane width of Ag nanoparticle with AB cycles determined from the SEM images. Reprinted with permission from [324]. Copyright (c) 2005, American Chemical Society.

\section{$5.5 \mathrm{Al}_{2} \mathrm{O}_{3} \mathrm{ALD}$ on $\mathrm{Au}$}

The detailed growth mechanism of $\mathrm{Al}_{2} \mathrm{O}_{3} \mathrm{ALD}$ on $\mathrm{Au}$ has not yet been reported. However, Qian et al. showed that the $\mathrm{Al}_{2} \mathrm{O}_{3}$ ALD thickness increases linearly with ALD cycles on nanoporous Au surfaces with a rate of $0.15 \mathrm{~nm} /$ cycle based on TEM measurements (Fig. 56) [326-328]. Similarly, Biener and co-workers illustrated linear $\mathrm{Al}_{2} \mathrm{O}_{3} \mathrm{ALD}$ on nanoporous $\mathrm{Au}$ using mass gain measurements [329], where they observed a growth rate of $\sim 0.25 \mathrm{~nm} /$ cycle. They also demonstrated that nanoporous Au coated with sub-nanometer thick alumina films (2 ALD cycles) were stable up to at least $900{ }^{\circ} \mathrm{C}$, while the uncoated Au sintered severely at temperatures below $400{ }^{\circ} \mathrm{C}$. Tian et al. also demonstrated the conformal coating of $\mathrm{Au}$ nanoparticles with $\mathrm{ALD} \mathrm{Al}_{2} \mathrm{O}_{3}$, which are used as shell-isolated nanoparticles for SERS 
applications [330]. In these studies however, the accessibility of the embedded $\mathrm{Au}$ nanoparticles for catalysis was not reported. Our recent work showed that the activity of $\mathrm{Au} / \mathrm{TiO}_{2}$ catalysts in $\mathrm{CO}$ oxidation was almost completely lost after only one ALD $\mathrm{Al}_{2} \mathrm{O}_{3}$ cycle, suggesting that the ultrathin alumina films on Au are dense.

\section{6 $\mathrm{Al}_{2} \mathrm{O}_{3} \mathrm{ALD}$ on $\mathrm{Cu}$}

DFT calculations show that TMA dissociation is endothermic to form $\operatorname{Al}\left(\mathrm{CH}_{3}\right)^{*}$ on $\mathrm{Cu}(111)$ surfaces with a free energy change of $0.72 \mathrm{eV}$, and only slightly exothermic on $\mathrm{Cu}(211)$ [312]. Consequently, $\mathrm{Al}_{2} \mathrm{O}_{3}$ ALD on clean $\mathrm{Cu}$ surface below $200{ }^{\circ} \mathrm{C}$ is thermodynamically more difficult than on Pd and Pt. Indeed, STM revealed no changes in surface features attributable to chemisorbed TMA after subjecting a clean $\mathrm{Cu}(111)$ crystal to a TMA exposure of $\sim 3000 \mathrm{~L}\left(2 \times 10^{-6}\right.$ Torr for $25 \mathrm{~min}$ ) at $200{ }^{\circ} \mathrm{C}$ (Compare Fig. 56a with b). Moreover, exposing the clean $\mathrm{Cu}$ surface to water $\left(1 \times 10^{-6}\right.$ Torr for $\left.\sim 200 \mathrm{~L}\right)$ prior to the 3000 L TMA exposure at $200{ }^{\circ} \mathrm{C}$ did not induce TMA chemisorption (Fig. 56c). This observation is consistent with previous studies in which no observable hydroxyl formation from water dissociation on the chemically inert $\mathrm{Cu}(111)$ surface was reported [331, 332].
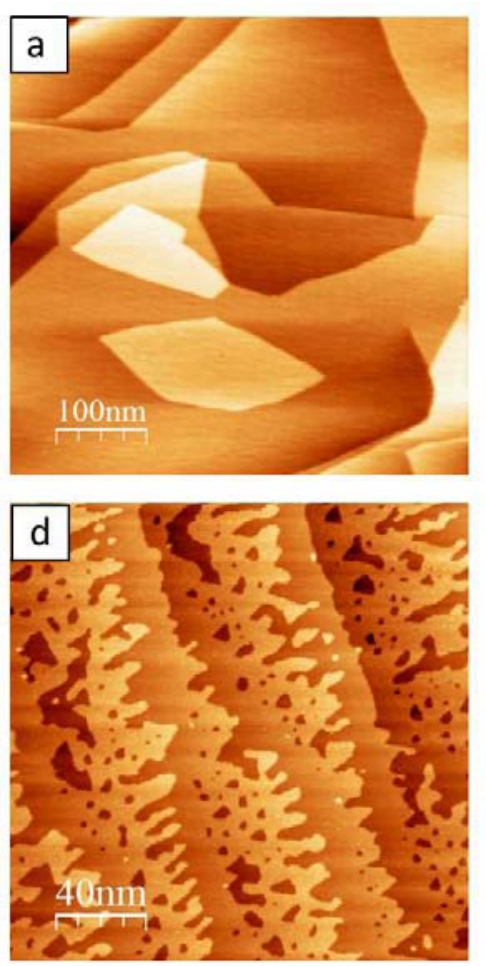
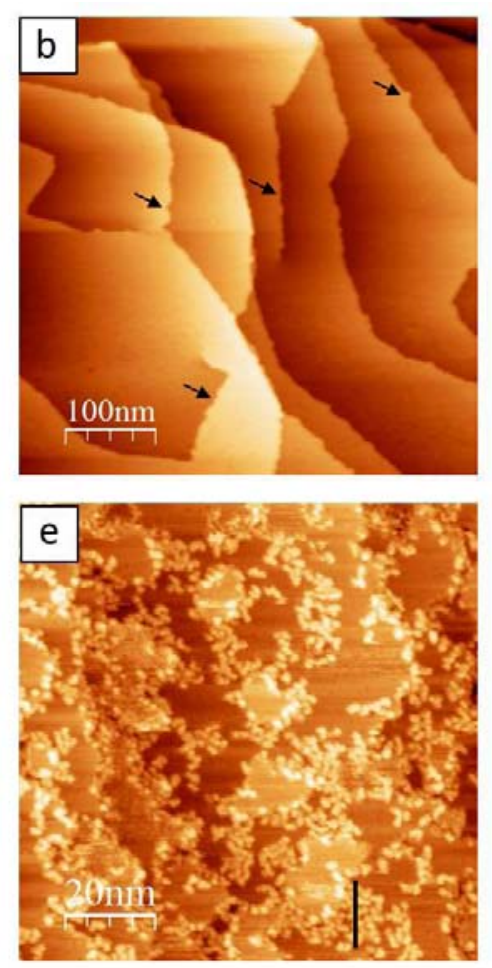
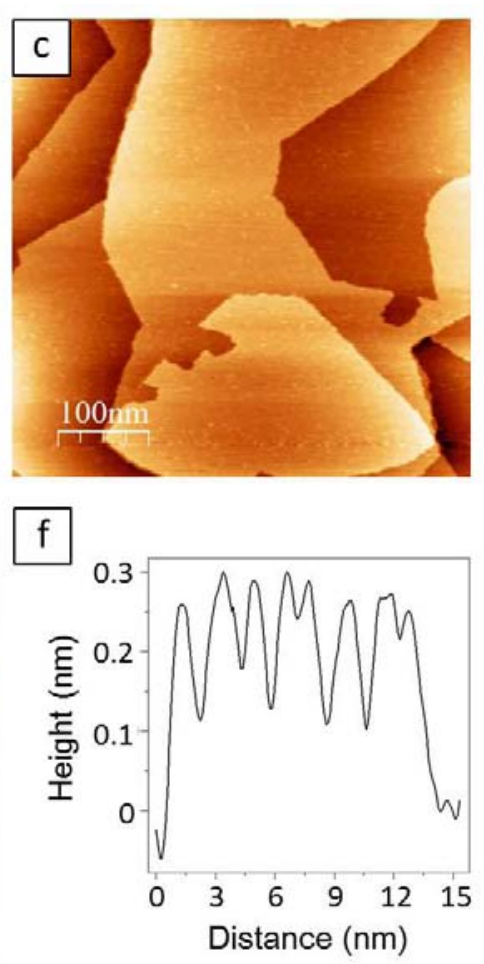

Fig. 56. STM images of (a) clean $\mathrm{Cu}$ (111) surface, V = -0.5 V, I = $1 \mathrm{nA}$; (b) STM image of $\mathrm{Cu}(111)$ surface after exposing TMA for $\sim 3000 \mathrm{~L}$ at $200{ }^{\circ} \mathrm{C}$, the corrugated step edges are highlighted by the black arrows, $\mathrm{V}=-0.5 \mathrm{~V}, \mathrm{I}=1 \mathrm{nA}$; (c) $\mathrm{Cu}(111)$ surface after sequentially 
exposing water and TMA for 200 and $3000 \mathrm{~L}$ at $200{ }^{\circ} \mathrm{C}$, respectively, $\mathrm{V}=-1 \mathrm{~V}, \mathrm{I}=1 \mathrm{nA}$; (d) $\mathrm{Cu}(111)$ surface after exposing oxygen for $\sim 3000 \mathrm{~L}$ at room temperature and water for $200 \mathrm{~L}$ at $200{ }^{\circ} \mathrm{C} ; \mathrm{V}=-2 \mathrm{~V}$, and $\mathrm{I}=0.2 \mathrm{nA}$; (e) $\mathrm{Cu}(111)$ surface after exposing TMA to the preoxidized and hydrated surface for $\sim 3000 \mathrm{~L}$ at $200{ }^{\circ} \mathrm{C} ; \mathrm{V}=-2 \mathrm{~V}$, and I = $0.2 \mathrm{nA}$; (f) height profile along the solid black line in (e), illustrating the height of alumina clusters. Reprinted with permission from [312]. Copyright (C) 2014, American Chemical Society.

In order to facilitate $\mathrm{Al}_{2} \mathrm{O}_{3} \mathrm{ALD}$ on $\mathrm{Cu}$, it was necessary to expose the $\mathrm{Cu}$ to oxygen and then water (Fig. 56d), since it was reported that the chemisorbed oxygen assists the water dissociation to produce submonolayer hydroxyls thereby rendering the surface reactive towards the TMA (Fig. 56e) [333]. STM images revealed two different regions on the $\mathrm{Cu}$ surface after the oxygen and water treatment. Based on literature reports [334, 335], the wellordered regions were assigned to hydroxyl-free $\mathrm{Cu}_{2} \mathrm{O}$, and the less ordered regions mainly near step edges or surface defects were assigned to hydroxylated $\mathrm{Cu}_{2} \mathrm{O}$. After exposing 3000 $\mathrm{L}$ TMA to the oxidized and hydroxylated $\mathrm{Cu}$ surface at $200{ }^{\circ} \mathrm{C}$, STM revealed $\mathrm{Al}\left(\mathrm{CH}_{3}\right)_{\mathrm{x}}{ }^{*}$ (x $=1,2$ ) species preferentially at the step edges with a height of $\sim 0.3 \mathrm{~nm}$ (Fig. 56e,f) and large "clean” patches on the terraces.

Based on XPS measurements, Zemlyanov and co-workers also found that no reaction between TMA and metallic Cu, consistent with our STM results (Fig. 56b). However, they found that TMA readily adsorbs on the $\mathrm{Cu}_{2} \mathrm{O} / \mathrm{Cu}(111)$ surface at $200{ }^{\circ} \mathrm{C}$, resulting in a parial reduction of the surface $\mathrm{Cu}^{1+}$ to metallic copper and the formation of a copper aluminate, most likely $\mathrm{CuAlO}_{2}$ according to the XPS measurements [336]. STM demonstrated formation of two-dimensional (2D) islands of the aluminate after the first TMA half-cycle on $\mathrm{Cu}_{2} \mathrm{O} / \mathrm{Cu}\left(111\right.$ ) (Fig. 57a,b). Following TMA exposure to the $\mathrm{Cu}_{2} \mathrm{O} / \mathrm{Cu}(111)$ surface, $\mathrm{O}_{2}$ was exposed to the resulting surface for $4500 \mathrm{~L}$ at $350{ }^{\circ} \mathrm{C}$ to complete one ALD cycle. STM revealed the formation of islands with an average height of $0.17 \mathrm{~nm}$ (marked by black arrows in Fig. 57c) and a reappearance of the well-ordered $\mathrm{Cu}_{2} \mathrm{O}$ structure in a large portion (Fig. 57d,e). According to their STM results, the alumina island coverage seems very low. DFT calculations further revealed that adsorption and sequential dissociation of TMA on the $\mathrm{Cu}_{2} \mathrm{O} / \mathrm{Cu}(111)$ surface is exothermic, in contrast with TMA reaction on metallic $\mathrm{Cu}$ (Fig. 58). TMA tends to first adsorb at the top position on $\mathrm{O}$ in the $\mathrm{Cu}-\mathrm{O}$ ring via an $\mathrm{Al}$ atom with a binding energy of $-0.93 \mathrm{eV}$. TMA then sequentially dissociates to form $\mathrm{Al}^{*}$ and $\mathrm{CH}_{3}$ * surface species. A simplified stoichiometric equation for TMA reaction with $\mathrm{Cu}_{2} \mathrm{O} / \mathrm{Cu}(111)$ is Equation 22: 


$$
2 \mathrm{Cu}_{2} \mathrm{O}+\mathrm{Al}\left(\mathrm{CH}_{3}\right)_{3} * \rightarrow \mathrm{CuAlO}_{2}+3 \mathrm{Cu}+2 \mathrm{CH}_{4}+\mathrm{CH}^{*}
$$

It is surprising that the morphology of ALD alumina films on $\mathrm{Cu}_{2} \mathrm{O} / \mathrm{Cu}(111)$ using TMA and $\mathrm{O}_{2}$ is largely different from that on hydroxylated $\mathrm{Cu}_{2} \mathrm{O} / \mathrm{Cu}(111)$ surfaces using TMA and water (Fig. 56e). Additional experimental studies, including a more detailed examination of the surface morphology and measurement of the gaseous reaction products, might explain these differences.
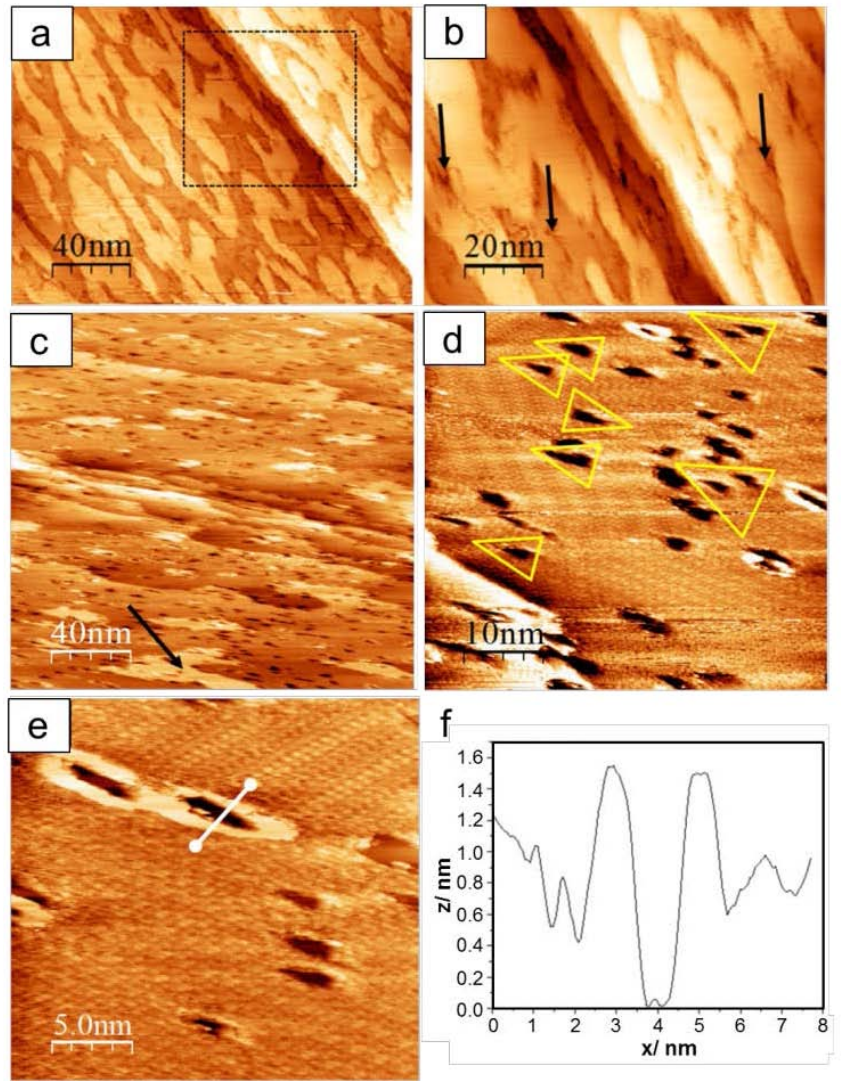

Fig. 57. STM images of the $\mathrm{Cu}_{2} \mathrm{O} / \mathrm{Cu}(111)$ surface exposed to $2000 \mathrm{~L}$ TMA at $200{ }^{\circ} \mathrm{C}$ (a) $200 \mathrm{~nm} \times 200 \mathrm{~nm}$ and (b) $100 \mathrm{~nm} \times 100 \mathrm{~nm}$. STM images after first $\mathrm{O}_{2}$ half-cycle $\left(4500 \mathrm{~L} \mathrm{O}_{2}\right.$ at $350{ }^{\circ} \mathrm{C}$ ) (c) $200 \mathrm{~nm} \times 200 \mathrm{~nm}$, (d) $50 \mathrm{~nm} \times 50 \mathrm{~nm}$, and (e) $25 \mathrm{~nm} \times 25 \mathrm{~nm}$. (f) Line profile along the solid white line indicated in image e. $\mathrm{V}=-0.75 \mathrm{~V}, \mathrm{I}=1.0 \mathrm{nA}$. Reprinted with permission from [336]. Copyright (C) 2015 American Chemical Society.

Dumesic and co-workers deposited $\mathrm{ALD} \mathrm{Al}_{2} \mathrm{O}_{3}$ on $\mathrm{Cu} / \gamma-\mathrm{Al}_{2} \mathrm{O}_{3}$ catalysts to improve their stability against sintering and leaching under liquid-phase conditions [48, 337, 338]. Using Solid state ${ }^{27} \mathrm{Al}$ magic-angle spinning (MAS) NMR spectroscopy, they detected that 6-, 5-, and 4-coordinate aluminum atoms in the as-prepared alumina overcoat. The presence of 5coordinate aluminum is consistent with the amorphous nature of the overcoat before calcination; after calcination at $700{ }^{\circ} \mathrm{C}$, the resonance corresponding to 5-coordinate 
aluminum disappears, and the ratio of 6- to 4-coordinate aluminum suggests crystallization. Densification upon crystallization might generate pores in the $\mathrm{Al}_{2} \mathrm{O}_{3}$ overcoat that modify the catalytic behavior of the Cu. STM measurements on the surface of a pre-oxidized and hydrated (i.e., exposed to air and then water) $\mathrm{Cu}(111)$ surface after four cycles of alumina (Fig. 59a) revealed that alumina preferentially decorates the step edges and defects of the $\mathrm{Cu}(111)$ surface [48]. After four cycles, alumina occupied $59 \pm 3 \%$ of the terrace sites and 91 $\pm 1 \%$ of the edge and defect sites. When this surface was heated to $500{ }^{\circ} \mathrm{C}$ under ultra-high vacuum, the coverage of $\mathrm{Cu}(111)$ terraces decreased relative to that of the edges (30 $\pm 4 \%$ of terraces vs. $80 \pm 3 \%$ of edges and defects; Fig. 59b). These results implied that alumina preferentially binds to under-coordinated copper surface atoms (e.g., steps), leaving most terraces open after annealing. The preferential decoration of under-coordinated $\mathrm{Cu}$ sites was further confirmed by DRIFTS CO chemisorption, where the broad band at lower wavenumber nearly disappeared on the ALD alumina overcoated $\mathrm{Cu} / \gamma-\mathrm{Al}_{2} \mathrm{O}_{3}$ catalysts (45ALD/Cu/ $\gamma-\mathrm{Al}_{2} \mathrm{O}_{3}-973$, Fig. 59e). In hydrogenation of furfural, a fully regenerable copper catalyst with excellent resistance to sintering and leaching was produced with only five ALD $\mathrm{Al}_{2} \mathrm{O}_{3}$ cycles [337].

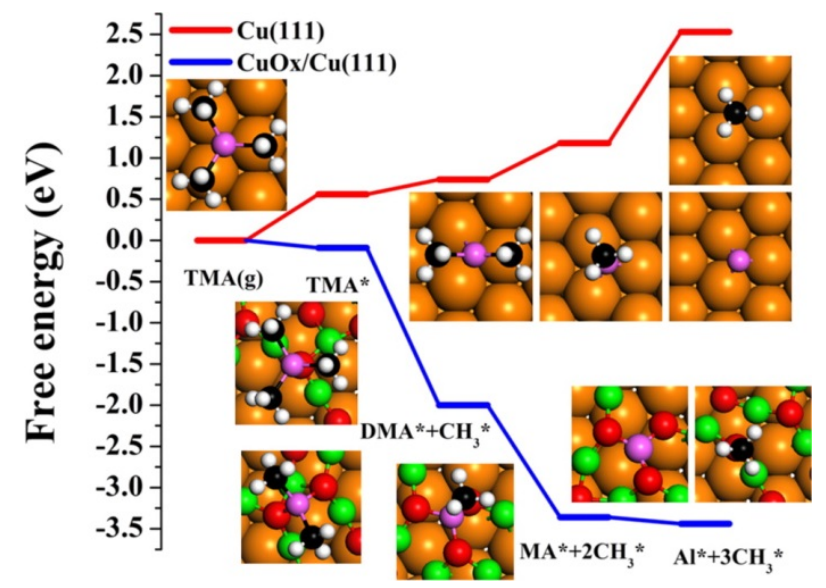

Fig. 58. Free energy diagrams of TMA dissociation on $\mathrm{Cu}(111)$ and $\mathrm{Cu}_{2} \mathrm{O} / \mathrm{Cu}(111)$. The insets are the optimized most stable structures of adsorbed TMA, dimethylaluminum (DMA), methylaluminum (MA), $\mathrm{Al}$, and $\mathrm{CH}_{3}$, respectively. The orange, green, pink, black, red, and white spheres represent $\mathrm{Cu}$ of $\mathrm{Cu}(111), \mathrm{Cu}$ of $\mathrm{Cu}_{2} \mathrm{O}, \mathrm{Al}, \mathrm{C}, \mathrm{O}$, and $\mathrm{H}$ atoms, respectively. Reprinted with permission from [336]. Copyright (C) 2015 American Chemical Society. 

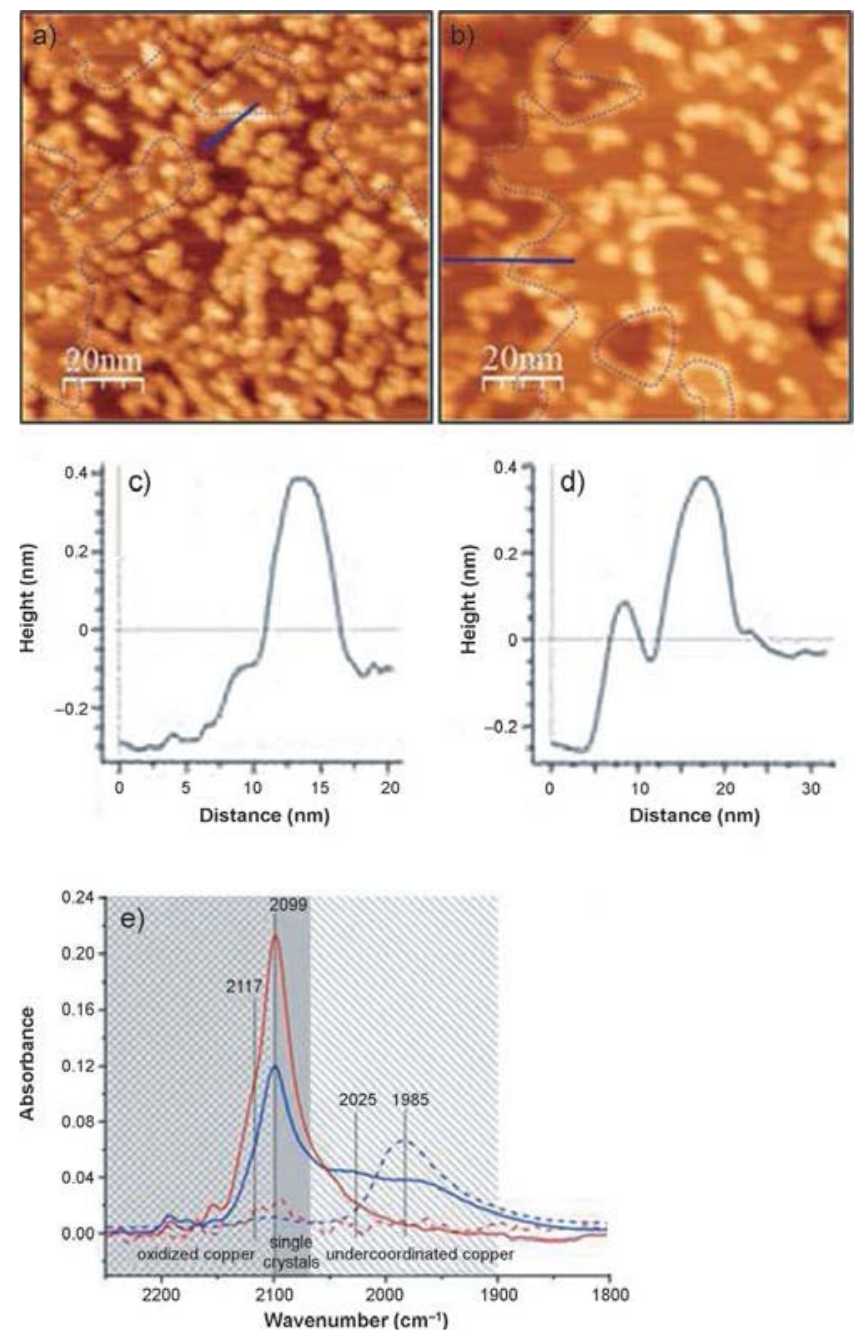

Fig. 59. a) STM image of an oxidized and hydrated $\mathrm{Cu}(111)$ surface after four cycles of exposure to TMA and water. b) STM image after annealing at $500{ }^{\circ} \mathrm{C}$ in vacuum. The dashed lines highlight the step edges. c, d) Height profiles along the solid blue lines (for a and b, respectively) indicate the position of a step edge. e) IR bands for $\mathrm{CO}$ adsorbed on $\mathrm{Cu} / \gamma-\mathrm{Al}_{2} \mathrm{O}_{3}$ (blue solid line) and $45 \mathrm{ALD} / \mathrm{Cu} / \gamma-\mathrm{Al}_{2} \mathrm{O}_{3}-973$ (red solid line) at -150 and $10{ }^{\circ} \mathrm{C}$ (dashed lines). The intensities are normalized by the pellet density and copper loading. Shaded regions indicate typical wavenumbers for $\mathrm{CO}$ adsorbed at different types of copper surface sites. Reprinted with permission from [48]. Copyright (C 2013 WILEY - VCH Verlag GmbH \& Co. KGaA, Weinheim.

\section{7 $\mathrm{TiO}_{2}$ ALD on Metals.}

Compared with $\mathrm{Al}_{2} \mathrm{O}_{3}$ ALD, there have been far fewer studies of $\mathrm{TiO}_{2}$ ALD on metal surfaces. In one study, Martinson et al. reported "island growth" of $\mathrm{TiO}_{2}$ ALD on Au using tetrakis(dimethylamido)titanium and water at $150{ }^{\circ} \mathrm{C}$, where a lower growth rate was observed by in situ QCM measurements during the first 30 cycles [339]. They commented 
that surface oxygen contamination of the nominally bare Au might have nucleated the $\mathrm{TiO}_{2}$ ALD. Recently, we also observed that $\mathrm{TiO}_{2}$ islands (highlighted by the black arrows) rather than uniform films formed on the corner and defect sites of Au nanocrystals after $20 \mathrm{TiO}_{2}$ ALD cycles using titanium tetraisopropoxide (TTIP) and $\mathrm{H}_{2} \mathrm{O}$ at $150{ }^{\circ} \mathrm{C}$ based on high resolution TEM (Fig. 60) [340]. Preferential nucleation of $\mathrm{TiO}_{2}$ on the low-coordinated $\mathrm{Au}$ sites was further confirmed by atomic force microscopy (AFM) and CO chemisorption DRIFTS measurements. Therein, the intensity of the CO peak at $2101 \mathrm{~cm}^{-1}$, assigned to linear $\mathrm{CO}$ on low-coordination neutral Au sites [341-344], decreased dramatically with $\mathrm{TiO}_{2}$ ALD cycles. This is not surprising since low-coordinated Au sites are expected to be more active than terrace sites for reaction with TTIP. The average growth rate of $\mathrm{TiO}_{2}$ overcoat on $\mathrm{Au}$ was estimated to be $\sim 0.3 \AA$ /cycle based on TEM measurements. In contrast, Biener and coworkers reported that 10 cycles of $\mathrm{TiO}_{2} \mathrm{ALD}$ using $\mathrm{TiCl}_{4}$ and water at $110{ }^{\circ} \mathrm{C}$ forms continuous and smooth $\mathrm{TiO}_{2}$ coatings, which completely encapsulate the nanoporous $\mathrm{Au}$, since the catalytic activity in $\mathrm{CO}$ oxidation disappears [329]. After annealing at $600{ }^{\circ} \mathrm{C}$, the continuous $\mathrm{TiO}_{2}$ film breaks into highly dispersed anatase $\mathrm{TiO}_{2}$ nanoparticles on nanoporous $\mathrm{Au}$, and exhibits an almost 3 times larger activity for CO oxidation compared to the uncoated Au. The different growth modes of $\mathrm{TiO}_{2} \mathrm{ALD}$ on $\mathrm{Au}$ might derive from variations in the nucleation for the different titanium precursors.

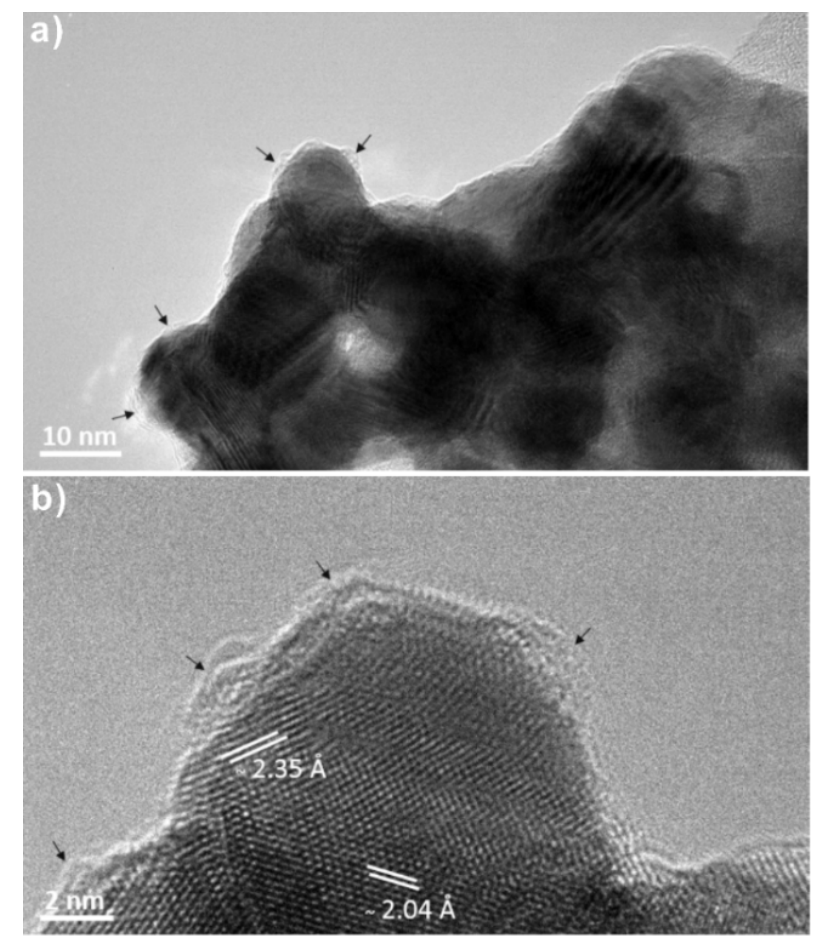

Fig. 60. HRTEM images of unsupported Au nanocrystals with 20 cycles of $\mathrm{TiO}_{2}$ overcoat at low (a) and high (b) magnifications. Here $\mathrm{TiO}_{2}$ islands formed on the Au nanocrystals are 
highlighted by the black arrows. Reprinted with permission from [340]. Copyright (C) 2016, American Chemical Society.

"Island growth" was also observed for $\mathrm{TiO}_{2}$ ALD on Ni using TTIP and $\mathrm{H}_{2} \mathrm{O}$ at $180{ }^{\circ} \mathrm{C}$ [345]. The $\mathrm{TiO}_{2}$ island density increased with increasing $\mathrm{ALDTiO}_{2}$ cycles (Fig. 61b,c) and coalesced to form a smooth film after 180 cycles. It was noted that the Ni surface was mostly oxidized to $\mathrm{Ni}_{2} \mathrm{O}_{3}$ in their work. After $10 \mathrm{TiO}_{2}$ ALD cycles, the $\mathrm{Ni}_{2} \mathrm{O}_{3}$ was partly reduced to $\mathrm{NiO}$, suggesting that the $180^{\circ} \mathrm{C}$ deposition temperature was sufficient to reduce the surface.

When $\mathrm{ALD} \mathrm{TiO}_{2}$ is used to overcoat supported metal catalysts, an enhancement in catalytic activity and improved stability are frequently seen. For instance, $\mathrm{TiO}_{2}$ coated $\mathrm{Au} / \mathrm{Al}_{2} \mathrm{O}_{3}$ catalysts showed a remarkable catalytic enhancement for CO oxidation [340]. Furthermore, the activity as a function of $\mathrm{TiO}_{2}$ ALD cycles showed a "volcano-like" behavior, providing direct evidence that the catalytic activities of $\mathrm{TiO}_{2}$ overcoated Au catalysts strongly correlate with the total length of perimeter sites at the $\mathrm{Au}-\mathrm{TiO}_{2}$ interface. Kim et al. also reported that $\mathrm{TiO}_{2}$ ALD not only improves the catalytic activity of $\mathrm{Ni}$ catalysts in the $\mathrm{CO}_{2}$ reforming of methane, but also effectively suppresses graphitic carbon deposition on the Ni surface [345, 346]. The high activity of the $\mathrm{TiO}_{2}$ coated $\mathrm{Ni}$ catalyst was maintained over $65 \mathrm{~h}$ at $800{ }^{\circ} \mathrm{C}$, whereas deactivation of the bare Ni surface began within $1 \mathrm{~h}$ under the same conditions (Fig. 62) [346]. Recently, Huber et al. demonstrated that a Co/C catalyst with a thin-layer overcoating of $\mathrm{ALD} \mathrm{TiO}_{2}$ exhibited 2.5 times higher turnover frequency (TOF) compared to the uncoated $\mathrm{Co} / \mathrm{C}$ catalyst in the electrochemical oxidation of water. The TOF of the $\mathrm{TiO}_{2}$ overcoated $\mathrm{Co} / \mathrm{C}$ catalyst increased from 5 to 60 with increasing $\mathrm{ALD} \mathrm{TiO}_{2}$ cycles [347]. Moreover, the $\mathrm{ALD} \mathrm{TiO}_{2}$ preserved the activity of the $\mathrm{Co} / \mathrm{C}$ catalyst and inhibited leaching and sintering of cobalt in aqueous-phase hydrogenation reactions. This behavior is in sharp contrast with $\mathrm{ALD} \mathrm{Al}_{2} \mathrm{O}_{3}$ overcoats which produced an irreducibile cobalt aluminate phase without any catalytic activity [348]. A similar trend was also observed for ALD $\mathrm{TiO}_{2}$ and $\mathrm{Al}_{2} \mathrm{O}_{3}$ overcoated copper chromite catalysts in the selective hydrogenation of furfural reaction [349]. 

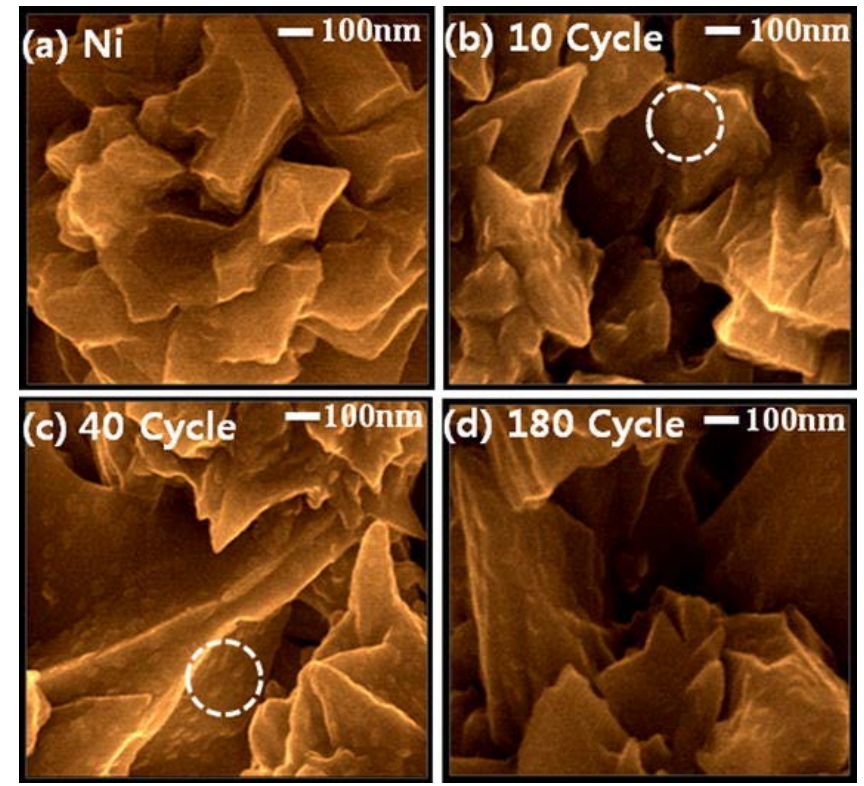

Fig. 61. SEM images of (a) bare and (b-d) $\mathrm{TiO}_{2}$-covered Ni surfaces. The number of ALD cycles used for $\mathrm{TiO}_{2}$ deposition is noted in the images. $\mathrm{TiO}_{2}$ islands are denoted by white circles. Reprinted with permission from [345].
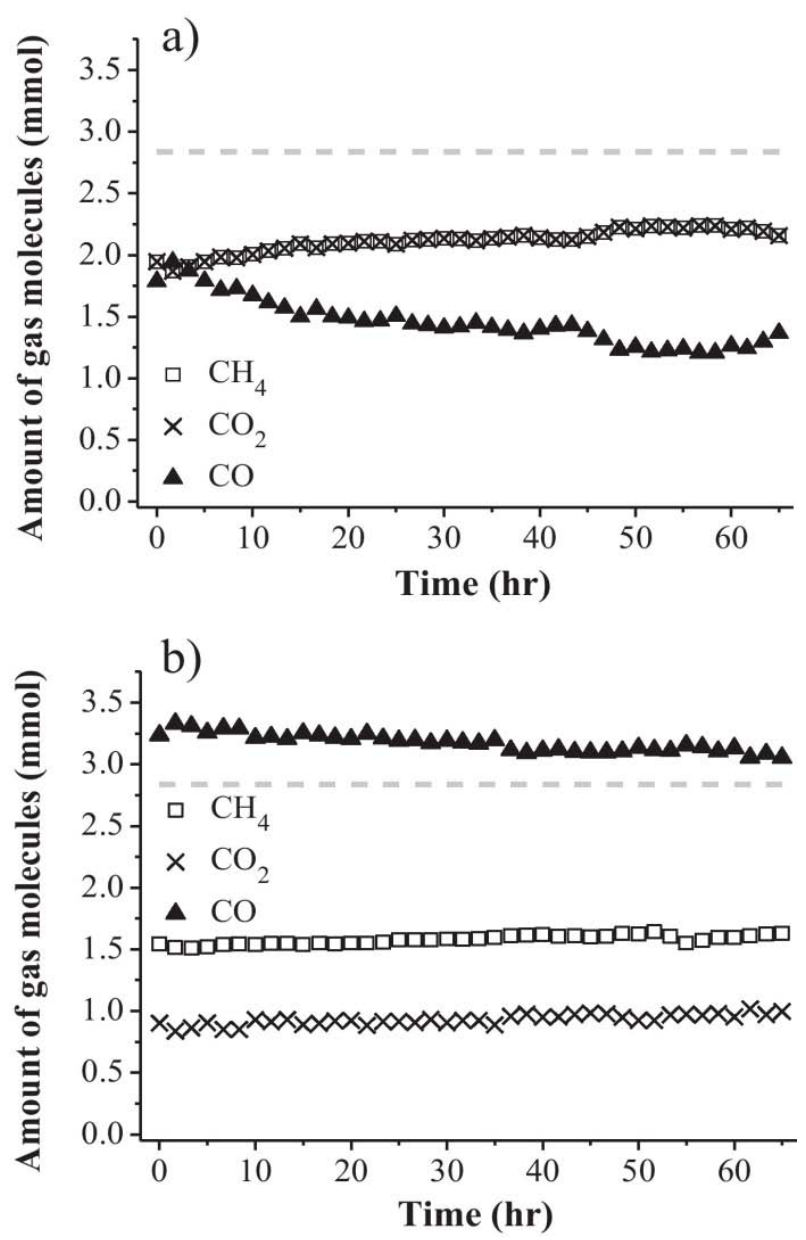

Fig. 62. Catalytic performance over (a) bare $\mathrm{Ni}$ and (b) $\mathrm{TiO}_{2}-\mathrm{Ni}$ catalysts at $800{ }^{\circ} \mathrm{C}$ in $\mathrm{CO}_{2}$ reforming of methane. Accumulated amount of gas flow at the outlet of the rector for every 
25 min was described in number of moles, and change in the amount (mmol) of each gas in the reactor outlet is plotted as a function of reaction time for $65 \mathrm{~h}$ at $800{ }^{\circ} \mathrm{C}$. $\mathrm{CO}_{2}$ and $\mathrm{CH}_{4}$ level (mmol) without sample was shown in a dashed gray line. Reprinted with permission from [346].

\subsection{Summary}

$\mathrm{Al}_{2} \mathrm{O}_{3}$ ALD has been extensively studied on a number of metal surfaces. The dissociative adsorption of TMA was found to be common on noble metal surfaces including Pd, Pt, and Ir, and also likely on $\mathrm{Ag}$ and $\mathrm{Au}$. In contrast, $\mathrm{Al}_{2} \mathrm{O}_{3} \mathrm{ALD}$ does not proceed on $\mathrm{Cu}$, a transition metal, and either hydroxylated $\mathrm{Cu}$ oxide or $\mathrm{Cu}_{2} \mathrm{O}$ is required to promote the TMA reaction. Beyond these examples, there have been relatively few studies of ALD oxide surface chemistry on other metal surfaces.

Precisely applying metal oxide overcoats on supported metal catalysts using ALD has drawn significant attention as a means to tailor their catalytic behavior. The self-limiting surface chemistry of ALD allows conformal deposition over high surface area supports, where the oxide overcoat thickness can be precisely controlled on the atomic level. As a consequence, the mass transfer resistance problem induced by thicker oxide overcoat is minimized. In general, it has been successfully demonstrated that ultrathin oxide ALD overcoats significantly improve the stability of supported metal catalysts under severe reaction conditions. While the activity changes by oxide overcoat depends on the overcoat material, the overcoat thickness, the embedded metal nanoparticles and the reactions. For instance, ultrathin alumina overcoats improves the activity of $\mathrm{Pd} / \mathrm{Al}_{2} \mathrm{O}_{3}$ catalysts in the methanol decomposition reaction [8], but considerably suppresses the activity of similar Pd catalysts in the selective hydrogenation of 1,3-butadiene [323]. On the other hand, $\mathrm{TiO}_{2}$ overcoats have shown potential to enhance the catalytic activity of metal catalysts in several reactions, such as $\mathrm{TiO}_{2}$ overcoated $\mathrm{Au}$ for $\mathrm{CO}$ oxidation [329, 350], $\mathrm{TiO}_{2}$ overcoated $\mathrm{Ni}$ catalyst for $\mathrm{CO}_{2}$ reforming of methane [345, 346], and $\mathrm{TiO}_{2}$ overcoated Co in electrochemical water oxidation [347]. Gorte et al. also illustrated that $\mathrm{ZrO}_{2}$ overcoats on $\mathrm{PdO} / \mathrm{Al}_{2} \mathrm{O}_{3}$ catalysts not only stabilizes $\mathrm{PdO}$ nanoparticles against sintering at high temperatures, but also enhances the methane oxidation activity [351].

It was discovered that micropores can be formed within various ALD oxides overcoat (such as $\mathrm{Al}_{2} \mathrm{O}_{3}[12,48,77,349,352], \mathrm{SiO}_{2}$ [300], $\mathrm{TiO}_{2}$ [329, 349, 350] and $\mathrm{ZrO}_{2}$ [351]) by high temperature treatment $[5,13]$, and these pores provide access to the nanoparticle surface for catalytic function. The pore size is controlled by the overcoat thickness and the 
pretreatment conditions. As a consequence, the catalytic behavior of metal catalysts, especially selectivity, might be tuned through the confinement effect induced by the micropores [77]. In addition, molecular layer deposition (MLD) might provide an alternative method for tuning the porosity within oxide overcoats. In this case, porosity is generated by first depositing an organic-inorganic hybrid film using a combination of MLD and ALD, followed by high temperature calcination to remove the organic portion to leave a highly porous oxide film [301, 353-355].

One particularly interesting case of catalyst selectivity control through ALD overcoating is the selective blocking of low-coordination metal sites while only leaving terrace sites accessible. This could provide a novel strategy for discerning the individual roles played by the low-coordinated and terrace sites of metal nanoparticles in structure-sensitive reactions to gain atomic level understanding of the reaction mechanism. When undesired side reactions take place at the low-coordination metal sites, preferential blocking of these undesirable sites would produce a more selective catalytic material [12, 320]. As a consequence, porous oxide overcoatings by ALD (or MLD) provide a promising way to tailor the catalytic performance of metal catalysts at the atomic level.

\section{Oxide ALD on oxide and carbon materials: synthesizing supported metal oxide catalysts and nanostructuring photocatalytic architectures at the atomic level}

Metal oxides represent another important and widely employed category of solid catalysts, and are used as both active phases and supports. Due to their unique acid-base and redox properties, metal oxides have been widely used in a broad range of reactions including catalytic cracking of hydrocarbons [356], alcohol dehydration [357], alkane partial oxidation [358], oxidative dehydrogenation of alkanes [359], selective reduction of $\mathrm{NO}$ with $\mathrm{NH}_{3}$ [360], biomass conversions [361], etc. Performing one or only a few ALD oxide cycles can produce an exceptionally uniform coverage of well dispersed metal oxide surface species with high catalytic activity. Upon increasing the number of ALD oxide cycles, these species coalesce to form a continuous film. Many of the ALD oxide films are in an amorphous phase (the most notable exception to this is $\mathrm{ALD} \mathrm{TiO}_{2}$ [78]) [25]. Consequently, post-annealing in an oxygen environment is often required to improve the crystallinity of the ALD oxide film as well as the quality of the interface between the ALD oxide layer and the substrate. Nonetheless, achieving epitaxial growth of crystalline film on single crystal substrates is possible. Deposition of photocatalytic oxide layers onto various supports or as passivation overlayers on photoelectrodes with atomic precision using ALD has drawn extensive attention in 
photocatalysis. On the other hand, ultrathin oxide layers on carbon materials illustrated potential in electrocatalysis.

\subsection{ALD of highly dispersed oxide species on oxide surfaces}

\subsubsection{VO $\mathrm{V}_{\mathrm{x}} \mathrm{ALD}$ on alumina}

Supported vanadium oxide (VOx) catalysts are widely used in heterogeneous catalysis $[362,363]$. The activity and selectivity of $\mathrm{VO}_{\mathrm{x}}$ depends strongly on its molecular structure [364, 365], since the electronic and chemical properties of the supported vanadia species change progressively from isolated monomers, to two-dimensional polymers, to threedimensional crystals [366, 367]. Significant effort has been devoted to achieving precise control over the structures of vanadia species with high homogeneity on supports.

Stair and co-workers investigated the nucleation of $\mathrm{ALD} \mathrm{VO}_{\mathrm{x}}$ on anodic aluminum oxide (AAO) by alternating exposures to vanadyl triisopropoxide (VOTP) and $\mathrm{H}_{2} \mathrm{O}_{2}$ at $100{ }^{\circ} \mathrm{C}$ [10]. They found that 1-cycle ALD $\mathrm{VO}_{\mathrm{x}}$ on AAO yielded a vanadium density of $2.8 \mathrm{~V} / \mathrm{nm}^{2}$, much less than the monolayer loading of $8 \mathrm{~V} / \mathrm{nm}^{2}$, indicating that a single ALD cycle does not completely cover the surface, due to the steric effect by the bulky ligands on the VOTP precursor. The edge energy of 1-cycle ALD $\mathrm{VO}_{\mathrm{x}}$ sample was $3.64 \mathrm{eV}$, which corresponds to isolated, tetrahedrally coordinated $\mathrm{VO}_{4}$ species according to the adsorption edge energy values in the reference compounds. They suggested that only $\mathrm{V}-\mathrm{O}-\mathrm{Al}$ bonds are formed in the first VOTP exposure based on the expected reaction between surface hydroxyl groups $(\mathrm{Al}-\mathrm{OH})$ and the isopropoxide ligands. Removal of the remaining isopropoxide ligands during the subsequent hydrogen peroxide exposure produces $\mathrm{V}-\mathrm{OH}$ species, as indicated in Fig. 63. With additional $\mathrm{ALD} \mathrm{VO}_{\mathrm{x}}$ cycles, reactions between $\mathrm{V}-\mathrm{OH}$ groups and VOTP result in the formation of $\mathrm{V}-\mathrm{O}-\mathrm{V}$ bonds, and progressively increase the average $\mathrm{VO}_{\mathrm{x}}$ domain size. As a consequence, the predominant form of the supported $\mathrm{VO}_{\mathrm{x}}$ transforms from monovanadate sites to polyvanadate domains with increasing $\mathrm{VO}_{\mathrm{x}}$ ALD cycles, indicated by the decrease in the edge energy observed in the UV-Vis spectra. In oxidative dehydrogenation $(\mathrm{ODH})$ of cyclohexane, the resulting ALD $\mathrm{VO}_{\mathrm{x}}$ catalysts showed specific activities between 2 and 7.5 times higher than catalysts of similar loading prepared by incipient wetness impregnation (IWI). This reflects the higher dispersion of the $\mathrm{VO}_{\mathrm{x}}$ species afforded by ALD compared to IWI. 


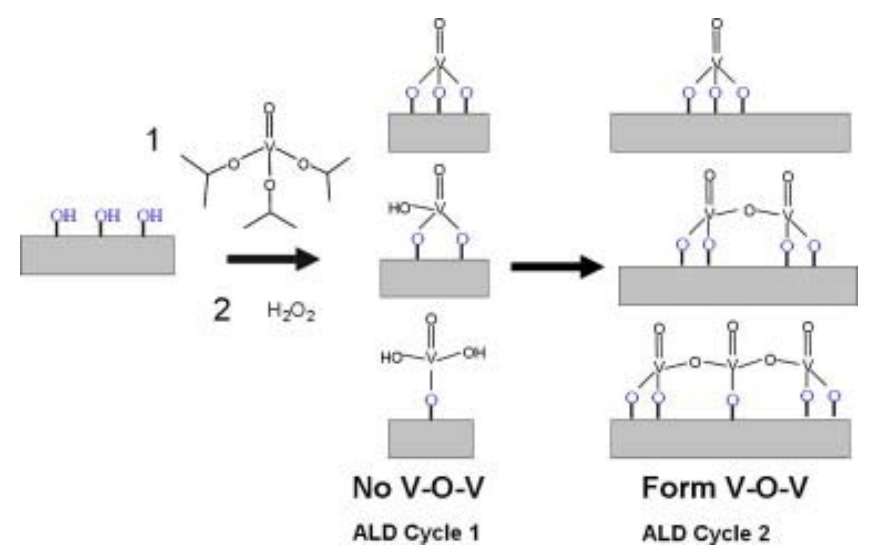

Fig. 63. Schematic illustration of proposed molecular structures of surface vanadyl species formed by $\mathrm{VO}_{\mathrm{x}}$ ALD using VOTP and $\mathrm{H}_{2} \mathrm{O}_{2}$. Reprinted with permission from [10].

\subsection{2 $W O_{x} A L D$ on $S B A-15$}

Peden and co-workers introduced a liquid phase ALD process to graft tungsten oxide species onto mesoporous silica (SBA-15) surfaces [368]. They used organic solvents and anhydrous conditions refluxed with $\mathrm{N}_{2}$ to control the tungsten oxide growth onto the silica surface and to avoid the formation of $\mathrm{WO}_{\mathrm{x}}$ oligomers prevalent in aqueous solutions at nearly neutral $\mathrm{pH}$. The adsorption edge energies for the samples of ALD $\mathrm{WO}_{\mathrm{x}} / \mathrm{SBA}-15$ up to a loading of 30 wt.\% were between 3.0-3.8 eV higher than the reference compound $\left(\left(\mathrm{NH}_{4}\right)_{10} \mathrm{~W}_{12} \mathrm{O}_{41}, 3.0 \mathrm{eV}\right)$, indicating that the ALD $\mathrm{WO}_{\mathrm{x}}$ domains are very small. Under the severe conditions of methanol dehydration reaction, the ALD $\mathrm{WO}_{\mathrm{x}} / \mathrm{SBA}-15$ samples showed enhanced stability against sintering compared to comparable IWI catalyst. The differences in activity observed between the samples prepared by ALD and IWI were attributed mainly to the improved resistance toward sintering of the ALD catalyst resulting from the higher density of Si-O-W moieties. In addition, the temperature-programmed oxidation results revealed that the samples prepared by ALD have a more uniform acid strength compared with the samples prepared by conventional impregnation.

\subsection{3 $\mathrm{SiO}_{2} \mathrm{ALD}$ on $\gamma$-alumina}

Stair and co-workers recently found that $\mathrm{SiO}_{2}$ ALD on $\gamma$-alumina selectively yields monomeric $\mathrm{SiO}_{\mathrm{x}}$ species using the exposures to tetraethylorthosilicate (TEOS) and $\mathrm{H}_{2} \mathrm{O}$ at $50{ }^{\circ} \mathrm{C}$ [369]. The highest loading was about $3.2 \mathrm{Si} / \mathrm{nm}^{2}$, even though multiple $\mathrm{SiO}_{2} \mathrm{ALD}$ cycles were performed (Fig. 64A). $\mathrm{NH}_{3}$ DRIFTS revealed that the TEOS preferentially nucleates at strong Lewis acid sites on the $\gamma$-alumina surface. When these sites are consumed, the film growth stops. The Si $2 p$ binding energy of the calcined $\mathrm{SiO}_{\mathrm{x}} / \mathrm{Al}_{2} \mathrm{O}_{3}$ is found to be 
$102.4 \pm 0.2 \mathrm{eV}$ for all Si loadings (Fig. 64B) and differs from that of bulk $\mathrm{SiO}_{2}(104.1 \mathrm{eV})$. The lower Si binding energy relative to bulk silica was attributed to Si-O-M structures where $\mathrm{M} \neq \mathrm{Si}$. Increased acidity in the silanol proton is attributable to this electronic effect. NMR further revealed that calcination enhances the Si site homogeneity and increases the density of Si-O-Al linkages, evidenced by narrowing and downfield displacement of the ${ }^{29}$ Si signal (Fig. 64C). Moreover the $\delta=-81 \mathrm{ppm}$ position suggests that the major Si surface species after calcination has an $\mathrm{Si}(3 \mathrm{Al}, \mathrm{OH})$ geometry. Interestingly, they found that the ratio of Brønsted acid to Lewis acid sites is linearly correlated with the Si surface density. Finally, they showed that the ALD-derived $\mathrm{SiO}_{\mathrm{x}} / \mathrm{Al}_{2} \mathrm{O}_{3}$ catalysts exhibited higher catalytic activity than $\gamma-\mathrm{Al}_{2} \mathrm{O}_{3}$ sites in cyclohexanol dehydration. In contrast to stronger Brønsted acid sites in a conventional silica-alumina catalyst, no carbon loss is detected, demonstrating the benefit of a catalyst having more uniform/less acidic $\mathrm{SiO}_{\mathrm{x}}$ sites.
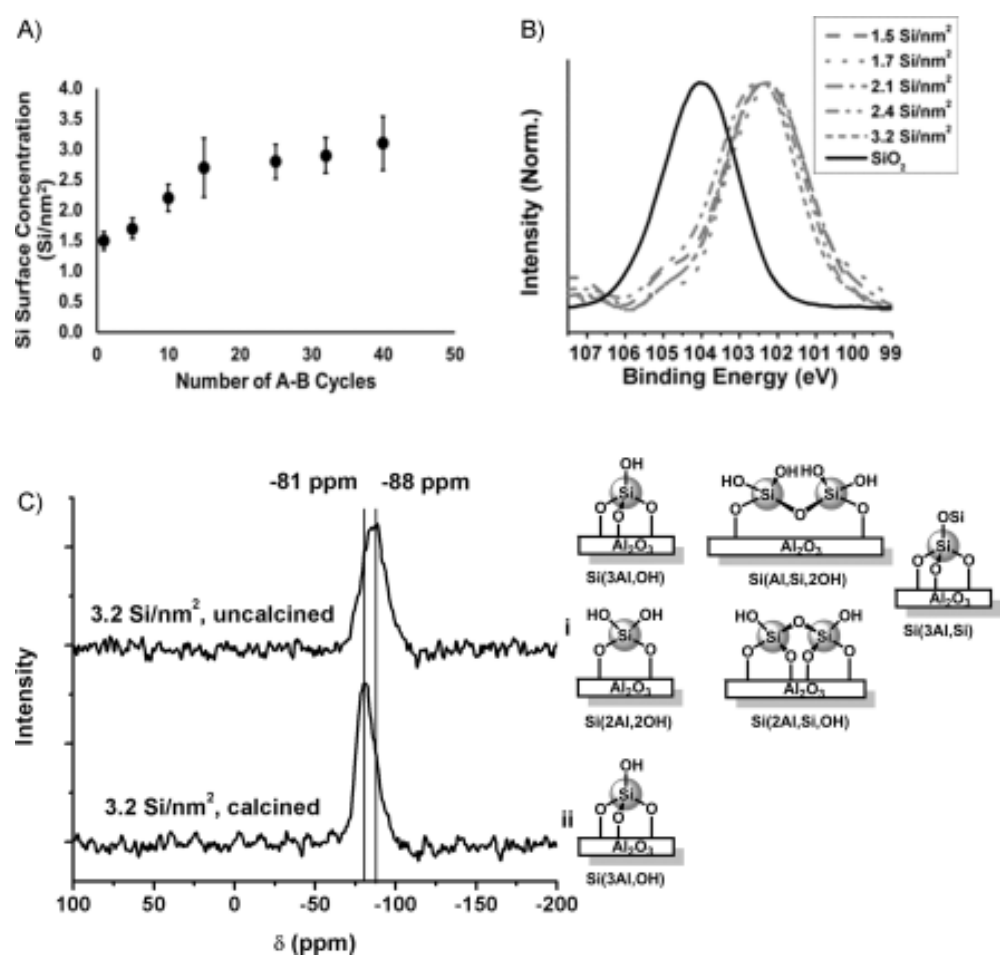

Fig. 64. (A) Si surface coverage in $\mathrm{Si} / \mathrm{nm}^{2}$ as determined by ICP. (B) Si (2p) XPS spectrum of $\mathrm{SiO}_{\mathrm{x}}$ catalysts. (C) DNP-enhanced ${ }^{29} \mathrm{Si}$ CPMAS NMR spectra before and after calcining. Spectra were obtained at $100 \mathrm{~K}$ using MAS rate $v_{\mathrm{R}}=10 \mathrm{kHz}$, recycle delay $\tau_{\mathrm{RD}}=1.5 \mathrm{~s}$, contact time $\tau_{\mathrm{CP}}=3 \mathrm{~ms}$, number of scans NS=2048, acquisition time AT=50 min. The surface structures $\mathrm{Si}(3 \mathrm{Al}, \mathrm{OH}), \mathrm{Si}(\mathrm{Al}, \mathrm{Si}, 2 \mathrm{OH}), \mathrm{Si}(2 \mathrm{Al}, 2 \mathrm{OH}), \mathrm{Si}(2 \mathrm{Al}, \mathrm{Si}, \mathrm{OH})$, and $\mathrm{Si}(3 \mathrm{Al}, \mathrm{Si})$ are depicted on the right. Note that $\mathrm{Si}(3 \mathrm{Al}, \mathrm{OH})$ is the principle species in the calcined sample. Reprinted with permission from [369]. (C) 2015 WILEY - VCH Verlag GmbH \& Co. KGaA, Weinheim. 


\subsection{Conformal ALD coatings on mesoporous materials for enhanced acidity}

\subsection{1 $\mathrm{Al}_{2} \mathrm{O}_{3} \mathrm{ALD}$ on mesoporous zeolite}

The TMA molecule has a kinetic diameter of ca. $0.55 \mathrm{~nm}$ [370]. Martens et al. recently reported TMA can penetrate into the ultrastable Y zeolite which has supercages with free diameters of ca. $1.2 \mathrm{~nm}$ and four apertures measuring $0.74 \mathrm{~nm}$ [371]. On the Y zeolite, ten alumina ALD cycles using TMA and water increased the Al content from 2428 to 3015 $\mathrm{mmol} / \mathrm{kg}$, corresponding to a change in the bulk $\mathrm{Al} /(\mathrm{Al}+\mathrm{Si})$ molar ratio from 0.146 to 0.175 . By measuring the $\mathrm{Al} /(\mathrm{Al}+\mathrm{Si})$ molar ratio at the surface of the zeolite, XPS showed a modest increase from 0.167 to 0.270 , which confirmed that the alumina introduced via ALD penetrated into the zeolite crystals and did not accumulate at the surface. ${ }^{27} \mathrm{Al}$ MAS NMR showed that the aluminum introduced via ALD is mostly in pentacoordinated and octahedral extra framework Al. The authors further characterized the acidity using pyridine FTIR. They found that the $\mathrm{Al}$ deposited into the $\mathrm{Y}$ zeolite increased the number of Brønsted acid sites from $488 \mathrm{mmol} / \mathrm{kg}$ to $570 \mathrm{mmol} / \mathrm{kg}$, while the Lewis acid site content increased only slightly from $151 \mathrm{mmol} / \mathrm{kg}$ to $156 \mathrm{mmol} / \mathrm{kg}$. In comparison, increasing the Al content of ZSM-5 from $\mathrm{Si} / \mathrm{Al}=49.6$ to 37.1 by desilication decreased the concentration of strong Brønsted acid sites from $256 \mathrm{mmol} / \mathrm{kg}$ to $179 \mathrm{mmol} / \mathrm{kg}$ as measured using the same pyridine adsorption technique. Increasing the aluminum content through desilication improves the accessibility of the acid sites via formation of secondary porosity but reduces the acidity in contrast to the alumina ALD. More recently, Martens et al. demonstrated that five cycles of alumina ALD on a purely siliceous zeolite (-COK-14) with intersecting 10- and 12-membered rings of tetrahedral pore systems resulted in an aluminum coordination of ca. $21 \%$ tetrahedral $\mathrm{Al}$, ca. $19 \%$ pentacoordinated or distorted tetrahedral $\mathrm{Al}$, and $60 \%$ octahedral extra-framework $\mathrm{Al}$ [372]. Interestingly, this modification causes a permanent conversion of the originally interrupted framework of -COK-14 to a fully connected OKO type framework, and generates new acid sites which are catalytically active for hydrocracking of n-decane. As a consequence, the introduction of aluminum into mesoporous zeolite and hierarchical materials by ALD was suggested to be an effective way to enhance the acidity and acid catalytic activity (Fig. 65) [371, 373]. However, one should keep in mind that ALD will only be effective for zeolites having pore sizes larger than the kinetic diameter of the ALD precursors. 


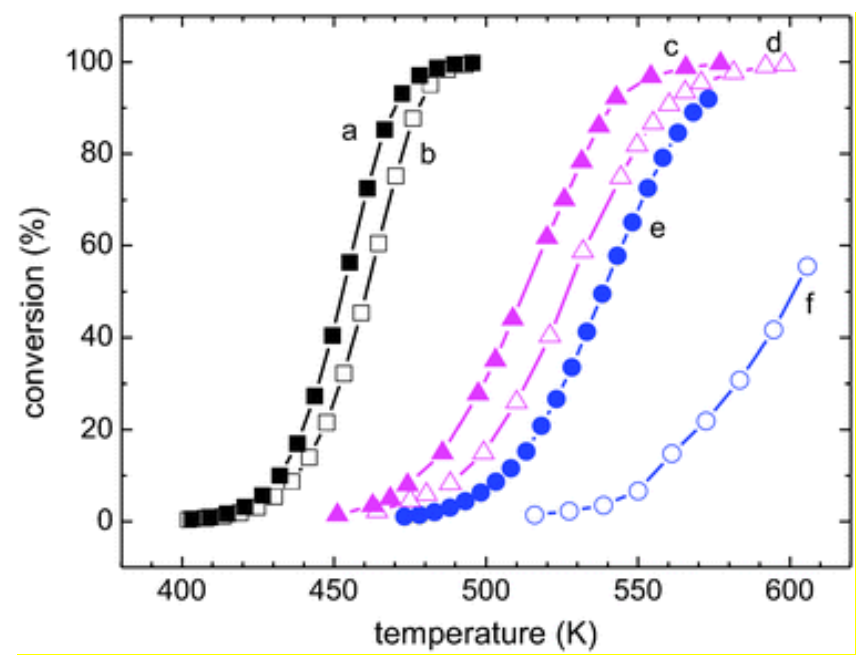

Fig. 65. Decane conversion over (a) Al-ALD (10 cycles) modified CBV-712, (b) parent CBV-712, (c) Al-ALD (30 cycles) modified CBV-760, (d) parent CBV-760, (e) Al-ALD (10 cycles) modified Zeotile-4 and (f) parent Zeotile-4 material. Reprinted with permission from [373]. Copyright (C) 2011, Royal Society of Chemistry

\subsection{2 $\mathrm{Nb}_{2} \mathrm{O}_{5} \mathrm{ALD}$ on $\mathrm{SBA}-15$}

Dumesic and co-workers successfully deposited conformal ALD $\mathrm{Nb}_{2} \mathrm{O}_{5}$ layers within the pores of a mesoporous silica (SBA-15) using alternating exposures to niobium(V) ethoxide $\left(\mathrm{Nb}\left(\mathrm{OCH}_{2} \mathrm{CH}_{3}\right)_{5}\right)$ and water at $200{ }^{\circ} \mathrm{C}$ (Fig. 66) [374]. Figure Fig. 66A shows a high-angle annular dark field STEM image of a sample of SBA-15 coated with 30 ALD Nb $\mathrm{O}_{5}$ cycles. In this image, silica walls appear dark while the niobia layers are brighter since STEM is based on $\mathrm{Z}$ contrast (atomic number) and niobia has a higher average $\mathrm{Z}$ value compared with silica. The thin dark lines sandwiched between pairs of bright niobia layers are the open pores within the structure and highlight the excellent conformality of the ALD coating. Nitrogen adsorption measurements revealed that SBA-15 has an initial pore diameter of $6.49 \mathrm{~nm}$, and that the pore diameter is progressively reduced to 5.8, 5.6, 4.75 and $3.74 \mathrm{~nm}$ after $1,10,19$ and 30 cycles of $\mathrm{Nb}_{2} \mathrm{O}_{5}$ ALD, respectively; meanwhile, the surface area decreased from 930 $\mathrm{m}^{2} / \mathrm{g}$ to $671,326,246$ and $126 \mathrm{~m}^{2} / \mathrm{g}$, respectively. Raman spectroscopy of the ALD niobiatreated SBA-15 and comparison with reference spectra for bulk specimens of amorphous and crystalline niobia revealed that the ALD $\mathrm{Nb}_{2} \mathrm{O}_{5}$ was hydrated and amorphous according to the Raman bands and 650 and $886 \mathrm{~cm}^{-1}$. Very interestingly, materials containing 10, 19, and 30 cycles showed remarkable hydrothermal stability, with minimal changes in porosity and structure after treatment in liquid water at $200{ }^{\circ} \mathrm{C}$. The mesoporous niobia material produced by 19 cycles was evaluated as an acid catalyst for the gas-phase dehydration of 2-propanol, 
and for the dehydration of 2-butanol in both the gas and liquid phases. It was superior to commercial niobia (HY-340) in both activity and stability.
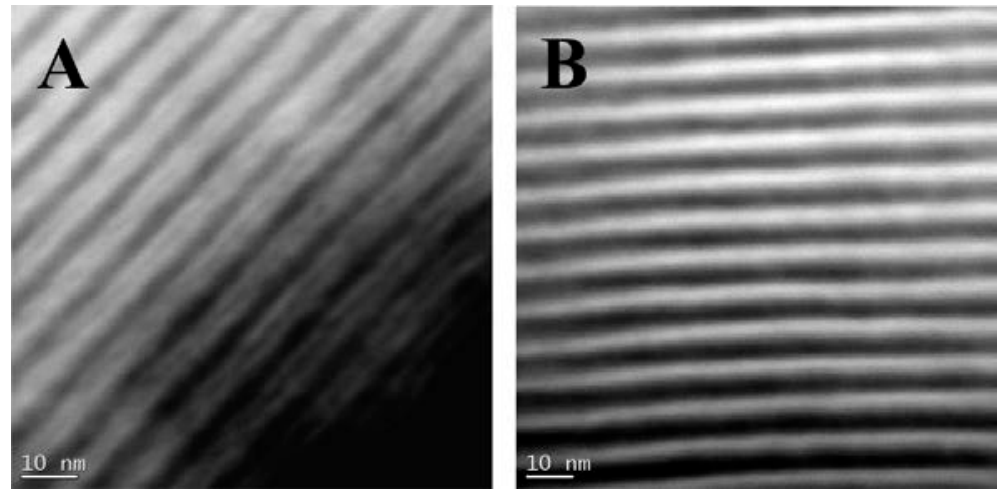

Fig. 66. High-magnification STEM images of (A) SBA-15 coated with 30 ALD cycles of $\mathrm{Nb}_{2} \mathrm{O}_{5}$ and (B) SBA-15. Reprinted with permission from [374]. Copyright (C) 2011, American Chemical Society.

\subsection{ALD oxide architectures for photocatalysis}

The possibility of depositing photocatalytic oxide layers by ALD onto electrically conducting nanostructured supports has drawn the attention of the photocatalysis community. This application requires precise control over the composition, structure, and thickness of the photocatalytic oxide layers. For instance, Martinson and co-workers showed that ALD $\mathrm{CoO}_{\mathrm{x}}$ deposited onto hematite photoanodes significantly enhanced the photoelectrochemical (PEC) water oxidation performance (Fig. 67) [375]. The optimal coating was found to be a single $\mathrm{CoO}_{\mathrm{x}}$ ALD cycle, which amounts to a submonolayer of $\mathrm{Co}(\mathrm{OH})_{2} / \mathrm{Co}_{3} \mathrm{O}_{4}$ according to ellipsometric, XPS and X-ray absorption near-edge spectroscopy (XANES) measurements.

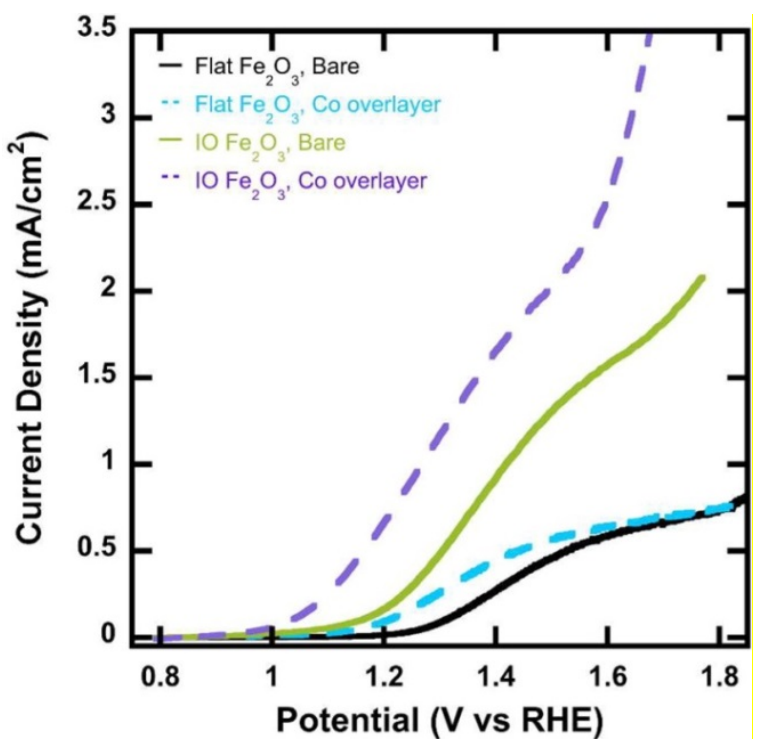

Fig. 67. J-E curves for $13 \mathrm{~nm}$ hematite photoanodes on a flat FTO-ITO substrate (black), on 
an ITO-coated inverse opal scaffold (green), on an equivalent flat electrode further coated with 1 CoCp2/O3 ALD cycle (blue, dashed), and on an equivalent inverse opal scaffold further coated with $1 \mathrm{CoCp} 2 / \mathrm{O} 3$ ALD cycle (purple, dashed). Performance was measured at pH 13.1 under 1 sun illumination. Reprinted with permission from [375]. Copyright (C) 2013, American Chemical Society.

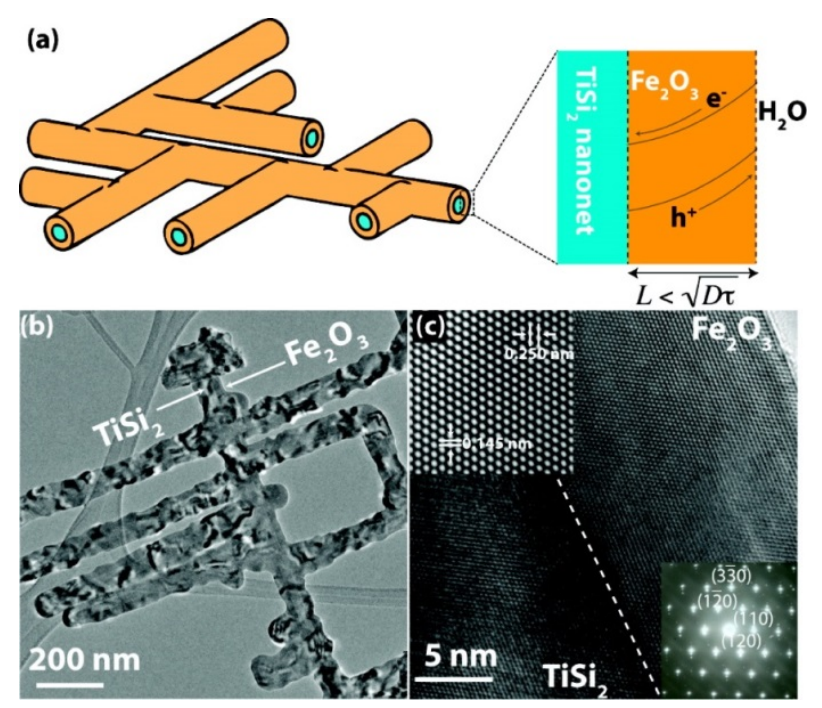

Fig. 68. (a) Schematic illustration of the design principle, which involves the use of a highly conductive $\mathrm{TiSi}_{2}$ nanonet as an effective charge collector. The electronic band structure is shown in the enlarged cross-sectional view. Efficient charge collection is achieved when the hematite thickness is smaller than the charge-diffusion distance. (b) Low-magnification TEM image showing the structural complexity of a typical hetero-nanostructure and its $\mathrm{TiSi}_{2}$ core/hematite shell nature. (c) High-resolution (HR) TEM data. A dashed line has been added at the interface as a guide to the eyes. Insets: (left) lattice-fringe-resolved HRTEM image showing the hematite lattice spacings for $(110)(0.250 \mathrm{~nm})$ and $(\overline{330})(0.145 \mathrm{~nm})$; (right) electron diffraction pattern of hematite. Reprinted with permission from [376].

ALD oxide films often grow in an amorphous phase, and in some cases post-deposition annealing in an oxygen environment is required to crystallize the ALD film and to improve the interface quality between the ALD oxide layer and the substrate. For instance, Wang et al. constructed $\mathrm{TiSi}_{2}$ nanonet-based hematite $\left(\alpha-\mathrm{Fe}_{2} \mathrm{O}_{3}\right)$ heterostructures by depositing $\mathrm{Fe}_{2} \mathrm{O}_{3}$ onto the $\mathrm{TiSi}_{2}$ nanonet using $\mathrm{Fe}_{2}(\mathrm{OtBu})_{6}$ and $\mathrm{H}_{2} \mathrm{O}$ at $140{ }^{\circ} \mathrm{C}$ [376]. Post-growth annealing at $500{ }^{\circ} \mathrm{C}$ in $\mathrm{O}_{2}$ was carried out to improve the crystallinity of the hematite, as evidenced by the structural characterization in Fig. 68. Without the addition of any oxygen-evolving catalysts, the $\mathrm{Fe}_{2} \mathrm{O}_{3} / \mathrm{TiSi}_{2}$ heterostructures $\left(\mathrm{Fe}_{2} \mathrm{O}_{3}\right.$ thickness $\left.25 \mathrm{~nm}\right)$ showed photocurrents of 1.6 and $2.7 \mathrm{~mA} / \mathrm{cm}^{2}$ at 1.23 and $1.53 \mathrm{~V}$ vs a reversible hydrogen electrode (RHE), respectively. The 
high surface area, conductive $\mathrm{TiSi}_{2}$ nanonets serve a dual role as a structural support and an efficient charge collector, allowing for maximum photon-to-charge conversion, benefited from the conformal coating $\alpha-\mathrm{Fe}_{2} \mathrm{O}_{3}$ and the defect-free interface between the $\mathrm{Fe}_{2} \mathrm{O}_{3}$ and the $\mathrm{TiSi}_{2}$. Wang et al. also devised a new method for $\mathrm{WO}_{3}$ ALD that eliminates the corrosive byproducts associated with the more common halogenated precursors by using $(\mathrm{tBuN})_{2}\left(\mathrm{Me}_{2} \mathrm{~N}\right)_{2} \mathrm{~W}$ and $\mathrm{H}_{2} \mathrm{O}$ as the tungsten and oxygen source, respectively at temperatures of $250-350{ }^{\circ} \mathrm{C}$ [377]. $\mathrm{WO}_{3}$ was deposited either on indium-tin oxide (ITO) or on $\mathrm{TiSi}_{2}$ nanonets. Post-annealing at $550{ }^{\circ} \mathrm{C}$ in $\mathrm{O}_{2}$ was carried out to improve the crystallinity of the $\mathrm{ALD} \mathrm{WO}_{3}$. When coated with a novel Mn-based catalyst, the resulting $\mathrm{WO}_{3}$ survives soaking in $\mathrm{H}_{2} \mathrm{O}$ at $\mathrm{pH} 7$ and produces oxygen by splitting $\mathrm{H}_{2} \mathrm{O}$ under illumination.

The surface modification of semiconductor photoelectrodes with passivating overlayers has been shown to be an effective strategy to improve the charge-separation and chargetransfer processes across the semiconductor-liquid interfaces, as well as the stability of photoelectrodes [17, 378-382]. Yang et al, showed that $0.8 \mathrm{~nm} \mathrm{ALD} \mathrm{TiO}_{2}$ (20 cycles) on hematite photoanodes considerably improved the PEC water oxidation performance, and reduced the overpotential by ca. $100 \mathrm{mV}$ [380]. McIntyre et al. [17] demonstrated that PEC water oxidation can be sustained using an $\mathrm{ALD} \mathrm{TiO}_{2}$ (2 nm thick) protected silicon anode for many hours in harsh $\mathrm{pH}$ and oxidative environments whereas comparable silicon anodes without the $\mathrm{TiO}_{2}$ coating quickly fail. The desirable electrochemical efficiency and corrosion resistance of these anodes was attributed to the low electron-tunneling resistance and uniform thickness of the ALD $\mathrm{TiO}_{2}$ layer. The thickness of the $\mathrm{TiO}_{2}$ protective layer is very critical (Fig. 69), because as the film becomes thicker, it no longer conducts holes via a tunneling mechanism and also introduces a large resistance, degrading its efficiency to low values [381]. Lewis and co-workers revealed that amorphous $\mathrm{ALD} \mathrm{TiO}_{2}$ is electronically defective and possibly nonstoichiometric and this allows very high $\left(>1 \mathrm{~A} / \mathrm{cm}^{2}\right)$ current densities to pass through the "leaky" dielectric. The electronic defects in amorphous $\mathrm{ALD} \mathrm{TiO}_{2}$ films presumably arise from structural disorder in the amorphous phase and/or chemical impurities such as carbon or nitrogen residues from the ALD precursors. In contrast, crystalline $\mathrm{TiO}_{2}$ films produced by thermal annealing create an interfacial tunneling barrier for photogenerated charge carriers. Amorphous $\mathrm{TiO}_{2}$ films with 4 to 143 nanometer thickness are sufficiently transparent to reach the light-limited performance of protected semiconductors. The authors demonstrated that ALD $\mathrm{TiO}_{2}$-coated GaAs and GaP photoelectrodes exhibited photovoltages of 0.81 and $0.59 \mathrm{~V}$ and light-limiting photocurrent densities of 14.3 and 3.4 milliamperes per square centimeter, respectively, for water oxidation [382]. 

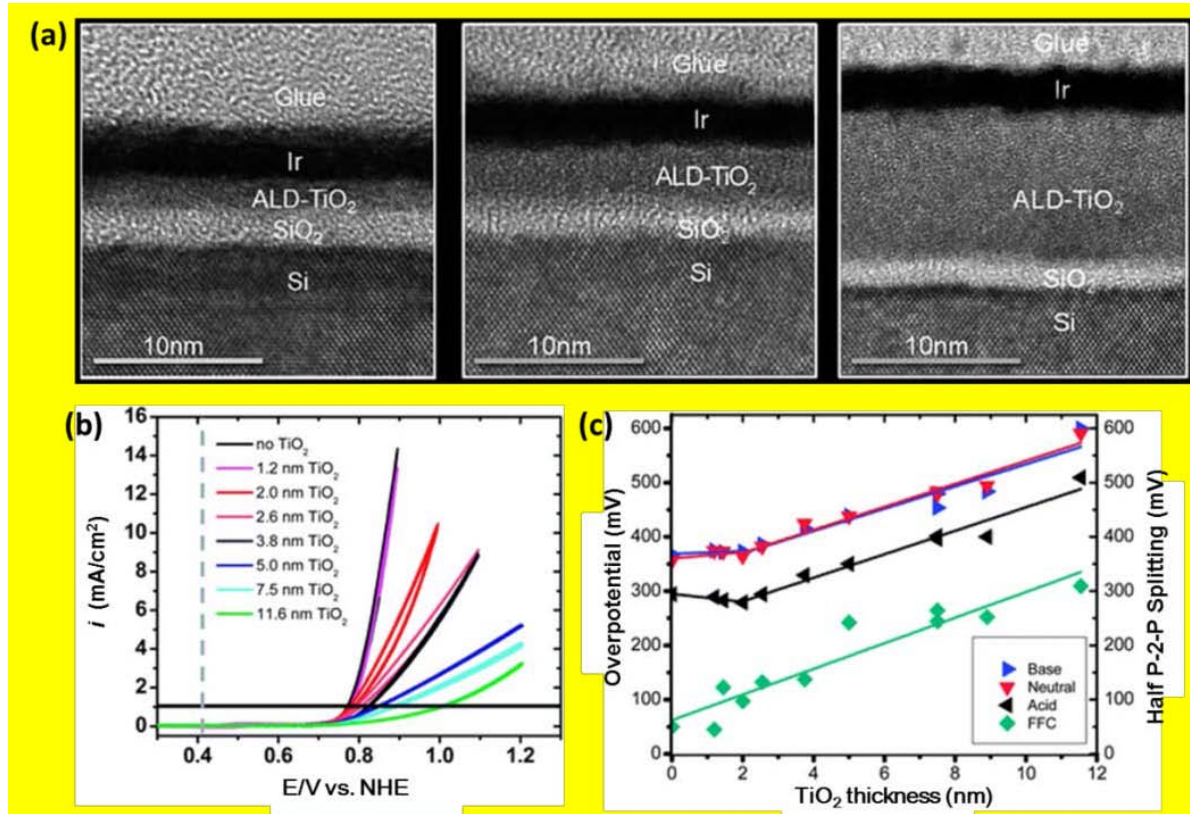

Fig. 69. (a) TEM images of of three ALD-TiO ${ }_{2}$ films of thickness $2 \mathrm{~nm}, 5 \mathrm{~nm}$, and $12 \mathrm{~nm}$ from left to right. (b) Water oxidation $i-E$ curves in basic solution using $\mathrm{Ir} / \mathrm{x} \mathrm{nm}$ of $\mathrm{TiO}_{2} / \mathrm{SiO}_{2} / \mathrm{p}^{+}-\mathrm{Si}$ anodes. The vertical dashed line indicates the thermodynamic potential for water oxidation in base, $0.404 \mathrm{~V}$, and the horizontal solid line indicates $1 \mathrm{~mA} / \mathrm{cm}^{2}$, the characteristic current density at which all overpotentials are measured. (c) Overpotentials for water oxidation at $1 \mathrm{~mA} / \mathrm{cm}^{2}$ and ferri/ferrocyanide half peak-to-peak splitting as a function of $\mathrm{TiO}_{2}$ thickness. Reprinted with permission from [381]. Copyright (C) 2013, Royal Society of Chemistry.

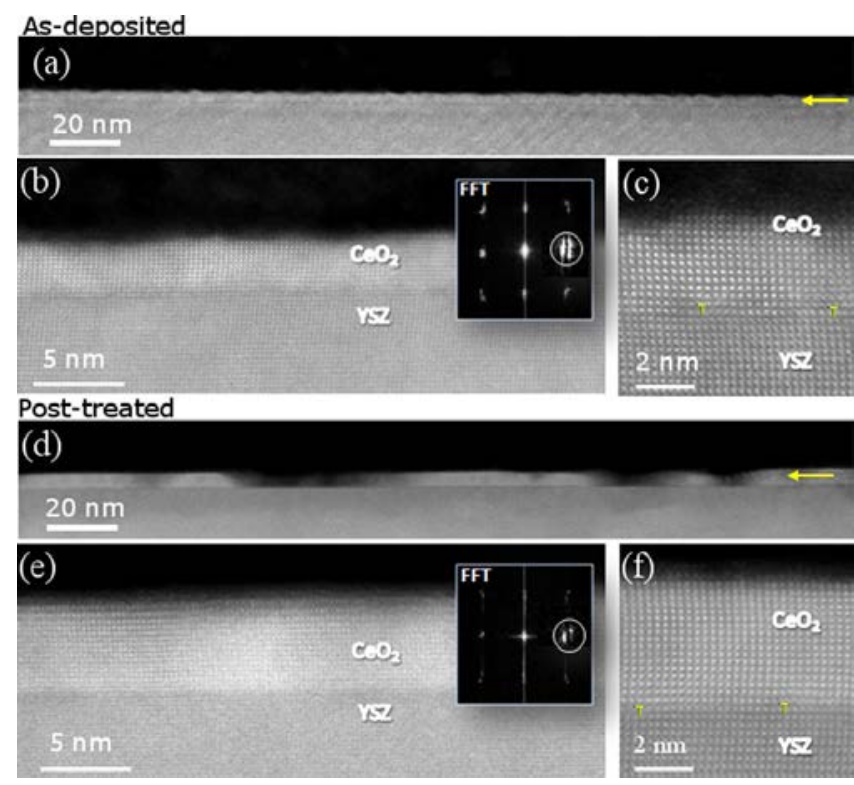

Fig. 70. HAADF-STEM images of 200 cycles $A L D-C_{2} O_{2}$ films grown on YSZ substrate and viewed along the $\mathrm{CeO}_{2}[100] / Y S Z[100]$ zone axis. Low and high magnification HAADF Zcontrast images of as-deposited (a, b and c) and post-treated (d, e, and f) $\mathrm{CeO}_{2}$ films, 
respectively. Insets show the corresponding FFT patterns. (a and d) Arrows point to the $\mathrm{CeO}_{2}$ layer. (c and f) High magnification Z-contrast images of the interface between ceria and the substrate of as-deposited and post-treated $\mathrm{CeO}_{2}$ films, respectively. ALD $\mathrm{CeO}_{2}$ films were post-treated at $900{ }^{\circ} \mathrm{C}, 15 \mathrm{~min}$ in oxygen. Arrows mark the position of misfit dislocations. Reprinted with permission from [383]. Copyright (C 2012, American Chemical Society.

It is possible to deposit highly crystalline films and even achieve epitaxial growth on lattice-matched substrates at low temperatures using ALD (also seen in the review elsewhere by Puurunen et al. [25] and the references therein). For instance, Grätzel et al. recently developed a low-temperature ALD process to deposit phase-pure and crystalline $\alpha-\mathrm{Fe}_{2} \mathrm{O}_{3}$ films at $230{ }^{\circ} \mathrm{C}$ using $\mathrm{N}$-(dimethylaminomethyl)ferrocene (DMAMFc) and ozone, as the Fe and $\mathrm{O}$ precursors, respectively [384]. The grow rate was $0.25 \pm 0.01 \AA$ /cycle. These asdeposited $\alpha-\mathrm{Fe}_{2} \mathrm{O}_{3}$ films were investigated as photoanodes for PEC water oxidation and found to be highly photoactive. Combined with a $\mathrm{TiO}_{2}$ underlayer and a low-cost $\mathrm{Ni}(\mathrm{OH})_{2}$ catalyst, hematite films of less than $10 \mathrm{~nm}$ in thickness reached photocurrent densities of $0.3 \mathrm{~mA} / \mathrm{cm}^{2}$ at $1.23 \mathrm{~V}$ vs RHE and a photocurrent onset potential of less than $0.9 \mathrm{~V}$ vs RHE. Coll et al. demonstrated highly epitaxial, ultrasmooth, and pure (001) $\mathrm{CeO}_{2}$ ultrathin films by ALD at a low deposition temperature of $275^{\circ} \mathrm{C}$ on single crystal substrates, such as $\mathrm{Y}$-stabilized $\mathrm{ZrO}_{2}$ (YSZ) (Fig. 70) [383]. The $\mathrm{CeO}_{2}$ ALD conditions were optimized using $\mathrm{Ce}(\text { thd })_{4}$ and ozone as precursors, and yielded a growth per cycle of $\sim 0.2 \AA$ /cycle. The authors speculated that the extremely low growth rates for the $\mathrm{CeO}_{2} \mathrm{ALD}(\sim 0.016 \mathrm{~nm} / \mathrm{min})$ along with the use of single crystal substrate, facilitates the epitaxial orientation of ceria films.

a

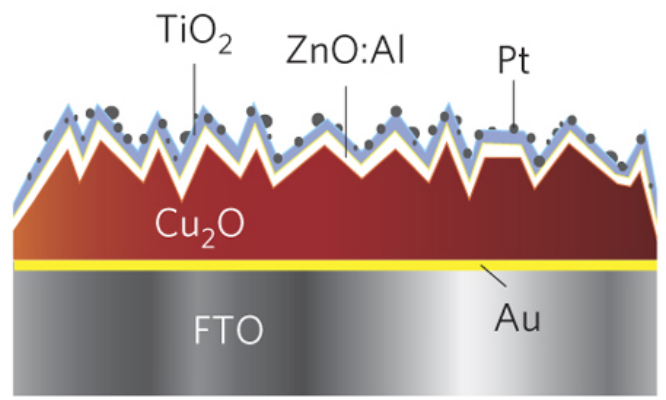

b

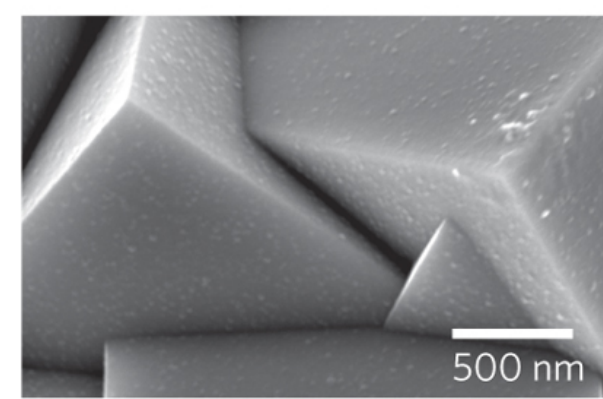

Fig. 71. (a) Schematic representation of the structure of the surface-protected $\mathrm{Cu}_{2} \mathrm{O}$ photocathode. (b) Scanning electron micrograph showing a top view of the electrode after ALD of $5 \times\left(4 \mathrm{~nm} \mathrm{ZnO} / 0.17 \mathrm{~nm} \mathrm{Al}_{2} \mathrm{O}_{3}\right) / 11 \mathrm{~nm} \mathrm{TiO}_{2}$ followed by electrodeposition of $\mathrm{Pt}$ nanoparticles. Reprinted with permission from [385]. Copyright (C) 2011, Rights Managed by Nature Publishing Group. 
ALD is well suited for growing nanostructured thin films consisting of different oxide materials since the composition, structure, and interfaces can be precisely tailored by controlling the sequence of precursor exposures. This capability has been exploited to create nanostructured electrodes for photocatalysis [385-388]. For example, Thimsen et al. [385] demonstrated that nanolayers of ALD Al-doped $\mathrm{ZnO}$ and $\mathrm{TiO}_{2}$ on $\mathrm{Cu}_{2} \mathrm{O}$ photocathodes effectively inhibit the photocathodic decomposition of $\mathrm{Cu}_{2} \mathrm{O}$ in aqueous electrolytes. Photocurrents up to $-7.6 \mathrm{~mA} / \mathrm{cm}^{2}$ at $0 \mathrm{~V}$ versus RHE were achieved using electrodes protected with catalysed layers of n-type oxides with the structure $5 \times(4 \mathrm{~nm} \mathrm{ZnO} / 0.17 \mathrm{~nm}$ $\mathrm{Al}_{2} \mathrm{O}_{3}$ )/11 nm $\mathrm{TiO}_{2}$ (Fig. 71). The electrodes remained active after $1 \mathrm{~h}$ of testing, and the $\mathrm{Cu}_{2} \mathrm{O}$ was found to be stable during the water reduction reaction and the Faradaic efficiency was estimated to be close to $100 \%$. The authors investigated the roles of the different surface protection components, and they found that $\mathrm{TiO}_{2}$ had a staggered type-II band offset, so that photogenerated electrons can flow from the $\mathrm{Cu}_{2} \mathrm{O}$ through the protective layer to the electrolyte to promote water reduction, whereas holes flow into the $\mathrm{Cu}_{2} \mathrm{O}$ bulk. Moreover, its conduction band is above the water reduction potential, ensuring no reductive degradation reactions at potentials in the bandgap. The $20 \mathrm{~nm} \mathrm{ZnO}$ buffer layer between the $\mathrm{Cu}_{2} \mathrm{O}$ and 10 $\mathrm{nm} \mathrm{TiO}_{2}$ was necessary to obtain stable electrodes. Finally, inserting monolayers of $\mathrm{Al}_{2} \mathrm{O}_{3}$ periodically into the $\mathrm{ZnO}$ was necessary to further improve the stability of the electrode without changing the photocurrent.

(a)

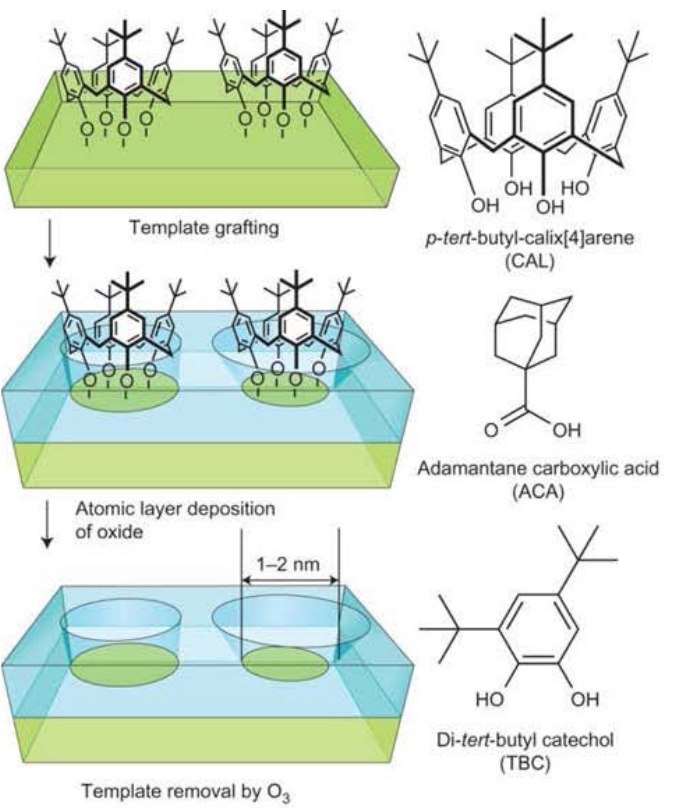

(b)

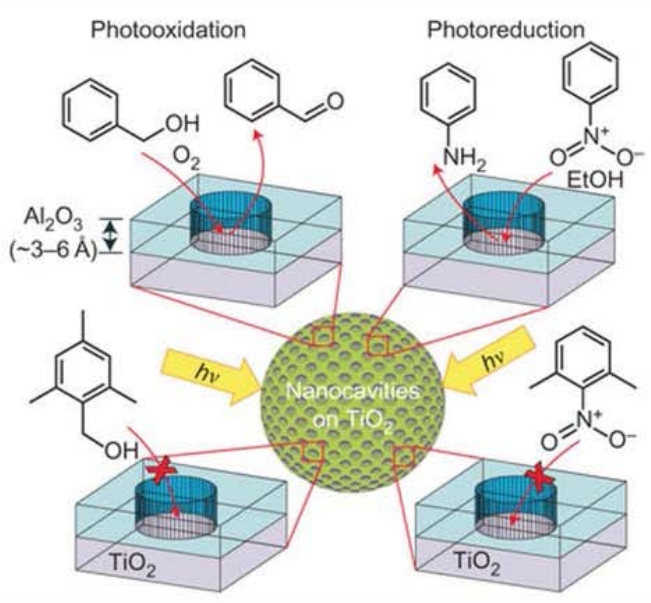

Fig. 72. (a) Synthesis of a nanocavity sieving layer onto a non-porous catalyst support using the molecular-templated ALD: (i) depositing a template (right) onto an existing catalyst 
surface, (ii) using ALD to synthesize an inert oxide film, $2 \mathrm{~nm}$ thick around, but not over, the templates, and (iii) treating the materials in $\mathrm{O}_{3}$ to remove the templates, revealing the underlying catalyst surface. (b) Selective photocatalytic oxidation and reduction of mixtures on CAL-templated nanocavities. Reprinted with permission from [389]. Copyright (C) 2012, Rights Managed by Nature Publishing Group.

\subsection{Oxide ALD using single-molecule sacrificial templates: Atomically-precise "bottom-up" synthesis of selective catalysts.}

Crystalline microporous oxides such as aluminosilicate zeolites are widely used as catalysts in fuels and commodities chemicals upgrading [390]. The materials typically have pore with diameters of $0.3-1.0 \mathrm{~nm}$. This pore size range enables microporous oxides to catalyze chemical transformations with excellent selectivity via reactant or transition-state shape selectivity. Recently, Notestein and co-workers demonstrated a novel approach for "bottom-up" synthesis of a shape-selective catalyst using ALD [389]. Therein, an ultrathin and cavity-containing oxide sieving layer was constructed on the surfaces of larger nonporous oxide catalyst particles by the new technique of molecular-templated ALD. As shown in the schematic illustration in Fig. 72a, an appropriate template molecule was first grafted onto an existing $\mathrm{TiO}_{2}$ photocatalyst surface. The template molecule is selected to be unreactive towards the ALD precursors so as to remain uncovered by the ALD film. Next, an ALD alumina film is selectively deposited on the $\mathrm{TiO}_{2}$ surface surrounding the template molecule to a thickness less than the template height. Finally, the template molecule is removed using $\mathrm{O}_{3}$ to reveal the underlying catalyst surface and activate the catalyst. The lateral dimension and depth of the nanocavity could be tuned by controlling the size the template molecule and the number of ALD alumina cycles, respectively. Using appropriate templates, the nanocavity dimensions were in the supermicroporous region (diameters of 1-2 $\mathrm{nm}$ ), where shape-selectivity is expected to occur for many reactants (Fig. 72b). Indeed, the authors demonstrated that these nanocavities resulted in a high selectivity (up to 9:1) towards less sterically-hindered reactants in otherwise unselective, competitive photocatalytic oxidation and transfer hydrogenation.

\subsection{Oxide ALD on carbon materials}

Oxides supported on carbon-based materials including CNTs, graphene and activated carbon etc., are of great interest in both heterogeneous and electrocatalysis [391-394]. These oxide/carbon hybrid materials have strong chemical attachment and electrical coupling 
between the electrocatalytic oxide nanoparticles and the carbon support, leading to nonprecious metal-based electrocatalysts with improved activity and durability for the oxygen reduction reaction for fuel cells and oxygen/hydrogen evolution reactions [394].

(a)

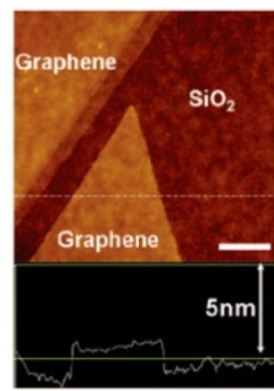

Graphene

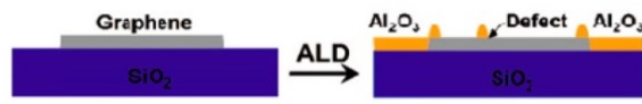

(c)
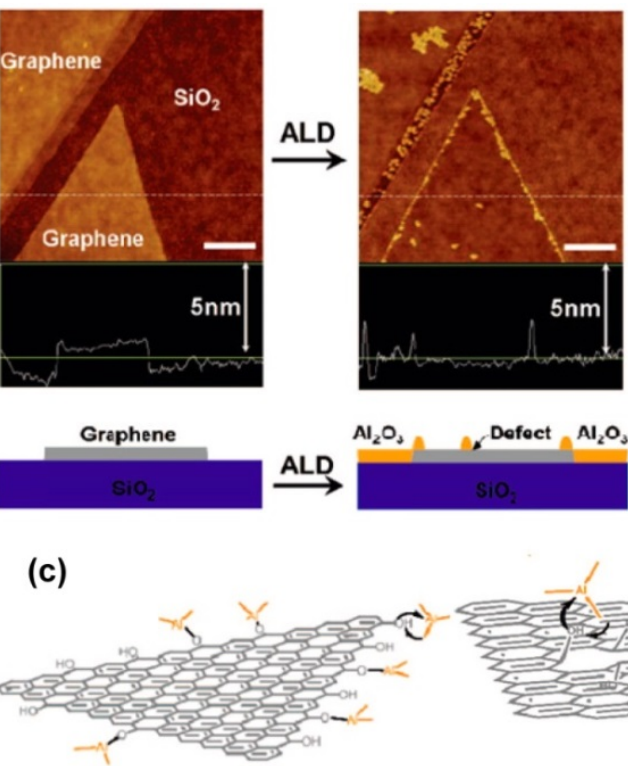

(b)

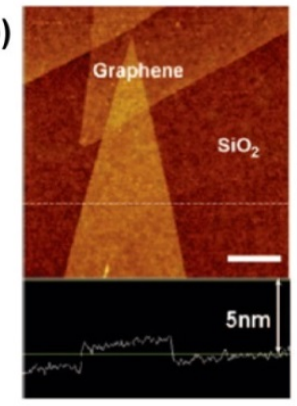

Graphene

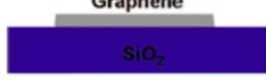

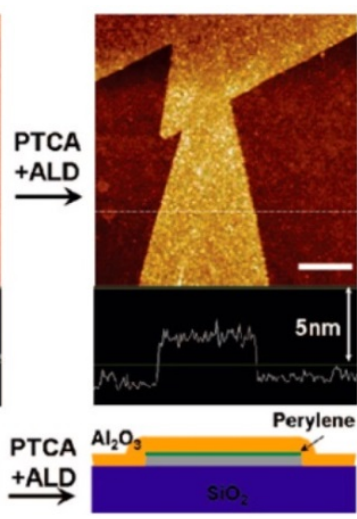

PTCA

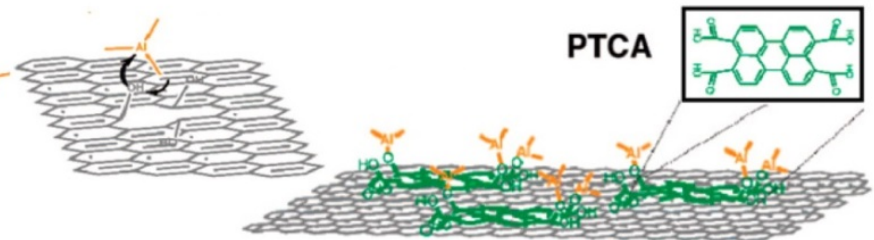

Fig. 73. (a) $\mathrm{ALD}$ of $\mathrm{Al}_{2} \mathrm{O}_{3}$ on pristine graphene, scale bar is $200 \mathrm{~nm}$. (b) $\mathrm{ALD}$ of $\mathrm{Al}_{2} \mathrm{O}_{3}$ on PTCA-coated graphene, scale bar is $500 \mathrm{~nm}$. (c) Schematics of $\mathrm{Al}_{2} \mathrm{O}_{3}$ deposition on various graphene substrates. Reproduced with permission from [150]. Copyright 2008 American Chemical Society. Copyright (C) 2008, American Chemical Society.

ALD provides an alternative way to directly deposit highly dispersed oxide species onto carbon-based materials with high homogeneity and precise control over coverage [126]. However, it turned out that the chemically inert nature of pristine graphitic carbon inhibits the nucleation of ALD materials, since the initiation of ALD growth requires functional surface groups or defects that act as nucleation sites for the ALD precursors. In these cases, the carbon surface must be functionalized prior to the ALD (also seen in the review paper elsewhere by Pinna et al. [126] and the references therein). For instance, George et al. found that $\mathrm{Al}_{2} \mathrm{O}_{3}$ ALD on untreated multiwall carbon nanotubes (MWCNTs) resulted in isolated $\mathrm{Al}_{2} \mathrm{O}_{3}$ nanospheres rather than a continuous film (Fig. 74a) [395], which was attributed to the low density of defects or active chemical species on the MWCNT surface. Once the MWCNTs were functionalized by a layer of adsorbed $\mathrm{NO}_{2}$ and TMA, a smooth and conformal $\mathrm{Al}_{2} \mathrm{O}_{3}$ coating was achieved (Fig. 74b). Dai et al. also reported that $\mathrm{Al}_{2} \mathrm{O}_{3} \mathrm{ALD}$ preferentially grew on the edges and defect sites of pristine graphene sheets (Fig. 73a), suggesting that the chemical groups on the edge and defect sites act as nucleation sites to 
interact with the $\mathrm{Al}_{2} \mathrm{O}_{3} \mathrm{ALD}$ precursors, whereas the basal plane of pristine graphene lacks such interactions [150]. When perylene tetracarboxylic acid (PTCA) was used to functionalize the graphene sheets, the perylene core could interact with the basal plane of graphene through $\pi-\pi$ interaction, while the carboxylic acid groups could interact and react with the ALD precursors. The resulting PTCA functionalized graphene could be uniformly coated with ultrathin $\mathrm{Al}_{2} \mathrm{O}_{3}$ layer (Fig. 73b).
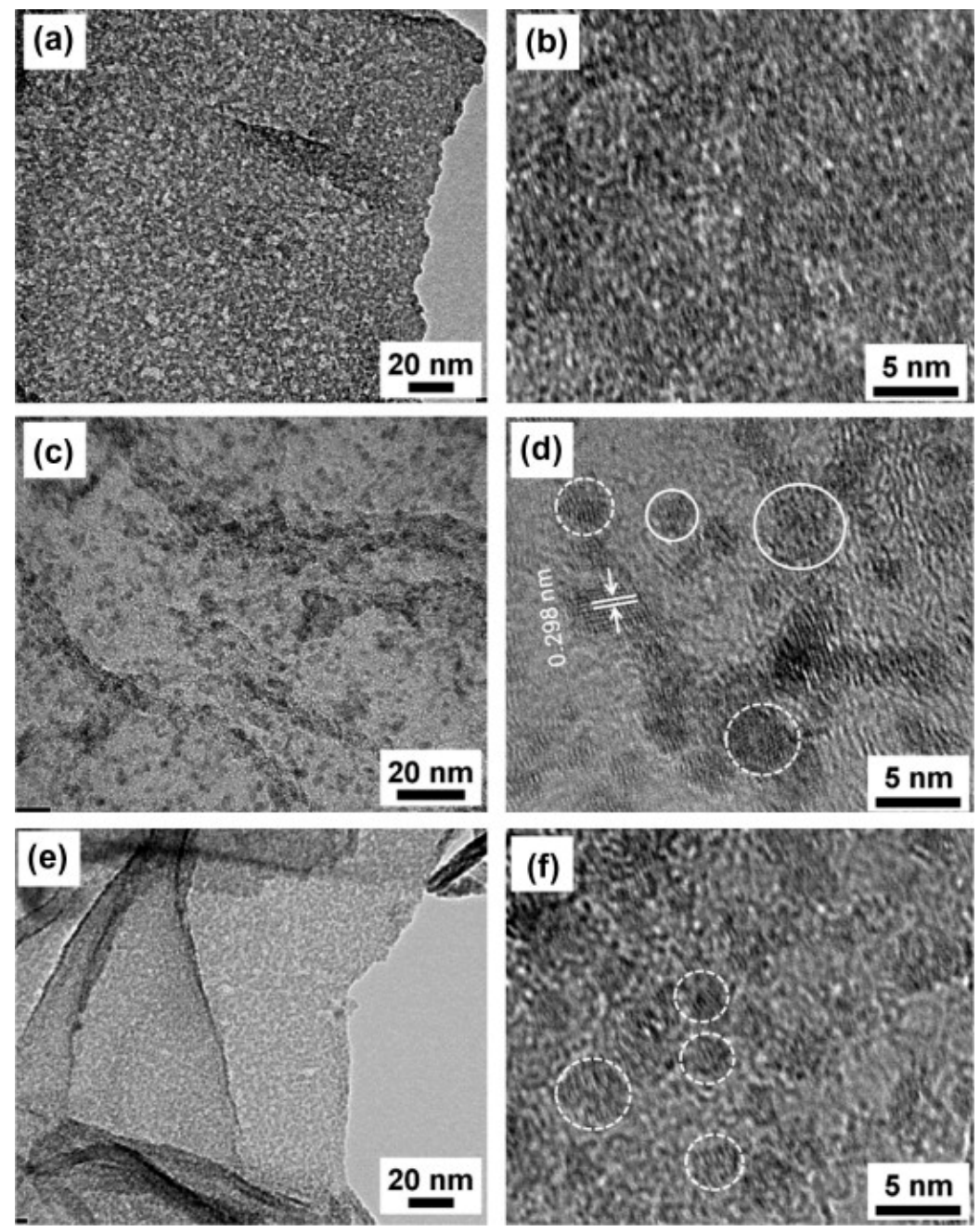

Fig. 76. TEM (a, c, e) and HRTEM (b, d, f) images of $\mathrm{ZrO}_{2}-\mathrm{GNS}$ nanocomposite prepared at $150{ }^{\circ} \mathrm{C}(\mathrm{a}, \mathrm{b}), 200{ }^{\circ} \mathrm{C}$ (c, d) and $250{ }^{\circ} \mathrm{C}$ (e,f) with 10 cycles. Reproduced with permission from [396]. Copyright (c 2012 Elsevier Ltd. All rights reserved.

A common method to generate oxygen-containing sites on carbon surfaces is to chemically treat the carbon using mineral acids such as $\mathrm{HNO}_{3}, \mathrm{H}_{2} \mathrm{SO}_{4}$, or a strong oxidizing agent such as $\mathrm{O}_{3}$ [127-129]. Sun et al. systematically investigated the ALD of $\mathrm{ZrO}_{2}$ on graphene nanosheets (GNS) using alternating exposures to tetrakis(dimethylamido)zirconium(IV) (TDMAZ) and water at 150, 200 and $250{ }^{\circ} \mathrm{C}$ [396]. Therein, the GNS were prepared by 
thermal reduction of graphite oxide. FTIR measurements showed a strong peak located at $3450 \mathrm{~cm}^{-1}$, corresponding to the stretching vibration of hydroxyl groups $(-\mathrm{OH})$. HRTEM showed that $\mathrm{ZrO}_{2}$ nanoparticles were formed on GNS after 10 cycles of $\mathrm{ZrO}_{2}$ ALD at all temperatures (Fig. 74). The reaction of TDMAZ with widely-separated surface -OH groups during the first cycle was suggested to initiate the $\mathrm{ZrO}_{2}$ nanoparticle growth. In addition, the crystallinity of the deposited $\mathrm{ZrO}_{2}$ was found to depend highly on the deposition temperature. The $\mathrm{ZrO}_{2}$ deposited at $150{ }^{\circ} \mathrm{C}$ was amorphous (Fig. 74a,b), but at a deposition temperature of $250{ }^{\circ} \mathrm{C}$ the $\mathrm{ZrO}_{2}$ was crystalline (Fig. 74e,f). The interplanar spacing of the crystalline nanoparticles was measured to be $0.298 \mathrm{~nm}$, agreeing well with the lattice distance between (101) planes of tetragonal $\mathrm{ZrO}_{2}$, as seen in Fig. 74d. With increasing ALD cycles, the $\mathrm{ZrO}_{2}$ nanoparticles coalesced so that the growth mode transitioned from "island growth" to "layerby-layer growth”.

\subsection{Summary}

As a consequence of the self-limiting, surface-controlled reactions that define ALD, it is possible to coat surfaces with metal oxide species for catalysis with precise control over the structure to create isolated monomers, two-dimensional polymers, or three-dimensional, thinfilm crystals using ALD techniques [10, 368, 369]. Furthermore, the dispersion of the catalytic surface species synthesized by ALD is frequently higher than that of conventional techniques, and this in turn provides higher catalytic activity [10]. The ALD of metal oxides inside of mesoporous zeolites or on the surface of hierarchical structures provides a powerful means to tune the pore size and to enhance the acid catalytic activity [373, 374]. Recently, Kuech et al. demonstrated that Mg-Al oxide ALD on $\gamma-\mathrm{Al}_{2} \mathrm{O}_{3}$ particles with varied $\mathrm{Mg} / \mathrm{Al}$ atomic ratios resulted in a systematic variation of the acid and base site areal densities [397].

The low deposition temperatures typical in metal oxide ALD often leads to amorphous films, and in some cases this produces unique and beneficial electronic properties [382]. In cases where crystalline metal oxides are desired, post-annealing in an oxygen environment can improve the crystallinity of the ALD oxide film and improve the quality of interface between the ALD layer and the substrate. The precise control over the film thickness and the capability to build complex structures comprised of multiple layers of different oxides or blends of oxide materials make ALD an extremely powerful method for constructing nanostructured architectures with optimized photocatalytic performance.

While the growth of oxides onto carbon-based materials using ALD has not been extensively explored, this strategy nevertheless holds great promise in catalysis, and 
especially in electrocatalysis. The chemically inert nature of pristine graphitic carbon leads inhibits the nucleation of ALD growth, and various methods have been demonstrated to impart functional groups prior to ALD that permit smooth, continuous films. Nonetheless, careful control over the density of functional groups might produce a high dispersion of catalytic species on carbon-based materials with extremely high homogeneity [59].

\section{Conclusions and outlook}

Catalyst synthesis with precise control over the catalytic active site structure on the atomic level is essential for understanding catalyst behavior and ultimately for the rational design of advanced catalysts with high performance. The unique self-limiting feature of ALD allows conformal deposition of catalytic materials on catalyst supports with high surface area and porosity. These catalytic materials can be precisely constructed on the support surface in a digital, step-by-step fashion by controlling the ALD cycles. As a consequence, ALD provides a "bottom-up” approach for nanostructuring supported catalysts with near atomic precision.

ALD has demonstrated the capability to achieve precise control over the particle size, composition and structure of supported metal nanoparticles. The resulting metal catalysts typically have a high dispersion, and show higher activity compared to catalysts prepared by conventional methods. Although ALD processes are carried out at elevated temperatures, single-atom metal catalysts can be prepared by carefully controlling the nucleation sites and deposition temperature. In addition, selective metal ALD on metal surfaces but not on supports enables the atomically-precise synthesis of supported bimetallic nanoparticles, a long-standing goal in catalyst synthesis, by digitally tailoring the ALD pulse sequences: the size of the bimetallic particles is determined by the total number of ALD cycles performed, the composition is dictated by the relative number of ALD cycles used for each component, and the structure of the bimetallic nanoparticles is be controlled by the order in which the individual cycles are executed. Such cycle-by-cycle "bottom up" bimetallic (or multiple components) nanoparticle growth on supports shows obvious advantages over conventional methods. However, it should be noted that surface segregation of metal atoms can occur in some cases, leading to different structures than intended.

ALD has proven effective for tailoring the catalytic performance and enhancing the stability of metal catalysts using ultrathin oxide overcoats. The conformality and thickness control afforded by ALD provide advantages over other alternative methods such as CVD and sol-gel chemistry. Besides improving the stability of metal catalysts against sintering and leaching, the activity and selectivity can be remarkably improved by ALD oxide overcoats. 
Differences in the oxide overcoat thickness and composition can both affect the catalytic activity. While the porosity within the oxide overcoat might have a remarkable impact on the catalyst selectivity via the confinement effect. In particular, selectively blocking the lowcoordination sites of metal nanoparticles with ALD oxide overcoats, while leaving the terrace site accessible, provides a new ideal model system for elucidating the individual roles of the low-coordinated and terrace sites of metal nanoparticles in structure-sensitive reactions. When undesired side reactions take place at the low-coordination metal sites, preferential blocking of these undesirable sites by oxide overcoats would produce a more selective catalytic material.

Cycle-by-cycle "bottom up" fabrication catalytic metal oxide species on a support by ALD also makes it advances in precise synthesis of supported metal oxide catalysts, where the structures of catalytic active sites is tuned from isolated metal oxide species, to twodimensional aggregates, and to large islands. Meanwhile, the catalyst acidity can be precisely modified by depositing different oxide materials. The low deposition temperatures typical in metal oxide ALD often leads to amorphous films, and in some cases this produces unique and beneficial electronic properties. In cases where crystalline metal oxides are desired, postannealing in an oxygen environment can improve the crystallinity of the ALD oxide film and improve the quality of interface between the ALD layer and the substrate. The precise control over the film thickness and the capability to deposit complex structures comprised of multiple layers of different oxides or blends of oxide materials make ALD an extremely powerful method for constructing nanostructured architectures with optimized photocatalytic performance.

ALD has commercialized in the microelectronics industry to manufacture a range of different devices, while synthesizing catalysts using ALD are oftentimes considered slow and expensive due to the limitations of current ALD strategies, equipment, and high cost of precursors. Moreover, ALD on powders at a commercial scale is still not realized, scaling up the process remains as the main technical challenge. Current work at the laboratory scale has demonstrated that ALD in a fluidized-bed reactor with a batch type process, or spatial ALD with continuous operation is potentially possible for scaling up. In addition, performing ALD at atmosphere pressure might be beneficial to decrease the cost, and simplify the requirements for the reactor design facilitating the development of scaling-up process.

\section{Acknowledgement}

The work was funded by the National Natural Science Foundation of China (21473169), 
the Young Scientists Fund of the National Natural Science Foundation of China (51402283), the Fundamental Research Funds for the Central Universities (WK2060030014, WK2060190026 and WK2060030017), One Thousand Young Talents Program under the Recruitment Program of Global Experts, the Scientific Research Foundation for the Returned Overseas Chinese Scholars and the start-up funds from University of Science and Technology of China. This work is also supported by Hefei Science Center (2015HSC-UP010). This material is based upon work supported as part of the Institute for Atom-efficient Chemical Transformations (IACT), an Energy Frontier Research Center funded by the U.S. Department of Energy, Office of Science, Office of Basic Energy Sciences. 


\section{References}

[1] T. Suntola, J. Antson, U.S. Patent 4,058,430 (1977).

[2] M. Ahonen, M. Pessa, T. Suntola, Thin Solid Films 65 (1980) 301-307.

[3] O. Sneh, R.B. Clark-Phelps, A.R. Londergan, J. Winkler, T.E. Seidel, Thin Solid Films 402 (2002) 248-261.

[4] E.L. Lakomaa, Appl. Surf. Sci. 75 (1994) 185-196.

[5] J.L. Lu, J.W. Elam, P.C. Stair, Acc. Chem. Res. 46 (2013) 1806-1815.

[6] J.A. Enterkin, W. Setthapun, J.W. Elam, S.T. Christensen, F.A. Rabuffetti, L.D. Marks, P.C. Stair, K.R. Poeppelmeier, C.L. Marshall, ACS Catal. 1 (2011) 629-635.

[7] H. Feng, J.W. Elam, J.A. Libera, W. Setthapun, P.C. Stair, Chem. Mater. 22 (2010) 31333142.

[8] H. Feng, J.L. Lu, P.C. Stair, J.W. Elam, Catal. Lett. 141 (2011) 512.

[9] S.T. Christensen, H. Feng, J.L. Libera, N. Guo, J.T. Miller, P.C. Stair, J.W. Elam, Nano Lett. 10 (2010) 3047-3051.

[10] H. Feng, J.W. Elam, J.A. Libera, M.J. Pellin, P.C. Stair, J. Catal. 269 (2010) 421-431.

[11] J.S. King, A. Wittstock, J. Biener, S.O. Kucheyev, Y.M. Wang, T.F. Baumann, S.K.

Giri, A.V. Hamza, M. Baeumer, S.F. Bent, Nano Lett. 8 (2008) 2405-2409.

[12] J.L. Lu, B.S. Fu, M.C. Kung, G.M. Xiao, J.W. Elam, H.H. Kung, P.C. Stair, Science 335 (2012) 1205-1208.

[13] B.J. O'Neill, D.H.K. Jackson, J. Lee, C. Canlas, P.C. Stair, C.L. Marshall, J.W. Elam, T.F. Kuech, J.A. Dumesic, G.W. Huber, ACS Catal. 5 (2015) 1804-1825.

[14] A.B.F. Martinson, J.W. Elam, M.J. Pellin, Appl. Phys. Lett. 94 (2009) 123107.

[15] J.A. Libera, J.N. Hryn, J.W. Elam, Chem. Mater. 23 (2011) 2150-2158.

[16] M. Nanu, J. Schoonman, A. Goossens, Adv. Mater. 16 (2004) 453.

[17] Y.W. Chen, J.D. Prange, S. Duhnen, Y. Park, M. Gunji, C.E.D. Chidsey, P.C. McIntyre, Nat. Mater. 10 (2011) 539-544.

[18] J.W. Elam, N.P. Dasgupta, F.B. Prinz, Mrs Bull 36 (2011) 899-906.

[19] I.D. Scott, Y.S. Jung, A.S. Cavanagh, Y.F. An, A.C. Dillon, S.M. George, S.H. Lee, Nano Lett. 11 (2011) 414-418.

[20] C.C. Chao, C.M. Hsu, Y. Cui, F.B. Prinz, Acs Nano 5 (2011) 5692-5696.

[21] S.M. George, Chem. Rev. 110 (2010) 111-131.

[22] N.M. Adarnczyk, A.A. Dameron, S.M. George, Langmuir 24 (2008) 2081-2089.

[23] Y. Du, S.M. George, J. Phys. Chem. C 111 (2007) 8509-8517.

[24] T. Suntola, J. Hyvarinen, Annu. Rev. Mater. Sci. 15 (1985) 177-195.

[25] V. Miikkulainen, M. Leskela, M. Ritala, R.L. Puurunen, J. Appl. Phys. 113 (2013)

021301.

[26] R.L. Puurunen, J. Appl. Phys. 97 (2005) 121301.

[27] S.I. Kol'tsov, V.B. Aleskovskii, Russ. J. Phys. Chem. 42 (1968) 630.

[28] S.I. Kol'tsov, V.B. Aleskovskii, Zh. Prikl. Khim. 40 (1967) 907.

[29] S.I. Kol'tsov, G.N. Kuznetsova, V.B. Aleskovskii, Zh. Prikl. Khim. 40 (1967) 2774.

[30] M. Leskela, M. Ritala, Angew. Chem. Int. Ed. 42 (2003) 5548-5554.

[31] H. Kim, H.B.R. Lee, W.J. Maeng, Thin Solid Films 517 (2009) 2563-2580.

[32] C.H. Bartholomew, R.J. Farrauto, Fundamentals of industrial catalytic processes, 2nd ed., Wiley, Hoboken, N.J., 2006.

[33] J.A. Schwarz, C. Contescu, A. Contescu, Chem. Rev. 95 (1995) 477-510.

[34] P. Munnik, P.E. de Jongh, K.P. de Jong, Chem. Rev. 115 (2015) 6687-6718.

[35] Y.X. Liu, G.F. Zhao, D.S. Wang, Y.D. Li, Natl. Sci. Rev. 2 (2015) 150-166.

[36] Z.Y. Zhou, N. Tian, J.T. Li, I. Broadwell, S.G. Sun, Chem. Soc. Rev. 40 (2011) 41674185. 
[37] J. Park, J. Joo, S.G. Kwon, Y. Jang, T. Hyeon, Angew. Chem. Int. Ed. 46 (2007) 46304660.

[38] R. Long, S. Zhou, B.J. Wiley, Y.J. Xiong, Chem. Soc. Rev. 43 (2014) 6288-6310.

[39] C.J. Jia, F. Schuth, Phys. Chem. Chem. Phys. 13 (2011) 2457-2487.

[40] C.H. Bartholomew, Appl. Catal. A. Gen. 212 (2001) 17-60.

[41] S.E. Wanke, P.C. Flynn, Catal. Rev. - Sci. Eng. 12 (1975) 92-135.

[42] C.T. Campbell, S.C. Parker, D.E. Starr, Science 298 (2002) 811-814.

[43] K. Morgan, A. Goguet, C. Hardacre, ACS Catal. 5 (2015) 3430-3445.

[44] E. Ruckenstein, X.D. Hu, Langmuir 1 (1985) 756-760.

[45] J. Barbier, Appl. Catal. 23 (1986) 225-243.

[46] J.A. Moulijn, A.E. van Diepen, F. Kapteijn, Appl. Catal. A. Gen. 212 (2001) 3-16.

[47] E.E. Wolf, F. Alfani, Catal. Rev. - Sci. Eng. 24 (1982) 329-371.

[48] B.J. O'Neill, D.H.K. Jackson, A.J. Crisci, C.A. Farberow, F.Y. Shi, A.C. Alba-Rubio, J. Lu, P.J. Dietrich, X.K. Gu, C.L. Marshall, P.C. Stair, J.W. Elam, J.T. Miller, F.H. Ribeiro, P.M. Voyles, J. Greeley, M. Mavrikakis, S.L. Scott, T.F. Kuech, J.A. Dumesic, Angew.

Chem. Int. Ed. 52 (2013) 13808-13812.

[49] S.H. Joo, J.Y. Park, C.K. Tsung, Y. Yamada, P.D. Yang, G.A. Somorjai, Nat. Mater. 8 (2009) 126-131.

[50] M. Cargnello, J.J.D. Jaen, J.C.H. Garrido, K. Bakhmutsky, T. Montini, J.J.C. Gamez, R.J. Gorte, P. Fornasiero, Science 337 (2012) 713-717.

[51] A.J. Forman, J.N. Park, W. Tang, Y.S. Hu, G.D. Stucky, E.W. McFarland, ChemCatChem 2 (2010) 1318-1324.

[52] Q. Zhang, I. Lee, J.B. Joo, F. Zaera, Y.D. Yin, Acc. Chem. Res. 46 (2013) 1816-1824.

[53] M. Seipenbusch, A. Binder, J. Phys. Chem. C 113 (2009) 20606-20610.

[54] M. Lindblad, L.P. Lindfors, T. Suntola, Catal. Lett. 27 (1994) 323-336.

[55] E.L. Lakomaa, M. Lindblad, T. Suntola, Stud. Surf. Sci. Catal. 92 (1995) 363-366.

[56] S. Haukka, E.L. Lakomaa, T. Suntola, Appl. Surf. Sci. 75 (1994) 220-227.

[57] S. Haukka, E.L. Lakomaa, T. Suntola, Adsorption and Its Applications in Industry and

Environmental Protection, Vol I: Applications in Industry 120 (1999) 715-750.

[58] S. Haukka, E.L. Lakomaa, O. Jylha, J. Vilhunen, S. Hornytzkyj, Langmuir 9 (1993) 3497-3506.

[59] H. Yan, H. Cheng, H. Yi, Y. Lin, T. Yao, C.L. Wang, J.J. Li, S.Q. Wei, J.L. Lu, J. Am. Chem. Soc. 137 (2015) 10484-10487.

[60] S.H. Sun, G.X. Zhang, N. Gauquelin, N. Chen, J.G. Zhou, S.L. Yang, W.F. Chen, X.B. Meng, D.S. Geng, M.N. Banis, R.Y. Li, S.Y. Ye, S. Knights, G.A. Botton, T.K. Sham, X.L. Sun, Sci. Rep. 3 (2013) 1775.

[61] K.L. Choy, Prog Mater Sci 48 (2003) 57-170.

[62] J. Hamalainen, E. Puukilainen, M. Kemell, L. Costelle, M. Ritala, M. Leskela, Chem. Mater. 21 (2009) 4868-4872.

[63] J. Hamalainen, E. Puukilainen, T. Sajavaara, M. Ritala, M. Leskela, Thin Solid Films 531 (2013) 243-250.

[64] J. Hamalainen, T. Hatanpaa, E. Puukilainen, T. Sajavaara, M. Ritala, M. Leskela, J.

Mater. Chem. 21 (2011) 16488-16493.

[65] J. Hamalainen, M. Ritala, M. Leskela, Chem. Mater. 26 (2014) 786-801.

[66] J.L. Lu, J.W. Elam, Chem. Mater. 27 (2015) 4950-4956.

[67] J.W. Elam, Z.A. Sechrist, S.M. George, Thin Solid Films 414 (2002) 43-55.

[68] J. Azadmanjiri, C.C. Berndt, J. Wang, A. Kapoor, V.K. Srivastava, C.E. Wen, J Mater Chem A 2 (2014) 3695-3708.

[69] J.L. Lu, K.B. Low, Y. Lei, J.A. Libera, A. Nicholls, P.C. Stair, J.W. Elam, Nat.

Commun. 5 (2014) 3264. 
[70] M. Ritala, M. Leskela, L. Niinisto, P. Haussalo, Chem. Mater. 5 (1993) 1174-1181.

[71] M. Ritala, M. Leskela, E. Rauhala, Chem. Mater. 6 (1994) 556-561.

[72] M. Ylilammi, Thin Solid Films 279 (1996) 124-130.

[73] R.L. Puurunen, Chem. Vap. Deposition 9 (2003) 249-257.

[74] H. Siimon, J. Aarik, J. Phys. D: Appl. Phys. 30 (1997) 1725-1728.

[75] R.L. Puurunen, Chem. Vap. Deposition 9 (2003) 327-332.

[76] M.D. Groner, F.H. Fabreguette, J.W. Elam, S.M. George, Chem. Mater. 16 (2004) 639645.

[77] H. Yi, H.Y. Du, Y.L. Hu, H. Yan, H.-L. Jiang, J.L. Lu, ACS Catal. 5 (2015) 2735-2739.

[78] J. Aarik, A. Aidla, T. Uustare, V. Sammelselg, J. Cryst. Growth 148 (1995) 268-275.

[79] J.S. King, E. Graugnard, C.J. Summers, Adv. Mater. 17 (2005) 1010-1013.

[80] Y. Widjaja, C.B. Musgrave, Appl. Phys. Lett. 80 (2002) 3304-3306.

[81] J.W. Klaus, O. Sneh, S.M. George, Science 278 (1997) 1934-1936.

[82] J.W. Klaus, A.W. Ott, J.M. Johnson, S.M. George, Appl. Phys. Lett. 70 (1997) 10921094.

[83] J.W. Klaus, S.M. George, Surf. Sci. 447 (2000) 81-90.

[84] J.D. Ferguson, E.R. Smith, A.W. Weimer, S.M. George, J. Electrochem. Soc. 151 (2004) G528-G535.

[85] B.B. Burton, M.P. Boleslawski, A.T. Desombre, S.M. George, Chem. Mater. 20 (2008) 7031-7043.

[86] H. Kim, I.K. Oh, Jpn. J. Appl. Phys. 53 (2014).

[87] H.B. Profijt, S.E. Potts, M.C.M. van de Sanden, W.M.M. Kessels, J. Vac. Sci. Technol. A 29 (2011).

[88] R.K. Grubbs, S.M. George, J. Vac. Sci. Technol. A 24 (2006) 486-496.

[89] H. Kim, C. Cabral, C. Lavoie, S.M. Rossnagel, J. Vac. Sci. Technol. B 20 (2002) 13211326.

[90] M. Funabiki, T. Yamada, K. Kayano, Catal. Today 10 (1991) 33-43.

[91] E. Iglesia, Appl. Catal. A. Gen. 161 (1997) 59-78.

[92] A.Y. Khodakov, W. Chu, P. Fongarland, Chem. Rev. 107 (2007) 1692-1744.

[93] D.M. Alonso, S.G. Wettstein, J.A. Dumesic, Chem. Soc. Rev. 41 (2012) 8075-8098.

[94] B.H. Shanks, Ind. Eng. Chem. Res. 49 (2010) 10212-10217.

[95] V.R. Stamenkovic, B.S. Mun, M. Arenz, K.J.J. Mayrhofer, C.A. Lucas, G.F. Wang, P.N. Ross, N.M. Markovic, Nat. Mater. 6 (2007) 241-247.

[96] F. Calle-Vallejo, M.T.M. Koper, A.S. Bandarenka, Chem. Soc. Rev. 42 (2013) 52105230.

[97] P.B. Wells, Platinum Metals Rev. 7 (1963) 18.

[98] Z. Guo, B. Liu, Q.H. Zhang, W.P. Deng, Y. Wang, Y.H. Yang, Chem. Soc. Rev. 43 (2014) 3480-3524.

[99] G.L. Bezemer, J.H. Bitter, H.P.C.E. Kuipers, H. Oosterbeek, J.E. Holewijn, X.D. Xu, F. Kapteijn, A.J. van Dillen, K.P. de Jong, J. Am. Chem. Soc. 128 (2006) 3956-3964.

[100] M. Valden, X. Lai, D.W. Goodman, Science 281 (1998) 1647-1650.

[101] M. Haruta, Catal. Today 36 (1997) 153-166.

[102] F. Zaera, Catal. Lett. 142 (2012) 501-516.

[103] G.C. Bond, Acc. Chem. Res. 26 (1993) 490-495.

[104] B.C. Gates, Chem. Rev. 95 (1995) 511-522.

[105] T. Aaltonen, A. Rahtu, M. Ritala, M. Leskela, Electrochem. Solid State Lett. 6 (2003)

C130-C133.

[106] T. Aaltonen, M. Ritala, Y.L. Tung, Y. Chi, K. Arstila, K. Meinander, M. Leskela, J. Mater. Res. 19 (2004) 3353-3358. 
[107] W.M.M. Kessels, H.C.M. Knoops, S.A.F. Dielissen, A.J.M. Mackus, M.C.M. van de Sanden, Appl. Phys. Lett. 95 (2009) 013114.

[108] T. Aaltonen, M. Ritala, T. Sajavaara, J. Keinonen, M. Leskela, Chem. Mater. 15 (2003) 1924-1928.

[109] J.W. Elam, A.V. Zinovev, M.J. Pellin, D.J. Comstock, M.C. Hersam, ECS Trans. 3 (2007) 271-278.

[110] A.J.M. Mackus, N. Leick, L. Baker, W.M.M. Kessels, Chem. Mater. 24 (2012) 17521761.

[111] R. Liu, L.H. Han, Z.Q. Huang, I.M. Ferrer, A.H.M. Smets, M. Zeman, B.S.

Brunschwig, N.S. Lewis, Thin Solid Films 586 (2015) 28-34.

[112] A.J.M. Mackus, M.A. Verheijen, N. Leick, A.A. Bol, W.M.M. Kessels, Chem. Mater. 25 (2013) 1905-1911.

[113] L. Baker, A.S. Cavanagh, D. Seghete, S.M. George, A.J.M. Mackus, W.M.M. Kessels, Z.Y. Liu, F.T. Wagner, J. Appl. Phys. 109 (2011).

[114] W. Setthapun, W.D. Williams, S.M. Kim, H. Feng, J.W. Elam, F.A. Rabuffetti, K.R.

Poeppelmeier, P.C. Stair, E.A. Stach, F.H. Ribeiro, J.T. Miller, C.L. Marshall, J. Phys. Chem. C 114 (2010) 9758-9771.

[115] T.D. Gould, A.M. Lubers, A.R. Corpuz, A.W. Weimer, J.L. Falconer, J.W. Medlin, ACS Catal. 5 (2015) 1344-1352.

[116] H. Wang, J.L. Lu, C.L. Marshall, J.W. Elam, J.T. Miller, H.B. Liu, J.A. Enterkin, R.M. Kennedy, P.C. Stair, K.R. Poeppelmeier, L.D. Marks, Catal. Today 237 (2014) 71-79.

[117] J. Lu, P.C. Stair, Langmuir 26 (2010) 16486-16495.

[118] J.L. Lu, P.C. Stair, Angew. Chem. Int. Ed. 49 (2010) 2547-2551.

[119] H.A. Gasteiger, S.S. Kocha, B. Sompalli, F.T. Wagner, Appl. Catal. B: Environ. 56 (2005) 9-35.

[120] A.S. Arico, S. Srinivasan, V. Antonucci, Fuel Cells 1 (2001) 133-161.

[121] J.H. Shim, X. Jiang, S.F. Bent, F.B. Prinz, J. Electrochem. Soc. 157 (2010) B793-B797.

[122] C. Liu, C.C. Wang, C.C. Kei, Y.C. Hsueh, T.P. Perng, Small 5 (2009) 1535-1538.

[123] H.B.R. Lee, S.F. Bent, Chem. Mater. 27 (2015) 6802-6809.

[124] C.T. Hsieh, Y.Y. Liu, D.Y. Tzou, W.Y. Chen, J. Phys. Chem. C 116 (2012) 2673526743.

[125] K. Kim, H.B.R. Lee, R.W. Johnson, J.T. Tanskanen, N. Liu, M.G. Kim, C. Pang, C. Ahn, S.F. Bent, Z.N. Bao, Nat. Commun. 5 (2014).

[126] C. Marichy, N. Pinna, Coordin. Chem. Rev. 257 (2013) 3232-3253.

[127] D.R. Dreyer, S. Park, C.W. Bielawski, R.S. Ruoff, Chem. Soc. Rev. 39 (2010) 228240.

[128] A. Hirsch, Angew. Chem. Int. Ed. 41 (2002) 1853-1859.

[129] S. Banerjee, T. Hemraj-Benny, S.S. Wong, Adv. Mater. 17 (2005) 17-29.

[130] J.W. Li, Z. Bin, Y. Chen, J.K. Zhang, H.M. Yang, J.W. Zhang, X.L. Lu, G.C. Li, Y.

Qin, Catal. Sci. Technol. 5 (2015) 4218-4223.

[131] J.W. Elam, A. Zinovev, C.Y. Han, H.H. Wang, U. Welp, J.N. Hryn, M.J. Pellin, Thin Solid Films 515 (2006) 1664-1673.

[132] E. Rikkinen, A. Santasalo-Aarnio, S. Airaksinen, M. Borghei, V. Viitanen, J. Sainio,

E.I. Kauppinen, T. Kallio, A.O.I. Krause, J. Phys. Chem. C 115 (2011) 23067-23073.

[133] J.L. Lu, P.C. Stair, Langmuir 26 (2010) 16486-16495.

[134] H. Feng, J.W. Elam, J.A. Libera, P.C. Stair, J.T. Miller, ACS Catal. 1 (2011) 665-673.

[135] S.M. George, D.N. Goldstein, Thin Solid Films 519 (2011) 5339-5347.

[136] Y. Lei, J.L. Lu, H.Y. Zhao, B. Liu, K.B. Low, T.P. Wu, J.A. Libera, J.P. Greeley, P.J. Chupas, J.T. Miller, J.W. Elam, J. Phys. Chem. C 117 (2013) 11141-11148. 
[137] Y. Lei, J. Lu, X.Y. Luo, T.P. Wu, P. Du, X.Y. Zhang, Y. Ren, J.G. Wen, D.J. Miller, J.T. Miller, Y.K. Sun, J.W. Elam, K. Amine, Nano Lett. 13 (2013) 4182-4189.

[138] T. Gong, L.J. Qin, W. Zhang, H. Wan, J. Lu, H. Feng, J. Phys. Chem. C 119 (2015) 11544-11556.

[139] X.F. Yang, A.Q. Wang, B.T. Qiao, J. Li, J.Y. Liu, T. Zhang, Acc. Chem. Res. 46 (2013) 1740-1748.

[140] M. Flytzani-Stephanopoulos, B.C. Gates, Annu. Rev. Chem. Biomol. Eng. 3 (2012) 545-574.

[141] M. Flytzani-Stephanopoulos, Acc. Chem. Res. 47 (2014) 783-792.

[142] B.T. Qiao, A.Q. Wang, X.F. Yang, L.F. Allard, Z. Jiang, Y.T. Cui, J.Y. Liu, J. Li, T. Zhang, Nat. Chem. 3 (2011) 634-641.

[143] M. Yang, S. Li, Y. Wang, J.A. Herron, Y. Xu, L.F. Allard, S. Lee, J. Huang, M. Mavrikakis, M. Flytzani-Stephanopoulos, Science 346 (2014) 1498-1501.

[144] X. Zhang, H. Shi, B.Q. Xu, Angew. Chem. Int. Ed. 44 (2005) 7132-7135.

[145] D.I. Kochubey, V.V. Chesnokov, S.E. Malykhin, Carbon 50 (2012) 2782-2787.

[146] E.J. Peterson, A.T. Delariva, S. Lin, R.S. Johnson, H. Guo, J.T. Miller, J.H. Kwak, C.H.F. Peden, B. Kiefer, L.F. Allard, F.H. Ribeiro, A.K. Datye, Nat. Commun. 5 (2014). [147] A. Corma, P. Concepcion, M. Boronat, M.J. Sabater, J. Navas, M.J. Yacaman, E.

Larios, A. Posadas, M.A. Lopez-Quintela, D. Buceta, E. Mendoza, G. Guilera, A. Mayoral, Nat. Chem. 5 (2013) 775-781.

[148] M. Moses-DeBusk, M. Yoon, L.F. Allard, D.R. Mullins, Z.L. Wu, X.F. Yang, G. Veith, G.M. Stocks, C.K. Narula, J. Am. Chem. Soc. 135 (2013) 12634-12645.

[149] S. Stambula, N. Gauquelin, M. Bugnet, S. Gorantla, S. Turner, S.H. Sun, J. Liu, G.X. Zhang, X.L. Sun, G.A. Botton, J. Phys. Chem. C 118 (2014) 3890-3900.

[150] X.R. Wang, S.M. Tabakman, H.J. Dai, J. Am. Chem. Soc. 130 (2008) 8152-8153.

[151] R.J. Silvennoinen, O.J.T. Jylha, M. Lindblad, J.P. Sainio, R.L. Puurunen, A.O.I.

Krause, Appl. Surf. Sci. 253 (2007) 4103-4111.

[152] J. Hamalainen, M. Kemell, F. Munnik, U. Kreissig, M. Ritala, M. Leskela, Chem. Mater. 20 (2008) 2903-2907.

[153] S.T. Christensen, J.W. Elam, Chem. Mater. 22 (2010) 2517-2525.

[154] D.J. Comstock, S.T. Christensen, J.W. Elam, M.J. Pellin, M.C. Hersam, Electrochem. Commun. 12 (2010) 1543-1546.

[155] T. Aaltonen, M. Ritala, V. Sammelselg, M. Leskela, J. Electrochem. Soc. 151 (2004) G489-G492.

[156] J. Hamalainen, T. Hatanpaa, E. Puukilainen, L. Costelle, T. Pilvi, M. Ritala, M.

Leskela, J. Mater. Chem. 20 (2010) 7669-7675.

[157] Y.H. Lim, H. Yoo, B.H. Choi, J.H. Lee, H.N. Lee, H.K. Lee, Phys. Status Solidi C 8 (2011) 891-894.

[158] S.W. Kim, S.H. Kwon, D.K. Kwak, S.W. Kang, J. Appl. Phys. 103 (2008).

[159] B.H. Choi, J.H. Lee, H.K. Lee, J.H. Kim, Appl. Surf. Sci. 257 (2011) 9654-9660.

[160] K. Knapas, M. Ritala, Chem. Mater. 23 (2011) 2766-2771.

[161] I.V. Babich, Y.V. Plyuto, P. VanDerVoort, E.F. Vansant, J. Chem. Soc. Faraday Trans. 93 (1997) 3191-3196.

[162] A.A. Tsyganenko, P.P. Mardilovich, J. Chem. Soc. Faraday Trans. 92 (1996) 48434852.

[163] L.B. Backman, A. Rautiainen, M. Lindblad, A.O.I. Krause, Appl. Catal. A. Gen. 360 (2009) 183-191.

[164] R.J. Silvennoinen, O.J.T. Jylha, M. Lindblad, H. Osterholm, A.O.I. Krause, Catal. Lett. 114 (2007) 135-144. 
[165] H. Vuori, A. Pasanen, M. Lindblad, M. Valden, M.V. Niemela, A.O.I. Krause, Appl. Surf. Sci. 257 (2011) 4204-4210.

[166] M. Kariniemi, J. Niinisto, T. Hatanpaa, M. Kemell, T. Sajavaara, M. Ritala, M.

Leskela, Chem. Mater. 23 (2011) 2901-2907.

[167] S.S. Masango, L.X. Peng, L.D. Marks, R.P. Van Duyne, P.C. Stair, J. Phys. Chem. C 118 (2014) 17655-17661.

[168] J. Rickerby, J.H.G. Steinke, Chem. Rev. 102 (2002) 1525-1549.

[169] P. Martensson, K. Larsson, J.O. Carlsson, Appl. Surf. Sci. 157 (2000) 92-100.

[170] P. Martensson, K. Larsson, J.O. Carlsson, Appl. Surf. Sci. 148 (1999) 9-16.

[171] A.U. Mane, S.A. Shivashankar, J. Cryst. Growth 275 (2005) E1253-E1257.

[172] C.S. Chen, J.H. Lin, J.H. You, C.R. Chen, J. Am. Chem. Soc. 128 (2006) 15950-15951.

[173] P. Martensson, J.O. Carlsson, J. Electrochem. Soc. 145 (1998) 2926-2931.

[174] M. Utriainen, M. Kroger-Laukkanen, L.S. Johansson, L. Niinisto, Appl. Surf. Sci. 157 (2000) 151-158.

[175] B.S. Lim, A. Rahtu, R.G. Gordon, Nat. Mater. 2 (2003) 749-754.

[176] Z.W. Li, A. Rahtu, R.G. Gordon, J. Electrochem. Soc. 153 (2006) C787-C794.

[177] B.H. Lee, J.K. Hwang, J.W. Nam, S.U. Lee, J.T. Kim, S.M. Koo, A. Baunemann, R.A.

Fischer, M.M. Sung, Angew. Chem. Int. Ed. 48 (2009) 4536-4539.

[178] B. Vidjayacoumar, D.J.H. Emslie, S.B. Clendenning, J.M. Blackwell, J.F. Britten, A.

Rheingold, Chem. Mater. 22 (2010) 4844-4853.

[179] T.J. Knisley, T.C. Ariyasena, T. Sajavaara, M.J. Saly, C.H. Winter, Chem. Mater. 23

(2011) 4417-4419.

[180] L.C. Kalutarage, S.B. Clendenning, C.H. Winter, Chem. Mater. 26 (2014) 3731-3738.

[181] J.S. Huo, R. Solanki, J. McAndrew, J. Mater. Res. 17 (2002) 2394-2398.

[182] Z. Guo, H. Li, Q. Chen, L.J. Sang, L.Z. Yang, Z.W. Liu, X.W. Wang, Chem. Mater. 27

(2015) 5988-5996.

[183] Z.W. Li, S.T. Barry, R.G. Gordon, Inorg. Chem. 44 (2005) 1728-1735.

[184] Q. Ma, H.S. Guo, R.G. Gordon, F. Zaera, Chem. Mater. 22 (2010) 352-359.

[185] M. Dai, J. Kwon, M.D. Halls, R.G. Gordon, Y.J. Chabal, Langmuir 26 (2010) 3911-

3917.

[186] Q. Ma, F. Zaera, R.G. Gordon, J. Vac. Sci. Technol. A 30 (2012).

[187] C.S. Chen, J.H. Lin, T.W. Lai, Chem. Commun. (2008) 6613-6613.

[188] C.S. Chen, J.H. Lin, T.W. Lai, B.H. Li, J. Catal. 263 (2009) 155-166.

[189] X.L. Tong, Y. Qin, X.Y. Guo, O. Moutanabbir, X.Y. Ao, E. Pippel, L.B. Zhang, M.

Knez, Small 8 (2012) 3390-3395.

[190] J. Bachmann, A. Zolotaryov, O. Albrecht, S. Goetze, A. Berger, D. Hesse, D. Novikov,

K. Nielsch, Chem. Vap. Deposition 17 (2011) 177-180.

[191] H.L. Lu, G. Scarel, C. Wiemer, M. Perego, S. Spiga, M. Fanciulli, G. Pavia, J.

Electrochem. Soc. 155 (2008) H807-H811.

[192] E. Lindahl, M. Ottosson, J.O. Carlsson, Chem. Vap. Deposition 15 (2009) 186-191.

[193] E. Thimsen, A.B.F. Martinson, J.W. Elam, M.J. Pellin, J. Phys. Chem. C 116 (2012) 16830-16840.

[194] J.W. Shim, C. Fuentes-Hernandez, A. Dindar, Y.H. Zhou, T.M. Khan, B. Kippelen, Org. Electron. 14 (2013) 2802-2808.

[195] T.S. Yang, W.T. Cho, M. Kim, K.S. An, T.M. Chung, C.G. Kim, Y. Kim, J. Vac. Sci. Technol. A 23 (2005) 1238-1243.

[196] J.H. Yang, S.Y. Lee, W.S. Song, Y.S. Shin, C.Y. Park, H.J. Kim, W. Cho, K.S. An, J. Vac. Sci. Technol. B 26 (2008) 1021-1024. 
[197] B.S. So, Y.H. You, K.H. Kim, J. Hwang, W. Cho, S.S. Lee, T.M. Chung, Y.K. Lee, C.G. Kim, K.S. An, Y.C. Kim, Y.H. Lee, W.S. Seo, Electrochem. Solid State Lett. 10 (2007) J61-J64.

[198] K.W. Do, C.M. Yang, I.S. Kang, K.M. Kim, K.H. Back, H.I. Cho, H.B. Lee, S.H.

Kong, S.H. Hahm, D.H. Kwon, J.H. Lee, J.H. Lee, Jpn. J. Appl. Phys. 45 (2006) 2975-2979. [199] W.H. Kim, H.B.R. Lee, K. Heo, Y.K. Lee, T.M. Chung, C.G. Kim, S. Hong, J. Heo, H. Kim, J. Electrochem. Soc. 158 (2011) D1-D5.

[200] T.D. Gould, A.M. Lubers, B.T. Neltner, J.V. Carrier, A.W. Weimer, J.L. Falconer, J.W. Medlin, J. Catal. 303 (2013) 9-15.

[201] J. Chae, H.S. Park, S.W. Kang, Electrochem. Solid State Lett. 5 (2002) C64-C66.

[202] C.J. Jiang, Z.Y. Shang, X.H. Liang, ACS Catal. 5 (2015) 4814-4818.

[203] Z. Gao, M. Dong, G.Z. Wang, P. Sheng, Z.W. Wu, H.M. Yang, B. Zhang, G.F. Wang, J.G. Wang, Y. Qin, Angew. Chem. Int. Ed. 54 (2015) 9006-9010.

[204] T. Aaltonen, A. Rahtu, M. Ritala, M. Leskela, Electrochem. Solid-State Lett. 6 (2003) C130-C133.

[205] T. Aaltonen, P. Alen, M. Ritala, M. Leskela, Chem. Vap. Deposition 9 (2003) 45-49.

[206] O.K. Kwon, J.H. Kim, H.S. Park, S.W. Kang, J. Electrochem. Soc. 151 (2004) G109G112.

[207] D.J. Lee, S.S. Yim, K.S. Kim, S.H. Kim, K.B. Kim, Electrochem. Solid-State Lett. 11 (2008) K61-K63.

[208] J.Y. Kim, D.S. Kil, J.H. Kim, S.H. Kwon, J.H. Ahn, J.S. Roh, S.K. Park, J.

Electrochem. Soc. 159 (2012) H560-H564.

[209] S.H. Kwon, O.K. Kwon, J.H. Kim, S.J. Jeong, S.W. Kim, S.W. Kang, J. Electrochem. Soc. 154 (2007) H773-H777.

[210] K. Kukli, J. Aarik, A. Aidla, T. Uustare, I. Jogi, J. Lu, M. Tallarida, M. Kemell, A.A.

Kiisler, M. Ritala, M. Leskela, J. Cryst. Growth 312 (2010) 2025-2032.

[211] K. Kukli, M. Ritala, M. Kemell, M. Leskela, J. Electrochem. Soc. 157 (2010) D35D40.

[212] J.Y. Park, S. Yeo, T. Cheon, S.H. Kim, M.K. Kim, H. Kim, T.E. Hong, D.J. Lee, J. Alloys Compd. 610 (2014) 529-539.

[213] W.H. Kim, S.J. Park, D.Y. Kim, H. Kim, J. Korean Phys. Soc. 55 (2009) 32-37.

[214] T. Aaltonen, M. Ritala, M. Leskela, Electrochem. Solid State Lett. 8 (2005) C99-C101.

[215] K.J. Park, G.N. Parsons, Appl. Phys. Lett. 89 (2006).

[216] J. Hamalainen, F. Munnik, M. Ritala, M. Leskela, J. Electrochem. Soc. 156 (2009)

D418-D423.

[217] H.B.R. Lee, W.H. Kim, J.W. Lee, J.M. Kim, K. Heo, I.C. Hwang, Y. Park, S. Hong, H.

Kim, J. Electrochem. Soc. 157 (2010) D10-D15.

[218] J. Kwon, M. Saly, M.D. Halls, R.K. Kanjolia, Y.J. Chabal, Chem. Mater. 24 (2012) 1025-1030.

[219] D. Seghete, G.B. Rayner, A.S. Cavanagh, V.R. Anderson, S.M. George, Chem. Mater. 23 (2011) 1668-1678.

[220] J.W. Elam, C.E. Nelson, R.K. Grubbs, S.M. George, Surf. Sci. 479 (2001) 121-135.

[221] F.H. Fabreguette, Z.A. Sechrist, J.W. Elam, S.M. George, Thin Solid Films 488 (2005) 103-110.

[222] J.W. Elam, C.E. Nelson, R.K. Grubbs, S.M. George, Thin Solid Films 386 (2001) 4152.

[223] B. Kalanyan, M.D. Losego, C.J. Oldham, G.N. Parsons, Chem. Vap. Deposition 19 (2013) 161-166.

[224] T.K. Eom, W. Sari, K.J. Choi, W.C. Shin, J.H. Kim, D.J. Lee, K.B. Kim, H. Sohn, S.H. Kim, Electrochem. Solid-State Lett. 12 (2009) D85-D88. 
[225] J.W. Klaus, S.J. Ferro, S.M. George, Thin Solid Films 360 (2000) 145-153.

[226] C.A. Wilson, J.A. McCormick, A.S. Cavanagh, D.N. Goldstein, A.W. Weimer, S.M.

George, Thin Solid Films 516 (2008) 6175-6185.

[227] F.H. Fabreguette, S.M. George, Thin Solid Films 515 (2007) 7177-7180.

[228] Z. Feng, M.E. McBriarty, A.U. Mane, J. Lu, P.C. Stair, J.W. Elam, M.J. Bedzyk, RSC

Adv. 4 (2014) 64608-64616.

[229] M.E. McBriarty, G.P. Campbell, T.L. Drake, J.W. Elam, P.C. Stair, D.E. Ellis, M.J.

Bedzyk, J. Phys. Chem. C 119 (2015) 16179-16187.

[230] F. Maroun, F. Ozanam, O.M. Magnussen, R.J. Behm, Science 293 (2001) 1811-1814.

[231] Z. Guo, B. Liu, Q. Zhang, W. Deng, Y. Wang, Y. Yang, Chem. Soc. Rev. 43 (2014)

3480-3524.

[232] J. Greeley, T.F. Jaramillo, J. Bonde, I.B. Chorkendorff, J.K. Norskov, Nat. Mater. 5 (2006) 909-913.

[233] R. Ferrando, J. Jellinek, R.L. Johnston, Chem. Rev. 108 (2008) 845-910.

[234] S. Alayoglu, A.U. Nilekar, M. Mavrikakis, B. Eichhorn, Nat. Mater. 7 (2008) 333-338.

[235] J.M. Thomas, B.F.G. Johnson, R. Raja, G. Sankar, P.A. Midgley, Acc. Chem. Res. 36

(2003) 20-30.

[236] R.T. Mu, Q.A. Fu, H. Xu, H.I. Zhang, Y.Y. Huang, Z. Jiang, S.O. Zhang, D.L. Tan,

X.H. Bao, J. Am. Chem. Soc. 133 (2011) 1978-1986.

[237] D.I. Enache, J.K. Edwards, P. Landon, B. Solsona-Espriu, A.F. Carley, A.A. Herzing, M. Watanabe, C.J. Kiely, D.W. Knight, G.J. Hutchings, Science 311 (2006) 362-365.

[238] F. Besenbacher, I. Chorkendorff, B.S. Clausen, B. Hammer, A.M. Molenbroek, J.K.

Norskov, I. Stensgaard, Science 279 (1998) 1913-1915.

[239] G.W. Huber, J.W. Shabaker, J.A. Dumesic, Science 300 (2003) 2075-2077.

[240] G.J. Hutchings, C.J. Kiely, Acc. Chem. Res. 46 (2013) 1759-1772.

[241] B. Lim, M.J. Jiang, P.H.C. Camargo, E.C. Cho, J. Tao, X.M. Lu, Y.M. Zhu, Y.N. Xia, Science 324 (2009) 1302-1305.

[242] Y. Liu, M.F. Chi, V. Mazumder, K.L. More, S. Soled, J.D. Henao, S.H. Sun, Chem.

Mater. 23 (2011) 4199-4203.

[243] J.X. Wang, H. Inada, L.J. Wu, Y.M. Zhu, Y.M. Choi, P. Liu, W.P. Zhou, R.R. Adzic, J. Am. Chem. Soc. 131 (2009) 17298-17302.

[244] P. Strasser, S. Koh, T. Anniyev, J. Greeley, K. More, C.F. Yu, Z.C. Liu, S. Kaya, D.

Nordlund, H. Ogasawara, M.F. Toney, A. Nilsson, Nat. Chem. 2 (2010) 454-460.

[245] F. Maroun, F. Ozanam, O.M. Magnussen, R.J. Behm, Science 293 (2001) 1811-1814.

[246] J.T. Wrobleski, M. Boudart, Catal. Today 15 (1992) 349-360.

[247] M. Harada, K. Asakura, N. Toshima, J. Phys. Chem. 97 (1993) 5103-5114.

[248] H. Yu, P.C. Gibbons, K.F. Kelton, W.E. Buhro, J. Am. Chem. Soc. 123 (2001) 9198-

9199.

[249] B. Lim, H. Kobayashi, T. Yu, J.G. Wang, M.J. Kim, Z.Y. Li, M. Rycenga, Y.N. Xia, J. Am. Chem. Soc. 132 (2010) 2506-2507.

[250] J. Rebelli, A.A. Rodriguez, S.G. Ma, C.T. Williams, J.R. Monnier, Catal. Today 160 (2011) 170-178.

[251] C.J. Serpell, J. Cookson, D. Ozkaya, P.D. Beer, Nat. Chem. 3 (2011) 478-483.

[252] N. Toshima, Y. Shiraishi, A. Shiotsuki, D. Ikenaga, Y. Wang, Eur Phys J D 16 (2001) 209-212.

[253] Turkevic.J, G. Kim, Science 169 (1970) 873.

[254] W.R. Lee, M.G. Kim, J.R. Choi, J.I. Park, S.J. Ko, S.J. Oh, J. Cheon, J. Am. Chem.

Soc. 127 (2005) 16090-16097.

[255] A. Sarkany, P. Hargittai, A. Horvath, Top. Catal. 46 (2007) 121-128. 
[256] A.M. Molenbroek, S. Haukka, B.S. Clausen, J. Phys. Chem. B 102 (1998) 1068010689.

[257] Y. Lei, B. Liu, J.L. Lu, R. Lobo, T. Wu, H. Feng, X. Xia, A.U. Mane, J.A. Libera, J.P. Greeley, J.T. Miller, J.W. Elam, Chem. Mater. 24 (2012) 3525-3533.

[258] A. Santasalo-Aarnio, E. Sairanen, R.M. Aran-Ais, M.C. Figueiredo, J. Hua, J.M. Feliu, J. Lehtonen, R. Karinen, T. Kallio, J. Catal. 309 (2014) 38-48.

[259] T.D. Gould, M.M. Montemore, A.M. Lubers, L.D. Ellis, A.W. Weimer, J.L. Falconer, J.W. Medlin, Appl. Catal. A. Gen. 492 (2015) 107-116.

[260] M.J. Weber, A.J.M. Mackus, M.A. Verheijen, C. van der Marel, W.M.M. Kessels, Chem. Mater. 24 (2012) 2973-2977.

[261] M.J. Weber, M.A. Verheijen, A.A. Bol, W.M.M. Kessels, Nanotechnology 26 (2015).

[262] K. Cao, Q.Q. Zhu, B. Shan, R. Chen, Sci. Rep. 5 (2015).

[263] A.C. Johansson, R.B. Yang, K.B. Haugshoj, J.V. Larsen, L.H. Christensen, E.V.

Thomsen, Int. J. Hydrogen Energy 38 (2013) 11406-11414.

[264] H.W. Wang, C.L. Wang, H. Yan, H. Yi, J.L. Lu, J. Catal. 324 (2015) 59-68.

[265] X.Q. Jiang, H. Wang, J. Qi, B.G. Willis, J. Vac. Sci. Technol. A 32 (2014).

[266] I.J. Hsu, B.E. McCandless, C. Weiland, B.G. Willis, J. Vac. Sci. Technol. A 27 (2009) 660-667.

[267] G. Barcaro, A. Fortunelli, M. Polak, L. Rubinovich, Nano Lett. 11 (2011) 1766-1769.

[268] N. Toshima, T. Yonezawa, New. J. Chem. 22 (1998) 1179-1201.

[269] K. Qian, W. Huang, Catal. Today 164 (2011) 320-324.

[270] J. Xu, T. White, P. Li, C.H. He, J.G. Yu, W.K. Yuan, Y.F. Han, J. Am. Chem. Soc. 132 (2010) 10398-10406.

[271] J. Edwards, B. Solsona, P. Landon, A. Carley, A. Herzing, C. Kiely, G. Hutchings, J. Catal. 236 (2005) 69-79.

[272] J.K. Edwards, B. Solsona, P. Landon, A.F. Carley, A. Herzing, M. Watanabe, C.J.

Kiely, G.J. Hutchings, J. Mater. Chem. 15 (2005) 4595.

[273] M. Chen, D. Kumar, C.W. Yi, D.W. Goodman, Science 310 (2005) 291-293.

[274] W.Y. Yu, G.M. Mullen, D.W. Flaherty, C.B. Mullins, J. Am. Chem. Soc. 136 (2014) 11070-11078.

[275] Y. Huang, X. Zhou, M. Yin, C. Liu, W. Xing, Chem. Mater. 22 (2010) 5122-5128.

[276] D.I. Enache, J.K. Edwards, P. Landon, B. Solsona-Espriu, A.F. Carley, A.A. Herzing, M. Watanabe, C.J. Kiely, D.W. Knight, G.J. Hutchings, Science 311 (2006) 362-365.

[277] W. Hou, N. Dehm, R. Scott, J. Catal. 253 (2008) 22-27.

[278] X. Yang, C. Huang, Z. Fu, H. Song, S. Liao, Y. Su, L. Du, X. Li, Appl. Catal. B:

Environ. 140-141 (2013) 419-425.

[279] C.Y. Ma, B.J. Dou, J.J. Li, J. Cheng, Q. Hu, Z.P. Hao, S.Z. Qiao, Appl. Catal. B:

Environ. 92 (2009) 202-208.

[280] A. Villa, N. Janjic, P. Spontoni, D. Wang, D.S. Su, L. Prati, Appl. Catal. A. Gen. 364 (2009) 221-228.

[281] Y. Chen, H. Lim, Q. Tang, Y. Gao, T. Sun, Q. Yan, Y. Yang, Appl. Catal. A. Gen. 380 (2010) 55-65.

[282] M. Sankar, N. Dimitratos, P.J. Miedziak, P.P. Wells, C.J. Kiely, G.J. Hutchings, Chem. Soc. Rev. 41 (2012) 8099-8139.

[283] R.C. Tiruvalam, J.C. Pritchard, N. Dimitratos, J.A. Lopez-Sanchez, J.K. Edwards, A.F. Carley, G.J. Hutchings, C.J. Kiely, Faraday Discuss. 152 (2011) 63-86.

[284] J. Pritchard, L. Kesavan, M. Piccinini, Q. He, R. Tiruvalam, N. Dimitratos, J.A. LopezSanchez, A.F. Carley, J.K. Edwards, C.J. Kiely, G.J. Hutchings, Langmuir 26 (2010) 1656816577. 
[285] S. Meenakshisundaram, E. Nowicka, P.J. Miedziak, G.L. Brett, R.L. Jenkins, N. Dimitratos, S.H. Taylor, D.W. Knight, D. Bethell, G.J. Hutchings, Faraday Discuss. 145 (2010) 341-356.

[286] N. Dimitratos, J.A. Lopez-Sanchez, J.M. Anthonykutty, G. Brett, A.F. Carley, R.C. Tiruvalam, A.A. Herzing, C.J. Kiely, D.W. Knight, G.J. Hutchings, Phys. Chem. Chem. Phys. 11 (2009) 4952-4961.

[287] A.M. Henning, J. Watt, P.J. Miedziak, S. Cheong, M. Santonastaso, M.H. Song, Y. Takeda, A.I. Kirkland, S.H. Taylor, R.D. Tilley, Angew. Chem. Int. Ed. 52 (2013) 14771480 .

[288] L. Zhang, A. Wang, J.T. Miller, X. Liu, X. Yang, W. Wang, L. Li, Y. Huang, C.-Y. Mou, T. Zhang, ACS Catal. 4 (2014) 1546-1553.

[289] A. Wang, X.Y. Liu, C.-Y. Mou, T. Zhang, J. Catal. 308 (2013) 258-271.

[290] S. Park, A. Wieckowski, M.J. Weaver, J. Am. Chem. Soc. 125 (2003) 2282-2290.

[291] H.J. Jeong, J.W. Kim, K. Bae, H. Jung, J.H. Shim, ACS Catal. 5 (2015) 1914-1921.

[292] H.J. Jeong, J.W. Kim, D.Y. Jang, J.H. Shim, J. Power Sources 291 (2015) 239-245.

[293] Q. Ma, H.S. Guo, R.G. Gordon, F. Zaera, Chem. Mater. 23 (2011) 3325-3334.

[294] A.C. Johansson, J.V. Larsen, M.A. Verheijen, K.B. Haugshoj, H.F. Clausen, W.M.M.

Kessels, L.H. Christensen, E.V. Thomsen, J. Catal. 311 (2014) 481-486.

[295] X.R. Jiang, T.M. Gur, F.B. Prinz, S.F. Bent, Chem. Mater. 22 (2010) 3024-3032.

[296] J.J. Senkevich, F. Tang, D. Rogers, J.T. Drotar, C. Jezewski, W.A. Lanford, G.C.

Wang, T.M. Lu, Chem. Vap. Deposition 9 (2003) 258-264.

[297] K. Yu, Z.C. Wu, Q.R. Zhao, B.X. Li, Y. Xie, J. Phys. Chem. C 112 (2008) 2244-2247.

[298] P.M. Arnal, M. Comotti, F. Schuth, Angew. Chem. Int. Ed. 45 (2006) 8224-8227.

[299] M. Cargnello, T. Montini, S. Polizzi, N.L. Wieder, R.J. Gorte, M. Graziani, P.

Fornasiero, Dalton T. 39 (2010) 2122-2127.

[300] Z. Ma, S. Brown, J.Y. Howe, S.H. Overbury, S. Dai, J. Phys. Chem. C 112 (2008)

9448-9457.

[301] X.H. Liang, J.H. Li, M. Yu, C.N. McMurray, J.L. Falconer, A.W. Weimer, ACS Catal. 1 (2011) 1162-1165.

[302] X.Y. Zhang, J. Zhao, A.V. Whitney, J.W. Elam, R.P. Van Duyne, J. Am. Chem. Soc. 128 (2006) 10304-10309.

[303] E. Baktash, P. Littlewood, R. Schomacker, A. Thomas, P.C. Stair, Appl. Catal. B:

Environ. 179 (2015) 122-127.

[304] J.L. Lu, B. Liu, J.P. Greeley, Z.X. Feng, J.A. Libera, Y. Lei, M.J. Bedzyk, P.C. Stair, J.W. Elam, Chem. Mater. 24 (2012) 2047-2055.

[305] J.D. Ferguson, A.W. Weimer, S.M. George, Thin Solid Films 371 (2000) 95-104.

[306] N.A. Ray, R.P. Van Duyne, P.C. Stair, J. Phys. Chem. C 116 (2012) 7748-7756.

[307] A.W. Ott, J.W. Klaus, J.M. Johnson, S.M. George, Thin Solid Films 292 (1997) 135144.

[308] A.C. Dillon, A.W. Ott, J.D. Way, S.M. George, Surf. Sci. 322 (1995) 230-242.

[309] A. Rahtu, T. Alaranta, M. Ritala, Langmuir 17 (2001) 6506-6509.

[310] M. Juppo, A. Rahtu, M. Ritala, M. Leskela, Langmuir 16 (2000) 4034-4039.

[311] J.W. Elam, M.D. Groner, S.M. George, Rev. Sci. Instrum. 73 (2002) 2981-2987.

[312] J.L. Lu, L. Bin, N.P. Guisinger, P.C. Stair, J.P. Greeley, J.W. Elam, Chem. Mater. 26 (2014) 6752.

[313] M.D. Detwiler, A. Gharachorlou, L. Mayr, X.K. Gu, B. Liu, J. Greeley, W.N. Delgass,

F.H. Ribeiro, D.Y. Zemlyanov, J. Phys. Chem. C 119 (2015) 2399-2411.

[314] J.A. McCormick, K.P. Rice, D.F. Paul, A.W. Weimer, S.M. George, Chem. Vap.

Deposition 13 (2007) 491-498. 
[315] T. Lear, R. Marshall, J. A. Lopez-Sanchez, S. D. Jackson, T. M. Klapotke, M. Baumer, G. Rupprechter, and H. J. Freund, D. Lennon, J. Chem. Phys. 123 (2005) 174706-174718. [316] K. Wolter, O. Seiferth, H. Kuhlenbeck, M. Baumer, H.J. Freund, Surf. Sci. 399 (1998) 190-198.

[317] S. Schauermann, J. Hoffmann, V. Johanek, J. Hartmann, J. Libuda, H.J. Freund, Angew. Chem. Int. Ed. 41 (2002) 2532.

[318] M. Huff, L.D. Schmidt, J. Phys. Chem. 97 (1993) 11815-11822.

[319] S. Helveg, C. Lopez-Cartes, J. Sehested, P.L. Hansen, B.S. Clausen, J.R. RostrupNielsen, F. Abild-Pedersen, J.K. Norskov, Nature 427 (2004) 426-429.

[320] H.B. Zhang, X.K. Gu, C. Canlas, A.J. Kropf, P. Aich, J.P. Greeley, J.W. Elam, R.J. Meyers, J.A. Dumesic, P.C. Stair, C.L. Marshall, Angew. Chem. Int. Ed. 53 (2014) 1213212136.

[321] N. El Kolli, L. Delannoy, C. Louis, J. Catal. 297 (2013) 79-92.

[322] A. Hugon, L. Delannoy, J.M. Krafft, C. Louis, J. Phys. Chem. C 114 (2010) 1082310835.

[323] D.C. Lee, J.H. Kim, W.J. Kim, J.H. Kang, S.H. Moon, Appl. Catal. A. Gen. 244 (2003) 83-91.

[324] A.V. Whitney, J.W. Elam, S.L. Zou, A.V. Zinovev, P.C. Stair, G.C. Schatz, R.P. Van Duyne, J. Phys. Chem. B 109 (2005) 20522-20528.

[325] J. Sung, K.M. Kosuda, J. Zhao, J.W. Elam, K.G. Spears, R.P. Van Duyne, J. Phys. Chem. C 112 (2008) 5707-5714.

[326] L.H. Qian, W. Shen, B. Shen, G.W.W. Qin, B. Das, Nanotechnology 21 (2010).

[327] L.H. Qian, B. Das, ESC Trans. 33 (2010) 3-7.

[328] L.H. Qian, W. Shen, B. Das, B. Shen, G.W.W. Qin, Chem. Phys. Lett. 479 (2009) 259263.

[329] M.M. Biener, J. Biener, A. Wichmann, A. Wittstock, T.F. Baumann, M. Baumer, A.V. Hamza, Nano Lett. 11 (2011) 3085-3090.

[330] J.F. Li, Y.F. Huang, Y. Ding, Z.L. Yang, S.B. Li, X.S. Zhou, F.R. Fan, W. Zhang, Z.Y. Zhou, D.Y. Wu, B. Ren, Z.L. Wang, Z.Q. Tian, Nature 464 (2010) 392-395.

[331] A. Mondal, H. Seenivasan, A.K. Tiwari, J. Chem. Phys. 137 (2012).

[332] S. Yamamoto, K. Andersson, H. Bluhm, G. Ketteler, D.E. Starr, T. Schiros, H.

Ogasawara, L.G.M. Pettersson, M. Salmeron, A. Nilsson, J. Phys. Chem. C 111 (2007) 78487850 .

[333] J. Lee, D.C. Sorescu, K.D. Jordan, J.T. Yates, J. Phys. Chem. C 112 (2008) 1767217677.

[334] J. Noh, K. Zong, J.B. Park, Bull. Korean Chem. Soc. 32 (2011) 1129-1130.

[335] T. Matsumoto, R.A. Bennett, P. Stone, T. Yamada, K. Domen, M. Bowker, Surf. Sci.

471 (2001) 225-245.

[336] A. Gharachorlou, M.D. Detwiler, X.K. Gu, L. Mayr, B. Kloetzer, J. Greeley, R.G. Reifenberger, W.N. Delgass, F.H. Ribeiro, D.Y. Zemlyanov, ACS Appl. Mater. Inter. 7 (2015) 16428-16439.

[337] B.J. O'Neill, C. Sener, D.H.K. Jackson, T.F. Kuech, J.A. Dumesic, Chemsuschem 7 (2014) 3247-3251.

[338] A.C. Alba-Rubio, B.J. O'Neill, F.Y. Shi, C. Akatay, C. Canlas, T. Li, R. Winans, J.W. Elam, E.A. Stach, P.M. Voyles, J.A. Dumesic, ACS Catal. 4 (2014) 1554-1557.

[339] J.R. Avila, E.J. DeMarco, J.D. Emery, O.K. Farha, M.J. Pellin, J.T. Hupp, A.B.F. Martinson, ACS Appl. Mater. Inter. 6 (2014) 11891-11898.

[340] C.L. Wang, H.W. Wang, Q. Yao, H. Yan, J.J. Li, J.L. Lu, J. Phys. Chem. C 120 (2016) 478-486. 
[341] F. Menegazzo, M. Manzoli, A. Chiorino, F. Boccuzzi, T. Tabakova, M. Signoretto, F. Pinna, N. Pernicone, J. Catal. 237 (2006) 431-434.

[342] J.D. Grunwaldt, M. Maciejewski, O.S. Becker, P. Fabrizioli, A. Baiker, J. Catal. 186 (1999) 458-469.

[343] K. Qian, L.F. Luo, H.Z. Bao, Q. Hua, Z.Q. Jiang, W.X. Huang, Catal. Sci. Technol. 3 (2013) 679-687.

[344] M. Boronat, P. Concepcion, A. Corma, J. Phys. Chem. C 113 (2009) 16772-16784.

[345] D.W. Kim, K.D. Kim, H.O. Seo, N.K. Dey, M.J. Kim, Y.D. Kim, D.C. Lim, K.H. Lee, Catal. Lett. 141 (2011) 854-859.

[346] H.O. Seo, J.K. Sim, K.D. Kim, Y.D. Kim, D.C. Lim, S.H. Kim, Appl. Catal. A. Gen. 451 (2013) 43-49.

[347] H.J. Kim, D.H.K. Jackson, J. Lee, Y.X. Guan, T.F. Kuech, G.W. Huber, ACS Catal. 5 (2015) 3463-3469.

[348] J.C. Lee, D.H.K. Jackson, T. Li, R.E. Winans, J.A. Dumesic, T.F. Kuech, G.W. Huber, Energ. Environ. Sci. 7 (2014) 1657-1660.

[349] H.B. Zhang, C. Canlas, A.J. Kropf, J.W. Elam, J.A. Dumesic, C.L. Marshall, J. Catal. 326 (2015) 172-181.

[350] A. Wichmann, A. Wittstock, K. Frank, M.M. Biener, B. Neumann, L. Madler, J.

Biener, A. Rosenauer, M. Baumer, ChemCatChem 5 (2013) 2037-2043.

[351] T.M. Onn, S.Y. Zhang, L. Arroyo-Ramirez, Y.C. Chung, G.W. Graham, X.Q. Pan, R.J. Gorte, ACS Catal. 5 (2015) 5696-5701.

[352] H.B. Zhang, Y. Lei, A.J. Kropf, G.H. Zhang, J.W. Elam, J.T. Miller, F. Sollberger, F. Ribeiro, M.C. Akatay, E.A. Stach, J.A. Dumesic, C.L. Marshall, J. Catal. 317 (2014) 284292.

[353] X.H. Liang, M. Yu, J.H. Li, Y.B. Jiang, A.W. Weimer, Chem. Commun. (2009) 71407142.

[354] B. Zhang, Y. Chen, J.W. Li, E. Pippel, H.M. Yang, Z. Gao, Y. Qin, ACS Catal. 5 (2015) 5567-5573.

[355] T.D. Gould, A. Izar, A.W. Weimer, J.L. Falconer, J.W. Medlin, ACS Catal. 4 (2014) 2714-2717.

[356] L.L. Murrell, D.C. Grenoble, C.J. Kim, N.C. Dispenziere, J. Catal. 107 (1987) 463-470.

[357] C.D. Baertsch, K.T. Komala, Y.H. Chua, E. Iglesia, J. Catal. 205 (2002) 44-57.

[358] M.L. Pena, A. Dejoz, V. Fornes, E. Rey, M.I. Vazquez, J.M.L. Nieto, Appl. Catal. A.

Gen. 209 (2001) 155-164.

[359] F. Cavani, N. Ballarini, A. Cericola, Catal. Today 127 (2007) 113-131.

[360] D.A. Pena, B.S. Uphade, P.G. Smirniotis, J. Catal. 221 (2004) 421-431.

[361] C.H. Zhou, X. Xia, C.X. Lin, D.S. Tong, J. Beltramini, Chem. Soc. Rev. 40 (2011)

5588-5617.

[362] B.M. Weckhuysen, D.E. Keller, Catal. Today 78 (2003) 25-46.

[363] G. Deo, I.E. Wachs, J. Catal. 146 (1994) 323-334.

[364] I.E. Wachs, B.M. Weckhuysen, Appl. Catal. A. Gen. 157 (1997) 67-90.

[365] A. Khodakov, B. Olthof, A.T. Bell, E. Iglesia, J. Catal. 181 (1999) 205-216.

[366] N. Ballarini, F. Cavani, A. Cericola, C. Cortelli, M. Ferrari, F. Trifiro, G. Capannelli, A. Comite, R. Catani, U. Cornaro, Catal. Today 91-2 (2004) 99-104.

[367] X. Rozanska, R. Fortrie, J. Sauer, J. Am. Chem. Soc. 136 (2014) 7751-7761.

[368] J.E. Herrera, J.H. Kwak, J.Z. Hu, Y. Wang, C.H.F. Peden, J. Macht, E. Iglesia, J. Catal. 239 (2006) 200-211.

[369] A.R. Mouat, C. George, T. Kobayashi, M. Pruski, R.P. van Duyne, T.J. Marks, P.C.

Stair, Angew. Chem. Int. Ed. 54 (2015) 13346-13351. 
[370] C. Cavallotti, I. Lengyel, M. Nemirovskaya, K.F. Jensen, J. Cryst. Growth 268 (2004) 76-95.

[371] S.P. Sree, J. Dendooven, T.I. Koranyi, G. Vanbutsele, K. Houthoofd, D. Deduytsche, C. Detavernier, J.A. Martens, Catal. Sci. Technol. 1 (2011) 218-221.

[372] E. Verheyen, S.P. Sree, K. Thomas, J. Dendooven, M. De Prins, G. Vanbutsele, E.

Breynaert, J.P. Gilson, C.E.A. Kirschhock, C. Detavernier, J.A. Martens, Chem. Commun. 50 (2014) 4610-4612.

[373] C. Detavernier, J. Dendooven, S.P. Sree, K.F. Ludwig, J.A. Martens, Chem. Soc. Rev. 40 (2011) 5242-5253.

[374] Y.J. Pagan-Torres, J.M.R. Gallo, D. Wang, H.N. Pham, J.A. Libera, C.L. Marshall, J.W. Elam, A.K. Datye, J.A. Dumesic, ACS Catal. 1 (2011) 1234-1245.

[375] S.C. Riha, B.M. Klahr, E.C. Tyo, S. Seifert, S. Vajda, M.J. Pellin, T.W. Hamann, A.B.F. Martinson, Acs Nano 7 (2013) 2396-2405.

[376] Y.J. Lin, S. Zhou, S.W. Sheehan, D.W. Wang, J. Am. Chem. Soc. 133 (2011) 23982401.

[377] R. Liu, Y.J. Lin, L.Y. Chou, S.W. Sheehan, W.S. He, F. Zhang, H.J.M. Hou, D.W. Wang, Angew. Chem. Int. Ed. 50 (2011) 499-502.

[378] M.G. Ahmed, I.E. Kretschmer, T.A. Kandiel, A.Y. Ahmed, F.A. Rashwan, D.W.

Bahnemann, ACS Appl. Mater. Inter. 7 (2015) 24053-24062.

[379] R. Liu, Z. Zheng, J. Spurgeon, X.G. Yang, Energ. Environ. Sci. 7 (2014) 2504-2517. [380] X.G. Yang, R. Liu, C. Du, P.C. Dai, Z. Zheng, D.W. Wang, ACS Appl. Mater. Inter. 6 (2014) 12005-12011.

[381] A.G. Scheuermann, J.D. Prange, M. Gunji, C.E.D. Chidsey, P.C. McIntyre, Energ. Environ. Sci. 6 (2013) 2487-2496.

[382] S. Hu, M.R. Shaner, J.A. Beardslee, M. Lichterman, B.S. Brunschwig, N.S. Lewis, Science 344 (2014) 1005-1009.

[383] M. Coll, J. Gazquez, A. Palau, M. Varela, X. Obradors, T. Puig, Chem. Mater. 24 (2012) 3732-3737.

[384] L. Steier, J. Luo, M. Schreier, M.T. Mayer, T. Sajavaara, M. Grätzel, Acs Nano 9 (2015) 11775-11783.

[385] A. Paracchino, V. Laporte, K. Sivula, M. Gratzel, E. Thimsen, Nat. Mater. 10 (2011) 456-461.

[386] F. Kayaci, S. Vempati, C. Ozgit-Akgun, I. Donmez, N. Biyikli, T. Uyar, Nanoscale 6 (2014) 5735-5745.

[387] C. Marichy, M. Bechelany, N. Pinna, Adv. Mater. 24 (2012) 1017-1032.

[388] T. Wang, Z.B. Luo, C.C. Li, J.L. Gong, Chem. Soc. Rev. 43 (2014) 7469-7484.

[389] C.P. Canlas, J. Lu, N.A. Ray, N.A. Grosso-Giordano, S. Lee, J.W. Elam, R.E. Winans, R.P. Van Duyne, P.C. Stair, J.M. Notestein, Nat. Chem. 4 (2012) 1030-1036.

[390] S.M. Csicsery, Zeolites 4 (1984) 202-213.

[391] M.A. Alvarez-Merino, M.F. Ribeiro, J.M. Silva, F. Carrasco-Marin, F.J. MaldonadoHodar, Environ. Sci. Technol. 38 (2004) 4664-4670.

[392] S. Linley, Y.Y. Liu, C.J. Ptacek, D.W. Blowes, F.X. Gu, ACS Appl. Mater. Inter. 6 (2014) 4658-4668.

[393] M. Zabihi, F. Khorasheh, J. Shayegan, RSC Adv. 5 (2015) 5107-5122.

[394] Y.Y. Liang, Y.G. Li, H.L. Wang, H.J. Dai, J. Am. Chem. Soc. 135 (2013) 2013-2036.

[395] A.S. Cavanagh, C.A. Wilson, A.W. Weimer, S.M. George, Nanotechnology 20 (2009).

[396] J. Liu, X.B. Meng, Y.H. Hu, D.S. Geng, M.N. Banis, M. Cai, R.Y. Li, X.L. Sun, Carbon 52 (2013) 74-82.

[397] D.H.K. Jackson, B.J. O'Neill, J. Lee, G.W. Huber, J.A. Dumesic, T.F. Kuech, ACS Appl. Mater. Inter. 7 (2015) 16573-16580. 